\section{Resúmenes de los Trabajos Libres del 75 Congreso Diamante de Neumología y Cirugía de Tórax (Guadalajara, Jalisco, 2016)*}

\author{
Asma \\ Efecto de la \\ exposición a ozono \\ y el material particulado \\ PM2.5 de la Ciudad \\ de México en un \\ modelo de asma en \\ cobayos $^{\mathrm{a}}$
}

Segura MP, * Falcón $R C l,{ }^{*}$ García $A L I, \neq$ Rosas PI, $\neq$ De Vizcaya $R A, \&$ Manzano LN," Osornio VA"

*INER Ismael Cosío Villegas; ‡UNAM; $\S$ CINVESTAV-IPN; "Instituto Nacional de Cancerología; "University of Alberta

El asma afecta a 300 millones de personas en el mundo y se estiman 100 mil casos más para 2025, asociados, en parte, con exposición a agresores ambientales. La Ciudad de México (CDMX) sufre un serio problema de contaminación por ozono $\left(\mathrm{O}_{3}\right)$ y material particulado fino (PM2.5). Diversos estudios demuestran que ambos contaminantes son capaces de agravar la sintomatología del asma, sin embargo, pocas investigaciones han evaluado sus efectos simultáneos. Nuestro objetivo fue determinar los efectos morfo-fisiopatológicos, inmunológicos y bioquímicos a la exposición conjunta a PM2.5 y $\mathrm{O}_{3}$ en modelo de asma alérgica: cobayos machos fueron expuestos a $\mathrm{O}_{3}$ y PM2.5 de manera aguda (3 días/5 $\mathrm{h} /$ diarias, $\mathrm{n}=30$ ) y crónica en época seca y de lluvias (3 semanas/5 h/diarias, $\mathrm{n}=40 \mathrm{c} / \mathrm{u})$. Los animales se sensibilizaron, con o sin $\mathrm{Al}(\mathrm{OH})_{3}$ (adyuvante) y ovoalbúmina (OA) como alérgeno. Los controles, se expusieron a aire filtrado (AF). Se realizaron pletismografías para evaluar la respuesta al reto y la sensibilidad a histamina. En lavados bronquioalveolares se realizó conteo celular total y diferencial, se midió el perfil inmunológico (TH1/TH2) y se obtuvieron macrófagos. Observándose que la resistencia de las vías aéreas se incrementó significativamente al reto antigénico, excepto en los grupos no sensibilizados/AF y PM2.5. Los animales sensibilizados sin adyuvante expuestos al PM2.5 respondieron significativamente, sugiriendo que el PM2.5 de la CDMX tiene poder adyuvante para inducir asma. Los animales asmáticos expuestos a PM2.5 y $\mathrm{O}_{3}$ respondieron severamente al antígeno y presentaron hiperreactividad, pero la combinación de ambos neutralizó su efecto. La exposición a PM2.5 indujo inflamación y aumento de la secreción de moco que se potenciaron por la sensibilización. Ambos contaminantes generaron cambios en la expresión de

\footnotetext{
* La transcripción de los resúmenes es responsabilidad de los autores y de acuerdo con las indicaciones y
} numeración otorgada por el Comité Científico de la Sociedad Mexicana de Neumología y Cirugía de Tórax. citocinas e incremento en la actividad del citocromo P450. La contaminación ambiental podría jugar un papel importante en el desarrollo de alergias en la población expuesta de la CDMX. SECITI/042/2013.

${ }^{a}$ Trabajo seleccionado para ser presentado de forma oral. Obtuvo premio como mejor trabajo de investigación básica.

\section{Expresión de laminina en el músculo liso en cobayos que no responden al reto antigénico $^{a}$}

Bazán-Perkins B, Pacheco Al

INER Ismael Cosío Villegas

Antecedentes: El alérgeno induce obstrucción de las vías aéreas en $\sim 80 \%$ de los cobayos sensibilizados (modelo de asma), pero el $\sim 20 \%$ no presentan respuesta obstructiva (NR). La laminina es un componente de matriz extracelular que se asocia con el fenotipo hipercontráctil y proliferante del músculo liso (ML). Hasta el momento se desconoce la relación entre los niveles de laminina en el ML de las vías aéreas en los cobayos del modelo de asma y NR. Objetivo: Comparar la expresión de laminina, y su receptor la integrina $\alpha 6 \beta 1$, en el ML de cobayos del modelo de asma y NR. Métodos: Cobayos machos se sensibilizaron y retaron con ovoalbúmina (OVA) cada diez días. Se seleccionaron seis con obstrucción bronquial después del reto antigénico (modelo de asma) y seis que no (NR). Al tercer y doceavo retos se determinó la presencia de hiperreactividad de las vías aéreas (HVA), y en los ML de 
las vías aéreas (MLVA) y vascular, de hipertrofia e hiperplasia así como la intensidad de marca inmunohistoquímica a laminina e integrina $\alpha 6 \beta 1$. El grupo control $(n=6)$ sólo recibió solución salina. Resultados: Los cobayos del modelo de asma y los NR del tercer reto presentaron HVA. El ML vascular en los NR y modelo de asma mostraron hiperplasia, pero no en el MLVA. La expresión de laminina en el ML vascular y MLVA del modelo de asma, NR del tercer reto y controles fue similar, sólo se incrementó en los NR de doce retos ( $\mathrm{p}<0.001)$. La integrina $\alpha 6 \beta 1$ aumentó en todos los grupos $(\mathrm{p}<0.05)$ salvo en los del tercer reto del modelo de asma. Conclusiones: La expresión de laminina en el ML no está asociada con los fenotipos hipercontráctil del MLVA ni proliferante del vascular. Es posible que la laminina participe en la contención crónica de la respuesta obstructiva alérgica.

a Trabajo seleccionado para ser presentado de forma oral. Obtuvo premio como mejor trabajo de investigación básica.

\section{Asociación entre la gravedad del asma y los niveles séricos de integrinas $\beta 1$ y $\beta 2^{\mathrm{a}}$}

Bazan-Perkins $\boldsymbol{B},{ }^{\star}$ Téllez-Jiménez Olivia, * Chapela Rocío, * Páramo Rl, * Trejo JCh, ${ }^{\star}$ López EE, * Miguel RJL, * Ramos-Ramírez $P^{\ddagger}$

*INER Ismael Cosío Villegas; ¥Krefting Research Centre, University of Gothenburg, Goeteborg, Västra Götaland, Suecia

Antecedentes: Los dominios extracelulares de algunas proteínas pueden ser cortados proteolíticamente para liberarse de las células. En un modelo crónico de asma en el cobayo los ectodominios de las integrinas $\alpha 1 \beta 1$ y $\alpha 2 \beta 1$ se acumulan en áreas acelulares de la pared de la vía aérea. La acumulación de estas integrinas se asoció con la magnitud de la hiperreactividad y la inflamación de las vías aéreas. Si las integrinas acelulares se acumulan en la pared de la vía aérea es probable que se encuentren en líquidos corporales como moléculas solubles. Objetivo: Evaluar la presencia de integrinas solubles en el modelo de asma en cobayo y en pacientes con asma. Método: Cobayos machos fueron sensibilizados y retados con antígeno (ovoalbúmina). En el doceavo reto antigénico se determinó los niveles de las subunidades de integrina $\alpha 1, \alpha 2$, $\beta 1$ y $\beta 2$ en el lavado broncoalveolar (LBA) y suero de cobayos por ELISA. Para el estudio en humanos, reclutamos pacientes con asma y voluntarios sanos para determinar los niveles de las subunidades de integrina en el suero. Resultados: Las subunidades $\alpha 1, \alpha 2, \beta 1$ y $\beta 2$ de integrina se detectaron en LBA y suero de los cobayos controles. Sólo las subunidades $\alpha 2$ y $\beta 2$ se incrementaron en el modelo de asma en el cobayo. En el suero de humanos sanos se detectaron las subunidades $\alpha 1, \alpha 2, \beta 1$ у $\beta 2$ y todas se encontraron incrementadas en pacientes con asma. Los niveles de $\beta 1$ y $\beta 2$ se asociaron directamente con la gravedad del asma, e inversamente con el FEV1. Conclusiones: Por primera vez se describe la presencia de la subunidades $\alpha 2$ y $\beta 1$ solubles en humanos. Es probable que las integrinas $\beta 1$ y $\beta 2$ solubles humanas, por su asociación con aspectos importantes de la fisiopatología del asma, pudieran funcionar como posibles biomarcadores de la enfermedad.

a Trabajo seleccionado para ser presentado de forma oral.

\section{Índice de aclaramiento pulmonar en niños asmáticos con diferentes grados de control en edades \\ de 5 a 14 años $^{a}$}

Urbina ME, Gochicoa RLG, Torre-Bouscoulet $L$

INER Ismael Cosío Villegas

Introducción: El asma sigue siendo un problema de salud pública, se hace necesario redefinir estrategias de eva- luación, diagnóstico y tratamiento de acuerdo con los avances tecnológicos y farmacéuticos. Una de las tecnologías prometedoras es el lavado de gas inerte. El índice de aclaramiento pulmonar (LCI) es un indicador que promete ayudarnos a predecir el comportamiento clínico del asma y detección de pacientes de riesgo. Objetivo principal: Describir la asociación de los resultados de LCI con el nivel de control del asma (ACT). Objetivos específicos: Evaluar el índice de aclaramiento pulmonar (LCI) en asmáticos comparado con los valores obtenidos en sanos; así como el efecto al salbutamol sobre el resultado del índice de aclaramiento pulmonar en sujetos asmáticos y conocer la correlación del índice de aclaramiento pulmonar con los parámetros espirométricos. Material y método: Se diseñó un estudio de corte transversal, descriptivo, prospectivo en niños y adolescentes mexicanos con edades de 5 a 14 años con asma, reclutados de la consulta externa de Neumología Pediátrica del Instituto Nacional de Enfermedades Respiratorias, de abril a julio de 2015, a quienes se les midió el índice de aclaramiento pulmonar y espirometría. Se comparó la espirometría con el lavado pulmonar con técnica de respiraciones múltiple pre- y posinhalación de salbutamol a dosis de 200 a $400 \mu \mathrm{g}$. Se comparó a 33 pacientes asmáticos con 116 controles sanos pareados. Dependiendo de la distribución de las variables se utilizaron medias, DE, medianas. Resultados: El LCI con punto de corte de 7 se asoció a pacientes no controlados o parcialmente controlados. También tuvo asociación con FEV1 predicho en litro y en porcentaje. Presentó una relación inversa entre LCI y edad, talla y peso. Conclusiones: LCI es una prueba que puede medir la heterogeneidad de la vía aérea periférica y capaz de discriminar a paciente de mal control.

a Trabajo seleccionado para ser presentado de forma oral.

\section{Efecto clínico del omalizumab en pacientes mexicanos}




\section{con asma de difícil control}

Que SMI, Salazar SAB, Chagoya BJC

Hospital Central Militar

Antecedentes: El asma de difícil control representa el $10 \%$ de los casos de asma, provoca una necesidad desproporcionada de los servicios médicos, puede consumir $80 \%$ del costo en asma al sector salud. Múltiples estudios han reportado que el tratamiento con omalizumab disminuye exacerbaciones, mejora los cuestionarios de control (ACT o ACQ), calidad de vida (AQLQ), y favorece la disminución en la dosis de corticosteroide inhalado. Objetivo: Evaluar el efecto clínico del uso de omalizumab en las exacerbaciones totales y graves presentadas en pacientes mexicanos con asma de difícil control. Material: Se realizó un estudio observacional, ambispectivo, longitudinal; en el que se incluyó a los pacientes con asma de difícil control del Hospital Central Militar que se encontraran en tratamiento con omalizumab, se realizó la revisión del expediente clínico, la información obtenida del año previo al tratamiento se comparó con la evolución clínica durante el primer año de tratamiento; las variables analizadas fueron número y tipo de exacerbaciones, calificación del cuestionario ACQ (asthma control questionnaire), AQLQ (asthma quality of life questionnaire), FEV1, dosis de corticosteroide inhalado. Resultados: Se incluyó a 31 pacientes, $64.5 \%$ (20) de género femenino, la edad fue de $50.22+15.22$ años. Se encontró una reducción en las exacerbaciones totales de $4.6+2.5$ a $1.51+1.50$ al año de tratamiento, con una $\mathrm{p}=6.0 \mathrm{E}-8$; el $48.4 \%$ (15) de los pacientes no había presentado exacerbaciones graves al 12/ vo de tratamiento; el ACQ mostró una disminución en al menos 0.5 puntos en el 80.6\% (25) de los pacientes, el cuestionario AQLQ registró un incremento en al menos 0.5 puntos en el $93.5 \%$ (29) de los pacientes. Conclusiones: El uso de omalizumab en el tratamiento de los pacientes con asma de difícil control ha demostrado disminuir de manera significativa el número de exacerbaciones, mejorar el control de la enfermedad y la calidad de vida.

\section{Tratamiento} ambulatorio versus hospitalario relacionado a agudizaciones en pacientes con asma desde una perspectiva institucional pública mexicana

Cordero CLM, * Huicochea BJL, Herran Díaz-Granados $S^{\ddagger}$

*Health Consultings; 拜oehringer Ingelheim

Objetivo: Estimar y comparar el uso y frecuencia de recursos médicos directos de atención de las agudizaciones por asma a nivel ambulatorio y hospitalario, desde la perspectiva del Instituto Mexicano del Seguro Social (IMSS). Métodos: De enero a diciembre del 2013 se realizó un estudio retrospectivo para estimar el costo médico directo de las agudizaciones de asma. Tanto el patrón de tratamiento, como la categorización de las agudizaciones fueron aquellos establecidos por la institución (guía de tratamiento IMSS). Los registros de pacientes fueron obtenidos de bases electrónicas públicas para una cohorte de pacientes con agudizaciones de asma. El tratamiento ambulatorio y hospitalario fueron los criterios para establecer el uso y frecuencia de recursos médicos, incluyendo consultas médicas familiares y de especialidades, consultas de urgencia, hospitalizaciones, estudios de laboratorio y gabinete y uso de medicamentos. Los costos unitarios fueron obtenidos de tabuladores y compras públicas (2014 IMSS). Mediante un análisis estadístico se obtuvo la media en costos. Resultados: En 2013 se reportaron 7,591 episodios de agudización de asma, de los cuales 5,274 corresponden a pacientes hospitalizados. Se observó un promedio de 4.5 días de estancia hospitalaria en el horizonte estudiado. El costo anual promedio de tratamiento de las agudizaciones en cuidado hospitalario y ambulatorio fue de $\$ 96,223$ y $\$ 20,274$, respectivamente. Un análisis detallado de costos del cuidado hospitalario versus el cuidado ambulatorio demostró un aumento significativo en el uso de medicamentos $(70 \%)$ y consultas de especialidades $(50 \%)$ entre otros. Conclusión: En el tratamiento de episodios de agudización en asma, el costo agregado por año del cuidado hospitalario versus el ambulatorio se estimo es $79 \%$ mayor. Reducir el riesgo de sufrir estos episodios con la elección correcta de tratamiento sería relevante para las instituciones mexicanas.

\section{Evaluación de conocimiento y destreza en el uso de dispositivos de inhalación del personal en formación del Instituto Nacional de Enfermedades Respiratorias}

Pavón KE, Garrido GC,
Del Razo RR

INER Ismael Cosío Villegas

Introducción: La medicación inhalada constituye el tratamiento de primera línea de enfermedades como el asma o la enfermedad pulmonar obstructiva crónica (EPOC), su efectividad está en relación con la cantidad de fármaco que logra depositarse más allá de la región orofaríngea, con el lugar en que se deposite y con la distribución uniforme o no del mismo. Objetivo general: Evaluar el conocimiento y destreza de los médicos residentes y técnicos en terapia respiratoria del Instituto Nacional de Enfermedades Respiratorias, en cuanto al uso de dispositivos de inha- 
lación. Material y métodos: Se diseñó un estudio observacional, descriptivo, prospectivo, transversal. Se evaluó con una rúbrica diseñada los pasos correctos de la técnica de inhalación de cinco dispositivos (inhalador de dosis medida, de dosis medida más cámara espaciadora y pieza bucal, Handihaler, Turbohaler $^{\circledR}$, Diskus ${ }^{\circledR}$ y Respimat $\left.{ }^{\circledR}\right)$; a los médicos residentes del INER (neumología, neumología pediátrica, alergología e inmunología, y estudiantes de terapia respiratoria). Se consideró una calificación satisfactoria $(>8)$, deficiente entre 6 y 8 e insuficiente por debajo de 6 pts. Resultados: Se aplicaron 109 encuestas, terapia respiratoria obtuvo las mejores calificaciones con el IDMp de 6.87, neumología pediátrica fue con IDMp + cámara espaciadora con mascarilla 7.58, neumología el mejor evaluado fue el Diskus ${ }^{\circledR}$ con $7.14 \mathrm{y}$ alergología con el Diskus ${ }^{\circledR}$ obtuvo 5.71. Encontramos que cuarto año obtuvo el mejor desempeño en cada uno de los dispositivos y los estudiantes de primer año tienen las peores calificaciones en casi todos los dispositivos $(\mathrm{p}<0.05)$. Conclusiones: 1. Los profesionales de la salud de todos los grados académicos mostraron conocimientos deficientes en todos los dispositivos evaluados. 2 . La inhabilidad del personal médico y no médico en el uso de los dispositivos de inhalación repercute en una pobre instrucción al paciente y como consecuencia una mala técnica de aplicación.

\section{Disfunción de las vías aéreas distales en adultos asmáticos de acuerdo al nivel de control}

\section{Benítez RE, Del Río HRF, Torre- Bouscoulet L, Gochicoa RL, Pérez El, Cadeza AJD, Marín A}

INER Ismael Cosío Villegas

Antecedentes: El asma es una enfermedad inflamatoria crónica de la vía aérea, de alta prevalencia a nivel mundial que todavía se asocia con elevada mortalidad y costos directos e indirectos. Lo cual se atribuye principalmente a los pacientes descontrolados. Entre los cuestionarios para evaluar el control del asma, el ACT es el más utilizado y validado. La puntuación obtenida por ACT y parámetros funcionales como FEV1 y FeNO se ha encontrado sustancialmente baja, pero la evaluación de la función pulmonar sigue es esencial en el seguimiento de los pacientes asmáticos. Pocos estudios han evaluado la prevalencia de alteraciones funcionales por otras pruebas respecto al grado de control. Objetivo: Evaluar la prevalencia de disfunción de las vías aéreas distales, medida por atrapamiento aéreo y/o hiperinflación pulmonar ( $\mathrm{RV}$, RV/TLC, TLC), resistencias totales pletismográficas y presiones máximas inspiratorias (Pimax) en pacientes asmáticos controlados vs. descontrolados/ parcialmente controlados de acuerdo con la puntuación del cuestionario ACT. Material y métodos: Estudio transversal. Incluyó 38 pacientes asmáticos de la Clínica de Asma del INER, sin tabaquismo activo ni índice tabáquico significativo. Se agruparon en: asmáticos controlados con una puntuación igual o mayor de 20 en el ACT y descontrolados/parcialmente controlados con una puntuación igual o menor de 19 en el ACT. Se les realizaron pruebas mecánicas de función respiratoria de acuerdo con estándares de ATS/ERS 2005. Resultados: 13 hombres y 25 mujeres. $50.5 \%$ (23) controlados y $39.4 \%$ (13) descontrolados/ parcialmente controlados. En el grupo de pacientes controlados 32.1 , 35 y $21 \%$ presentaron datos de atrapamiento aéreo por RV y/o por relación RV/TLC e hiperinflación pulmonar por TLC. $36 \%$ tenía resistencias totales incrementadas por pletismografía con disminución de Pimax. Conclusiones: Un tercio de asmáticos que se perciben controlados por el cuestionario ACT presentan evidencia de disfunción de la vía aérea distal pudiendo encontrarse en riesgo de daño pulmonar irreversible.

\section{Asma asociada a Wolff Parkinson}

\section{White, reporte de un caso}
Topete MLE, Del Razo RR, Rodríguez BEJ, Sánchez UMG

INER Ismael Cosío Villegas

P.B.R.O./Fem./8 años. AHF: negados. APNP: negados. Esquema de vacunación completo. Combe: negado. Antecedentes perinatales: sin importancia. Desarrollo psicomotor: normal. Antecedentes personales patológicos: dermatitis atópica. Quirúrgicos: ablación por Sx de Wolff Parkinson White el 26/8/2014, hospitalizada por tres días Instituto Nacional de Cardiología. USO DE MDI: combivent, flixotide $500 \mu \mathrm{g} /$ día desde hace dos meses. Sibilancias previas: diciembre 2014, Tx con MNB combivent por tres ocasiones únicamente. Síntomas respiratorios (último mes): tos con el ejercicio 2/7, síntomas nasales (último mes): congestión nasal 3/7. Síntomas digestivos: negados. Padecimiento actual: 21/05/2015 referida de Hospital Ignacio Chávez por crisis asmática y Sx de Wolff Parkinson White, madre indica que 21.05.15 escucha sibilancias por la noche sin dificultad respiratoria administra flixotide $250 \mu \mathrm{g}$ MDI, 22.05.15 presenta tos, la cual se ha incrementado, seca, no cianosante no disneizante, sin predominio de horario, indica no fiebre, no dificultad respiratoria, no sibilancias, consulta a Hospital Ignacio Chávez por evento de pérdida de la conciencia, con Dx. de evento de preexcitación con pérdida del estado de alerta y stock Adams, manejada con MNB con ipratropio en tres se desconoce dosis, se refiere saturación de oxígeno $82-83 \%$ por lo que deciden referirla a este instituto con cita el día 25-5-2015 para valoración de nueva ablación por arritmia. A la E.F. inspección tórax tiraje intercostal y retracción supraesternal. Palpación con amplexión y amplexación. Auscultación: disminución de ruidos respiratorios, presencia de estertores crepitantes de manera bilateral diseminados y sibilancias espiratorias en ambos hemitórax. Ruidos 
cardíacos rítmicos, con taquicardia. Resto sin alteraciones evidentes. Radiografía tórax (22.05.15): anteroposterior, hemitórax derecho se observa imagen radioopaca paracardíaca derecha, heterogénea que hace signo de silueta + , se observa patrón reticular bilateral en ambos hemitórax. Espirometría: FVC 42\% FEV1 31\% FEV1/FVC 74\%. Obstrucción grave. Paraclínicos: $\mathrm{BH}$ : leucos 10.6/neutrófilos 50.8\%/linfocitos $34.20 \% /$ monocitos $4.8 /$ eosinófilos 9.9\%/basófilos $0.30 \% / H G B$ 14.4/HCT 43.8/PLT 269/GLU 98. ES: dentro de rangos.

Validación de
listas de cotejo,
en evaluación por
competencias, en el
uso de dispositivos de
inhalación y
aerocámaras por
panel de expertos

Moysen SG, García VBAS, Cruz OF

UMAE, HG CMN “La Raza”

Introducción: La aerosolterapia es el método más utilizado para suministrar fármacos en el manejo de patologías respiratorias, su principal inconveniente es la dificultad de los pacientes para realizar una técnica adecuada. Por lo cual, los profesionales de la salud deben de tener un adiestramiento previo con la finalidad de minimizar los errores. Justificación: Debido a que hemos observado un sin fin de errores en el personal de salud al aplicar o indicar aerosolterapia, consideramos necesario realizar listas de cotejo basados en competencias, para tener los instrumentos adecuados en una evaluación integral al personal de salud. Objetivo general: Validar cinco listas de cotejo, por panel de expertos (IDM y espaciador mascarilla, IDM y espaciador tipo boquilla, polvo seco tipo Diskus, polvo seco tipo turbohaler e inhalador se suave dispersión). Material y método: La validación llevó seis etapas: primera etapa, consistió en preparar instrucciones y planillas (listas de cotejo). Segunda etapa, seleccionar expertos, los cuales fueron dos neumólogos de adultos, 11 neumólogos pediatras y dos maestros en educación. Tercera etapa, se proporcionó bibliografía reciente. Cuarta etapa, validación del contenido donde se presentó a los 15 jueces, en planillas los ítems por separado de cada lista de cotejo se les explicó el procedimiento, y calificaron cada ítem. Quinta etapa, fue establecer acuerdos. Sexta etapa, prueba piloto, con las listas ya validadas para analizar la consistencia interna de las listas de cotejo, bajo el coeficiente alfa de Cronbach excediendo de 0.7 como valor mínimo para determinar la confiabilidad de las listas de cotejo. Séptima etapa, consiste en la aplicación de los instrumentos. Se estableció un escalafón, conocimiento de experto de 91-100 puntos, suficiente de 71-90 puntos, escaso de 51-70 puntos y pobre de $<50$ puntos. La innovación en las formas de evaluar, es importante por eso el desarrollo de estas listas de cotejo.

\section{Evaluación por competencias, en el uso de dispositivos de inhalación y aerocámaras, en los residentes de pediatría de la UMAE Hospital General Gaudencio González Garza Centro Médico Nacional "La Raza"}

Moysen SG, García VBAS,

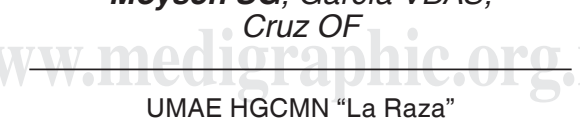

Introducción: El uso de dispositivos y espaciadores tiene como principal inconveniente, la dificultad de los pacientes para realizar una técnica adecuada. Se trata de una circunstancia de vital importancia, el que los profesionales de la salud realicen un adiestramiento minucioso en los pacientes, sobre el uso adecuado de los inhaladores con la finalidad de minimizar los errores. Objetivo: Evaluar el nivel de conocimientos por competencias en el uso de dispositivos para inhalación y aerocámaras de los residentes de Pediatría de la UMAE Hospital General, Centro Médico Nacional "La Raza”. Material y métodos: A los residentes de pediatría del CMN "La Raza” se les aplicó las listas de cotejo por competencias, previamente validadas por juicio de expertos, cada lista de cotejo consta de tres dominios, conocimientos, habilidades y actitudes. Las listas de cotejo se calificarán de 0 a 100, según las respuestas emitidas, listas A (IDM con espaciador mascarilla), lista B (IDM con espaciador tipo boquilla), lista $\mathrm{C}$ (polvo seco Diskus), lista D (polvo seco tipo turbohaler) y lista E (inhalador de suave dispersión). Se contabilizó la puntuación en cada una de las listas de cotejo, se llenó la hoja de captura de datos y se analizaron los resultados en el programa SPSS 2.0. Resultados: Participaron 51 residentes de los tres últimos años de pediatría. De las cinco listas, la mejor calificada fue la referente a IDM con aerocámara mascarilla con 55/100 calificándose como conocimiento escaso, la lista más baja fue la referente a polvo seco turbohaler con 27.6/100. Según los dominios calificados por competencias se encontró que las calificaciones más altas en general están en actitudes y habilidades, siendo el conocimiento el dominio más bajo. Conclusiones: Las calificaciones en todas las listas de cotejo reflejan conocimiento pobre o escaso; lo que evidencia la necesidad de mayor capacitación en el uso de dispositivos inhalados y aerocámaras.

\section{Valoración del}

nivel de ansiedad en padres de niños con neumopatías crónicas que llegan de primera vez al Servicio de Neumología Pediátrica 


\section{Moysen SG, Galicia RCP, Cruz OF}

Clínica de Enfermedades Lisosomales y Servicio de Neumología Pediátrica, UMAE HGCMN "La Raza"

Introducción: La enfermedad del niño es siempre un problema familiar, su calidad de vida está íntimamente relacionada con el apoyo familiar, los padres reaccionarán de manera distinta de acuerdo con su grado de vulnerabilidad. Esta reacción dependerá de factores tales como experiencia en situaciones de crisis y problemas médicos, estatus socio-económico, nivel de conocimientos, calidad de los servicios sanitarios y educativos y sistemas de apoyo. Justificación: En las valoraciones de Neumología Pediátrica, en la consulta de primera vez, encontramos que los padres cursan con un alto nivel de ansiedad, desconociendo el nivel de ésta y cómo ayudarlos. Objetivo general: Determinar el nivel de ansiedad de los padres de pacientes con neumopatía crónica, que acuden por primera vez al servicio de Neumología Pediátrica, de la UMAE, Hospital General Centro Médico "La Raza”. Material y método: En consulta externa se captó a padres con hijos que acudían por primera vez al servicio de Neumología Pediátrica. Se llenó la hoja de consentimiento informado, la hoja de captura de datos y el test de ansiedad de Beck (BAI), se buscaron porcentajes y asociaciones. Resultados: Se estudiaron 40 padres, de los cuales el $64 \%$ presentó algún grado de ansiedad. El nivel de ansiedad más frecuente fue leve en un $58 \%$. Los pacientes que tardan más de 24 meses en llegar al servicio de Neumología Pediátrica presentan el grado más alto de ansiedad, siendo ansiedad severa en un 35\%. Conclusiones: Se observó $64 \%$ de ansiedad en padres de niños con neumopatías crónicas que acuden por primera vez a neumopediatría. El nivel de ansiedad incrementa si el tiempo de llegada aumenta, encontrando la ansiedad severa predominantemente en el grupo que tardaba más de 24 meses en llegar a su consulta. Con lo anterior debemos tomar estrategias en disminuir el tiempo de llegada a la consulta de primera vez.

\section{Pruebas funcionales respiratorias en el asma bronquial. Estudio de 30 pacientes}

\section{Fernández $M$, * Jané $L A,{ }^{*}$ Clúa $C A,{ }^{\ddagger}$ Lima $A M{ }^{*}$}

${ }^{\star}$ Centro de Investigaciones Clínicas. Playa. La Habana. Cuba; ${ }^{\ddagger}$ Ministerio de Salud Pública. Plaza. La Habana. Cuba

Resumen: El asma bronquial, desde el punto de vista funcional respiratorio, en su fisiopatología pueden existir varios patrones. La espirometría forzada, pletismografía y la difusión del monóxido de carbono (DLCO) son de los estudios funcionales respiratorios que nos ayudan al diagnóstico y seguimiento de los casos. Objetivo: Describir el comportamiento de algunas de las variables del estudio de función pulmonar en pacientes asmáticos. Métodos: Se realizó investigación con método observacional de corte transversal. Se seleccionaron 30 pacientes asmáticos adultos escogidos al azar; que asistieron al Departamento de Pruebas Funcionales Respiratorias del Centro de Investigaciones Clínicas de Playa, La Habana, Cuba, para estudio, con síntomas diversos no reconocidos como de asma bronquial. Resultados: De los 30 pacientes que se les realizó espirometría basal 29 (97\%) presentaron limitación del flujo aéreo teniendo en cuenta la relación VEF1/CV < LIN, y 21 (70\%) presentaron limitación del flujo aéreo teniendo en cuenta la relación VEF1/ CVF $<70$. De los casos con obstrucción bronquial por la relación FEV1/VC, 12 (42\%) presentaron un FEV1 $\geq 80 \%$ y de estos casos con FEV1/VC < LIN y con $\mathrm{FEV} 1 \geq 80 \%, 10(84 \%)$ presentaron FEF25-75 $<60 \%$ del predicho y de ellos el $50 \%$ mejoró un $20 \%$ su valor posbroncodilatador (salbutamol espray $400 \mu \mathrm{g}$ ). Se realizaron 24 estudios de la DLCO, de ellos 23 cumplían criterio de obstrucción, de éstos 11 (48\%) presentaron una $\mathrm{Dsb} \geq 100 \%$ del predicho. Se realizaron estudios de pletismografía a los 30 casos estudiados, de ellos 3 $(10 \%)$ presentaron atrapamiento aéreo con un VR $\geq 120 \%$ del predicho. Conclusiones: Se evidenció la importancia del análisis del cociente VEF1/CV por debajo del LIN para determinar un proceso de tipo obstructivo y en los casos de pacientes obstructivos el análisis de la pequeña vía aérea para su diagnóstico y seguimiento.

\section{Cirugía}

\section{Experiencia en procedimientos de traqueoplastía en dos hospitales públicos de alta especialidad en el Bajío mexicano}

Narváez $\mathbf{S},{ }^{*}$ Ruiz $J,{ }^{*}$ Domínguez $M G,{ }^{*}$
Ayala $C,{ }^{*}$ Miranda $A,{ }^{\ddagger}$ Martínez $J L^{\ddagger}$

*Hospital Regional de Alta Especialidad del Bajío; ¥UMAE 1 Bajío

Introducción: El estándar de oro en el manejo de la estenosis traqueal benigna posintubación es la reconstrucción con anastomosis término terminal o traqueoplastía. De éstas, más del $90 \%$ de las cicatrices se producen en el tercio superior de la tráquea, pero no todas son susceptibles de intervención por la cercanía con las cuerdas vocales. En otros pacientes, la presencia de tumores que obstruyen la luz de la tráquea semejan el mismo cuadro de obstrucción. Esta revisión presenta la experiencia acumulada de estos procedimientos en los últimos siete años (2008-2015) en dos hospitales de tercer nivel en la ciudad de León, Guanajuato. Discusión: Se identificaron un total de 60 cirugías, realizados en 40 pacientes del sexo masculino y 20 del femenino, con una edad promedio de 32.9 años (14-80). Se realizaron 20 laringotraqueoplastías, 38 traqueoplastías cervicales y dos traqueoplastías torácicas. Las etiologías fueron: relacionadas a algún tipo de accidente o trauma (24), neumonía complicada (8), tumores de tráquea (2), y otras enfermedades con afección sistémica (20). El promedio de estancia 
hospitalaria fue de 4.6 días (3-8). Cita de control subsecuente al mes y a los tres meses para valoración y egreso. Mortalidad: un paciente $(1.6 \%)$ en el período posoperatorio mediato, debido a fuga aérea y neumonía asociada. Morbilidad: seis pacientes tuvieron complicaciones que derivaron en reestenosis (10\%), aunque en tres de ellos la nueva cicatriz no abarca más del $30 \%$ y se mantienen asintomáticos. Los tres restantes cuentan con cánula de traqueostomía. Conclusiones: La traqueoplastía es un procedimiento seguro en pacientes bien seleccionados y tiene un porcentaje de éxito de entre el $90-94 \%$, con rango de reestenosis de entre 3.4-5.6\%. Nuestra casuística, aunque breve, nos permite ir adquiriendo la experiencia necesaria para lograr las metas de satisfacción del procedimiento.

\section{Función pulmonar en pacientes pediátricos postrasplante alogénico de células hematopoyéticas}

\section{Hernández RFI, ${ }^{\star}$ Del Razo RR, * Olaya VA, ${ }^{\neq}$Ramírez URMN, $\neq$ López HG, ${ }^{\ddagger}$ Pérez $G M^{\ddagger}$}

*INER Ismael Cosío Villegas; 沼stituto Nacional de Pediatría

Introducción: La enfermedad injerto contra huésped (EICH) pulmonar incluye daño alveolar difuso como bronquiolitis obliterante (BO). 40-60\% de los pacientes postrasplante alogénico de células hematopoyéticas (TACH) tienen complicaciones pulmonares (CP) con mortalidad en un tercio de los casos y pueden manifestarse como patrón restrictivo u obstructivo. Existe reducción de la función pulmonar en $85 \%$ de los pacientes durante el primer año posTACH. $20 \%$ de los pacientes son asintomáticos con alteración de las pruebas de función respiratoria (PFR). Las PFR clasifican la gravedad. En $62 \%$ de los pacientes pediátricos se reporta una disminución del $10 \%$ de la función pulmonar en los primeros tres a nueve meses después del trasplante. Objetivo: Describir la función pulmonar en pacientes post TACH en función del FEV1. Material y método: Realizamos espirometría simple y posbroncodilatador a 23 pacientes de una cohorte posTACH: 10 tienen calidad adecuada, $80 \%$ masculinos, 8 trasplantados con células de sangre periférica (CSP) y 2 con sangre de cordón umbilical (CSCU). Cinco pacientes cumplieron criterios de $\mathrm{CP}$ tardía, todos recibieron trasplante de CSP. La mayoría tenían infiltrados en tomografía, un paciente había tenido CP temprana, dos tienen diagnóstico de $\mathrm{BO}$ y éstos recibieron trasplante de SC. Resultados: Espirométricamente encontramos cinco pacientes con patrón obstructivo y tres sugestivos de restricción (parece haber más pacientes obstruidos en el grupo de CSP sin haber sido estadísticamente significativo). Conclusiones: $80 \%$ de los pacientes posTACH presentan alteraciones espirométricas, la más frecuente es patrón obstructivo y el mismo porcentaje tiene alteraciones tomográficas sin asociarse el patrón espirométrico con el patrón radiológico.

\section{Síndrome de opérculo torácico. Experiencia en 5 años en el Hospital Civil de Guadalajara "Fray Antonio Alcalde"}

\section{Preciado AN, Mojica RCE, Sánchez VS, López TJG, Otazu ARM}

Hospital Civil de Guadalajara "Fray Antonio Alcalde"

El síndrome de opérculo torácico se caracteriza por la compresión de estructuras del paquete neurovascular en su paso desde la abertura torácica superior hacia la extremidad torácica determinando así, una variedad sintomatológica que hace una patología de difícil diagnóstico como tratamiento. La compresión puede traducirse en sintomatología neurológica, vascular o mixta y ésta a menudo es muy inespecífica, por lo que se requiere del conocimiento de esta entidad para su sospecha y realizar así, un plan de abordaje diagnóstico y proponer la estrategia quirúrgica. Objetivo: Presentar una serie de casos retrospectiva y observacional tratados desde el 01 de enero del 2010 al 31 de diciembre de 2015 en el Servicio de Cirugía de Tórax y Cardiovascular. Resultados: El número de cirugías realizadas fueron 25 casos en 24 pacientes; uno de ellos requirió una segunda cirugía dos años después debido a recidiva de la sintomatología. La compresión afectó a 15 pacientes en el lado derecho y 10 en el lado izquierdo. Con respecto al tipo de sintomatología, en 13 pacientes fue neurológico, 8 venosos y 4 arteriales. El abordaje utilizado fue axilar en 20 casos y supraclavicular en cinco. Procedimientos asociados con la descompresión fueron venoplastía en un caso, embolectomía en un caso y bypass subclavio axilar. Conclusión: El síndrome de opérculo torácico es una entidad subdiagnosticada por la gran variedad de sintomatología que ofrece dicha patología. La cirugía es un procedimiento reservado para aquellos casos en los que la rehabilitación, en caso de compresión neurológica ha resultado fallida. Mientras que en casos de compresión vascular es el tratamiento de elección asociado con procedimientos de descompresión como el bypass.

\section{Factores predisponentes de fístulas broncopleurales en pacientes operados de neumonectomía}

\section{Berrios MJA, Guzmán de Alba E, De la Rosa APA}

INER Ismael Cosío Villegas

Fístula broncopleural es la comunicación entre un bronquio y el espacio 
pleural, siendo de interés en este trabajo aquellas de origen central secundarias a neumonectomía. Una complicación inusual, con una incidencia del $4.5 \%$ luego de una neumonectomía, con una mortalidad reportada del 16-72\%, su tratamiento representa un verdadero reto. Hemos revisado nuestra experiencia con el objetivo de identificar los factores que influyen en la aparición de una fístula broncopleural. Material y métodos: Se realizó una revisión retrospectiva, de enero de 2002 a diciembre de 2013, incluyó 116 neumonectomías, se evaluaron variables locales y sistémicas, así como perioperatorias incluidas: sangrado, manejo del cierre bronquial, y la incidencia de fístula broncopleural y empiema, para el análisis estadístico se utilizó SPSS IBM 20, el valor de p se tomó como significativo 0.05 . Resultados: La incidencia global 7.6\% (9/116), predominó masculino, promedio de edad entre 36 a 65 años, etiología predominante fue neoplasias en $35 \%$, el hemitórax izquierdo se operó en un $57 \%$, pero con un $66 \%$ de FBP en el lado derecho, el $32 \%$ de los pacientes con un sagrado transoperatorio mayor a $\operatorname{los} 1,000 \mathrm{~mL}$, $70 \%$ de los cierres bronquiales fue con engrapadora quirúrgica. Se presentó un $7.7 \%$ de FBP y de los nueve pacientes fistulizados $66 \%$ tenían albúmina < $3.5 \mathrm{~g} / \mathrm{dL}$. Al asociar la hipoalbuminemia se encontró que el $13.9 \%$ (6/37) presentó fístula, en cambio el $4.28 \%$ (3/70) de los paciente sin hipoalbuminemia presentó fístula (p 0.05). Los bronquios cerrados con sutura manual, presentaron fístula broncopleural en el $17.8 \%(5 / 28)$, en comparación con el 5\% (4/79) de los pacientes cerrados con engrapadora ( $\mathrm{p}$ 0.05). Conclusiones: La hipoalbuminemia y el empleo de sutura manual para el manejo del muñón bronquial fueron los factores identificados como predictores de fístulas broncopleurales en pacientes neumonectomizados.

\section{Metastasectomías pulmonares en sarcomas}

Berrios MJA, Téllez BJL

INER Ismael Cosío Villegas

E1 30\% de los pacientes con neoplasia maligna sólida desarrollará metástasis pulmonar. En estudios retrospectivos se documenta aumento de la sobrevida a cinco años en pacientes con resección completa de $36 \%$ comparado con $13 \%$ de los pacientes con resección incompleta. Nos proponemos documentar los resultados de los pacientes sometidos a metastasectomía. Métodos: Se realizó una revisión retrospectiva de pacientes operados de metastasectomía con diagnóstico de sarcoma de enero 2008 a diciembre 2013, se incluyeron 16 pacientes, para el análisis estadístico se utilizó IBM SPSS Statistic 20. Resultados: Se incluyeron 16 pacientes sometidos a metastasectomía pulmonar, se excluyeron 2 por expedientes incompletos, 11 (69\%) masculinos, media de edad 29 años. La estirpe más frecuente fue osteosarcoma en el 64\%, seguido de sarcoma sinovial (22\%). 10 casos con presentación bilateral (62\%), los cuales fueron resecados de forma secuencial, la media de metástasis fue 6.13 con media de tamaño 2.38 $\mathrm{cm}$, el $75 \%$ de los casos se resecaron más frecuentemente por toracotomía, siendo la resección segmentaria el procedimiento más frecuente en el 12 (87.5\%); se documentó macroscópicamente resección radical en el $100 \%$, con una recurrencia de $43.8 \%$, con un tiempo medio a la recurrencia de 4.69 meses, la metastasectomía se repitió en el $37.5 \%$ de los casos, el muestreo de los nódulos del mediastino se realizó en el $6.3 \%$. La sobrevida media fue de 19.13 meses, IC 95\%: 14.4-23.7 meses. En los pacientes que presentaron un metástasis la media de sobrevida fue de 36 meses, en comparación con 16.71 meses en los que tenían más de un metástasis ( $p$ 0.003). Conclusiones: La metastasectomía es una intervención que aumenta la sobrevida de los pacientes con sarcoma; un menor número de metástasis se relaciona con una mayor sobrevida.

\section{Cierre de fístula bronquioesofágica mediante colocación de stent bronquial, reporte de un caso}

\section{Farah SI, Martínez AM, Moreno TJA, Romero DFN}

Centro Médico ISSEMyM, Toluca

Introducción: Las fístulas bronquioesofágicas son una entidad rara, clasificándose como congénitas o adquiridas, estas últimas presentándose como consecuencia de neoplasias, infecciones o trauma, se han propuesto diversos tratamientos donde la cirugía es el método de elección. En este caso presentamos la colocación de endoprótesis como tratamiento. Descripción: Mujer de 38 años, la cual inicia con síntomas de neumonía, agregándose disfagia y dolor torácico, realizándose endoscopia reportando estenosis esofágica distal, posteriormente presenta SIRA y salida de secreción gástrica por cánula orotraqueal, se realiza TC tórax y broncoscopia donde se evidencia la fístula, se realiza toracotomía izquierda por cirujano cardiovascular encontrando lesión de $2 \mathrm{~cm}$ en la pared posterior del bronquio principal izquierdo, realizándose cierre primario, esofagostomía y yeyunostomía, continuando con mala evolución y persistencia de la fístula, se decide colocar stent vascular recubierto mediante broncoscopia en bronquio principal izquierdo, presentando mejoría y remisión de la fístula, retirándose la ventilación mecánica y siendo egresada a los 30 días. Estudio histopatológico correspondiente a esofagitis, sin datos de malignidad. Discusión: Se ha aceptado la cirugía como el tratamiento de elección de esta etiología, pese a la poca información en la literatura reportándose tasas de complicaciones $>50 \%$, con recurrencias de hasta en $10 \%$, en este caso el manejo quirúrgico no fue resolutivo, por lo que recurrimos a un abordaje por broncoscopia y la colocación de stent vascular, a pesar de que existe poca 
evidencia sobre las endoprótesis en la vía aérea se reporta menor incidencia de complicaciones, pero mayor tasa de recurrencia, en nuestro caso la paciente evolucionó de manera satisfactoria a los tres meses. Conclusiones: La cirugía es el tratamiento más aceptado de las fístulas bronquioesofágicas; sin embargo, las complicaciones y los avances en mínima invasión han conducido a la búsqueda de nuevos tratamientos como la colocación de endoprótesis en la vía aérea.

\section{Complicaciones asociadas a operación de Nuss para corrección de pectus excavatum. Reporte de 3 casos}

Hanssen CF, Cárdenas ESM

IMSS

El pectus excavatum se define como una deformidad congénita de la pared torácica anterior, que afecta al esternón y a los 4-5 cartílagos costales inferiores, formando una concavidad. La operación de Nuss para la corrección del pectus excavatum consiste en la instalación bajo visión toracoscópica de una barra metálica retroesternal a través de incisiones laterales en el tórax por un período de dos a tres años. Se reporta una muy baja morbimortalidad. Se trata de tres pacientes con diagnóstico de pectus excavatum sin antecedentes de importancia ingresados a nuestro hospital. El primer paciente masculino de 21 años, a quien se le había colocado las barras hace cuatro años ingresó para recolocación por pobre respuesta, posterior al procedimiento se da de alta y siete días después regresa por presentar herida infectada más derrame pericárdico por lo que se decide retiro de barras. El segundo paciente masculino de 15 años el cual posterior a la cirugía presenta fiebre persistente, en la radiografía de tórax se documenta derrame pleural

derecho, mismo que se punciona y se deja catéter pleural para drenaje. En los cultivos de líquido pleural se documenta acinetobacter por lo que se da manejo antibiótico con mejoría del cuadro. El tercer paciente masculino de 18 años, el cual posterior a la cirugía se complica con hidroneumotórax izquierdo, se le realiza tomografía de tórax corroborándose éste, se le coloca sonda pleural para drenaje dando cultivo positivo de líquido pleural para acinetobacter y Staphylococcus epidermidis ameritando tratamiento antibiótico con vancomicina y piperacilina tazobactam para su resolución. La corrección del pectus excavatum por la operación de Nuss a pesar de ser mínimamente invasiva presenta complicaciones importantes dentro de las cuales, las principales vistas en nuestro hospital son: infección de herida, neumotórax, desplazamiento de la barra y pericarditis.

\section{Cirugía torácica UNIPORTAL, una opción más, una herida}

\section{menos}

\section{Céspedes MEE, Ruiz FJ, Tort MA, Echavarri AJM}

\section{ISSSTE}

Antecedentes: La cirugía torácica de mínima invasión ha ido en aumento a nivel mundial en los últimos años. Los beneficios de este abordaje incluyen: menor tiempo de recuperación, menor uso de analgésicos, regreso temprano al trabajo, mayor estética. De manera clásica, la VATS (video assisted thoracic surgery) se ha realizado-dependiendo del procedimiento- con 2 a 4 puertos. La cirugía torácica uniportal es una opción que permite retirar el resto de las incisiones con el mismo resultado quirúrgico. Objetivos: Llevar a cabo la cirugía torácica de mínima invasión por técnica uniportal. Métodos: Se seleccionaron todos los pacientes candidatos a cirugía torácica de mínima invasión y se aplicó la técnica uniportal. En decúbito lateral, bajo intubación selectiva y anestesia general se realizó incisión de toracotomía utilitaria a nivel del quinto o sexto espacio intercostal de 3 a $5 \mathrm{~cm}$ y se practicó la cirugía programada. Se utilizó material quirúrgico convencional y diseñado para VATS. Resultados: Del período comprendido del 01 de noviembre de 2015 al 15 de enero de 2016 se operaron 14 casos. Las edades comprendidas fueron de 40 a 73 años. Las cirugías realizadas fueron: resección de nódulo pulmonar (cuña): 5, biopsia pleural/pleurodesis: 3 , lavado y decorticación: 4, lobectomía: 2. Hubo dos conversiones: 1) cambio a técnica biportal por imposibilidad para alcanzar la región torácica posterior con instrumentos convencionales, y 2) conversión a técnica abierta por incapacidad para mantener la ventilación unipulmonar. No hubo mortalidad transquirúrgica. Conclusiones: La cirugía torácica uniportal es una opción más dentro de la mínima invasión en el tórax. Tiene la ventaja de una visión directa del objetivo quirúrgico y mayor estética al utilizar una sola herida. Puede realizarse de manera segura y es reproducible.

\section{¿Técnica abierta versus mínima invasión para la timectomía?}

Arriola JM, Ávalos BA

INER Ismael Cosío Villegas

Introducción: La timectomía consiste en la extirpación del timo. Blalock et al. en 1939 publicaron la primera timectomía de un paciente con un tumor mediastinal y MG. Desde entonces varios abordajes se han descrito para la realización de esta cirugía siendo preferentes las técnicas abiertas (TA) para los pacientes con timoma. Objetivo: Determinar los beneficios de la cirugía mínimamente invasiva (CMI) en la cirugía tímica. Métodos: Estudio descriptivo, retrospectiva en pacientes con timectomía entre los años 2006 y 2014. Se dividieron los pacientes en tres períodos. El período 1 entre los años 
2006 al 2011 correspondía al tiempo en donde la CMI era infrecuente. Período 2 el tiempo de transición en los abordajes por TA y CMI, en los años 2012 al 2013. Período 3 cuando la CMI ya era un procedimiento familiar para el cirujano, en el 2014. Resultados: 28 pacientes, 21 del sexo femenino y 7 masculinos, con una mediana de edad 37 años (Q1, 26 Q3, 55). La indicación para la cirugía fue $82 \%(\mathrm{n}=23)$ para MG y $12 \%(\mathrm{n}=5)$ para los timoma. El $10 \%(n=3)$ de los pacientes con MG tenían asociado timoma. Se realizó $69 \%(\mathrm{n}=18)$ y $31 \%$ de cirugías con TA y CMI teniendo 61 y $88 \%$ de mejoría clínica, respectivamente, en los pacientes con MG. Pacientes con timoma el $100 \%$ tuvo resultados satisfactorios en el primer año de vida en ambas técnicas. Dos pacientes (22\%) con complicaciones asociados con la CMI fueron observadas en el período de transición (período 2). Únicamente se observó mortalidad en la TA correspondiente al $5 \%(\mathrm{n}=1)$ siendo asociada a neumonía nosocomial. Conclusiones: La CMI presenta resultados similares a la cirugía con TA en los pacientes con MG y timoma recomendando su uso.

\section{Identificación de potenciales donadores de pulmón en la Ciudad de México}

Herrera JJ, * Mora GJ, * Santillán DPJ, * Rivera DE, Bolaños MFV, López JJL

*INER Ismael Cosío Villegas; ‘INNN Manuel Velasco Suárez; §INCMN Salvador Zubirán

Antecedentes: El trasplante de pulmón (TP) es la última opción terapéutica de pacientes que sufren enfermedades pulmonares en fase terminal. Actualmente, el número de pacientes potenciales para TP supera con creces al número de órganos trasplantables disponibles, tanto por el desconocimiento de las características del donador pulmonar como por la escasez de donadores de órganos. Objetivos: Identificar las características de los dona- dores cadavéricos en la Ciudad de México (CDMX) y determinar el cumplimiento de criterios de donación pulmonar. Métodos: Estudio prospectivo, transversal, cuya población son los donadores cadavéricos de la CDMX reportados por la red de los institutos y hospitales de la Secretaría de Salud (InSalud). Resultados: En dos años se atendieron 102 llamadas. Se evaluaron a los potenciales donadores y el cumplimiento de criterios de donación pulmonar. En $45 \%$ de los casos hubo negativa familiar, en el $34 \%$ el potencial donador tenía una contraindicación médica para donar y en el $21 \%$ se concretó la donación. Excluyendo las contraindicaciones de donación y tomando en cuenta a los potenciales donadores; 7 donadores (8.5\%) cumplieron criterios estándar de donación pulmonar, 7 donadores $(8.5 \%)$ cumplieron criterios ampliados, 11 donadores (13\%) cumplieron criterios extendidos de y 57 donadores (70\%) se encontraron fuera de criterios de donación pulmonar. Al corregir el índice de Kirby a la altura de la CDMX, tenemos que 19 pacientes tuvieron una $\mathrm{PaO}_{2} / \mathrm{FiO}_{2}=291.01+35.01 \mathrm{mmHg}$, 10 pacientes una $\mathrm{PaO}_{2} / \mathrm{FiO}_{2}=204.3+$ $10.5 \mathrm{mmHg}$ y 11 pacientes $\mathrm{PaO}_{2} / \mathrm{FiO}_{2}=$ $163.3+9.9 \mathrm{mmHg}$, lo que se tradujo en un aumento del número de potenciales donadores, quedando de la siguiente forma: 12 donadores (15\%) cumplieron criterios estándar, 14 donadores (17\%) cumplieron criterios ampliados y 11 donadores (13\%) cumplieron criterios extendidos. Conclusiones: Dentro del grupo de donadores cadavéricos de la CDMX existen potenciales donadores de pulmón.

\section{Endoscopia}

\section{Broncoscopia en el adulto mayor \\ Bautista D, Núñez PRC,Cicero SR}

Hospital General de México

Introducción: El aumento en la sobrevida ha hecho más notorio la prevalencia de enfermedades en el adulto mayor, entre ellas, las enfermedades respiratorias. Parte de su abordaje diagnóstico y terapéutico incluye realizar una broncoscopia, la cual tiene una baja morbimortalidad. Sin embargo, existen pocos estudios de broncoscopia en el adulto mayor publicados en décadas pasadas. Justificación: la broncoscopia continúa siendo un estudio necesario en el diagnóstico de enfermedades respiratorias en el adulto mayor. Material y métodos: Estudio observacional y descriptivo de pacientes adultos mayores (60 años o más), con indicación para broncoscopia (del período $1^{\circ}$ de enero al 31 de diciembre del 2015). Se calculó el riesgo quirúrgico (ASA). En todos los casos se usó anestesia local con lidocaína, y algunos requirieron sedación con midazolam o propofol. Se hizo revisión con luz blanca y se realizaron lavados bronquiales, cepillados y biopsias según la indicación. Resultados: Se hicieron un total de 547 broncoscopias, 175 en adultos mayores de 60 años (32\%), la edad máxima fue de 97 años, con una media de 68 años. Los principales diagnósticos: cáncer broncogénico $41 \%$ (57) y tuberculosis pulmonar $18.8 \%$ (26). La mayoría tuvo un ASA II 64.4\% (89). Las complicaciones fueron leves con una frecuencia de $28 \%$ (39). No hubo ninguna defunción. La mayoría de los pacientes aceptaría realizarse una nueva broncoscopia. Discusión: El estudio permitió el diagnóstico en la mayoría de los casos, las complicaciones fueron mínimas y se resolvieron durante el procedimiento. Conclusiones: La broncoscopia continúa siendo un estudio necesario en el diagnóstico y tratamiento de las enfermedades respiratorias del adulto mayor. Por el contrario a lo esperado, es un estudio seguro a pesar del mayor número de comorbilidades y los cambios anatómicos en las vías aéreas del adulto mayor.

\section{Lavado mediastinal, alternativa diagnóstica útil para evaluar la sobrevida del paciente con cáncer pulmonar}

Martínez M, * Morales GJ,‡ Peña $M E^{\ddagger}$

*Centro Médico ISSEMyM, Toluca; ‡INER Ismael Cosío Villegas 
Antecedentes: Numerosas publicaciones han comparado la exactitud de la mediastinoscopia y la tomografía computarizada (TC) en la estatificación de los pacientes con cáncer de pulmón, observando un número excesivamente alto de falsos negativos en la evaluación del compromiso mediastinal con TC (10 a $30 \%)$. A pesar de que la combinación de TC y tomografía por emisión de positrones (PET) ha demostrado mejorar la sensibilidad y especificidad, la información de estos estudios señala que esta estrategia no elimina la necesidad de una certificación histológica de la invasión de los ganglios mediastinales por mediastinoscopia. Objetivo: 1) El uso del lavado mediastinal en la mediastinoscopia es útil para el diagnóstico y estadificación en cáncer pulmonar. 2) Demostrar que la progresión de la invasión ganglionar ocurre del centro a la periferia invadiendo primero la cápsula y posterior el tejido adyacente. Método: Se realizó lavado mediastinal en tres tiempos diferentes como complemento a las mediastinoscopias realizadas del mes de agosto del 2012 a febrero del 2014, con conteo celular en todos los campos de los tres tiempos y se comparó con el reporte de la biopsia ganglionar, se analizaron los resultados. Resultados: Se realizaron 24 mediastinoscopias, 17 cumplieron con las características del estudio, en todos los casos se obtuvo reporte definitivo por citología de lavado mediastinal, nueve casos $(52.9 \%)$ presentaron positividad para involucro mediastinal, en seis casos $(66.6 \%)$ se modificó el estadío clínico realizado por PET + TC. Todos los casos en que se reportó positivo al lavado mediastinal tenían involucro ganglionar, estos casos correlacionan a lo reportado en la literatura como N3 con sobrevida del 6\%. Conclusiones: El lavado mediastinal como complemento de la mediastinoscopia es útil para diagnóstico y estatificación. La sobrevida de los pacientes con lavado mediastinal positivo tiene sobrevida similar a lo descrito en la literatura como N3.

\section{Rendimiento de la broncoscopia}

como método diagnóstico de cáncer de pulmón en el Centro Médico Nacional de Occidente-IMSS

Contreras FJ, Mendoza TLA, Hernández GD, Esparza $Q A L$

IMSS-Centro Médico Nacional de Occidente

Antecedentes: El cáncer pulmonar es la primera causa de muerte por cáncer a nivel mundial. La broncoscopia es una herramienta importante en el proceso de diagnóstico, el rendimiento depende de la visualización del tumor en el árbol bronquial, con rentabilidad total del 85\%. Objetivo: Evaluar el rendimiento de la broncoscopia en el diagnóstico de cáncer pulmonar en el CMNO-IMSS. Pacientes y métodos: Estudio observacional, descriptivo y retrolectivo. Se incluyeron todos los pacientes sometidos a broncoscopia diagnóstica con sospecha de cáncer pulmonar en el Hospital de Especialidades del Centro Médico Nacional de Occidente del IMSS en un período de seis meses. La información fue obtenida de los reportes de broncoscopia en los expedientes clínicos y de los registros anatomopatológicos. Se utilizó estadística descriptiva. Resultados: Se realizaron 175 broncoscopias en 68 (39\%) por sospecha de cáncer pulmonar, $60 \%$ hombres, la mediana de edad de 62 años. Se reportó obstrucción por compresión extrínseca o disminución de la luz en $38 \%$ (26/68); edema, atrofia o hipertrofia de mucosa respiratoria $35 \%$ (24/68), irregularidad de mucosa en $11 \%(8 / 68)$, tumor visible en $14 \%$ (10/68). En todos los pacientes se realizó biopsia bronquial, lavado y cepillado bronquial. La mediana del número de biopsias fue 4 . Se obtuvo diagnóstico en $42.6 \%$ de las broncoscopias realizadas $(29 / 68)$, en presencia de tumor visible $80 \%$ (8/10), irregularidad de la mucosa $87 \%$ (7/8), en presencia de obstrucción extrínseca o disminución de la luz 50\% $(13 / 26)$, en presencia de edema, atrofia o hipertrofia de mucosas $0.04 \%(1 / 24)$. El 51\% (15/29) fueron adenocarcinoma pulmonar, $13 \%$ (4/29) carcinoma epidermoide, 34\% (10/29) otros tipos. No hubo complicaciones asociadas. Conclusiones: La broncoscopia es un procedimiento útil y seguro en el diagnóstico de cáncer pulmonar. En presencia de tumoración visible o irregularidad de la mucosa el rendimiento broncoscópico es mayor.

\section{Pseudohemoptisis masiva en paciente con infarto agudo del miocardio, un diagnóstico difícil}

Cepeda VEA, * Sánchez JM, * Rodríguez GM, ${ }^{*}$ Cruz RF, ${ }^{*}$ Contreras GFJ, * Pérez SFJ, * García AKG*

*PEMEX; ‡IMSS

Introducción: La hemoptisis es un signo y a la vez un síntoma que con frecuencia acompaña a las enfermedades broncopulmonares, su diagnóstico diferencial puede ser a menudo difícil. Presentación del caso: Masculino 63 años, tabaquismo positivo índice tabáquico 49, alcoholismo positivo, no otras enfermedades crónico degenerativas, acudió a urgencias por dolor opresivo retroesternal, diagnosticándosele. Infarto agudo del miocardio más de 12 h de evolución, durante su estancia presentó tres eventos de expulsión de sangre por la boca cuantificados en $300 \mathrm{~mL}$ cada uno catalogándose hemoptisis masiva de origen a determinar, agudizándose el dolor retroesternal, gastroenterología realizó panendoscopia con dx de gastritis sin hemorragia, interconsulta a neumología, en interrogatorio el paciente refirió que la hemorragia se presentó al comer, rx de tórax normal, TC de tórax normal, fibrobroncoscopia resultado normal, por lo que se descartó razonablemente origen broncopulmonar, decidimos hacer una exploración minuciosa de estructuras supraglóticas faringe y 
retrofaringe encontrando una lesión exofítica con huellas de hemorragia en la base de la lengua, a quien ORL lo llevó cirugía logró la extirpación de la lesión, histológicamente quiste linfoepitelial de la base de la lengua corroborado por inmunohistoquímica. Discusión: El origen de la expulsión de sangre por la boca puede ser inferido por el aspecto macroscópico, en este caso la cantidad y aspecto de la misma orientaba a origen broncopulmonar, es importante recalcar que se hubiera podido terminar el estudio con un reporte de broncoscopia normal; sin embargo, fue determinante el interrogatorio para enfatizar la búsqueda de lesiones sospechosas. Conclusiones: Se trata de un caso con hemorragia catalogado como hemoptisis masiva y con factores de riesgo para $\mathrm{Ca}$ broncogénico, estudios de imagen normales, árbol raqueobronquial normal lo que obligó durante la broncoscopia aumentar la acuciosidad en la exploración y lograr un diagnóstico definitivo y tratamiento exitosos.

\section{Videomediastinoscopia sin videomediastinoscopio, una opción}

\section{Céspedes MEE, Ruiz FJ, Tort MA, Echavarri AJM}

\section{ISSSTE}

Antecedentes: La mediastinoscopia es un procedimiento fundamental para el cirujano de tórax. Permite la estadificación del cáncer pulmonar y el diagnóstico de otras enfermedades mediastinales. La videomediastinoscopia permite una mejor visión de las estructuras mediastinales debido a la magnificación de las imágenes, además de permitir el ingreso de instrumental adicional por el mismo campo de trabajo. Objetivos: Realizar videomediastinoscopia utilizando un laringoscopio y cámara de laparoscopia. Métodos: Se utilizó el mango de un laringoscopio convencional con hoja 4 recta y cámara de video de 5 o $10 \mathrm{~mm}$ y 30 grados. Con el paciente en decúbito dorsal, con hiperextensión cervical, bajo anestesia general e intubación no selectiva se realizó incisión cervical de 2 a $5 \mathrm{~cm}$, se ingresó a mediastino a través de la fascia pretraqueal y se introdujo laringoscopio con hoja recta y videocámara. Se utilizó instrumentación convencional de cirugía de nariz y laparoscopia. Resultados: Del período comprendido del $1^{\circ}$ de enero de 2013 al 15 de enero de 2016 se operaron 14 casos. Las edades comprendidas fueron de 40 a 84 años. Los diagnósticos fueron: linfoma: 6 casos; cáncer pulmonar: 6 casos; cáncer de mama: 1 caso; timoma: 1 caso. No hubo complicaciones. No hubo mortalidad posquirúrgica. Conclusiones: La videomediastinoscopia puede realizarse de manera segura con un laringoscopio convencional y una lente de 30 grados. Puede acceder a los lugares convencionales de la mediastinoscopia por video.

\section{Comparación del rendimiento diagnóstico del lavado bronquioloalveolar y la biopsia transbronquial en pacientes con neumonía e infección por VIH}

\section{Guadarrama C, Martínez MD,} Reyes TG, Sánchez CO

INER Ismael Cosío Villegas

Antecedentes: La broncoscopia es una herramienta diagnóstica fundamental para la evaluación de los pacientes con enfermedad pulmonar e infección por VIH. La realización de técnicas broncoscópicas de lavado bronquioloalveolar (LBA) y biopsia transbronquial (BTB) han demostrado diferentes rendimientos diagnósticos según la patología encontrada en los estudios reportados. Justificación: Este trabajo contribuirá a mejorar el rendimiento diagnóstico broncoscópico del paciente con VIH y neumonía, aplicando en la práctica clínica el co- nocimiento derivado de la investigación clínica para brindar un mejor y más oportuno diagnóstico, mejorando los desenlaces de los pacientes. Objetivo: Evaluar el rendimiento diagnóstico del LBA en comparación con la BTB en pacientes con neumonía e infección por VIH. Material y métodos: Estudio retrospectivo descriptivo de pacientes hospitalizados consecutivos con diagnóstico de neumonía y VIH, de agosto 2013 a abril 2015 en el INER. Se aplicó estadística descriptiva para cada una de las variables, utilizando medidas de tendencia central y de dispersión para las variables cuantitativas y frecuencias y porcentajes para las variables cualitativas. Análisis bivariado utilizando la prueba de $\chi^{2}$ y prueba exacta de Fisher para datos categóricos y t-Student para variables cuantitativas. Se determinó significancia estadística entre grupos tomando un valor de p menor de 0.05. Se midió el rendimiento diagnóstico del LBA y las biopsias utilizando como el estándar de oro el diagnóstico final. Resultados: Se incluyeron 199 pacientes, media de edad de 34 años (34-38), predominaron los hombres $(91.5 \%)$. La relación $\mathrm{PaO}_{2} / \mathrm{FiO}_{2}$ tuvo una diferencia estadísticamente significativa entre los dos grupos. El rendimiento diagnóstico global del LBA tuvo una sensibilidad de $66.7 \%$ y especificidad $100 \%$, VPP del $100 \%$ y VPN del $30 \%$. Mientras que la BTB presentó una sensibilidad diagnóstica de $91.4 \%$, especificidad $100 \%$, VPP $100 \%$, VPN $62.5 \%$. Conclusiones: El rendimiento diagnóstico de la BTB fue mayor (91.4\%) en comparación con el LBA (66.7\%). La BTB deberá ser considerada como primera opción dentro del abordaje diagnóstico de los pacientes con neumonía y VIH.

\section{Experiencia en la} extracción broncoscópica de cuerpos extraños en lactantes

Rodríguez I, Ramírez FJL, Furuya MMEY, Vargas BMH

Hospital de Pediatría, CMN SXXI 
Antecedentes: La aspiración de cuerpos extraños en niños es una urgencia frecuente y potencialmente letal. La incidencia es de $0.33 \%$ a $0.9 \%$ del total de ingresos por urgencias en los hospitales pediátricos. El tratamiento consiste en la extracción del cuerpo extraño mediante broncoscopia; existe controversia en la utilidad del broncoscopio flexible para el manejo de esta patología; las publicaciones sobre su aplicación en niños, principalmente preescolares o mayores, reportan tasas de éxito similares al broncoscopio rígido. Objetivo: Analizar la experiencia de la Unidad de Endoscopia Respiratoria del Hospital de Pediatría CMN SXXI en el uso de la broncoscopia para la extracción de CE de la vía aérea de lactantes. Métodos: Se realizó un estudio retrospectivo, observacional y descriptivo se revisaron las broncoscopias realizadas desde enero de 1994 a junio de 2015; de un total de 4,660 broncoscopias se seleccionaron las realizadas a lactantes con diagnóstico final de aspiración de cuerpo extraño y se hizo un análisis descriptivo de las variables. Resultados: Se encontraron 63 pacientes con cuerpo extraño $62 \%$ hombres y $38 \%$ mujeres, la mediana de edad fue de 15 meses; con una mediana del tiempo de evolución desde la aspiración del cuerpo extraño hasta su extracción de cinco días. El tratamiento inicial fue mediante broncoscopia rígida en 28 pacientes $(44.4 \%)$ siendo exitosa en 26 casos $(92.8 \%)$ y flexible en 35 pacientes (55.6\%), con éxito en 29 casos $(82.8 \%)$. Entre los cuerpos extraños predominaron los orgánicos (74.7\%), con una localización predominantemente en el bronquio principal derecho (42.8\%). Se analizó la elección del tipo de broncoscopia en dos períodos: de 1994 a 2004, predominando la broncoscopia rígida y de 2005 a 2015 la flexible $(\mathrm{p}<0.0001)$. Conclusiones: Tanto la broncoscopia rígida como la flexible fueron exitosas. La broncoscopia flexible en nuestro medio es el tratamiento de elección para la extracción de cuerpo extraño en los últimos años.

\section{Experiencia inicial en el uso de}

videotoracoscopia en derrame pericárdicos en el Instituto Nacional de Ciencias Médicas y Nutrición Salvador Zubirán

Herrera JJ, * Bolaños MFV, * Domínguez OD, * Catrip TJM, * Santillán DPJ"

*INER Ismael Cosío Villegas; ‡INCMN Salvador Zubirán

Antecedentes: El derrame pericárdico puede tener etiología benigna y maligna. Actualmente en pacientes con estabilidad hemodinámica el tratamiento de elección se realiza con técnicas de mínima invasión. Objetivos: Estandarizar el abordaje toracoscópico con ventana 4 x $4 \mathrm{~cm}$ en pacientes con derrame pericárdico y estabilidad hemodinámica. Métodos: Estudio prospectivo, descriptivo, observacional de tres meses (octubre 2015-enero 2016) cuya población fueron nueve pacientes con derrame pericárdico presentados al Servicio de Cirugía de Tórax del INNSZ. Se evaluaron las variables: edad, sexo, tiempo de estancia preoperatoria, postoperatoria, morbilidades. Las muestras obtenidas se mandaron a cultivo y patología. Resultados: En un período de tres meses se realizaron nueve ventanas pericárdica de 4 x 4 $\mathrm{cm}$ vía toracoscópica. Al diagnóstico el $100 \%$ presentó cardiomegalia grado III/IV en la radiografía de tórax y alteraciones electrocardiográficas. De los nueve pacientes, cinco fueron hombres y cuatro mujeres, la edad promedio 51 años (20-83 años). El diagnóstico preoperatorio de derrame pericárdico se hizo en el $66.6 \%$ y en el $33.3 \%$ tamponade. Sólo en un tercio fue conocida la causa que originó el derrame pericárdico. El tiempo quirúrgico fue de 47.7 minutos (20-63 minutos), la estancia posoperatoria fue de 5.7 días (4-12 días). El promedio de volumen evacuado fue de $1,505 \mathrm{~cm}^{3}(800-2,000$ $\mathrm{cm}^{3}$ ). Los drenajes se retiraron al quinto día posquirúrgico, con $150 \mathrm{~mL}$ en $24 \mathrm{~h}$.
No hubo complicaciones y sólo un paciente presentó recidiva. Conclusión: En pacientes con inestabilidad hemodinámica se debe realizar pericardiocentesis de urgencia. En caso de que no se logre la pericardiocentesis, se debe realizar una ventana pericárdica subxifoidea. En pacientes con estabilidad hemodinámica, la ventana pericárdica vía toracoscópica es un procedimiento factible, seguro y reproducible. En nuestra experiencia este abordaje pudiera ser el tratamiento estándar de oro en el manejo de derrame pericárdicos.

\section{EPOC Y tabaquismo}

\section{Polimorfismos rs1801272[A], rs28399433[G] y rs4105144[T] en CYP2A6 asociados con la adicción a la nicotina en mestizos mexicanos $^{a}$}

López-Flores LA, Pérez-Rubio G, Noé-Díaz V, García-Gómez L, Contreras-Romero R, RamírezVenegas A, Sansores-Martínez $R$, Falfán-Valencia $R$

INER Ismael Cosío Villegas

Antecedentes: La adicción a la nicotina es una enfermedad compleja y multifactorial, incluye factores ambientales y genéticos. La enzima codificada por el gen CYP2A6 es responsable de más del $80 \%$ del metabolismo de la nicotina. Fumadores modulan su comportamiento de fumar para obtener los niveles deseados de nicotina según los alelos que porten de CYP2A6. Objetivos: Identificar susceptibilidad genética asociada con polimorfismos en CYP2A6 a la adicción a la nicotina en fumadores mestizos mexicanos. Métodos: Se seleccionaron 658 fumadores mestizos mexicanos clasificados de acuerdo con: patrón de consumo de cigarros por día, edad de inicio al tabaquismo, test de Fagerström de dependencia a la nicotina (FTND), 
índice de gravedad de tabaquismo (HSI) y cesación tabáquica. Se genotipificaron los rs1801272, rs28399433 y 4105144 mediante sondas TaqMan por el ensayo de discriminación alélica (PCR en tiempo real). Se consideraron asociaciones estadísticamente significativas cuando p $<0.05$. Resultados: En la comparación de fumadores con dependencia alta (DA, FTND $\geq 7$ ) a la nicotina contra fumadores con dependencia leve (DL, FTND $\leq 3)$, el alelo rs1801272 [A] está asociado con dependencia leve $(\mathrm{p}=$ 0.031 , OR $=0.214$ ). Por otro lado, mediante el HSI, el rs28399433[G] en la comparación de fumadores con DA a la nicotina (HSI $\geq 5$ ) con fumadores con DL a la nicotina (HSI $\leq 2$ ), se obtuvo un valor $\mathrm{p}=0.027$, $\mathrm{OR}=0.416$; además, en la comparación de fumadores con DL a la nicotina (evaluada por HSI) con fumadores sin dependencia $(\mathrm{SD}=$ 0 HSI) se obtuvo un valor $\mathrm{p}=0.005$, $\mathrm{OR}=2.407$ (IC 95\% 1.297-4.469). En el rs4105144 [T] en la comparación de los fumadores que tuvieron éxito a la cesación contra los que no intentaron dejar de fumar, se obtuvo un valor ( $p$ $=0.008)$. Conclusiones: Las variantes genéticas rs1801272[A], rs28399433[G] y rs4105144 [T] en el gen CYP2A6 están involucrados en el comportamiento de la adicción a la nicotina en fumadores mexicanos mestizos.

a Trabajo seleccionado para ser presentado de forma oral.

Identificación de variantes genéticas de alto riesgo en el receptor de serotonina 2A (HTR2A) que predisponen a consumo de cigarro y mayor grado de adicción a la nicotina ${ }^{a}$

Pérez G, Ramírez-Venegas A, Sansores-Martínez R, Camarena OÁ, Noé DV, Contreras RR, García GL, Falfán-Valencia $R$

INER Ismael Cosío Villegas
Antecedentes: La adicción a la nicotina afecta al sistema nervioso central; el receptor de serotonina $2 \mathrm{~A}$, codificado por HTR2A, debido a su función es de gran interés; en población caucásica existen SNPs asociados con mayor consumo de cigarro. Objetivo: Identificar SNP en HTR2A, asociados con consumo de cigarro y mayor grado de adicción en población mestiza mexicana. Métodos: Sujetos mestizos mexicanos, $\geq 30$ años; divididos en tres grupos: 438 no fumadores (NF), 583 fumadores ligeros (FL, consumo de 1-10 cigarros por día [cpd]) y 574 fumadores pesados (FP, $\geq 20 \mathrm{cpd}$ ). Se genotipificaron ocho SNP mediante PCR en tiempo real. Para evaluar la asociación a consumo de cigarro se compararon los grupos FP y FL vs. NF; para la asociación al grado de adicción a la nicotina se realizó la comparación FP vs. FL. El análisis alélico se realizó mediante una $\chi^{2}$ y valor de p con corrección de Bonferroni. Resultados: El alelo A del rs6313 (exón 1) se encuentra asociado con riesgo de consumo de cigarro, en las comparaciones FL vs. NF y FP vs. NF (OR = 2.13 y 3.30 , respectivamente). El alelo $\mathrm{T}$ del rs6311 (promotor) fue asociado con mayor consumo de cigarro en la comparación FP vs. NF. El alelo A del rs6313 se encontró asociado con mayor grado de adicción a la nicotina $(\mathrm{OR}=1.55)$. Conclusiones: En población mestiza mexicana, el consumo elevado de cigarros se encuentra influenciado por los alelos rs6313A y rs6311T ubicados en el gen HTR2A; mientras que el riesgo de presentar mayor grado de adicción se encuentra asociado con la presencia del alelo rs6313A. Polesskaya en 2006 reportó que estos polimorfismos se encuentran en regiones ricas en islas $\mathrm{CpG}$, éstas afectan el patrón de metilación del gen y como consecuencia, los niveles de expresión del mismo.

a Trabajo seleccionado para ser presentado de forma oral.

\section{Variantes en los genes HSPA1} asociadas con susceptibilidad genética y gravedad de la EPOC secundaria a tabaquismo ${ }^{a}$

\begin{abstract}
Ambrocio E, * Pérez-Rubio G, * Abarca-Rojana E, Ramírez-Venegas $A,{ }^{*}$ Sansores $R,{ }^{*}$ Velázquez-Uncal $M,{ }^{*}$ Hernández-Zenteno $R$, * VelázquezMontero $A$, * Sánchez $C$, ${ }^{*}$ Flores-Trujillo $F,{ }^{*}$ Espinoza de los Monteros $C$, ${ }^{*}$ Falfán-Valencia $R^{*}$
\end{abstract}

*INER Ismael Cosío Villegas;

†Instituto Politécnico Nacional

Antecedentes: La enfermedad pulmonar obstructiva crónica (EPOC) es un padecimiento inflamatorio complejo, atribuible a factores ambientales y genéticos. Los genes HSPA codifican proteínas encargadas de regular respuestas en contra de agentes oxidantes, inflamación crónica. La presencia de SNP en los genes que las codifican puede contribuir a la gravedad de la EPOC y el padecimiento en edades más tempranas. Objetivos: Describir la asociación entre polimorfismos en genes HSPA1, la susceptibilidad y gravedad de la EPOC secundaria a tabaquismo. Metodología: Se incluyeron 743 fumadores sin EPOC (FSE) y 380 pacientes con EPOC secundaria a tabaquismo (EPT). Se genotipificaron ocho variantes tipo SNP en HSPA1A, HSPA1B y HSPA1L mediante PCR en tiempo real. Se compararon las frecuencias genotípicas, y la presencia de haplotipos asociados con el padecimiento, así como asociaciones entre SNP y variables fenotípicas cuantitativas mediante regresión lineal. Resultados: Los genotipos rs562047 CG ( $\mathrm{p}=0.0010)$, rs1008438 AA $(\mathrm{p}=$ $0.0215)$ en HSPA1A; rs6457452 CT (p $=0.0079), \mathrm{rs} 2763979 \mathrm{CC}(\mathrm{p}=0.0046)$ en HSPA1B y rs178586061 GC ( $\mathrm{p}=$ 0.000003.) en HSPA1L están asociadas a un riesgo aumentado de padecer EPOC (OR 1.47-1.94). Al estratificar los casos por gravedad GOLD ( + II vs. III + IV); se identificó que los genotipos rs562047 CG ( $\mathrm{p}=0.0006$, $\mathrm{OR}=2.0213.), \operatorname{rs} 6457452 \mathrm{GC}(\mathrm{p}=$ 0.06339, OR = 1.5768.), rs $2763979 \mathrm{CC}$ $(\mathrm{p}=0.03869, \mathrm{OR}=1.5559)$ y rs6457452 
$\mathrm{GC}(\mathrm{p}=0.0000045, \mathrm{OR}=2.3993$. están asociados con estadíos menos severos de la enfermedad; por otro lado los genotipos rs1008438 AA ( $\mathrm{p}=$ $0.00011, \mathrm{OR}=2.5899)$ y rs6457452 CT $(\mathrm{p}=0.02442, \mathrm{OR}=2.0747)$. Adicionalmente, encontramos que el decline de la función pulmonar correlaciona con los $\operatorname{rs} 1008438(\mathrm{p}=0.002, \beta=-0.119)$, rs6457452 ( $\mathrm{p}=0.001, \beta=-0.124) \mathrm{y}$ rs2763979 ( $\mathrm{p}=0.0000, \beta=0.147)$. Conclusiones: Existe una fuerte asociación entre SNP en los genes HSPA1 y el riesgo de padecer EPOC secundaria a tabaquismo, así como a la gravedad de la misma.

a Trabajo seleccionado para ser presentado de forma oral.

\section{Cambios de sonidos torácicos posterior a tratamiento con pirfenidona en síndrome combinado fibrosis-enfisema}

\section{Bogetti M, Mejía M, Charleston- Villalobos S, Aljama-Corrales T, González-Camarena R, Mateos $H$, Buendía-Roldán I}

INER Ismael Cosío Villegas

Introducción: El síndrome combinado fibrosis-enfisema (SCFE) consiste en una combinación de enfisema pulmonar en regiones apicales y fibrosis en regiones basales. Es una entidad poco estudiada y al igual que la fibrosis pulmonar idiopática (FPI) carece de un tratamiento específico. Es posible que estudios y tratamientos novedosos como el análisis computarizado de sonidos pulmonares y la pirfenidona aporten nueva información con respecto a esta entidad. Material y métodos: Se realizó un estudio prospectivo en el Instituto Nacional de Enfermedades Respiratorias utilizando una muestra por conveniencia de pacientes con diagnóstico de SCFE de marzo a julio del 2014 que recibieron tratamiento con pirfenidona $1800 \mathrm{mg} / \mathrm{d}$. Se efectuaron estudios de sonidos pulmonares al momento basal y a los seis meses de seguimiento. Resultados: Se identificaron 15 pacientes con SCFE, seis fueron excluidos y tres eliminados, seis pacientes completaron el estudio. Los parámetros analizados del estudio multicanal de sonidos pulmonares fueron las frecuencias percentilares, encontrando diferencias significativas a los seis meses en las percentilas f25, f50 y fmax. Se observó que estas diferencias estuvieron localizadas en las zonas apicales, en comparación con las basales. Discusión: Los sonidos pulmonares empeoraron a los seis meses a pesar del tratamiento con pirfenidona. La discrepancia entre regiones apicales y basales, sin embargo, hace referencia a que las zonas fibróticas tuvieron una tendencia hacia la estabilidad en comparación con las zonas enfisematosas. Conclusiones: La pirfenidona, al parecer, beneficia al SCFE, estabilizando las regiones fibróticas ya que a los seis meses no hubo evidencia de progresión como se ha reportado en FPI, sin embargo, las zonas con enfisema no se vieron modificadas con este tratamiento. Es necesario ampliar el tamaño de la población para confirmar que estos resultados sean verídicos y evaluar cuáles pueden ser las mejores opciones terapéuticas para SCFE (antifibrosantes/broncodilatadores).

\section{Costo del tratamiento ambulatorio vs. \\ Tratamiento hospitalario en pacientes con enfermedad pulmonar obstructiva crónica en una Institución Pública de Salud Mexicana}

Cordero CLM, * Huicochea BJL, Herran Díaz-Granados S, ${ }^{\ddagger}$ Báez RFB ${ }^{\ddagger}$

*Health Consultings; ‘Boehringer Ingelheim

Objetivos: Estimar los costos de atención necesarios para el tratamiento de exacerbaciones en EPOC en pacientes ambulatorios y hospitalarios en el Instituto Mexicano del Seguro Social (IMSS). Metodología: De enero a diciembre del 2013, se realizó un estudio retrospectivo para estimar los costos de atención de las exacerbaciones en EPOC. La categorización de las exacerbaciones y los patrones de tratamiento en este estudio fueron aquellos establecidos por la institución (guía de tratamiento del IMSS). Los registros de pacientes fueron obtenidos de bases electrónicas públicas para una cohorte de 11,822 pacientes que sufren EPOC. Tratamiento ambulatorio y hospitalario fueron los criterios para establecer el uso de frecuencia y recursos médicos, incluyendo consultas médicas familiares y de especialidades así como la utilización de servicios de urgencias, al igual que los insumos utilizados en la atención (medicamentos, laboratorios, etc.). Los costos de atención utilizados fueron obtenidos de los tabuladores del IMSS publicados en 2015 por el IMSS del 1 de enero al 31 de diciembre de 2015. Con esta información se calculó el costo de la atención de acuerdo con el tipo de servicio según costos unitarios publicado por la institución. Resultados: En 2013, se reportaron 16,122 episodios de exacerbaciones por los pacientes considerados en el estudio. Pacientes mayores a 45 años representan el $97 \%$ de los casos; donde individuos mayores a 65 años (81\%) fueron los más frecuentes. Pacientes hospitalizados reportaron un promedio de 5.6 días de estancia. El costo promedio anual de tratamiento ambulatorio asciende a los $\$ 21,528.93$ pesos mientras que, en tratamiento hospitalario asciende a $\$ 212,962.44$ pesos. Un análisis unitario de costos de cuidados muestra que pacientes hospitalarios $v s$. ambulatorios requieren un incremento significativo de uso de medicamentos (372\% más) y un aumento en el uso de servicios de emergencia (50\% más), entre otros gastos. Conclusión: El costo agregado del tratamiento de exacerbaciones en pacientes con EPOC muestra que atención hospitalaria $v s$. atención ambulatoria es 9.89 veces más alto. Esto indica que para que los gastos no escalen muy alto, 
es necesario escoger los tratamientos adecuados que ayuden a controlar estos eventos y con ello reducir el impacto económico que representa esta enfermedad para las instituciones de salud.

\section{Enfermedad pulmonar obstructiva crónica, prevalencia de insuficiencia cardíaca derecha y comorbilidades asociadas}

\begin{abstract}
Juárez LE, Orea TA, González ID, Hernández ZR, Cintora MC, SánchezSantillán R, Pineda JJ, Peláez HV, Pablo SR, Velázquez MA, Contreras RE, Herrera SR, Sansores MR, Flores TF, Espinosa de los Monteros $C$, Santellano JB, Ramírez VA
\end{abstract}

INER Ismael Cosío Villegas

Introducción: En los pacientes con enfermedad pulmonar obstructiva crónica (EPOC) las comorbilidades son comunes y tienen gran impacto en el estado de salud y pronóstico, especialmente las cardiovasculares cuya prevalencia es alta. De éstas, la insuficiencia cardíaca (IC) alcanza el 30 a 36\%. Objetivo: Describir la prevalencia de ICD, así como describir las comorbilidades de los pacientes con EPOC en presencia y ausencia de ICD. Metodología: Estudio transversal en pacientes con EPOC $(\mathrm{n}=132)$ del Instituto Nacional de Enfermedades Respiratorias Ismael Cosío Villegas, realizado de septiembre a diciembre del 2015. Se evaluaron variables demográficas y comorbilidades. Las variables cualitativas fueron evaluadas por $\chi^{2}$ y las cuantitativas por t-Student para muestras independientes. Resultados: De 132 pacientes con EPOC la prevalencia de ICD fue de $53.8 \%$. Las características entre los pacientes que presentaron ICD y los que no fueron: edad (73.87 $\pm 8.14 \mathrm{vs}$. $73.88 \pm 9.37, \mathrm{p}=0.99)$, hombres $(44.4 \%$ vs. $48.3 \%, \mathrm{p}=0.65)$, respecto a las comorbilidades se encontraron diferencias estadísticamente significativas en dislipidemias $(5.6 \%$ vs. $18.3 \%, \mathrm{p}=$

$0.028), \operatorname{EVC}(27.8 \%$ vs. $10 \%, \mathrm{p}=0.011)$ y tromboembolia pulmonar $(27.8 \%$ vs. $13.3 \%, \mathrm{p}=0.043)$, mientras que en el resto de las comorbilidades no se observó diferencia: diabetes $(30.6 \%$ vs. $36.7 \%, \mathrm{p}=0.45)$, cáncer $(11.3 \%$ vs. $11.7 \%, \mathrm{p}=0.94)$, asma (12.9\% vs. $25 \%$, $\mathrm{p}=0.075)$, SAOS (6.9\% vs. $8.3 \%, \mathrm{p}=$ $0.76)$, hipertensión pulmonar (34.7\% vs. $26.7 \%, \mathrm{p}=0.31$ ), enfermedad vascular $(19.4 \%$ vs. $18.3 \%, \mathrm{p}=0.87)$, insuficiencia renal $(15.3 \%$ vs. $20 \%, \mathrm{p}=0.47)$, hipertensión arterial (67.1\% vs. 59.3\%, $\mathrm{p}=0.35)$, enfermedad coronaria $(17.9 \%$ vs. $19.6 \%, \mathrm{p}=0.8)$.

\section{Ansiedad y depresión en pacientes con enfermedad pulmonar obstructiva crónica: diferencias por etiología}

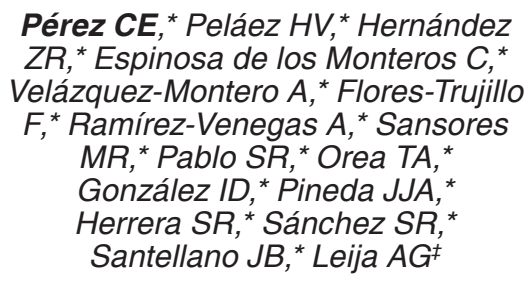

*INER Ismael Cosío Villegas; \#Instituto Politécnico Nacional

Antecedentes: La etiología de la EPOC es principalmente el antecedente tabáquico; sin embargo, un porcentaje considerable de la población que la desarrolla está expuesto a humo de biomasa. La depresión y ansiedad son de las principales comorbilidades, lo que afecta la calidad de vida y contribuye con peor pronóstico, teniendo como resultado ser la tercera enfermedad a nivel mundial de mortalidad. Objetivos: Comparar la proporción de pacientes con EPOC que presentan ansiedad y/o depresión dependiendo de etiología (humo de leña, humo de tabaco). Método: Se realizó un estudio descriptivo-transversal, donde se aplicó la escala de ansiedad y depresión hospitalaria (HADS) a 45 pacientes (62.2\% hombres); edad promedio 70.5 años, con diferente etiología de EPOC.
Los resultados fueron analizados con la prueba $\chi^{2}$. Resultados: Por antecedente etiológico y grado de ansiedad se encontró lo siguiente; a) humo de tabaco: ausencia $45.9 \%$, leve-moderada $43.2 \%$, severa $10.8 \%$; b) humo de leña: ausencia $15.4 \%$, leve-moderada $69.2 \%$, severa $15.4 \%$. Para depresión; a) humo de tabaco: ausencia $18.9 \%$, leve-moderada $59.5 \%$, severa $21.6 \%$ $\left.\left(\chi^{2}=10.025(2), \mathrm{p}<.007\right) ; \mathrm{b}\right)$ humo de leña: ausencia 7.7\%, leve-moderada $23.1 \%$, severa $69.2 \%\left(\chi^{2}=10.33(2), p<\right.$ .006). Para ansiedad no se encontraron diferencias significativas. Conclusiones: El grado de depresión muestra diferencias cuando la etiología de la enfermedad es distinta. Con humo de leña se encontró mayor grado severo de depresión en comparación con humo de tabaco, posiblemente por factores de riesgo relacionados como sexo, nivel educativo y sociodemográfico. Lo que sugiere retomar la importancia de éstos en estudios posteriores. Los resultados presentados son preliminares, por lo que se propone ahondar en el estudio.

\section{Insuficiencia cardíaca derecha como factor de riesgo para evento vascular cerebral en pacientes con enfermedad pulmonar obstructiva crónica}

\section{Orea TA, Hernández ZR, Bozada GK, González ID, Santellano JB, Cíntora MC, Sánchez SRN, Pineda JJ, Peláez HV, Flores TF, Pablo SR, Ramírez VA, Sansores MR, Contreras RE, Herrera SR, Espinosa de los Monteros $C$, Pérez CE, Leija AG, Velázquez MA}

INER Ismael Cosío Villegas

Antecedentes: La enfermedad pulmonar obstructiva crónica (EPOC) es una entidad con elevada morbimortalidad a nivel mundial, para el año 2020 se estima en el tercer puesto sólo superada 
por la cardiopatía isquémica y la enfermedad cerebrovascular (EVC). Los pacientes con EPOC tienen un mayor riesgo de morbimortalidad por causas cardiovasculares como: cardiopatía isquémica, insuficiencia cardíaca, arteriopatía periférica, diabetes mellitus, depresión, enfermedad tromboembólica, hipertensión pulmonar, insuficiencia renal, arritmias cardíacas y obesidad. La prevalencia de insuficiencia cardíaca (IC) en pacientes con EPOC es de 27\%. Objetivo: Evaluar la prevalencia de eventos vasculares cerebrales (EVC) en pacientes con IC derecha y determinar si ésta es factor de riesgo para desarrollar EVC en pacientes con EPOC. Material y métodos: Estudio de cohorte retrospectivo, en el cual se enrolaron 90 pacientes mayores de 18 años con diagnóstico de EPOC del Instituto Nacional de Enfermedades Respiratorias Ismael Cosío Villegas del año 1999 a julio del 2015. Los criterios de inclusión fueron: diagnóstico de EPOC confirmado por espirometría e IC derecha confirmada mediante ecocardiograma y el EVC mediante TAC de cráneo y ecocardiografía. Los pacientes con fibrilación atrial fueron excluidos. Se realizó una t Student para muestras independientes con la finalidad de observar las diferencias de los pacientes con y sin EVC. Para evaluar el riesgo de presentar EVC en IC derecha, se realizó una regresión logística, ajustada por variables confusoras: edad, sexo, enfermedad vascular periférica, diabetes mellitus y hemoglobina. Resultados: Se evaluaron 90 pacientes (edad: $74.74 \pm 7.40$ años). Las diferencias entre los pacientes que con y sin y EVC fueron: diabetes mellitus $(53.8 \%$ vs. $25.4 \%, \mathrm{p}=0.010)$, tromboembolia pulmonar $(69.2 \%$ vs. $28.1 \%, \mathrm{p}=0.001)$, cardiopatía isquémica ( $8 \%$ vs. $32.8 \%$, $\mathrm{p}=0.016)$, enfermedad vascular periférica $(65.4 \%$ vs. $21.9 \%, \mathrm{p}=0.001)$, hipertensión arterial pulmonar $(88.5 \%$ vs. $50 \%, \mathrm{p}=0.001)$, insuficiencia cardíaca $(96.2 \%$ vs. $78.1 \%, \mathrm{p}=0.038)$, IC derecha $(83.33 \%$ vs. $27.87 \%$, p < 0.001$)$, PCR (3.4 [3.4-4.2] vs. 2.3 [2.3-2.97], p $<0.001)$. Los pacientes con IC derecha tuvieron mayor riesgo de EVC (35.93 [IC: 3.21-401.49, p = 0.004]) dicho valor ajustado por edad, sexo, diabetes mellitus, hemoglobina y enfermedad vascular periférica. Conclusión: La insuficiencia cardíaca derecha es un factor de riesgo independiente para EVC probablemente debido a la estasis cerebral por congestión de la vena cava superior.

\section{Insuficiencia cardíaca derecha como factor de riesgo para exacerbación en pacientes con enfermedad pulmonar obstructiva crónica}

Hernández ZR, Orea TA, González $I D$, Santellano JB, Cintora MC, Sánchez SR, Pineda JJ, Peláez HV, Espinosa de los Monteros C, Pablo $S R$, Velázquez MA, Contreras RE, Herrera SR, Pérez CE, Flores TF, Ramírez VA, Sansores MR

INER Ismael Cosío Villegas

Los pacientes con enfermedad pulmonar obstructiva crónica (EPOC) y exacerbaciones tienen una progresiva y generalizada enfermedad vascular. La insuficiencia cardíaca (IC) es común en ellos, con una prevalencia de 10$40 \%$ y está implicada en mayor número de exacerbaciones, morbimortalidad y hospitalización. La prevalencia de IC no diagnosticada en pacientes con EPOC que se presentan en los servicios de urgencias es del 20.9\%. Objetivo: Determinar si la ICD es un factor de riesgo independiente para presentar exacerbación por EPOC. Materiales y métodos: Estudio de cohorte retrospectiva en pacientes con EPOC del Instituto Nacional de Enfermedades Respiratorias Ismael Cosío Villegas de 2009-2015. Se diagnosticó EPOC de acuerdo con FEV1/FVC $<70$. Se excluyeron pacientes con hiperreactividad bronquial o con crisis asmática. Se realizó una $\chi^{2}$ y t-Student para muestras independientes con la finalidad de comparar las diferencias entre los grupos con y sin exacerbación y una regresión logística múltiple para evaluar el riesgo de exacerbaciones en pacientes con ICD ajustando por variables confusoras. Resultados: Se incluyeron 250 pacientes con diagnóstico de EPOC, con edad de $72.22 \pm 10$ años, $48 \%$ fueron hombres, de ellos 105 (42\%) tuvieron exacerbación. Las diferencias entre los sujetos con y sin exacerbaciones fueron: ICD (63.9\% vs. $58.8 \%, \mathrm{p}=0.66)$, hipertensión arterial pulmonar (HAP: $7.6 \% v s$. $1.6 \%, \mathrm{p}=0.04)$, neumonía $(24.2 \% \mathrm{vs}$. $51.4 \%, \mathrm{p}=0.001)$, enfermedad tiroidea ( $1.1 \%$ vs. $10 \%, \mathrm{p}=0.01)$. No se observaron diferencias en sexo, edad, GOLD, diabetes, HAS, dislipidemias, cáncer, IC diastólica o sistólica entre los dos grupos. Sin embargo, ajustando por edad, sexo, hemoglobina, hematocrito, leucocitos, neumonía, asma, HAS, diabetes, IC sistólica y diastólica los pacientes con IC derecha tuvieron 5.78 (HR: 5.78; IC 95\%: 1.13-29.49) veces el riesgo de sufrir exacerbaciones por EPOC. Conclusión: ICD es factor de riesgo independiente desarrollar exacerbaciones.

\section{Presencia de depresión y ansiedad en pacientes fumadores activos y no activos diagnosticados con enfermedad pulmonar obstructiva crónica}

Pablo SR, * Pérez CE, * Peláez HV, * Orea TA, ${ }^{*}$ González IDG, ${ }^{*}$ Pineda JJA, * Contreras RE, * Cintora MC, * Leija $A G, \neq$ Sansores MR, * Hernández $Z R$, * Velázquez MA, * Flores TF, Espinosa de los Monteros $C$,* Ramírez-Venegas $A^{*}$

*INER Ismael Cosío Villegas; ‡Instituto Politécnico Nacional

Antecedentes: La EPOC tiene una alta prevalencia en el mundo, alrededor del $10 \%$. Su fisiología y alta comorbilidad con factores emocionales como ansiedad y depresión afecta de manera significativa la vida de las personas. Su causa principal es el consumo de taba- 
co, el cual es suspendido o restringido como parte del tratamiento; situación que podría afectar aún más su estado emocional, que también debería ser atendido. Objetivo: Comparar el nivel de ansiedad y depresión en pacientes con diagnóstico de EPOC fumadoresactuales y exfumadores. Método: Estudio descriptivo-transversal. Se evaluaron 37 pacientes con edad promedio de edad de 70.6 años, de los cuales $56.8 \%$ son hombres, con diagnóstico de EPOC del Instituto $\mathrm{Na}$ cional de Enfermedades Respiratorias Ismael Cosío Villegas con la escala de ansiedad y depresión hospitalaria (HADS). Los cuales se dividieron en dos grupos fumadores activos y no activos. Los resultados obtenidos se analizaron con la prueba $\chi^{2}$ para determinar diferencias entre grupos. Resultados: Pacientes no fumadores reportan niveles más altos de sintomatología depresiva leve-moderada $(50 \%)$ y severa $(38.2 \%)$ en comparación con fumadores, mostrando diferencias estadísticamente significativas ( $\mathrm{p}=$ 0.008). Respecto a la sintomatología ansiosa a pesar de que más del $50 \%$ de los pacientes se encuentran en la clasificación leve-moderada $(52.9 \%)$ y severa $(11.8 \%)$, no se obtuvieron diferencias estadísticamente significativas ( $p=0.292)$. Conclusión: Los niveles de depresión y ansiedad se asocian con la abstinencia del tabaco. La comorbilidad psicológica en pacientes con EPOC debe ser considerada dentro del tratamiento. Esto ayudará a evitar que afecte en los resultados del tratamiento y evitar el desarrollo de comorbilidades. Los resultados son preliminares, por lo que se recomienda ahondar en esta línea de investigación.

\section{Validación del inventario de la teoría de la conducta planeada para adherencia terapéutica de pacientes con enfermadas respiratorias}

Leija AG, ${ }^{\star}$ Peláez HV, ${ }^{\ddagger}$ Pérez $C E,{ }^{\ddagger}$ Pablo SR, Orea TA, $\neq$ González ID, $\neq$ Pineda JJA, ${ }^{\neq}$Herrera $S R, \neq$ Sánchez $S R, \neq$ Santellano JB,

Ramírez-Venegas $A,{ }^{\ddagger}$ HernándezZenteno $R, \neq$ Espinosa de los Monteros $C$, Velázquez-Montero $A, \neq$ Flores-Trujillo F, Sansores $\mathrm{MR}^{\ddagger}$

*IPN; ‡INER Ismael Cosío Villegas

Introducción: Cada vez hay más estrategias terapéuticas para conseguir un buen control y mejorar la calidad de vida de los pacientes con enfermedades respiratorias crónicas. Sin embargo, estudios realizados en pacientes con asma reportan que $50-70 \%$ de los pacientes no se adhirieren al tratamiento prescrito y sólo alrededor del $35 \%$ tienen controlada la enfermedad. En el caso de EPOC se estima que el grado de adherencia terapéutica no supera el 50\%. El modelo de la conducta planeada surge como explicación de los factores psicosociales que predicen la adherencia a los tratamientos, incluye cuatro factores: normas subjetivas, actitudes, intenciones y autoeficacia. Objetivo: Realizar la validación estadística del inventario de la teoría de la conducta planeada para adherencia terapéutica de pacientes con enfermadas respiratorias. Método: Se realizó un estudio descriptivo-transversal. Participaron 134 pacientes (74\% mujeres, edad media 47 años) con diagnóstico de enfermedad respiratoria crónica, quienes fueron evaluados con la versión original del inventario, 19 reactivos con escala tipo Likert de 1 (nunca) a 5 (siempre). Fueron incorporados cuatro reactivos para evaluar autoeficacia. Resultados: El inventario quedó conformado por 18 reactivos. El análisis de confiabilidad mostró alfa de Cronbach $=0.809$. El análisis factorial de pasos sucesivos, con rotación varimax, arrojó cuatro factores que explican el $58.8 \%$ de la varianza: normas subjetivas $(\alpha=0.636)$, actitudes ( $\alpha=0.837)$, intenciones ( $\alpha$ $=0.820)$ y autoeficacia $(\alpha=0.818)$. Conclusión: Este instrumento presentó buenas propiedades psicométricas, lo cual servirá para identificar aspectos cognitivos y conductuales que pueden influir en la adherencia terapéutica de los pacientes con enfermedad respiratoria crónica. Conocer estas variables permitirá diseñar programas de intervención dirigidos a fortalecer la adherencia terapéutica y mejorar el pronóstico del paciente. Agradecimiento: el presente trabajo fue apoyado por el Proyecto aprobado por la SIP con registro 20151036. Se agradece el apoyo del IPN para la presentación de esta ponencia.

\section{Relación de la obesidad con la limitación del flujo aéreo en la EPOC en el Hospital General de México durante el 2012-2015}

\author{
Serrano CP,,$\neq \neq$ Vargas $H G, \neq$ \\ Mares $G M Y,{ }^{*}$ Rodríguez de MSJI,§ \\ Hernández PRR, ${ }^{\S}$ Rodríguez OAM
}

*Hospital General de México; ‡Universidad Anáhuac; ${ }^{\S}$ AstraZeneca México

Antecedentes: La enfermedad pulmonar obstructiva crónica (EPOC) es la cuarta causa de muerte mundial. Se caracteriza por la limitación de flujo aéreo persistente generalmente progresiva, debido a una respuesta inflamatoria pulmonar por la exposición a diferentes factores de riesgo que la exacerban cuando el paciente cursa con comorbilidades como la obesidad, siendo ésta uno de los principales problemas de salud en México. Objetivo: Describir por índice de masa corporal (IMC), edad y género, la relación que existe entre la limitación del flujo aéreo y la obesidad en la EPOC en el HGM durante el 2012-2015. Métodos: Estudio retrospectivo, longitudinal para evaluar la espirometría realizada a una población de 1,000 pacientes del Servicio de Neumología del HGM. Muestreo no probabilístico de casos consecutivos. Criterios de inclusión: > 18 años, diagnóstico de EPOC (GOLD 2015). Resultados: El número total fue de 1,000 pacientes; de los cuales 65 fueron diagnosticados con EPOC; 37 fueron mujeres y 28 hombres y de acuerdo con 
el IMC, 3 desnutridos, 21 normopeso, 22 con sobrepeso y 19 obesos (leve 15 , moderada 2 y grave 2) y por edad: 18 a 30 años (5), 31 a 40 (5), 41 a 50 (7), 51 a 60 (20) y > 60 (28). Conclusiones: La mayoría de los sujetos estudiados (67\%) presentaron peso corporal fuera de los límites normales, 63\% límites superiores (sobrepeso 34\%, obesidad $29 \%$ ) por lo que se demostró la relación entre la obesidad y la limitación del flujo aéreo (EPOC). Existe mayor predisposición de la EPOC y obesidad en mujeres debido a que la mayoría tenía entre 40 a 60 años.

\section{Neumonitis química por hidrocarburos. Presentación de caso}

\section{Rodríguez BREJ, Topete MLE, Del Razo RR}

INER Ismael Cosío Villegas

Introducción: El 13.2\% de las intoxicaciones en población pediátrica en México, corresponde a sustancias químicas. Al aspirarse los hidrocarburos producen inhibición del surfactante pulmonar originando colapso alveolar, alteración de ventilación/perfusión e hipoxemia, seguido por neumonitis química con hiperemia, edema y hemorragia alveolar. Presentación de caso: Femenino de 2 años de edad, previamente sana, quien cuatro días previos a su ingreso tuvo ingesta de petróleo con emesis secundaria. Radiografía al ingreso sin alteraciones, presentando fiebre leucocitosis con neutrofilia. Se dio manejo con ceftriaxona 75 mgkgdi y metilprednisolona 1 mgkgdi. Control radiográfico a las 36 horas con radiopacidad heterogénea en hemitórax derecho con patrón de llenado alveolar y desaturación de $84 \%$ con $\mathrm{FiO}_{2} 21 \%$ siendo trasladado a nuestra institución. A la exploración física sin datos de dificultad, murmullo vesicular disminuido en hemitórax derecho, gasométricamente $\left(\mathrm{FiO}_{2} 26 \%\right)$ alcalosis respiratoria descompensada, hipoxemia corregida e hiperlactatemia. Radiografía de tórax al quinto día con aumento de la radiopacidad, con patrón de llenado alveolar paracardíaco derecho. Tomografía axial computarizada de tórax simple con aumento de la densidad, de forma heterogénea, con broncograma aéreo en ambos lóbulos inferiores. Durante su estancia, con adecuada evolución logrando destete de oxígeno suplementario. Discusión: El 25-40\% de los pacientes con ingesta de hidrocarburos presentan neumonitis química. Nuestra paciente se mantuvo en vigilancia ya que puede presentar dificultad respiratoria, cianosis, atelectasias, hemoptisis e inclusive paro cardiorrespiratorio. La evolución del cuadro clínico es en promedio de 2 a 5 días con resolución radiológica dos semanas posteriores. Las complicaciones asociadas son neumatoceles, neumotórax, enfisema subcutáneo y derrame pleural, por lo que daremos seguimiento. Conclusión: Los pacientes con ingesta de hidrocarburos son poco frecuentes; sin embargo, tienen riesgo de complicaciones tanto en período agudo como a largo plazo, a pesar del uso de antimicrobianos y esteroides. El factor prevención es determinante para evitar estos sucesos.

\section{Enfermedad digestiva como causa de neumonía recurrente}

\section{Castillo MC, Sánchez UMG, Salcedo ChM, Rodríguez BREJ, Falcón SV. Izunza SS}

INER Ismael Cosío Villegas

Las enfermedades que predisponen a un niño a padecer neumonías recurrentes pueden ser múltiples, entre ellas la participación de hernia hiatal asociado a ERGE. La prevalencia en niños no es conocida, existen diferentes autores que han reportado incidencia $6.3-41 \%$ en niños sanos. Se puede presentar tos e hiperreactividad bronquial en un $8.5 \%$. Femenina de 13 meses. Antecedente: Producto primera gesta, embarazo normoevolutivo, obtenida cesárea por oligohidramnios, APGAR 8/9, peso y talla adecuados; Capurro 41SDG.
Hospitalización: nacimiento 10 días por hiperbilirrubinemia multifactoria, tratamiento fototerapia, caída del cordón a los 60 días. Personales patológicos: hospitalizada en siete ocasiones previas en otra institución: primera al nacimiento, seis más por cuadros de neumonía, en la quinta ocasión por tres meses, siendo meritorio manejo en UTIP, con VM por tres semanas, encontrando RGE grado III, realizando funduplicatura; último cuadro hace tres meses. Comentando cursaba en dichos cuadros con sibilancias, recibiendo tratamiento con micronebulizaciones. Padecimiento actual: inicia dos días previos con accesos de tos productiva, rubicundizante, no emetizante, acompañado de rinorrea hialina, agregándose a las $24 \mathrm{~h}$ taquipnea, E/F observa abundante rinorrea hialina, faringe discreta hiperemia, taquipnea, tiraje intercostal leve, disminución de murmullo vesicular, sibilancias espiratorias. Radiografía torácica sin hallazgos anormales. Saturando 89\%, por lo que se decide ingreso. Gammagrama esofágico: RGE grado III, vaciamiento gástrico normal. TAC: a nivel de mediastino imagen retrocardíaca, redondeada, heterogénea, que al administrar contraste hidrosoluble por VO se confirma hernia hiatal. Referida a gastroenterología para corrección quirúrgica. La tasa de falla de cirugía antirreflujo primaria varían 3-30\% dependiendo de la experiencia. Un grupo de pacientes operados manifestará síntomas recurrentes o persistentes después de la intervención. Debido al aumento en número de funduplicaturas primarias practicadas, las cirugías antirreflujo fallidas son un hallazgo cada vez más común. Las etiologías más comunes de la falla son recurrencia de hernia hiatal y disrupción de funduplicatura representando entre 50-65\%.

\section{Fisiología}

\section{Análisis de función pulmonar en lactantes, experiencia en el Laboratorio de Función}




\section{Pulmonar año 2015, Centro Médico Nacional "La Raza"a}

Bernardino AK, Fernández F, Sánchez MMÁ

IMSS

Estudio descriptivo: Se estudiaron un total de 21 pacientes, $76 \%$ hombres en el período de 1 de junio a 31 de diciembre de 2015, los valores se expresan en medias e ICC, para la edad es de 17. 6 meses (11.5-23.7), la media de peso es de $9.6 \mathrm{~kg}$ (8.2 a 11), la media de la talla es de $79 \mathrm{~cm}(76.2-84.7 \mathrm{~cm})$, saturación de oxígeno promedio de $91 \%$ (89-93\%), la media de ayuno fue de $9.3 \mathrm{~h}$ (IC 7.9-10.3 h), con una media de $6.2 \mathrm{~h}$ de desvelo (IC 5.2-7.2 h), en el 66.6\% de los pacientes se utilizó midazolam nasal como medicamento para sedación el resto fue con dexmetomidina, en el $42 \%$ de los casos se necesitó sólo una dosis, en el $23 \%$ se requirió una segunda dosis, el 28\% de una tercera dosis y sólo un caso necesitó seis dosis, sólo un paciente del grupo de dexmetomidina requirió más de una dosis, con duración de la sedación de 55 min (IC 39.2-72.4 min), la media para el volumen corriente es de $92.61 \mathrm{~mL}$ (IC 71.42-113.81 mL), para la frecuencia respiratoria la media es de 32 respiraciones (IC 27-37), TPTEF/TE media fue de 21.34 (IC 15.88-26.80), la media de TI fue de $0.77 \mathrm{seg}$ (IC 0.65-0.89 seg), TE $1.25 \mathrm{seg}$ (IC 1.07-1.44 seg), Rel TI/TE 0.61 (IC 0.54-0.69), compliance 139.94 (IC 108.53-171.35), resistencias 3.71 (IC 2.62-4.79), FRC mL 256.9 (IC 196.52317.27 ), se determinaron volúmenes forzados en $33.33 \%$ de los pacientes con una media de FEV1 de $82.9 \mathrm{~mL}$ (IC 24.16-141.74), FVC 92.9 mL (IC 35.7-150.1 mL), siete de los pacientes tuvieron un patrón normal, cuatro tuvieron patrón restrictivo y 10 pacientes presentaron obstrucción al flujo de aire, con atrapamiento aéreo. Estudio bien tolerado en nuestra población.

a Trabajo seleccionado para ser presentado de forma oral. Obtuvo premio como mejor trabajo de investigación clínica.

\section{Función pulmonar en pacientes pediátricos con antecedente de premature $^{a}$}

\section{Sánchez MG, * Del Razo RR, * Barrera $R R H^{\ddagger}$}

*INER Ismael Cosío Villegas; \#Instituto Nacional de Perinatología "Isidro Espinoza de los Reyes"

La displasia broncopulmonar (DBP) es la enfermedad pulmonar crónica más frecuente del lactante, con morbilidad en los primeros años de vida y riesgo de secuelas; se caracteriza por hipoplasia alveolar y falta de desarrollo vascular pulmonar. Los niños con DBP muestran disminución del flujo de aire sugestivo de cambios en la función pulmonar que pueden no ser sólo explicados por la prematurez. En los lactantes con DBP, la distensibilidad pulmonar mejora con el tiempo, mientras que la disminución de los flujos espiratorios persiste toda la infancia. Objetivo principal: Describir hallazgos espirométricos de los pacientes prematuros. Objetivos secundarios: Describir los antecedentes y cuadro clínico de los pacientes. Observar las diferencias entre grupo de DBP vs. sin DBP. Material y métodos: Estudio observacional, descriptivo, transversal, tomado de una cohorte. Previo autorización se realizó un interrogatorio dirigido al familiar responsable, revisión de expediente de niños que acudían a seguimiento a consulta externa del Instituto Nacional de Perinatología (INPer), posteriormente se procedió a realizar espirometría. Resultados: De 33 pacientes con espirometría valorable (calidad A, B, C), $41 \%$ cumplió criterios de DBP, $62 \%$ con DBP moderada. Se encontró asociación con el uso de VM ( $\mathrm{p}=0.004)$, CPAPn y aplicación de surfactante, así como apneas ( $\mathrm{p}=$ 0.002) en el grupo de DBP. Se encontró un paciente del grupo sin DBP con obstrucción leve al flujo aéreo sin respuesta significativa a broncodilatador (5.88\%); seis pacientes del grupo con DBP presentaron obstrucción (37.5\%): cinco leve y una moderada, $43 \%$ tuvieron reversibilidad $(\mathrm{p}=0.02)$ y sólo uno de ellos tenía diagnóstico previo de asma. No se encontró reversibilidad en los pacientes del grupo sin DBP, pese a que uno tenía el diagnóstico previo de asma. Conclusión: Existen cambios en la función pulmonar en pacientes con antecedentes de prematurez, por lo que es necesario el seguimiento neumológico de estos pacientes a largo plazo. a Trabajo seleccionado para ser presentado de forma oral. Obtuvo premio como mejor trabajo de investigación clínica.

\section{Hallazgos clínicos y polisomnográficos en niños con deformidad de caja torácica $^{\mathrm{a}}$ \\ García CER, Torres FMG, Carrillo-Alduenda JL}

INER Ismael Cosío Villegas

Las alteraciones del tórax causan restricción pulmonar, contribuyendo al desarrollo de hipoventilación nocturna que, si no se trata, progresará a hipercapnia crónica y graves complicaciones. Objetivo: Describir condiciones clínicas y hallazgos polisomnográficos en escolares con alteraciones de caja torácica. Metodología: Se analizaron registros de menores de 18 años con diagnóstico de malformación de caja torácica primaria o secundaria que acudieron a la Clínica de Sueño en los últimos cinco años. Respondieron un cuestionario estandarizado de síntomas de sueño y comorbilidades, les realizamos polisomnografía basal y ventilatoria de acuerdo con el caso. Se realizó estadística descriptiva, asociaciones con el coeficiente de correlación de Spearman o Pearson de acuerdo con la distribución. Programa estadístico STATA versión 13. Resultados: Analizamos 33 niños: 7 (21\%) tuvieron alteraciones primarias; 26 restantes deformidades secundarias, 18 asociadas con enfermedades neuromusculares. Edad promedio de $11 \pm 4.1$ años y $22(67 \%)$ sexo mas- 
culino. Comorbilidades importantes: desnutrición (54.5\%), antecedentes de neumonía (49\%) y cardiopatías (28\%). Elevada prevalencia de síntomas de sueño: siestas múltiples $(34 \%)$, mala calidad de sueño (53.2\%), despertares nocturnos $(47 \%)$, ronquido $(68 \%)$, sólo 19\% hipertrofia amigdalina. En PSG: latencia prolongada a sMOR (160 \pm 72 min), disminución en su proporción $(17.5 \pm 26 \%)$, alta proporción de WASO con mediana de 39.5 min (IIC 10 - 105 min), mediana de IAH de 6.5 (IIC 2-16), $84 \%$ cumplieron criterio de SAOS. La espirometría sugirió patrón restrictivo grave $(\mathrm{n}=18)$ : mediana de VEF1/ FVC 84 (mín.-máx. 59-95\%); FVC 35 (10-104). Debilidad de músculos respiratorios $(\mathrm{n}=12)$ : PImax $46 \%(13-$ 77) y PEmax 38\% (10-94); volúmenes pulmonares $(n=5)$ con restricción: TLC $57 \%(38-121)$ y atrapamiento aéreo: VR 116\% (76-164), VR/TLC $48.7 \%$ (35-71). Gasometría arterial (n = 14) con $\mathrm{PaO}_{2} 59.3 \mathrm{mmHg}$ (34-73), $\mathrm{PaCO}_{2} 34.4 \mathrm{mmHg}$ (29-52), $\mathrm{HCO}_{3} 22$ $\mathrm{mEq} / 1$ (17-30 mEq/L), $\mathrm{SpO}_{2} 90 \%$ (5895). Sin diferencias entre alteraciones primarias y secundarias. Conclusiones: Los niños con deformidad de caja torácica tienen condiciones graves de salud al ser referidos: comorbilidades importantes, alteraciones funcionales respiratorias graves, repercusión en la calidad de sueño y alta frecuencia de trastornos respiratorios del dormir sin asociación con hipertrofia amigdalina, que condicionan alteraciones en la calidad de sueño.

aTrabajo seleccionado para ser presentado de forma oral.

\section{Oscilometría de} impulso y flujo pico en estenosis traqueal posintubación ${ }^{a}$

\section{Berrios MJA, Guzmán de Alba E}

INER Ismael Cosío Villegas

Es necesario definir los mejores parámetros para el diagnóstico y seguimiento de los pacientes con estenosis traqueal, con elementos objetivos y medibles, que complemente la clínica. Limitadas son las revisiones realizadas de oscilometría, Horan reportó 10 pacientes con lesión neurológica y estenosis laringotraqueal, encontró fuerte correlación de resistencias de la vía aérea y el diámetro de la estenosis. Objetivo del estudio: Determinar la correlación significativa entre el grado de estenosis traqueal y la resistencia a $20 \mathrm{hz}$ en pacientes con estenosis traqueal, así como una correlación negativa entre el grado de estenosis y el flujo espiratorio pico. Metodología: Estudio observacional, prospectivo, realizado en el Servicio de Cirugía de Tórax del INER, México, DF. En un período de febrero 2014 a diciembre 2015. Selección de la muestra no probabilística, a los participantes se le realizó TAC de vía aérea con reconstrucciones coronales y sagitales, espirometría simple y oscilometría de impulso, los resultados fueron analizados en IBM SPSS Statistics 22.0, se aplicó frecuencias, medias así como coeficiente de correlación (IC). Resultados: 25 pacientes reclutados, principalmente hombres en $70 \%$, con una media de edad de 35 años, media de porcentaje de estenosis $60 \%$, con la progresión del grado de estenosis traqueal se incrementa la resistencia 20 hz IC: 0.65, p 0.029; se reduce el flujo pico IC-0.77, p 0.008. La relación FEV1/ FVC IC-0.53, p 0.013. Conclusiones: En los resultados preliminares se evidencia una correlación importante entre el porcentaje de obstrucción por estenosis traqueal y la oscilometría de impulso a $20 \mathrm{hz}$ así como con el flujo pico. Siendo un método no invasivo, no dependiente de esfuerzo del paciente y sin contraindicaciones, la oscilometría de impulso se perfila como método preferente de seguimiento de paciente son estenosis traqueal.

a Trabajo seleccionado para ser presentado de forma oral.

Efecto del trasplante renal sobre valores de espirometría en pacientes con enfermedad renal crónica $^{a}$
Flores SPJ, Loeza IJA, Salcedo CMG, Mendoza TLA, Ibarra IR

IMSS

Pacientes con enfermedad renal crónica (ERC) han descrito alteraciones pulmonares, más frecuente son alteraciones como derrame pleural, edema pulmonar, fibrosis, calcificaciones, hipertensión pulmonar. Funcionalmente presentan reducción de la capacidad vital, correlación negativa entre niveles de $\mathrm{CO}_{2}$ y urea e incremento líquido intersticial. Objetivo: Evaluar el efecto del trasplante renal (TR) en espirometría, en Unidad de Trasplantes del CMNO. Metodología: Estudio cohorte prospectiva. Incluyeron pacientes con ERC, se realizó TR de 16-75 años, cualquier género, causa de ERC, tipo de diálisis. Se excluyeron sujetos con cualquier tipo de enfermedad pulmonar. Se comparó grupo expuesto (pacientes que recibieron TR) y el control (donadores). Se les realizó historia clínica, exploración, laboratoriales, radiografías, gasometría y espirometría. Las evaluaciones se realizaron un día previo al TR, al mes, tres, seis meses después del mismo. Resultados: Se estudiaron 22 receptores y 21 donadores. Promedio de edad de los receptores fue $25 \pm 8$ años y de donadores $40 \pm 9$ años. Se observó mejoría de parámetros al final seguimiento, CVF\% (basal $87 \pm 12 v s$. final $100 \pm 11, \mathrm{p}=0.001)$, FEV1\% (basal $89 \pm 12$ vs. final $105 \pm$ 15, p $\leq 0.0001$ ), FEF $75 \%$ (basal 77 \pm 19 vs. final $86 \pm 25, \mathrm{p}=0.01), \mathrm{FEF}$ $50 \%$ (basal $81 \pm 18 v s$. final $95 \pm 16, \mathrm{p}$ $\leq 0.0001$ ), FEF $25 \%$ (basal $91 \pm 17 v s$. final $106 \pm 17, \mathrm{p} \leq 0.0001)$, e IT (basal $100 \pm 5 v s$. final $104 \pm 6 \mathrm{p}=0.032$ ) Se incrementó $28 \%$ la proporción de pacientes con función pulmonar normal al final del seguimiento. Se encontraron las PFP al final del seguimiento similar en los receptores y donadores. Se encontró mejoría de $\mathrm{PO}_{2}$ y acidosis metabólica persistente. Conclusiones: El trasplante mejora los valores de la espirometría de los receptores renales. Se puede considerar en el protocolo de evaluación del paciente trasplantado para seguimiento. 
${ }^{\text {a }}$ Trabajo seleccionado para ser presentado de forma oral

\section{Índice de aclaramiento pulmonar por lavado de nitrógeno de múltiples respiraciones en niños sanos mexicanos}

Del-Río HRF, Gochicoa RLG, TorreBouscoulet L, Mora RUJ, Guerrero ZS, Benítez PRE, Rodríguez ML, Fernández PMR, Villca AN

INER Ismael Cosío Villegas

Antecedentes: El lavado de nitrógeno es una prueba útil para evaluar la vía aérea periférica así como la homogeneidad de la ventilación; el compromiso de la homogeneidad de la ventilación está bien establecido en enfermedades respiratorias como asma y fibrosis quística. No contamos con valores de referencia locales para el índice de aclaramiento pulmonar (LCI) en niños. Objetivos: Establecer el límite superior de normalidad (LSN) de LCI en niños mexicanos. Describir qué factores favorecen obtener resultados aceptables y repetibles. Métodos: Se incluyeron niños de 4-12 años de edad del área metropolitana del D.F., sin diagnóstico previo o sospecha de enfermedad aguda o crónica respiratoria. Se realizó la prueba «lavado de nitrógeno» con el equipo NDD EasyOne ProLab, se verificó aceptabilidad y repetibilidad con respecto a estándares internacionales (ATS/ERS 2013). Se investigaron las asociaciones entre LCI y variables independientes mediante el coeficiente de correlación de Spearman, así como el valor del percentil 95 de LCI. Resultados: Se reclutaron 165 niños de los cuales 103 (62.4\%) cumplían los criterios de aceptabilidad y repetibilidad; los pacientes que lograron obtener los criterios de aceptabilidad realizaron en promedio un total de cuatro maniobras (mín. 2, máx. 8) en promedio tenían 8.3 años (mín. 4.5, máx. 12.3) versus los pacientes que no lograron obtener los criterios de aceptabilidad; realizaron en promedio tres maniobras (mín. 1, máx. 6) en promedio tenían 7.2 años (mín. 4, máx. 11.9). No se encontró una buena correlación entre el LCI y el peso, talla ni edad, asimismo, no se encontró una diferencia relacionada con el género. El valor del percentil 95 de LCI es 7.93. Conclusiones: El LSN de LCI es 7.93. El peso, edad, talla y género del paciente no son determinantes del LSN. La edad y cantidad de maniobras son determinantes para una adecuada aceptabilidad y repetibilidad.

\section{Medición del pico de flujo espiratorio. Valores normales e interpretación en la clasificación del paciente asmático}

\section{Fernández $M,{ }^{*}$ Jané $L A,{ }^{*}$ Clúa $C A, \neq$ Lima $A M I^{*}$}

${ }^{*}$ Centro de Investigaciones Clínicas. Playa. La Habana. Cuba; ¥Ministerio de Salud Pública

Resumen: La valoración de la función pulmonar mediante la espirometría o con la medición del pico de flujo espiratorio, confirman o no, la obstrucción de las vías aéreas en los pacientes asmáticos. Objetivo: Evaluar la utilidad del uso de medidores de pico de flujo espiratorio en pacientes asmáticos. Métodos: La investigación se realizó en dos grupos y se utilizó el método observacional de corte transversal. El primer grupo estuvo compuesto por una muestra de sujetos sanos procedentes de la población atendida en el policlínico Héroes de Playa Girón, del municipio Cerro, en La Habana, Cuba. El segundo grupo estuvo constituido por pacientes asmáticos adultos, atendidos en las consultas de neumología de los hospitales Benéfico Jurídico de La Habana, Saturnino Lora de Santiago de Cuba y Hospital General de Baracoa de Guantánamo. Resultados: Se presentaron los resultados provenientes del estudio realizado a cada grupo. Entre las ecuaciones recomendadas por la ATS (American Thoracic Society) para determinar la normalidad de PEF, la de Tinker 1961 para PEF, fue la que más se igualó a la obtenida a partir de las mediciones realizadas en los sujetos del grupo I, tanto por los coeficientes de la regresión, el análisis de la ecuación en general y por la representación gráfica de los valores predictivos de las poblaciones estudiadas. Se comprobó la importancia de la medición del pico de flujo en la clasificación de la severidad del asma y se ejemplificó el efecto que provoca utilizar dos estándares diferentes en los sujetos del grupo II. Conclusiones: Ambas clasificaciones se diferencian significativamente, lo que demuestra la importancia de realizar estudios de normalidad en la población cubana con el fin de decidir la ecuación y el autor que más se ajusten a cada localidad hasta que se determinen los valores normales para nuestra población.

\section{Infecciones no micobacterianas}

Polimorfismos en IFITM3 se asocian con susceptibilidad genética y gravedad clínica en pacientes con influenza A H1N1 y enfermedad similar a influenza ${ }^{a}$

\section{Falfán-Valencia R, Ambrocio-Ortiz E, Pérez-Rubio G, Del Ángel-Pablo AD, Ramírez-Venegas $A$}

INER Ismael Cosío Villegas

Antecedentes: IFITM3 es una proteína que se ha descrito desempeña un papel fundamental en el sistema inmune contra la influenza; los niveles elevados de IFITM3 mantienen los niveles virales bajos, la eliminación de IFITM3 permite que el virus se multiplique sin control. Recién se identificó un polimorfismo 
de un solo nucleótido (SNP) en el gen IFITM3 asociado con la gravedad en personas hospitalizadas con influenza pandémica A H1N1. Se cree que la prevalencia de esta mutación es $<1 / 400$ en las poblaciones europeas, se desconoce en mexicanos. Objetivos: Identificar polimorfismos en IFITM3 asociados con susceptibilidad y gravedad clínica de la influenza A H1N1. Métodos: Se incluyeron pacientes con enfermedad similar a influenza (ESI, $\mathrm{n}=92)$, con diagnóstico de influenza AH1N1 (INF$\mathrm{P}, \mathrm{n}=195)$ y un grupo de contactos sanos asintomáticos (CSA, $\mathrm{n}=218$ ) intradomiciliarios y no relacionados biológicamente. Se genotipificaron 4 SNPs en IFITM3: rs12252C/T, rs28602580A/G, rs34481144A/G, rs35409983A/C mediante sondas TaqMan por ensayo de discriminación alélica (PCR en tiempo real). Se compararon las frecuencias entre grupos, además se realizó regresión logística binaria con variables clínicas de gravedad. Se consideraron asociaciones estadísticamente significativas cuando $\mathrm{p}<0.05$. Resultados: El alelo rs28602580/G se encuentra asociado en la comparación ESI vs. CSA ( $\mathrm{p}=$ $0.01863, \mathrm{OR}=1.69 \mathrm{IC} 95 \%=1.09-2.66)$, mientras que el genotipo AA para el mismo SNP es más frecuente en CSA (16.97\%) en comparación con pacientes AH1N1 + ESI $(10.14 \%$ p $<0.05)$. En el análisis con variables de gravedad identificamos al rs28602580 asociado con el género masculino ( $\mathrm{p}=0.04$, OR $=1.995$, IC $95 \%=1.032-3.856)$, diabetes $(\mathrm{p}=0.023, \mathrm{OR}=12.02$, IC $95 \%=1.417$ 102.016), cefalea, y diarrea $(\mathrm{p}<0.05)$; mientras que la fiebre se asocia con el rs12252 ( $\mathrm{p}=0.024)$. Conclusiones: El rs12252 reportado a mayor gravedad en otras poblaciones en pacientes mexicanos sólo se asoció con fiebre; sin embargo, el rs28602580 se encontró como un factor de susceptibilidad genética, además de estar asociado con variables de mayor gravedad clínica.

a Trabajo seleccionado para ser presentado de forma oral. Obtuvo mención honorífica.

\section{Procalcitonina como biomarcador de}

\section{infección pleural en el abordaje de derrame pleural unilateral ${ }^{\mathrm{a}}$}

Vega ÁE, Che-Morales JL, Vargas-Mendoza GK, Cortés-Télles A

Hospital Regional de Alta Especialidad de la Península de Yucatán

Antecedentes: El derrame paraneumónico (DPN) y empiema representan las patologías más comunes de infección pleural. Ambas ocurren como consecuencia de un proceso infeccioso del parénquima pulmonar. De forma considerable, en la última década se ha reportado un incremento absoluto del $50 \%$ en la frecuencia del DPN y/o empiema (7.6 a 14.9\%). La relevancia de este escenario clínico está vinculada con mortalidad; cuando el origen del padecimiento es comunitario la frecuencia es del 20\%; no obstante, las cifras se duplican en escenarios nosocomiales (47\%). Entre los pendientes de las líneas de investigación en infecciones pleurales se encuentra la búsqueda de algún biomarcador que respalde tratamientos oportunos. Procalcitonina (PCT) es un indicador sérico con evidencia suficiente para demostrar un proceso bacteriano sistémico. Sin embargo, reportes muy escasos se circunscriben en analizar la PCT en DPN y empiema. Objetivo: Analizar si PCT tiene utilidad en el diagnóstico de infección del espacio pleural durante el abordaje del derrame pleural unilateral. Material y métodos: Se realizó un estudio de casos y controles. Los casos fueron representados por todos los DPN y empiema, en tanto, los controles incluyeron todos los derrames pleurales no infecciosos. El reclutamiento tuvo una duración de 18 meses. De forma sistematizada se realizaron mediciones séricas de PCT y otras variables durante la evaluación hospitalaria inicial. Resultados: Se incluyeron 26 casos y 23 controles. Cuando el valor de PCT sérica es $\geq 0.5 \mathrm{ng} / \mathrm{dL}$, la posibilidad de infección pleural es ocho veces superior versus su contraparte no infecciosa [OR 8.4 (IC 95\% 2.0-35.8; $\mathrm{p}=0.004$ )]. Más aún, el valor con mejor sensibilidad, especificidad y razones de verosimilitud para infección es $\geq 2 \mathrm{ng} / \mathrm{dL}$ [OR 4.1 (IC 95\% 1.1-15.3; $\mathrm{p}=0.038)]$. Conclusiones: Procalcitonina es un marcador útil en el diagnóstico de infección pleural. Sin embargo, más estudios deben ser realizados para comprobar nuestros resultados.

${ }^{\text {a }}$ Trabajo seleccionado para ser presentado de forma oral. Obtuvo mención honorífica.

\section{Actinomicosis pulmonar. Causa de nódulo pulmonar solitario inusual que se confunde con neoplasias}

\section{Mireles ACA, Hernández VD, Robles CYD}

Hospital Ángeles del Carmen

Introducción: La actinomicosis pulmonar es una enfermedad crónica, con una progresión lenta e insidiosa que imita padecimientos como neoplasias, tuberculosis o abscesos pulmonares. Informamos el caso de una paciente con un nódulo pulmonar en la que se sospechó de malignidad y con la biopsia se demostró la presencia de Actinomyces. Descripción del caso: Mujer de 66 años, fumadora de 32 paquetes año, inició su padecimiento seis meses previos al internamiento con disnea leve a medianos esfuerzos, pérdida de peso significativa en los últimos meses; acompañado de dolor pleurítico en hemitórax izquierdo, una tomografía computada de tórax mostró nódulo en la língula pulmonar de $17.12 \mathrm{~mm}$, sin adenopatías; se realizó resección del nódulo y el segmento; encontrando en histopatología un conglomerado bacteriano, quedando como diagnóstico final actinomicosis pulmonar. Discusión: En pacientes en los que se encuentra como hallazgo un nódulo pulmonar, debe calcularse el riesgo de malignidad para decidir la pauta a seguir en su abordaje diagnóstico, si su probabilidad de 
cáncer es alta (> 65\%), el estándar de oro para su diagnóstico definitivo es la resección quirúrgica en cuña. Conclusiones: El nódulo pulmonar solitario es una entidad con un abordaje complejo, en pacientes con factores de riesgo se hace imprescindible la biopsia para el diagnóstico, la actinomicosis pulmonar es una enfermedad con una incidencia muy baja a nivel mundial, lo que la hace muy difícil de sospechar en pacientes con alto riesgo de malignidad.

\section{Mediastinitis necrotizante descendente}

López JJ, López TJG, Bojorquez H, Rea MG

Hospital Civil Fray A. Alcalde

El mediastino es un espacio complicado debido a la ausencia de estructuras anatómicas que limitan el avance de un proceso infeccioso. La mediastinitis aguda es una grave enfermedad, de frecuencia variable con una elevada mortalidad, independientemente de la literatura consultada. El tratamiento se basa en una antibioticoterapia de amplio espectro y el tratamiento quirúrgico oportuno y agresivo. Existe recomendación de utilizar irrigación continua con antibióticos sobre el área afectada. Si bien el manejo agresivo inicial mejorará el pronóstico, evitar la esternotomía es recomendable. Se presenta el caso de un paciente masculino de 34 años de edad, sin antecedentes de importancia. Inicia su padecimiento con infección odontogénica, con tratamiento antibiótico inicial. Evoluciona desfavorablemente, presentando lesiones cutáneas abscedadas en región cervical y pectoral derecha con datos de choque séptico. Se evidencia colección en mediastino anterior alimentado por trayecto fistuloso con origen en piso de la boca. Se decide ingreso inmediato a quirófano para realizar cervicotomía amplia siguiendo trayecto fistuloso hasta región pectoral afectada. Colocación de drenaje mediastinal anterior con salida subxifoidea y preservación de es- ternón. La evolución fue satisfactoria, tras cierre espontáneo de fístula orocervical en 25 días aproximadamente de estancia hospitalaria, a expensas de aseo, mediastinoclisis (amikacina) y nutrición enteral por sonda nasogástrica. Se comenta con relación en la literatura que el manejo inicial agresivo y combinado en la mediastinitis le otorga mayor tasa de éxito al tratamiento. En caso de trayectos fistulosos hacia mediastino, la exclusión de este último es una buena alternativa. La irrigación continua con antibióticos de la región afectada parece favorecer la resolución del cuadro. Evitar la esternotomía es una conducta adecuada. A edades más tempranas y sin comórbidos, el éxito terapéutico es mayor.

\section{Infecciones \\ respiratorias e inmunodeficiencia común variable. ¿Qué debemos saber?}

\section{Hernández RFI, Camacho ON, Garrido GCL, Urbina MME, García CML}

INER Ismael Cosío Villegas

Introducción: La inmunodeficiencia común variable (IDCV) es la inmunodeficiencia primaria (IDP) sintomática más común. Uno de los picos de presentación es en la primera década de la vida. Las infecciones respiratorias recurrentes son la primera manifestación. Presentamos el caso de un paciente con historia de infecciones respiratorias de repetición y diagnóstico de IDCV. Caso clínico: Masculino de 10 años de edad. No historia autoinmunidad o consanguinidad. Desde los siete años con otitis 4 veces/año, sinusitis 3/año, tos crónica. Diarrea crónica desde los nueve años. Antecedente de un internamiento por NAC basal derecha a los 10 años manejado con cefotaxima y dicloxacilina. A $\operatorname{los} 10$ años 7 meses ingresa para protocolo de estudio por infecciones respiratorias de repetición y bronquiectasias. TACAR con bronquiectasias cilíndricas bilaterales. Broncoscopia datos de inflamación aguda en árbol bronquial, isomerismo izquierdo de bronquio de lóbulo superior derecho. Exámenes de laboratorio: IgG 33.3, IgA 6.67, IgM 19.9, IgE 5. Subpoblaciones de linfocitos T normales. Isohemaglutininas negativas. Se descartan causas secundarias de hipogammaglobulinemia y se confirma diagnóstico de IDCV. Se inicia manejo con gammaglobulina intravenosa ( $1 \mathrm{~g} / \mathrm{kg}$ cada tres semanas). Actualmente el paciente está en seguimiento por consulta externa. Recibe gammaglobulina en forma periódica a dosis de restitución y no ha presentado nuevos eventos de infecciones. Conclusiones: Los síntomas respiratorios de repetición representan una señal de alarma para descartar IDP. Se debe realizar el abordaje inicial con biometría hemática e inmunoglobulinas a todos los pacientes con infecciones respiratorias graves de repetición, necesidad de antibióticos intravenosos y/o bronquiectasias. Los estudios de imagen y pruebas de función respiratoria juegan un papel importante en la detección, caracterización y cuantificación del daño pulmonar. El diagnóstico temprano disminuye las complicaciones y mejora el pronóstico en estos pacientes.

\section{Aspergiloma pulmonar, experiencia en el Hospital General de México}

\section{Luis ME, * Hernández SA, * Gutiérrez DCME, * Yescas SG, * Landa APD, * Saavedra de RSI, ${ }^{*}$ Cicero $S R^{\ddagger}$}

*Hospital General de México "Dr. Eduardo Liceaga"; ;Facultad de Medicina, UNAM

Introducción: Se desconoce la incidencia real en el mundo de las micosis pulmonares; sin embargo, han tenido un incremento notable, el aspergiloma representa una de las formas más comunes, surge como resultado de la colonización del Aspergillus en una cavidad, quiste o bula preexistentes, en la mayoría de los casos secundaria a cavidades por tuberculosis. Gene- 
ralmente tiene un curso benigno, sin embargo, puede debutar con hemoptisis que de ser masiva compromete la vida. Objetivo: Determinar la frecuencia y los factores de riesgo para el desarrollo de aspergiloma y sus características clínicas. Metodología: Se realizó un estudio retrospectivo, observacional, con pacientes con el diagnóstico de egreso de aspergiloma pulmonar que acudieron con el Hospital General de México del 2010 al 2015. Resultados: Se identificaron siete pacientes con diagnóstico de aspergiloma pulmonar, seis del sexo masculino (85\%), uno femenino (15\%), edad promedio de 42 \pm 12 , dentro de los factores de riesgo las cavidades por tuberculosis fueron las más frecuentes en tres casos (42\%), seguido de bronquiectasias en un caso (15\%) y nódulo pulmonar solitario en un caso (15\%). La manifestación principal fue la hemoptisis en cuatro pacientes (57\%); el diagnóstico se hizo con los hallazgos tomográficos característicos y biopsia quirúrgica en cuatro pacientes (57\%), cultivo en dos pacientes (28\%), detección de antígenos (galactomanano) sérico y en lavado bronquial en un paciente $(15 \%)$, un paciente falleció (15\%). Conclusión: De acuerdo con lo reportado en la literatura, las cavidades por tuberculosis son el antecedente principal para desarrollar aspergiloma pulmonar y la manifestación clínica más frecuente es la hemoptisis, la que es una complicación que puede ser mortal, por lo cual la instauración de un tratamiento oportuno y eficaz es importante.

\section{Hidatosis pulmonar en paciente pediátrico, reporte de un caso} Meza BJH, Velázquez SJR,
Hernández RFI, Lechuga TI

INER Ismael Cosío Villegas

Introducción: La hidatosis pulmonar es una infección parasitaria, la cual es causada por Echinoccocus granulosus, multiocularis y vogeli, ocurre posterior al contacto en el parénquima pulmonar en forma quística de la larva. Presentación del caso: Femenino de 8 años, cuenta con antecedentes de relevancia tabaquismo pasivo, residen en comunidad rural, convivencia con ganado ovino, sin otros antecedentes. Inició cuadro clínico tres días previos a ingreso con dolor abdominal punzante en región de hipocondrio derecho, de intensidad variable, valorado por facultativo en su comunidad, descartando proceso de abdomen agudo, inició manejo con antiespasmódico, analgésico y metronidazol sin presentar mejoría. Acude a hospital de segundo nivel donde le realizan radiografía de tórax encontrando imagen quística en base de hemitórax derecho, por lo que es enviada a nuestro instituto. Ingresó sin dificultad respiratoria, en regulares condiciones generales, paraclínicos normales. Se solicita tomografía de tórax, se observan dos imágenes de paredes delgadas de 4 mm en lóbulo medio e inferior derecho, anexo a zona peribronquial, con contenido líquido, 6.3 x $6.1 \mathrm{~cm}$ y 4.6 x $5.5 \mathrm{~cm}$, respectivamente, con presencia de pared de hasta $6 \mathrm{~mm}$ entre ellas, no incrementa la atenuación con administración del contraste, zonas de atelectasia por compresión y consolidación en lóbulo inferior derecho. Se realizó intervención quirúrgica encontrando quiste con contenido agua de roca, endoquiste muy vascularizado con adherencias. Reporte de patología con quistes pulmonares por Echinoccocus granulosus, presencia de parásitos intraalveolares e intravasculares, parénquima pulmonar con inflamación crónica peribronquial. Discusión: El diagnóstico de hidatosis pulmonar es raro en nuestra comunidad, la edad de presentación no es la común, los reportes de casos encontrados en la literatura se refieren con edad media de cinco años. Llama la atención la exposición a ganado ovino de manera indirecta. Conclusiones: Ante la presencia de lesión quística pulmonar debemos de tomar en cuenta esta patología.

\section{Histoplasmosis en pediatría. Reporte de casos}

Pavón KE, Del Razo RR

INER Ismael Cosío Villegas

Objetivo: Describir una serie de casos de pacientes con histoplasmosis diagnosticados en nuestro hospital de 2000-2015. Presentación de casos: Se revisaron expedientes de seis pacientes, cuatro con forma pulmonar $\mathrm{y}$ dos diseminadas, tres femeninos y tres masculinos, cuatro procedentes de Morelos y dos del Estado de México. El 50\% se había expuesto a murciélagos y $33 \%$ gallinas. $50 \%$ habían visitado cuevas y tenían contacto con humedad. Todos inmunosuficientes, $83 \%$ previamente sanos, todos habían tenido un familiar con histoplasmosis. El tiempo de evolución fue $22+12.04159$ días. El síntoma predominante fue fiebre (100\%), seguido por astenia, cefalea y tos $(66.7 \%)$, mialgias y vómito $(50 \%)$. Un paciente curso con dificultad respiratoria. A su ingreso tres presentaban polipnea, uno dificultad respiratoria, ninguno taquicardia ni desaturación; tuvieron crepitantes más frecuente que sibilancias y dos pacientes tenían síndrome infiltrativo (hepatoesplenomegalias y adenopatías cervicales). Todos mostraban alteraciones radiológicas, en la placa de tórax la más encontrada fue el patrón nodular $(100 \%)$ de los casos, seguido por hiperinsuflación y ensanchamiento mediastinal (33.33\%). A todos se les realizó tomografía computada encontrándose el patrón micronodular predominante en frecuencia $(50 \%)$. Cuatro pacientes requirieron broncoscopia, con positividad de lavado bronquioloalveolar en dos pacientes, PCR en uno, determinación por patología en dos. El 50\% tuvieron positividad a histoplasmina, al igual que serología positiva. Se pudieron realizar dos espirometrías, encontrándose patrón obstructivo en ellas. Se dio tratamiento a todos los pacientes con itraconazol, pero dos requirieron anfotericina por considerarse diseminada y grave. Discusión: Debemos tener alto índice de sospecha de histoplasmosis pulmonar en los pacientes que presentan contacto con familiares enfermos y originarios del estado de Morelos y que muestren 
patrón nodular en la tomografía de tórax. Conclusión: La histoplasmosis por Histoplasma capsulatum, es la micosis sistémica más prevalente en el ser humano: presentamos seis casos todos inmunosuficientes con contacto con adultos diagnosticados.

\section{Evaluación funcional respiratoria longitudinal en pacientes que sobrevivieron a neumonía grave por influenza AH1N1 en el período 2013-2014}

Jaquez MA, Guerrero ZS, Torre-Bouscoulet $L$

INER Ismael Cosío Villegas

El virus de la influenza ha sido descrito desde tiempos muy antiguos causando varias pandemias, esto se debe a que su genoma es único entre los virus y a la aparición frecuente de variantes antigénicas, que continúan dando lugar a epidemias y pandemias. La mayoría de los casos graves de influenza A H1N1 se presentaron en adultos jóvenes; en los cuales el SIRA fue la principal causa de muerte, con una tasa de mortalidad más elevada que para el SIRA de otras causas, debido al daño en las células epiteliales inducido por el virus. Descripción del estudio: Se contactaron un total de 48 pacientes que padecieron neumonía grave por influenza A H1N1, de los cuales aceptaron participar en el estudio 32 pacientes, con un seguimiento a un año de 26 pacientes y seis pacientes a seis meses. Se registraron variables clínicas y tomográficas de acuerdo con la escala de Kazerooni, calificada por un radiólogo experto en tórax del INER de la hospitalización, a partir del expediente clínico de aquellos pacientes que cumplan criterios de inclusión y aceptaron participar en el estudio. Durante las citas de seguimiento a seis meses y un año se realizarán: el cuestionario de calidad de vida (cuestionario respiratorio SF-
36) y pruebas de función respiratoria completas que incluyen espirometría forzada, pletismografía corporal, DLco, gasometría arterial en reposo, pimax, pemax y cm6min. Es un estudio de cohorte prospectiva. Las variables continuas se expresaron en mediana e intervalo intercuartílico. Valor de significancia estadística con $\mathrm{p} \leq 0.05$ bimarginal. Conclusiones: No hay evidencia de alteración funcional respiratoria posterior al SIRA por influenza A H1N1. Existe recuperación de la capacidad de intercambio gaseoso después de neumonía grave por H1N1. Existe recuperación de la capacidad de intercambio gaseoso después del Neumonía grave por influenza A H1N1 y SIRA grave.

\section{Desenlaces en}

pacientes hospitalizados con neumonía por influenza $A(\mathrm{H} 1 \mathrm{~N} 1)$ PDM09 que requirieron uso de terapia con oseltamivir, prolongada o combinada de antivirales en el Instituto Nacional de Enfermedades Respiratorias de noviembre del 2013 a mayo del 2014

Rosales GA, Martínez OJA

INER Ismael Cosío Villegas

Antecedentes: El virus de la influenza ha sido de las causas más importantes de infecciones del tracto respiratorio. En 2009 surgió un nuevo virus de influenza $\mathrm{A}(\mathrm{H} 1 \mathrm{~N} 1)$. Se han asociado cepas resistentes a tratamientos convencionales; se desconoce si esto u otros factores podrían contribuir al uso de terapia prolongada o combinada de antivirales y/o muerte por falta de respuesta a tratamiento. Objetivos: determinar causas de pobre respuesta a tratamiento y necesidad de empleo de diferentes terapias antivirales. Métodos: Se tomaron pacientes hospitalizados en el INER con diagnóstico de influenza $\mathrm{A}(\mathrm{H} 1 \mathrm{~N} 1)$ pdm09 por método de construimos modelos multivariados mediante regresión logística para identificar factores independientemente asociados a uso de las diversas terapias empleadas. Resultados: Encontramos $12.7 \%$ de pacientes con inmunosupresión, 35 pacientes $(23.5 \%)$ requirieron estancia en UTI, 40 pacientes $(26.8 \%)$ requirieron VMNI y $69(46.3 \%)$ requirieron VMI. Estancia hospitalaria media de 13.63 días. Ocho pacientes $(6.3 \%)$ no recibieron tratamiento antiviral; de los que usaron cualquier tipo de terapia, la media de tratamiento antiviral fue de $9,111(88.1 \%)$ recibieron monoterapia con oseltamivir; 88 pacientes $(69.8 \%)$ recibieron terapia prolongada y $6(4.8 \%)$ recibieron algún tipo de terapia combinada; $1(0.8 \%)$ con la combinación de amantadina/ rimantadina, en $5(4 \%)$ triple terapia y en $1(0.8 \%)$ combinación de oseltamivir/ribavirina. Se reportó mortalidad hospitalaria de $16.7 \%$; tres no tuvieron tratamiento, $17(80.95 \%)$ tratamiento con oseltamivir y uno $(4.76 \%)$ recibió terapia triple. Los pacientes con terapia prolongada $26.2 \%$ estuvieron en UTI, $59.5 \%$ cumplieron con criterios diagnósticos de SIRA, seis pacientes fallecieron vs. ocho con terapia estándar. Conclusiones: Encontramos que el tabaquismo, linfopenia al ingreso, uso de VMI y presentar SIRA al ingreso se asociaban de forma significativa al uso de terapia prolongada. Pacientes con terapia prolongada tuvieron menor riesgo de muerte a 30 días; con mayor asociación en aquellos que no estuvieron en UTI.

\section{Triple infección}

pulmonar en paciente con inmunodeficiencia común variable: primer reporte de caso 
Téllez NNA, Machuca VNJ, Becerril VE, Martínez OJA

INER Ismael Cosío Villegas

Introducción: La inmunodeficiencia común variable (ICV) es la inmunodeficiencia primaria más frecuente. Se define como una reducción en suero de $I g G$ y presencia de infecciones recurrentes que afectan a diferentes órganos y sistemas, principalmente vías respiratorias superiores e inferiores y el tracto gastrointestinal. Las infecciones bacterianas son las más frecuentes, siendo las infecciones por oportunistas y hongos poco frecuentes. Presentación de caso: Hombre de 40 años con antecedente de dos neumonías. El cuadro clínico inició con síntomas respiratorios: tos productiva, hemoptoicos, disnea, y fiebre durante dos semanas. Requirió ventilación mecánica e ingreso a la UCI, recibió tratamiento antibiótico por neumonía atípica y se inició protocolo diagnóstico, reportándose en el cultivo del LBA desarrolló $S$. pneumoniae, las tinciones para hongos con reporte hifas y el cultivo con crecimiento de Paecilomyces $s p p$, el PCR de virus respiratorios se reportó Rhinovirus. Por linfopenia persistente se realizó prueba de VIH y fue no reactiva, se encontró disminuido el nivel de inmunoglobulinas compatible con una ICV. Recibió tratamiento con meropenem, anfotericina y gammaglobulina, presentado mejoría clínica y radiológica. Discusión: En personas con ICV las infecciones respiratorias por Rhinovirus y bacterias encapsuladas $S$. Pneumoniae y $H$. influenzae son frecuentes. En nuestro caso el paciente presenta una coinfección viral, bacteriana y por Paecilomyces; hongo filamentoso contaminante común del aire y el suelo, que se encuentra en la naturaleza como saprófito, se ha aislado en la tierra y en los vegetales en descomposición, es un patógeno humano poco común, pero puede tener importancia clínica en pacientes inmunocomprometidos. Este es el primer caso reportado de infección por
Paecilomyces en pacientes con ICV. Conclusiones: Este caso enfatiza la importancia de considerar infecciones fúngicas cuando el sistema inmune está comprometido, requiere de abordaje microbiológico e inicio de terapia fúngica empírica. El diagnóstico oportuno previene hospitalizaciones recurrentes.

\section{Síndrome de dificultad respiratoria aguda secundario a varicela complicada, presentación de caso}

\section{Leal T, Martínez VLF, Lule MMS, Alejandre GA}

INER Ismael Cosío Villegas

Introducción: En la actualidad se considera a la varicela como la enfermedad exantemática más frecuente en pacientes pre y escolares. La enfermedad puede dar lugar a complicaciones graves, $1 / 3$ de los que fallecen ocurre como consecuencia de neumonía. Presentación: Paciente masculino de 14 años, originario y residente del D.F. Asma desde los tres años de edad en control durante 11 años, suspendiendo tratamiento inhalado (LABA) hace tres años. Última crisis hace dos años. Inició su padecimiento con hiporexia, odinofagia y fiebre, se agregan lesiones vesiculares en espalda, acudió con facultativo quien indica quinolona y AINE, se agrega presencia de tos, disnea y sibilancias audibles a distancia iniciando esquema de rescate con salbutamol, sin mejoría, instaurándose dificultad respiratoria por lo que acude a nuestra unidad. A su ingreso $\mathrm{SatO}_{2} 83 \%$, con taquipnea, taquicardia y presencia de lesiones diseminadas en forma de máculas, pápulas, pústulas, vesículas y costras. Tórax con sibilancias espiratorias en regiones subescapulares. Se inicia tratamiento con base en B2 agonista inhalado, con mala respuesta, ameritando sulfato de magnesio así como aminofilina en infusión, con desarrollo de SDRA, se indica oxigenoterapia con flujos altos, colocación de CVC e inicio de cobertura antimicrobiana con base en ceftriaxona, vancomicina y aciclovir. No se pudo hacer uso de la VMNI debido a las condiciones del paciente (lesiones impetiginizadas en cara). Alto riesgo de requerir VMI. Radiografía tórax: datos de atrapamiento aéreo, patrón en vidrio deslustrado bilateral. Tomografía: engrosamiento peribroncovascular, bronquiectasias cilíndricas y patrón en vidrio deslustrado bilateral. Discusión: En todo el mundo las complicaciones por varicela ocurren en un 2 a $5 \%$. La neumonía como tal es más común en adultos que en niños alrededor de 25 veces. Conclusiones: Continúa en controversia el uso de esteroide sistémico en pacientes con desarrollo de varicela debido a la posibilidad de perpetuar estado de inmunosupresión; sin embargo, es el tratamiento de elección para SDRA, por lo que se decide su uso, considerando riesgo-beneficio, logrando la remisión del daño pulmonar agudo, evitando uso de VMI. Se egresa paciente con favorable evolución clínica.

\section{Caracterización clínica y sociodemográfica de la neumonía complicada en un hospital pediátrico de tercer nivel}

Aguilar AA, Silva RAG, Hernández RR, Ruiz GHH, Membrila MJ, Rivera GS, de Borbon $A B$

IMSS

La neumonía complicada constituye una importante causa de morbilidad en la edad pediátrica, con un incremento anual de casos a nivel mundial en los últimos años. Objetivo: Determinar las características clínicas y sociodemográficos en pacientes con diagnóstico de neumonía complicada atendidos en UMAE Hospital de Pediatría de Centro Médico Nacional de Occidente en un período de cuatro años. Material y métodos: Se realizó un estudio descriptivo 
retrospectivo en la UMAE Hospital de Pediatría CMNO. Se incluyeron todos los pacientes que ingresaron al Servicio de Neumología Pediátrica con diagnóstico de neumonía complicada de enero de 2011 a enero de 2015 con un total de 77 pacientes. Se realizó revisión de expedientes y llenado de hojas de recolección de datos; las variables fueron sexo, edad, tiempo de estancia, sintomatología respiratoria, tipo de complicación, comorbilidades y presencia de secuelas al egreso; así como la elaboración de una base de datos y su análisis estadístico. Resultados: El grupo etario más afectado fue entre 1 y 5 años de edad, sin diferencia de género; el $62.3 \%$ tenía antecedente de inmunización contra neumococo y el $70.1 \%$ correspondía a niños previamente sanos. Los síntomas clínicos más frecuentes fueron fiebre en $92.2 \%$ y tos en $61 \%$. La complicación más frecuente fue el derrame pleural con $74 \%$, requiriendo sonda pleural en $68.8 \%$ y el $28.6 \%$ requirió algún procedimiento quirúrgico, siendo más frecuente la toracotomía abierta en $50 \%$. Conclusiones: La neumonía complicada constituye un problema de salud pública actual, dado el incremento anual de los casos a nivel mundial y por ser causa importante de morbilidad pediátrica, lo que traduce un alto costo para las instituciones de salud. A pesar de que el manejo ideal de los pacientes con neumonía complicada de acuerdo con la evidencia actual es la toracoscopia, continúa siendo un recurso poco disponible en nuestro medio.

\section{Coccidioidoma como simulador de nódulo pulmonar solitario, reporte de un caso}

Valdez BJL, Valdés LHG, Montemayor ChM, Mejía BRM

\section{IMSS}

Introducción: La coccidioidomicosis es la infección causada por los hongos dimórficos del género Coccidioides
(C. immitis y C. posadasii).La mayoría de las infecciones están causadas por la inhalación de esporas. En México, dicha zona corresponde a los estados de Nuevo León, Coahuila, Chihuahua, Sonora, Baja California y Tamaulipas. Presentación del caso: Se presenta el caso de masculino de 45 años de edad, de oficio traumatólogo activo quien previamente inicia su padecimiento hace tres meses con astenia, adinamia, hiporexia, agregándose cefalea frontoparietal bilateral, además de fiebre de un mes de evolución de predominio vespertino hasta $39.5{ }^{\circ} \mathrm{C}$ que remitía con paracetamol, niega diaforesis, pérdida de peso de $6 \mathrm{~kg}$ en tres meses no intencional. En la tomografía de tórax, nódulo pulmonar derecho de 10 x 6.7 $\mathrm{mm}$, homogéneo de $21 \mathrm{UH}$, bordes bien definidos. Se realizó toma de biopsia mediastinal por toracotomía axilar derecha, en el reporte histopatológico definitivo proceso inflamatorio granulomatoso secundario a coccidioidomicosis. Discusión: El coccidioidoma es un residuo crónico de neumonitis coccidioidal que varía de pocos milímetros hasta 4 o $5 \mathrm{~cm}$ de diámetro. La mayor parte de los coccidioidomas se encuentra a menos de $5 \mathrm{~cm}$ del hilio, por lo que la afección bronquial explica la tos en accesos y la hemoptisis. Conclusión: La coccidioidomicosis es una patología que muestra una amplia gama de manifestaciones y hallazgos, algunos de ellos inespecíficos, y que en algunas ocasiones en el proceso de abordaje ante la evidencia tomográfica o radiológica de nódulo pulmonar sospechoso, es importante descartar la procedencia benigna de este tipo de lesiones y tener el coccidioidoma como alternativa en el diagnóstico de coccidioidomicosis.

Coinfección de pneumocystis jirovecii y citomegalovirus en biopsias pulmonares de pacientes $\mathrm{VIH}$ en el INER durante los años 2013 y 2014
Briseño HAA, de León FJP, Luna $R C$

Instituto Nacional de Enfermedades Respiratorias

Antecedentes: Onusida-Censida reportó que en México a finales del 2013 existían 180 mil personas viviendo con VIH y SIDA. Las infecciones oportunistas eran la principal causa de morbi-mortalidad en estos pacientes siendo las más frecuentes neumonías por Pneumocystis Jirovecii, enfermedades por micobacterias y enfermedades por hongos. Material y métodos: Se realizó revisión del archivo del servicio de Anatomía Patológica para elaborar una base de datos de pacientes con diagnóstico de infección por Pneumocystis Jirovecii mediante biopsia transbronquial, en los años 2013 y 2014. Los bloques de parafina seleccionados fueron tratados para obtener microarreglos y se realizaron reacciones de inmunohistoquímica para citomegalovirus (CMV). Se evaluaron en conjunto para valorar la correlación con resultados de conteo de linfocitos y carga viral. Resultados: La población con infección por Pneumocystis fue de 51 pacientes masculinos $(83.6 \%)$. La edad promedio fue de 36 años (24-65 años). El estudio sérico de CMV fue positivo en 51 pacientes (82\%), cinco pacientes presentaron valor sérico negativo y cinco pacientes carecían de estudio sérico para CMV; el valor medio fue de 14,372 copias por $\mathrm{mL}$. El estudio de IMHQ con anticuerpo primario para CMV fue positivo en 11 casos (18\%). Los recuentos de linfocitos CD4 fueron menores a $50 \mathrm{CD} 4 / \mathrm{mL}$ en 10 pacientes $(16 \%)$ con resultado positivo de IMHQ para CMV en la biopsia pulmonar. Conclusiones: Los pacientes con VIH con infección oportunista por Pneumocystis tienen conteos menores a $50 \mathrm{CD} 4 / \mathrm{mL}$ en el $84 \%$ de los casos. El 18\% de los pacientes con SIDA asociada a VIH con infección oportunista por Pneumocystis presenta infección concomitante con citomegalovirus en 
la biopsia transbronquial demostrado por estudio de inmunohistoquímica. El estudio en sangre periférica de citomegalovirus no tiene correlación con el desarrollo de infección pulmonar concomitante en pacientes con SIDA asociado a VIH con diagnóstico de $P$. Jirovecii.

\section{Procalcitonina como predictor de mortalidad en pacientes con neumonía adquirida en la comunidad}

Ruiz F, Carrillo RG, Suárez T, Alonso
$D$, Quiñones F, Salazar MÁ, Jaime T

INER Ismael Cosío Villegas

La neumonía adquirida en la comunidad de acuerdo con la OMS, sigue siendo un problema de salud pública con alta mortalidad. Recién se han estudiado diversos biomarcadores, entre ellos la procalcitonina para determinar la gravedad de la neumonía, el manejo antibiótico, sala general o de cuidados intensivos y ha sido un mejor predictor de mortalidad. El objetivo es establecer el comportamiento clínico de las NAC, de acuerdo con la determinación de PCT y evaluar el impacto en la mortalidad con los niveles detectados. Se estudiaron 85 pacientes que ingresaron al Servicio de Urgencias al INER con diagnóstico de NAC, se clasificaron de acuerdo con la escala de CURB 65 y se determinó el nivel de procalcitonina al ingreso. Fue analizado la mortalidad, la gravedad de acuerdo al CURB 65 y los esquemas antibióticos usados. Se consideró un valor positivo a los pacientes que presentaron procalcitonina mayor a $0.25 \mathrm{ng} / \mathrm{mL}$ y se buscó la relación con su mortalidad. Cincuenta y siete por ciento de los pacientes tuvo procalcitonina mayor a $0.25 \mathrm{ng}$. El valor promedio de PCT en los pacientes fallecidos fue de $7.4 \mathrm{ng} / \mathrm{mL}$ significativamente mayor respecto a los que no murieron $4.2 \mathrm{ng} /$ $\mathrm{mL}(\mathrm{p}<0.05)$. La relación entre la PCT y la escala de CURB 65, mostró una tendencia de correlación positiva sin significancia estadística. Los leucocitos no mostraron impacto en la mortalidad y la correlación con la PCT fue negativa sin significancia estadística. La mortalidad a los 30 días con niveles mayores a 3 ng de PCT fue del $40 \%$, en contraste con los pacientes con niveles menores fue del 18\% ( $\mathrm{p}<0.02)$. De acuerdo con nuestros resultados, la procalcitonina se puede considerar factor predictor de mortalidad en neumonías, al igual a lo descrito con la escala de CURB 65.

\section{Empiema pleural secundario a fiebre de malta}

Ramírez JF, Molina J, Rentería A

\section{IMSS}

Empiema pleural secundario a fiebre de malta. Reporte de caso, Neumología UMAE 34 IMSS, Monterrey, N.L., México. La brucelosis o fiebre de malta, predominante en zonas rurales afecta el sistema reticuloendotelial, en raras ocasiones cursa con afectación pulmonar, tal vez la poca información que hay sobre el compromiso pulmonar se debe a falta de acceso de atención médica especializada en vías respiratorias y por lo atípico del cuadro clínico. Femenina de 41 años de edad, originaria de Coahuila residente de Monterrey, ama de casa, niega tabaquismo y alcoholismo, no exposición a biomasa, ingesta frecuente de queso de cabra, niega crónico degenerativas, VIH y COMBE negado. Inicia padecimiento hace tres meses con dolor punzante en hemitórax anterior izquierdo, intensidad 2/10 intermitente, acompañado de fiebre sin predominio de horario hasta $38{ }^{\circ} \mathrm{C}$, diaforesis vespertina, tos seca en accesos, en ocasiones emetizante, agregándose disnea mMRC 1, tratada en múltiples ocasiones con tratamiento sintomático y antibiótico como infecciones de vías respiratorias, sin mejoría, con exacerbación del dolor torácico tipo anginoso con irradiación a cuello y hombro izquierdo, intensidad 9/10 acudiendo a urgencias donde considera probable infarto al miocardio procediendo a trombolisis sin mejoría, ante los hallazgos radiográficos se decide realizar una TAC de tórax enviándose a nuestro servicio de neumología como probable tumoración y derrame pleural. Se corrobora diagnóstico de empiema secundario a Brucella abortus por cultivo de líquido pleural, se inicia tetraciclina-amikacina, con mejoría clínica. Conclusión: Presentamos este caso diagnosticado por cultivo de líquido pleural, así pues dentro del diagnóstico diferencial de las causas de empiema se debe tomar en cuenta la etiología por brucelosis, además de otras manifestaciones respiratorias como neumonía, nódulos pulmonar solitario o múltiples, absceso pulmonar, derrame pleural, hemoptisis, adenopatías mediastinales secundario a brucelosis.

\section{Micosis pulmonares. Reporte de casos clínicos}

\section{Márquez GC, Navarro VDI, Tinoco LE, Flores IAA}

CMN "La Raza", IMSS

Introducción: Las infecciones fúngicas invasivas son una causa importante de morbimortalidad en pacientes inmunocomprometidos, principalmente en neutropénicos. Los principales agentes causantes son Aspergillus spp. y Candida albicans; con un incremento en la incidencia de otros agentes: mucorales, Cryptococcus spp. y Fusarium spp. En este trabajo se presenta una serie de casos de pacientes con micosis pulmonares invasivas no neutropénicos. Presentación de series de casos: Presentamos cuatro casos con criterios de enfermedad fúngica invasiva: todos hombres, promedio de edad 73 años ( \pm 6 ); comorbilidades: diabetes mellitus 2 (2), hipertensión arterial (2), enfermedad renal crónica terminal (1), enfermedad pulmonar obstructiva crónica (2). Cuadro clínico: tos productiva (4), disnea (3), fiebre (3), pérdida de peso (2). Hallazgos de 
imagen: consolidación bilateral por Candida albicans; consolidación con necrosis y derrame pleural en mucormicosis; signo de luna creciente y del halo (micetoma) por Aspergillus fumigatus y cavitaciones bilaterales de lóbulos superiores con consolidación izquierda por Aspergillus spp. Diagnóstico microbiológico: aislamiento en lavado bronquial (Aspergillus spp. y Candida albicans), histopatológico (Aspergillus fumigatus y mucormicosis) y uno por galactomanano sérico elevado. El tratamiento quirúrgico y farmacológico fue necesario en dos casos (mucormicosis y aspergiloma); sólo farmacológico con voriconazol en aspergilosis y fluconazol en candidiasis. Tres defunciones (candidiasis, mucormicosis y aspergilosis). Discusión: Los principales factores de riesgo para enfermedad fúngica invasiva se reportan neutropenia, trasplante de precursores hematopoyéticos, tratamientos inmunosupresores, inmunodeficiencias primarias, infección por VIH, cáncer y diabetes mellitus descontrolada. El tratamiento depende del agente aislado. Conclusiones: Las micosis pulmonares son subdiagnosticadas por enfermedades de mayor prevalencia (cáncer pulmonar, tuberculosis). Su diagnóstico generalmente requiere de procedimientos invasivos, incluyendo quirúrgicos, como en la mucormicosis. El pronóstico de estas infecciones depende del diagnóstico temprano, tratamiento oportuno y grado de inmunocompromiso.

\section{Histoplasmosis pulmonar}

\section{Escobedo JL, * Moreira-Meyer \\ $A,{ }^{*}$ Iñarra-Hiriart $A,{ }^{*}$ Rosas RMA, ${ }^{*}$ Velázquez FLK, * Peláez GHE, Niezen LSF, $\neq$ Esquerra APS, $\neq$ Baley Al, *Vázquez BMC, * González GH, Ramírez CE}

*Hospital General de México; ҰUniversidad Anáhuac

La histoplasmosis es una micosis endémica en zonas tropicales, se desarrolla en tierras ricas en sustancias orgánicas con deyecciones de aves y murciélagos, los microconidios son la forma infectante. Son infecciones benignas, pero los inmunocomprometidos presentan formas diseminadas con un curso fatal si no son tratados. Masculino 44 años, VIH (-), con exposición a murciélagos. Presenta fiebre, dolor torácico tipo pleurítico, tomografía: nódulo pulmonar solitario en lóbulo pulmonar inferior izquierdo, se decide resección. Ziehl-Neelsen (-), Lowenstein (-). Biopsia con inflamación crónica granulomatosa, cultivo Sabouraud positivo a Histoplasma capsulatum. Masculino 35 años, PPD: 0, VIH (+), CD4 9, pérdida de $10 \mathrm{~kg}$, fiebre, tos, expectoración purulenta, disnea. Radiografía y TAC con infiltrado, cavernas apicales. Broncoscopia: ZN (-), Lowenstein (-), X-PERT (-). Se da tratamiento antituberculoso mejora. A los 10 meses, acude con radiografía con nuevo infiltrado y cavernas bilaterales, broncoscopia con Grocott y cultivo Sabouraud positivo para Histoplasma capsulatum. Masculino 29 años, HIV (-) dolor abdominal, pérdida de $23 \mathrm{~kg}$, fiebre, PET-CT adenopatías cervicales, supraclaviculares, mediastinales, retroperitoneales, actividad metabólica ganglionar supra e infradiafragmática, hepatoesplenomegalia. Biopsia ganglionar linfadenitis granulomatosa, Ziehl-Neelsen y Lowenstein positivo, además de linfoma Hodgkin, posteriormente con nuevo infiltrado micronodular, broncoscopia: cultivo de hongos positivo para Histoplasma capsulatum. Discusión y conclusiones: La gravedad de la enfermedad depende del inóculo y de la respuesta inmune del huésped. Dos pacientes eran inmunocomprometidos tenían, además, tuberculosis, durante el tratamiento se infectaron de histoplasmosis presentando formas pulmonares con infiltrados difusos. El otro paciente presenta un histoplasmoma, lesión única con calcificaciones laminares, al igual que el tuberculoma pueden dar imágenes falsas positivas en el PET-CT, la histoplasmosis es la micosis que más mimetiza al cáncer pulmonar. Es útil para el diagnóstico los antígenos en suero y orina por ELISA, detección de anticuerpos por Western-Blot, detección de anticuerpos por fijación de complemento, tinciones y cultivos.

\section{Diferencias clínicas y paraclínicas del síndrome coqueluche vs. coqueluchoide}

\section{Martínez VLF, Del Razo RR, Leal AT, Castillo VC, Lechuga TI}

INER Ismael Cosío Villegas

Antecedentes: La tos ferina es una enfermedad infectocontagiosa causada por Bordetella pertussis. Afecta del $80-90 \%$ de personas no inmunizadas. A nivel mundial se estiman 50 millones de casos/año y 300,000 muertes. Es el quinto lugar como causa de muerte en menores de cinco años y muestra un patrón oscilatorio con exacerbaciones cada tres a cinco años, la última reportada en México en el 2009. Ha ocurrido una reemergencia, se cree secundario a uso de vacuna acelular. Objetivo: Describir cuadro clínico y apoyos diagnósticos en pacientes pediátricos con síndrome coqueluche (SC) y coqueluchoide (SCL) en el instituto del 2000-2015. Material y métodos: Estudio observacional, descriptivo, retrospectivo y transversal; revisamos expedientes de pacientes con diagnóstico de SC y SCL, 0-16 años, ambos sexos. Se eliminaron los que no tenían resultado de PCR para Bordetella pertussis. Resultados: Incluimos 35 pacientes: 9 con PCR positiva para Bordetella pertussis; edad cuatro meses (IIC 3-9), 14 femeninos y 21 masculinos, $56 \%$ con vacunación completa. Síndrome coqueluche tiene más frecuente hacinamiento (67 vs. $23 \% \mathrm{p}=0.018$ ). Síndrome coqueluchoide se presenta más en otoño-invierno, con tos en accesos (91.4\%) o quintosa $(42.9 \%)$. La cianosis es más frecuente en SC (88.9 vs. $46.2 \% \mathrm{p}=0.026$ ) tienen, además, fiebre y dificultad respiratoria; los SCL rinorrea, tos emetizante y fiebre. SC tienen cifras menores de $\mathrm{SatO}_{2}$ FiO 21\% (82\% IIC 80-84 vs. 86\% IIC $83-88 \mathrm{p}=0.035)$ e hipoxemia $\left(\mathrm{PaO}_{2}\right.$ 
$44 \mathrm{mmHg}$ IIC 39.45-47.8 $\mathrm{p}=0.0481)$, más frecuente leucocitosis (67 vs.16\% $\mathrm{p}=0.004)$ y linfocitosis (44.44 vs. $8 \mathrm{p}$ $=0.048$ ) y mayores cifras (leucocitos 20.5 x 103/mL IIC 17.1-36.3 p = 0.0132; linfocitos 10.6 x 103/mL IIC 6.66-23). Los SC tiene mayores complicaciones como hipoxemia refractaria, SIRA, convulsiones (22\% vs. $0 \mathrm{p}=0.013)$. Conclusiones: Bordetella pertussis causa brotes cada 3-5 años, es importante su identificación ya que se asocia con complicaciones; la diferencia entre síndrome coqueluche y coqueluchoide es clínica al presentar cianosis, así como hipoxemia incluso refractaria, apoyada por leucocitosis y linfocitosis.

\section{Papilomatosis respiratoria recurrente bronquial. Reporte de caso}

\section{Arriola JM, Guzmán de Alba E}

INER Ismael Cosío Villegas

Introducción: La papilomatosis respiratoria recurrente (PRR) término utilizado para describir la infección del tracto respiratorio por el virus del papiloma humano (VPH). Caso: Femenino 63 años, antecedentes de hipertensión arterial. Consulta por tos crónica de 9 años de evolución tratada como asma sin mejoría. Realizan tomografía torácica dos meses después en donde se visualiza lesión intraluminal del bronquio principal izquierdo localizado a $2.6 \mathrm{~cm}$ de la carina principal. Se realiza broncoscopia observándose papilomas en bronquio principal izquierdo (BPI) que obstruyen el $100 \%$ de la luz bronquial a $2 \mathrm{~cm}$ de la carina principal (CP). Intentando tratamientos endoscópicos en varias ocasiones (resección de papilomas, dilataciones neumáticas, mitomicina) con resultados desalentadores a corto plazo. Es operada un año después presentando estenosis del BPI, reacción inflamatoria y fibrosis, se reseca BPI con lesiones BPI con luz del 100\% libre de papilomas, presentando lesiones papilomatosas en tráquea a dos anillos traqueales arriba de CP resecándolos con crioterapia obteniendo buenos re- sultados. Discusión: PRR es causada principalmente por VPH de bajo riesgo 6 y 11, identificando tipo 16 en varios casos. VPH se pueden dividir en tipos de alto y bajo riesgo, pudiendo causar transformación maligna de células, además de problemas pulmonares como neumonías obstructivas, atelectasias y hasta pérdida de la funcionalidad de un pulmón. El ADN de VPH se ha encontrado en el $20 \%$ de todos los casos de cáncer de pulmón, con los tipos de VPH 16 y 18. Estudios recientes muestran que la presencia de los oncogenes de los VPH son requisito previos para el desarrollo del cáncer, lo que refuerza la hipótesis de que el VPH está implicado en la carcinogénesis bronquial. Conclusión: Es importe realizar seguimiento meticuloso a los pacientes con PRR por su alto número de recidivas, complicaciones neumológicas y potencial de trasformación maligna, así lograr su radicación.

\section{Hemoptisis masiva por mucormicosis pulmonar: reporte de caso}

\section{Navarro VDI, * Barragán PG, Cicero $S R, \neq$ Núñez PRC, $\neq$ Saavedra de $\left.R S\right|^{\ddagger}$}

*IMSS; 捛ospital General de México

Introducción: La mucormicosis es una infección oportunista, causada por especies de Rhizopus, Rhizomucor y Cunninghamella. La mucormicosis pulmonar ocurre con frecuencia en pacientes neutropénicos, con cáncer bajo quimioterapia y receptores de trasplante hematopoyético de células madre. La mortalidad global es alta, reportada hasta $76 \%$, lo cual es mayor en pacientes con inmunosupresión severa. Las manifestaciones clínicas de mucormicosis pulmonar no son específicas y no pueden diferenciarse fácilmente de otras infecciones por hongos. Presentación del caso: Mujer de 56 años con enfermedad renal crónica, etiología no determinada, receptora de riñón cadavérico en mayo 2013. Recibió timoglobulina, micofenolato, tacrolimus y prednisona con adecuada función del trasplante. Presentó fiebre, tos, expectoración hialina y disnea, en estudios de imagen observándose cavitación en lóbulo superior derecho. Inicia tratamiento antituberculoso empírico. Evoluciona con misma sintomatología; por sospecha de aspergiloma inicia voriconazol sin mejoría. La biopsia por aspiración con aguja fina reveló Rhizomucor pusillus. Inicia anfotericina B; presentó hemoptisis masiva que provoca su fallecimiento. Discusión: La mucormicosis es una infección rara en receptores de trasplante renal, con mal pronóstico si reciben terapia agresiva antirrechazo, como ocurrió en este caso. El diagnóstico es difícil y se hace por cultivo. Con un diagnóstico temprano los resultados son mejores bajo tratamiento quirúrgico de la lesión conjuntamente con tratamiento médico. Conclusiones: En este caso se aisló Rhizopus pusillus. El paciente falleció por el posible efecto vasotrópico de este agente ocasionando destrucción tisular finalmente provocando hemoptisis incoercible sin oportunidad de tratamiento radical.

\section{Anormalidades de la función pulmonar en pacientes con neumonía por Pneumocystis jirovecii y coinfección por VIH SIDA}

Flores ÁP, García IIR

INER Ismael Cosío Villegas

Antecedentes: La neumonía por Pneumocystis jirovecii es una infección oportunista que afecta a pacientes con infección por VIH con recuento de linfocitos $\mathrm{T}$ CD4+ $<200$ células $/ \mu \mathrm{L}$ (SIDA). La función pulmonar de estos pacientes puede afectarse; sin embargo, no se ha explorado si está asociada con la severidad de la neumonía, al estado inmunológico u otros factores. Objetivos: Primario: describir la 
función pulmonar posterior a la resolución de neumonía por Pneumocystis jirovecii en pacientes con VIH-SIDA. Secundario: correlacionar la severidad de la neumonía por Pneumocystis jirovecii en pacientes con VIH-SIDA medida por PSI con variables de la espirometría, pletismografía, DLCO y caminata de seis minutos. Metodología: Estudio prospectivo, longitudinal, descriptivo de los patrones funcionales respiratorios. Se reclutaron 25 pacientes hospitalizados con diagnóstico de VIH-SIDA y neumonía por Pneumocystis jirovecii en el INER. Se tomaron registros de deshidrogenasa láctica sérica, carga viral de VIH, linfocitos CD4+, gasometría arterial, índice de severidad de la neumonía y $\mathrm{PaO}_{2} /$ $\mathrm{FiO}_{2}$. Se realizaron espirometría con broncodilatador, DLCO y caminata de seis minutos al egreso hospitalario tomando control de estas mismas pruebas al mes. Se realizó pletismografía al egreso y al mes sólo a los pacientes que presentaron espirometría sugestiva de restricción. Se compararon los resultados funcionales, se correlacionaron con las categorías de PSI. Resultados: El análisis estadístico descriptivo de las variables estudiadas se resumió según su tipo y distribución. Las correlaciones fueron analizadas mediante la prueba de Pearson. Conclusiones: Las anormalidades funcionales respiratorias más frecuente encontrada fue el patrón espirométrico sugestivo de restricción. No hubo relación de la severidad de la neumonía por PSI con niveles séricos de deshidrogenasa láctica, carga viral, cuenta de linfocitos $\mathrm{CD} 4+$, relación $\mathrm{PaO}_{2} / \mathrm{FiO}_{2}$, ni con los patrones funcionales respiratorios presentados.

\section{Actinomyces spp., una causa rara de neumonía necrotizante. Reporte de un caso}

\section{Lechuga I, Del Razo RR, Castillo VMC, Martínez VLF}

INER Ismael Cosío Villegas
Introducción: La actinomicosis es una enfermedad rara en niños. Las especies de actinomices son bacterias anaerobias facultativas que constituyen flora habitual de orofaringe, tracto gastrointestinal y genital. La afectación torácica ocurre en el $15 \%$ de los casos. Los signos y síntomas más frecuentes son dolor torácico, fiebre, pérdida de peso, hemoptisis y tos. Los hallazgos radiológicos son consolidación pulmonar crónica en lóbulos inferiores, con o sin adenopatías, derrame pleural y periostitis de la costilla. La afectación pulmonar crónica no mejora con el tratamiento antibiótico convencional. Presentación del caso: Masculino de 9 años, originario del Estado de México, previamente sano, cuadro de seis meses de tos productiva, expectoración, fiebre, radiografía de tórax inicial normal, se indicó ampicilina por siete días con incremento de la tos y pérdida de $7 \mathrm{~kg}$ en cuatro meses. Dos semanas previas a su ingreso presenta disnea, radiografía de tórax con derrame pleural izquierdo. A su ingreso afebril, síndrome pleuropulmonar de derrame pleural. Biometría hemática con leucocitosis y neutrofilia; tomografía computada con consolidación en lóbulo inferior izquierdo, adenomegalias y derrame; ultrasonido reporta derrame pleural no loculado. Baciloscopias y hemocultivos: negativos; Toracocentesis obteniendo material purulento; broncoscopia: lavado bronquioloalveolar reportó inflamación inespecífica. Recibió tratamiento con ceftriaxona con mala evolución, realizándose lobectomía inferior izquierda. Reporte de patología: paquipleuritis con inflamación aguda, neumonía necrotizante por Actinomyces spp. con fibrosis irregular y bronquiolitis folicular tinción Grocott +. Tratamiento con amoxicilina/clavulanato por seis meses, con seguimiento y resolución exitosa. Conclusión: En la mayoría de los casos se encuentra un factor predisponente, sin embargo, nuestro paciente era previamente sano. Es causa rara de neumonía con derrame y existen pocos casos reportados en la literatura. El diagnóstico diferencial de neumonía crónica suele establecerse con procesos infecciosos, la tubercu- losis es la primera posibilidad, aunque otros patógenos como Histoplasma o Echinococcus y Actinomyces, deberían ser considerados.

\section{Coccidioidomicosis crónica. Reporte de un caso}

Márquez GC, Navarro VDI, Basaldúa ZPX

CMN "La Raza”, IMSS

Introducción: La coccidioidomicosis es una micosis endémica cuya incidencia se ha modificado en los últimos años por la migración. La forma aguda, que suele ser asintomática, suele ser subdiagnosticada, desarrollándose la forma crónica. La forma diseminada suele asociarse con mal pronóstico y se observa en pacientes con inmunocompromiso. Presentación de caso: Hombre de 34 años. Originario y residente de Guasave, Sinaloa. Ocupación: sembrador. Viajes frecuentes a Baja California y Arizona. Hemoptoicos ocasionales desde los 16 años, que aumentaron en frecuencia desde 2011. Se diagnosticó coccidioidomicosis en 2013 mediante serología y microbiología, recibiendo tratamiento con anfotericina y fluconazol por 1 año y 6 meses, con remisión de los hemoptoicos durante ese tiempo. En marzo 2015 presenta episodios recurrentes de hemoptisis mayor ingresando al servicio. Se realizó fibrobroncoscopia reportando proceso inflamatorio. Panel viral negativo. Se descartó malformación arteriovenosa por angiotomografía. BAAR y cultivos para micobacterias negativos en lavado bronquioalveolar y esputo. Reporte de esférulas por tinción y Coccidioides immitis en cultivo de esputo. Tratamiento con fluconazol un año. Discusión: La forma crónica de coccidioidomicosis suele desarrollarse en 3 a $5 \%$ de los casos de enfermedad aguda y cerca del $75 \%$ de los casos no presentan los síntomas de la forma inicial. Generalmente se asocia con condiciones de supresión de la inmunidad celular, así como a una 
morbimortalidad elevada. La principal manifestación radiológica de la forma crónica es de neumonía lobar persistente con adenopatías mediastinales. Conclusiones: La coccidioidomicosis crónica se consideraba una forma poco común de la enfermedad. Debido a que suele evadirse el diagnóstico de la forma aguda, la forma crónica ha aumentado su incidencia, además de un incremento en el número de pacientes con inmunocompromiso. Esto se ha visto favorecido por el curso asintomático de la enfermedad aguda y el enorme espectro de manifestaciones radiológicas de la forma crónica.

\section{Intersticio}

\section{Alteración de los AGEs/RAGE en fibrosis pulmonar idiopática ${ }^{\mathrm{a}}$}

Vicens $\boldsymbol{V},{ }^{*}$ Machahua $C,{ }^{*}$ Montes-Worboys $A,{ }^{\ddagger}$ Llatjós $R, \$$ Escobar I,\& Planas $L,{ }^{\ddagger}$ Dorca J,, Molina $\mathrm{MM}^{\ddagger}$

*Laboratorio de Neumología Experimental. Grupo de Investigación Neumológica. IDIBELL. Universidad de Barcelona. Hospital Universitario de Bellvitge (Barcelona); ${ }^{\ddagger}$ Centro de Investigación Biomédica en Red Respiratorio (CIBERES). España; §Unidad Funcional de Intersticio Pulmonar. Servicio de Neumología. Hospital Universitario de Bellvitge (Barcelona)

Introducción: Estudios recientes sugieren una relación entre la fisiopatología de la fibrosis pulmonar y los productos finales de la glicación (AGEs), implicados en el estrés oxidativo, y la expresión de su receptor (RAGE), encargado de la transducción de señal y su depuración. Objetivos: Evaluar la expresión y localización de AGEs/ RAGE en pulmón control y pulmón de pacientes con fibrosis pulmonar idiopática (FPI). Metodología: Se obtuvieron 16 muestras pulmonares procedentes de pacientes biopsiados para el diagnóstico de enfermedad pulmonar intersticial difusa. Todas las muestras presentaron un patrón histológico de neumonía intersticial usual (NIU). Como control se obtuvieron nueve muestras pulmonares procedentes del área más distal de lobectomías por cáncer. La expresión de AGEs/RAGE se evaluó en los homogenados tisulares mediante RTPCR y Western blot. Su localización en el tejido pulmonar fue valorada por inmunohistoquímica. Resultados: La expresión proteica y génica del RAGE estaba disminuido en pacientes con FPI respecto a las muestras control. $\mathrm{Su}$ localización en el pulmón control estuvo restringida a las células del epitelio alveolar y macrófagos. Por otro lado, tanto el análisis por western blot como la inmunotinción mostraron una acumulación significativa de AGEs en los tejidos fibróticos en comparación a los controles, asociados con la membrana celular del epitelio alveolar y en la matriz extracelular. Conclusión: Los hallazgos confirman una disminución de la expresión del RAGE junto con un incremento de los AGEs en los tejidos fibróticos. Este desequilibrio entre AGEs y RAGE podría tener relevancia en la patogénesis de la fibrosis pulmonar.

a Trabajo seleccionado para ser presentado de forma oral. Obtuvo mención honorífica.

\section{Alelos de HLA clase II diferentes} a DR4 se asocian al desarrollo de neumopatía intersticial difusa en pacientes con artritis reumatoide ${ }^{a}$

Del Ángel PAD, * Ambrocio OE, * Mobayed $F,{ }^{*}$ Rojas SJ, ${ }^{*}$ Pérez $R D$, Mejía ÁME, * Buendía RI, * Rodríguez HP, ${ }^{\ddagger}$ Falfán V ${ }^{\star}$

*INER Ismael Cosío Villegas; 怙ospital General "Dr. Manuel Gea González"

Antecedentes: La neumopatía intersticial difusa (NID) forma parte un grupo de afecciones que afectan principalmente al intersticio pulmonar; se puede presentar en pacientes con artritis reumatoide (AR), enfermedad crónica e inflamatoria que daña especialmente las articulaciones. Ambas son enfermedades autoinmunes y complejas, se han descrito diversos factores genéticos involucrados en su desarrollo, particularmente el denominado epítope compartido de HLADR4, sin embargo, no se ha estudiado en su conjunto a la clase II del sistema HLA. Objetivo: Identificar alelos de HLA clase II en los loci DRB1, DQB1 y DPB1 asociados con el desarrollo de NID en pacientes mexicanos mestizos con AR. Materiales y métodos: Se incluyeron 130 pacientes (AR + NID, $\mathrm{n}=51$ y AR $\mathrm{n}=79$ ). Se genotipificaron los loci HLA-DRB1, -DQB1 y -DPB1 por medio de PCR-SSP. Los resultados fueron analizados por medio de Arlequín v.13.1 y para la comparación de frecuencias se usó EPI Info v.7.1. Resultados: Los alelos HLA-DRB1*04, -DRB1*14 y -DRB1*10 son los más frecuentes en el grupo de pacientes $\mathrm{AR}+\mathrm{NID}$, mientras que para el grupo AR los más frecuentes son -DRB1*04, -DRB1*14 y -DRB1*08. Para el locus DPB1 los alelos -DPB1*04:01:01 y -DPB1*04:02 se presentan en mayor proporción para ambos grupos. Interesantemente, tres alelos se encontraron asociados con riesgo disminuido (OR < 1) HLA-DRB1*04, -DRB1*08:02:01/02 y -DQB1*03:02:01/02; mientras que el HLA-DRB1*10 se identifica como un fuerte factor genético de riesgo a desarrollar NID en pacientes con AR (p $=0.00035, \mathrm{OR}=10.4, \mathrm{IC}=2.23-47.5)$. Conclusión: El HLA-DRB1*10 se encuentra asociado con el desarrollo de NID en pacientes mexicanos mestizos con AR; el alelo HLA-DR4, que porta el epítope compartido no se encontró asociado a riesgo.

a Trabajo seleccionado para ser presentado de forma oral.

Comparación de índices de pronóstico entre pacientes con síndrome combinado (SC), fibrosis pulmonar 


\section{idiopática (FPI) y enfermedad pulmonar obstructiva crónica $(\text { EPOC) })^{a}$}

Guzmán BNE, Vargas DCIA, Buendía RI, Selman LM, Mejía ÁME

INER Ismael Cosío Villegas

Antecedentes: Las enfermedades pulmonares crónicas son limitantes y en múltiples ocasiones incapacitantes, la comorbilidad cardiovascular condiciona un incremento de morbilidad y mortalidad. Actualmente no existe un sistema que nos permita detectar complicaciones y predecir el pronóstico tempranamente. Los índices de pronóstico buscan detectar complicaciones subclínicas, permitir dar tratamiento de forma temprana disminuyendo deterioro y muerte. Tanto en EPOC como en FPI se ha buscado desarrollar índices de pronóstico que logren predecir el desenlace de la enfermedad; éstos no han sido comparados entre los distintos grupos; más aún, en los pacientes con síndrome combinado, quienes presentan un peor desenlace y menor sobrevida, en parte por mayor grado de hipertensión pulmonar, no existe ningún índice que permita guiar el manejo y dar un pronóstico acertado. Estudios han demostrado que la integración de variables de función pulmonar podrían dar información de pronóstico. Objetivos: Evaluar el comportamiento de cinco índices de pronóstico entre los tres grupos de estudio. Métodos: Estudio prospectivo, longitudinal y descriptivo, con tres grupos de pacientes. Muestreo por conveniencia, realizado en el INER, seguimiento a 12 meses. Se realizó evaluación tomográfica, ecocardiográfica y de función respiratoria. Resultados: Se obtuvo una diferencia significativa en el CPI. El SC mostró el mayor valor de FVC/DLco, sin embargo, sin correlación con la ePSAP. La FVC baja se asocia con mortalidad, especialmente siendo menor a 1.5 litros. Hubo significancia estadística entre hipertensión pulmonar e índice de desaturación. Conclusiones: La FVC es un buen predictor de mortalidad. El índice fisiológico compuesto y el descrito por Zisman muestran rendimiento únicamente para FPI. Por el gran espectro de presentación de estas patologías, se puede estar omitiendo información clave que nos ayude a determinar mejor el riesgo de mortalidad, por lo que hasta el momento no hay un método adecuado para predecir el curso clínico de estas enfermedades pulmonares.

a Trabajo seleccionado para ser presentado de forma oral.

\section{Enfermedad secuelar} enfisematosa intersticial en los niños: propuesta de una clasificación operativa y experiencia en el tratamiento conservador y quirúrgico ${ }^{a}$

\section{Sancho HR, ${ }^{*}$ Cuevas SFJ, Gutiérrez MG, * Alva ChA, * Solorio $R L,{ }^{\ddagger}$ López $C E^{*}$}

*Instituto Nacional de Pediatría; 沼stituto Nacional de Perinatología

Antecedentes y objetivos: La enfermedad enfisematosa intersticial (EEI) es un grupo de afecciones que condicionan atrapamiento ectópico de aire en el intersticio pulmonar en el contexto de una lesión sistémica y secuelar subyacente; se propone una clasificación operativa que permita una orientación diagnóstica-terapéutica en cuatro grupos. Material y métodos: Estudio descriptivo, retrospectivo y observacional en 15 pacientes durante seis años en el INP con los diagnósticos de EEI confirmados por patología y por la evaluación radiológica y funcional. Se dividieron en cuatro grupos: enfisema lobar intersticial adquirido (ELIA), enfisema intersticial neonatal (EIN), enfisema buloso y neumotórax espontáneo (EBNE) y enfisema intersticial y barotrauma (EIB). Se excluyeron las causas congénitas por el análisis histopatológico, se investigaron factores infecciosos y de ventilación mecánica, respuesta a estrategias conservadoras y quirúrgicas, mortalidad y complicaciones. Resultados: En tres del grupo ELIA se diagnosticaron bronquiolitis obliterante y enfisema intersticial persistente, se practicó resección pulmonar con evolución satisfactoria y en otro biopsia diagnóstica con evolución insidiosa de su vasculopatía hipertensiva; EIN: 4, en tres la lobectomía erradicó la hipertensión y el corto circuito pulmonar y se evitó la progresión de la broncodisplasia y otro respondió al manejo conservador con ventilación de alta frecuencia; EBNE: 2, con fibrosis pulmonar y bronquiolitis obliterante se procedió a segmentectomía de su afección bulosa y pleurectomía en uno, en el segundo su neumotórax espontáneo remitió con tratamiento conservador, evolución insidiosa; EIB: 6, recibieron tratamiento con drenaje pleural y representan el grupo de mayor letalidad asociado con neumonía y con presiones ventilatorias elevadas. Conclusiones: Esta clasificación permite una orientación diagnóstica y terapéutica: el grupo ELIA y EIN muestran mejoría pronóstica con la lobectomía; el grupo EBNE podrían beneficiarse de resecciones limitadas y del control sistémico de su enfermedad y el grupo EIB del manejo conservador y estrategias ventilatorias gentiles.

a Trabajo seleccionado para ser presentado de forma oral.

\section{Neumopatía intersticial asociada a síndrome de Hermansky Pudlack}

Trejo DA, Cicero SR, Salinas PL

Hospital General de México

El síndrome de Hermansky Pudlack, descrito desde 1959 por Hermansky F y Pudlack P, comprende una entidad caracterizada por la Asociación de Albinismo Oculocutáneo, diátesis hemorrágica caracterizada por ausencia de gránulos plaquetarios que puede o no dar alteraciones en tiempos de 
coagulación o tiempo de sangrado y acumulación de ceroide lipofuscina en tejidos de diferenciación final, se han descrito nueve tipos de mutación en el gen HPS siendo el HPS 1 el que abarca el 50\% de los casos de los no puertorriqueños, se estima una incidencia de 1 en 5,000,000 de personas con albinismo no puertorriqueños. El cuadro clínico comprende trastornos hemorrágicos en $30 \%$ de los pacientes, fibrosis pulmonar de progresión rápida hasta en $68 \%$ de los pacientes y depósito de lipofuscina en miocardio, riñón y cerebro, se encuentran alteraciones radiológicas y tomográficas en 49 y $82 \%$, respectivamente. La progresión de la enfermedad y el mal pronóstico de la misma hacen difícil el tratamiento; actualmente las opciones terapéuticas consideran el uso de corticoesteroides orales, el uso de pirfenidona y el trasplante pulmonar con resultados muy variables. Se presenta el caso de una paciente de 28 años de edad con albinismo oculocutáneo y afección pulmonar con historia de un año de tos no productiva de inicio insidioso sin factores desencadenantes, disnea de esfuerzos sin referir trastornos hemorrágicos, los estudios de imagen fueron compatibles con neumopatía intersticial no específica, se sometió a pruebas de función respiratoria con volúmenes conservados, capacidad vital con difusión disminuida gravemente, ecocardiograma con PSAP de 31 $\mathrm{mmHg}$, se realizó biopsia pulmonar y el estudio histopatológico reportó neumopatía intersticial descamativa con focos de fibrosis y vacuolización de neumocitos tipo II; se estableció diagnóstico de neumopatía intersticial asociada con síndrome de Hermansky Pudlack.

\section{Diferencias en la presentación de enfermedad pulmonar intersticial en pacientes con síndrome de Sjögren primario versus secundario}

López-González B, Mejía M, Buendía-Roldán I, Rojas-Serrano J, Mateos-Toledo H, Estrada A, Castillo-Pedroza J, Selmán M

INER Ismael Cosío Villegas

Antecedentes: El involucro pulmonar es una de las alteraciones sistémicas más comunes en el síndrome de Sjögren primario (SSp) y secundario (SSs) que se ha relacionado con mal pronóstico. Hasta el momento no hay estudios que evalúen las diferencias clínicas, funcionales y tomográficas en estos subgrupos. Por lo que fue de nuestro interés conocer el comportamiento de estas cohortes y si las diferencias entre ellas tienen repercusión en el pronóstico. Material y métodos: $\mathrm{Se}$ realizó un estudio retrospectivo de la cohorte de enfermedad intersticial secundaria a SSp y SSs en el Instituto Nacional de Enfermedades Respiratorias, se revisaron los datos clínicos, tomográficos y de función pulmonar al momento del diagnóstico y al año de iniciar tratamiento. Se compararon las características de interés de ambos grupos. Resultados: Se identificaron 104 pacientes en el período de 2008 al 2013. Se analizó la información de 90 pacientes que contaban con todos los parámetros, $55(57.4 \%)$ con SSp y 35 (37.2\%) con SSs. No hubo diferencia significativa en los patrones tomográficos, perfil de anticuerpos y pruebas funcionales respiratorias al comparar ambos grupos. Conclusiones: Nuestros resultados muestran que es de gran dificultad el distinguir el compromiso pulmonar causado por el síndrome de Sjögren exclusivamente, ya que no se identificaron diferencias en el tipo de afección intersticial entre el SSp y el SSs, lo que marca la pauta para buscar en forma intencionada las manifestaciones sistémicas de otras enfermedades autoinmunes subyacentes en el estudio de estos pacientes, la evolución clínico-funcional fue similar en ambos grupos y al año de tratamiento no identificamos diferencias pronósticas por lo que no se pudo demostrar si la afección causada por el SS es el que le confiere la gravedad pronóstica o las manifesta- ciones sistémicas asociadas, por lo que se requieren estudios a mayor plazo.

Comparación de índices en espirometría y DLco entre pacientes con síndrome de Sjögren, fibrosis pulmonar idiopática y neumonitis por hipersensibilidad crónica

\section{Bandera AJM, Buendía RI, Mejía M, Selman LM}

INER Ismael Cosío Villegas

Comparación de índices en espirometría y DLco entre pacientes con síndrome de Sjögren, fibrosis pulmonar idiopática y neumonitis por hipersensibilidad crónica. Introducción: Las enfermedades intersticiales son un grupo de patologías heterogéneas con características funcionales y clínicas comunes, la mecánica funcional del aparato respiratorio centran la mayor parte de los problemas pulmonares, las pruebas de función respiratoria son útiles para el pronóstico y seguimiento de los pacientes. En la espirometría y DLco, los índices RV/TLC (hiperinsuflación y atrapamiento aéreo), DLCO/ VA (intercambio gaseoso) y $\mathrm{FVC/}$ DLCO (predictor de hipertensión arterial pulmonar) son de ayuda para una mejor interpretación y útiles en pacientes con EPOC. Objetivo: Comparar el índice FVC/DLco, DLCO/VA, RV/TLC entre pacientes con síndrome de Sjögren, fibrosis pulmonar idiopática, neumonitis por hipersensibilidad crónica y controles. Diseño: Estudio transversal, prolectivo con muestra por conveniencia, se reclutaron 25 pacientes de cada grupo y se realizó espirometría forzada simple y difusión de monóxido de carbono (DLco). Se calcularon los índices DLCO/VA, RV/TLC y FVC/DLCO. Se realizaron comparaciones de las variables demográficas y clínicas en los 
cuatro grupos y prueba T de Student al comparar cada grupo contra controles. Se aplicó correlación de Spearman para las variables de interés. Resultados: Los índices utilizados para EPOC, no permiten diferenciar entre las enfermedades intersticiales, únicamente RV/ TLC y DLCO/VA mostraron diferencia significativa en el grupo de neumonitis que puede explicarse por atrapamiento aéreo mientras que FVC/DLCO se encuentra incrementado en pacientes con fibrosis pulmonar idiopática. Conclusión: Los índices FVC/DLCO, DLCO/VA y RV/TLC no agregan mayor información por separado a las pruebas de función respiratoria; sin embargo, algunos de ellos se correlacionan de manera positiva con las variables de progresión de enfermedad por lo que se requieren estudios longitudinales para valorar estos índices.

\section{Caracterización de pacientes con neumonía intersticial \\ con rasgos autoinmunes \\ asociada con enfermedad de tejido conjuntivo no clasificable}

Barajas-Ugalde OD, Mateos-Toledo $\mathrm{H}$, Rojas-Serrano J, Estrada $A$, Castillo-Pedroza J, Mejía M

INER Ismael Cosío Villegas

Antecedentes: Muchos pacientes con neumonía intersticial idiopática (NII) presentan rasgos que sugieren una enfermedad autoinmune subyacente, pero no cumplen con los criterios establecidos del Colegio Americano de Reumatología (CAR) para ser clasificados como enfermedad del tejido conjuntivo (ETC) considerándose que cursan con una «neumonía intersticial con rasgos autoinmunes» (NIRA) que puede ser la expresión limitada de las diferentes entidades. Métodos: Estudio descriptivo y retrospectivo, noviembre 2010 a abril
2015, en la Clínica de Enfermedades Intersticiales del Instituto Nacional de Enfermedades Respiratorias (INER). Se incluyeron sólo casos que cumplieran con los criterios de Kínder para ETC no clasificable y criterios de la ATS/ERS para una NII. Objetivo: Conocer características clínicas, tomográficas, funcionales e inmunológicas en los pacientes catalogados como NIRA por consenso en la Clínica de Enfermedades Intersticiales del INER. Resultados: Se incluyeron 42 pacientes, el patrón tomográfico fue: 29 con neumonía intersticial no específica (NINE) y 13 con neumonía intersticial usual (NIU). El grupo NINE tiene un dominio clínico (artritis, fenómeno de Raynaud, xerostomía y xeroftalmia, ERGE), un dominio serológico (ANA positivo con patrón homogéneo, moteado fino y centromérico). El grupo NIU tiene características similares a fibrosis pulmonar idiopática (FPI), pero con autoinmunidad a títulos altos. Conclusiones: La caracterización de NIRA sugiere dos fenotipos predominantes, el primero con rasgos relacionados esclerosis sistémica (ES) y el segundo con artritis reumatoide (AR). Por nuestra parte consideramos importante realizar estudios prospectivos, para valorar la evolución y el pronóstico de estos pacientes, de igual manera recomendamos que todos los pacientes con enfermedad pulmonar intersticial sean evaluados para descartar ETC/NIRA. Los anticuerpos autoinmunes se deberán solicitar sistemáticamente aun en ausencia de signos clínicos o síntomas de ETC.

\section{Enfermedad pulmonar} intersticial difusa (EPID) y anticuerpos asociados y específicos

de miositis: los

pacientes presentan

manifestaciones

clínicas similares a

pesar de tener un

perfil serológico

heterogéneo y un

pronóstico diferente
Rojas J, Pérez-Román D, Herrera-Bringas $D$, Castorena-García $P$, Mateos-Toledo H, Estrada A, Castillo-Pedroza J, Mejía M

INER Ismael Cosío Villegas

Objetivo: Describir las manifestaciones clínicas, el perfil serológico, el desenlace de pacientes con EPID y autoanticuerpos específicos y asociados con miositis y evaluar los nuevos criterios del ATS/ERS 2015 para neumonía intersticial con manifestaciones autoinmunes (NIRA). Métodos: Se incluyeron pacientes con enfermedad pulmonar intersticial difusa (EPID) y autoanticuerpos asociados o específicos de miositis. Se registraron las características clínicas relevantes, patrón de daño pulmonar ATS/ERS 2013 y la extensión del daño pulmonar en tomografía utilizando los índices de Goh y Kazerooni. Se realizó análisis de supervivencia. Resultados: Se incluyeron 73 pacientes, los que presentaron una importante heterogeneidad de autoanticuerpos, siendo el anti Jo1 el más frecuente $(60.27 \%)$, seguidos por no Jo1 (27.4\%), anticuerpos anti PM/SCL en el $4.11 \%$ y patrón citoplásmico en el $8.22 \%$. Las manifestaciones previamente descritas en el síndrome antisintetasa también se presentaron en los pacientes con PM/SCL positivos y patrón citoplásmico. Sólo el 55\% de los pacientes cumplieron criterios de Bohan y Peter (ByP). Todos los pacientes negativos a ByP cumplieron los criterios de NIRA. Los pacientes con anti Jo1 positivo presentaron mejor pronóstico (Log Rank, $\mathrm{p}<0.007)$. La extensión del daño inflamatorio pulmonar se asoció con mortalidad (puntaje de Goh, HR: 1.04 (IC 95\%: 1.01-1.07); puntaje de Kazerooni, HR: 3.72 (95\% CI: 1.93-7.16). Conclusiones: Los pacientes con EPID y anticuerpos específicos y asociados con miositis tienen manifestaciones clínicas similares a pesar de tener autoanticuerpos diferentes. La mortalidad es mayor en el grupo de pacientes no Jo y en aquellos con mayor extensión del daño pulmonar inflamatorio. Todos los pacientes que no cumplieron criterios suficientes de ByP para ser clasificados 
como miopatías inflamatorias cumplieron los criterios propuestos por la ATS/ ERS 2015 para NIRA.

\section{Comparación de índices pronósticos en pacientes con enfermedades intersticiales pulmonares}

Romero VP, Ortiz-Lobato L, Selman M, Mejía M, Buendía-Roldán I

INER Ismael Cosío Villegas

Antecedentes y objetivo: La predicción del riesgo de mortalidad en pacientes con enfermedades intersticiales es un reto debido a la variabilidad entre la progresión tanto clínica como funcional. Se han descrito diferentes índices pronósticos (GAP-ILD y RMFPI) para estas enfermedades, nuestro objetivo fue correlacionarlos para determinar si su uso puede ser indistinto. Métodos: Estudio retrospectivo observacional descriptivo de la cohorte del servicio de enfermedades intersticiales del INER con diagnóstico de ingreso de EPID en un período de un año. Los resultados de los índices fueron homogeneizados en una categoría arbitraria del 1-4 dependiendo del porcentaje de riesgo de mortalidad calculado a un año, posteriormente realizamos correlación (Spearman) entre los índices en la totalidad de nuestros pacientes y por grupo de enfermedad. Resultados: Estudiamos 97 pacientes divididos en tres grupos: 44 con neumonitis por hipersensibilidad crónica (NHc), 39 con fibrosis pulmonar idiopática (FPI) y 14 con síndrome combinado (SC), predominó el género masculino en FPI (92\%) y SC (100\%), en NHc mujeres $(80 \%)$. Los pacientes con SC presentaron IT mayor $(38 \pm 30)$. Los pacientes con FPI y SC el $21 \%$ presentaron al menos una hospitalización de causa respiratoria en los primeros seis meses posteriores al diagnóstico, $82 \%$ de las muertes en los dos primeros años de diagnóstico. La mayor mortalidad en pacientes con SC en el primer año de diagnóstico, sólo el
$20 \%$ de ellos eran progresores rápidos. Al realizar el análisis de ambos índices se encontró que no hubo correlación ( $\mathrm{n}=97, \mathrm{r}=0.47$ ) entre ellos ni entre grupos (FPI r = 0.28, SC r $=0.1$, NHc $r=0.28)$. Conclusión: Ambos modelos de predicción subestiman el riesgo de mortalidad, principalmente el índice GAP en pacientes con SC, por lo que es necesaria la creación de un nuevo modelo de predicción de mortalidad que integre variables de ambos modelos y añadir variables de la caminata de seis minutos.

Recuperación de la frecuencia cardíaca en la prueba de caminata de 6 minutos como predictor pronóstico en pacientes con neumonitis por hipersensibilidad subaguda y crónica

Chavarría DCM, Mejía ÁME, Miguel RJL, Mateos TH, Torre-Bouscoulet L, Estrada GA

INER Ismael Cosío Villegas

Antecedentes: La tasa de recuperación de la frecuencia cardíaca (RFC) al primer minuto y al minuto dos posterior al ejercicio se ha asociado con un incremento en la mortalidad en pacientes con padecimientos pulmonares. No existen estudios que evalúen la RFC en pacientes con neumopatías intersticiales diferentes a fibrosis pulmonar idiopática. Objetivo: Investigar la correlación entre la RFC al minuto 1 y 3 posterior a una caminata de seis minutos (PC6M), así como el producto distancia-desaturación y pruebas de función respiratoria (PFR), calidad de vida con cuestionario de Saint George (CRSG) al momento del diagnóstico $\mathrm{y}$ a los seis meses de seguimiento. Metodología: Se incluyeron a sujetos con diagnóstico de neumonitis por hipersensibilidad (NH) subaguda y crónica de la Clínica de Enfermedades Intersticiales del INER de enero a julio 2015. Se realizó en forma basal: PC6M, espirometría, pletismografía, gasometría, difusión de monóxido de carbono (DLco), CRSG y tomografía de alta resolución. Las PFR y cuestionario se repitieron a los seis meses. Se midió la RFC al minuto 1,3 y 5 posterior al ejercicio. Para estudiar asociaciones entre variables se utilizó la prueba de Spearman o Pearson. Resultados: La RFC al minuto uno se encontró asociada con FEV1 ( $\mathrm{rs}=0.50, \mathrm{p}=0.011)$, FVC ( $\mathrm{rs}=0.52 \mathrm{p}=0.008)$, TLC $(\mathrm{rs}=0.54$, $\mathrm{p}=0.005)$, distancia recorrida en la PC6M ( $\mathrm{rs}=0.55, \mathrm{p}=0.005)$, producto distancia-desaturación $(\mathrm{rs}=0.55, \mathrm{p}=$ 0.004). La RFC al minuto tres, se encontró asociado con distancia recorrida ( $r s=0.43, p=0.031)$. La comparación de NH subaguda y crónica no demostró diferencias en RFC al minuto 1 y 3 . En las pruebas de seguimiento a seis meses no se encontraron correlaciones significativas. Conclusiones: Se ha identificado una asociación en el momento del diagnóstico de pacientes con NH subaguda y cónica de la RFC posterior a la PC6M al minuto 1 y 3 con parámetros funcionales que definen enfermedad grave.

\section{Frecuencia de diagnósticos de la cohorte de enfermedades pulmonares intersticiales del Instituto Nacional de Enfermedades Respiratorias en 5 años}

\section{Betanzos PJI, Váldez AJ, Buendía RI, Mejía ÀME \\ INER Ismael Cosío Villegas}

Antecedentes: Las enfermedades pulmonares intersticiales tienen una baja prevalencia, pero alta morbimortalidad, por lo que es de interés conocer el comportamiento de las diferentes entidades en la cohorte del Servicio de Enfer- 
medades Pulmonares Intersticiales Difusas (EPID) del INER. Objetivos: Describir la frecuencia y las características de las EPID en el servicio clínico 1. Metodología: Realizamos un estudio observacional, retrospectivo, descriptivo, solicitando al Servicio de Bioestadística los diagnósticos de egreso de pacientes atendidos en la clínica 1 en el período del 2010 al primer semestre del 2015. Resultados: Se estudiaron 1,254 casos con diagnóstico de EPID, en 2010: 220 casos; 2011: 235 casos; 2012: 229 casos; 2013: 218 casos; 2014: 218 casos y durante el primer semestre 2015: 134 casos. La patologías que más se presentaron fueron en 2010; neumonía intersticial difusa (NID) $30 \%$, neumonitis por hipersensibilidad (NH) 21\%, 2011; NID 29\%, fibrosis pulmonar idiopática (FPI) 20\%, 2012; NID 41\%, FPI 30\%, 2013: NID 39\%, NH 17\%, 2014: NID 60\%, NH 16\%, 2015: NID 64\%, NH 22\%. La enfermedad con mayor letalidad fue la FPI: 2010; 28\%, 2011; 30\%, 2012; 15\%, 2013; 27\%, 2014; $29 \%$ y 2015 17\%. Los días promedio de estancia para el diagnóstico definitivo fueron: 2010: $18 \pm 2.7,2011$ : $12 \pm 1,2012: 12.7 \pm 0.7,2013: 14.5 \pm 3$, 2014: $15 \pm 4$ y $201513 \pm 1.1$. Conclusiones: El promedio de pacientes egresados de la clínica de EPID es de 209 casos por año. La FPI es la enfermedad con mayor mortalidad y la segunda en frecuencia en esta cohorte. Se observa una tendencia a reducir los días para llegar al diagnóstico definitivo.

\section{La pericia diagnóstica en la enfermedad de Besnier-Boeck: caso clínico}

\section{Cárdenas ESM, Garzón CMA, Hanssen $C F$}

\section{IMSS}

Mujer de 60 años, profesora de primaria, tabaco (-). Rinitis alérgica de 10 años de evolución y enfermedad por reflujo gastroesofágico. Siete años con mialgias y artralgias, catalogada como
AR; a la par cuadros de obstrucción bronquial atribuidos al componente atópico. Los últimos tres años lesiones dérmicas (eritematosas, pruriginosas, con relieve, en tórax, antebrazos, cara y espalda), además de tos seca en accesos y disnea progresiva, sin fiebre o pérdida de peso. Durante su abordaje diagnóstico Rx de tórax (2013) con ensanchamiento mediastinal y TAC de tórax que corrobora las adenopatías; se propuso biopsia por sospecha de linfoma, pero no aceptó por recomendación hematología (cuadro clínico no sugestivo). Hace dos años hospitalización por supuesta neumonía de focos múltiples (2014), y hace un año por fibrosis pulmonar, con baciloscopias y cultivos negativos. Derivan a neumología para trámite de oxígeno. Exploración física: Lesiones cutáneas antes descritas, estertores en velcro subescapular bilateral, sibilancias espiratorias, artritis de AMCF, $\mathrm{SaO}_{2}$ basal y en ejercicio normal; $\mathrm{Rx}$ de tórax (octubre 2015): opacidades reticulares, trazos fibrosos y quistes pequeños en ambos lóbulos inferiores. Espirometría con patrón mixto. Ante ese contexto se inició esteroide oral, broncodilatadores, se solicitó biopsia de piel. Al mes de tratamiento mejoría, tanto en lesiones cutáneas como en síntomas respiratorios. Reporte histopatológico: Proceso inflamatorio crónico granulomatoso con presencia de células gigantes multinucleadas tipo Langhans, inmunohistoquímica positiva para CD 68. Diagnóstico: Sarcoidosis pulmonar, enfermedad multisistémica granulomatosa de causa desconocida se presenta con linfadenopatía hiliar bilateral, infiltración pulmonar y lesiones oculares y cutáneas, con prevalencia de 10.9/100,000 en raza blanca y de 35.5 en negros, y pico de mayor presentación entre los 20 y 30 años. En esta paciente: sarcoidosis pulmonar estadío IV, con manifestaciones articulares y dérmicas asociadas.

\section{Pacientes con fibrosis pulmonar idiopática en tratamiento compasivo con nintedanib}

Barreto RJO, * Buendía RI, * Mejía ÁME, ${ }^{\star}$ Domínguez $P A,{ }^{\ddagger}$ Bringas $L E,{ }^{\circ}$ Narro GE," Robledo PJC," Sarmiento PJR, ${ }^{* *}$ Álva y Pérez $\mathrm{JL}^{\ddagger \ddagger}$

*INER Ismael Cosío Villegas; ‘Hospital Christus Muguerza; ${ }^{\S}$ Hospital Ángeles de Puebla; "Hospital Regional del Rio Reynosa; "Hospital Regional de Alta Especialidad "Juan Graham Casasus"; **Centro Médico "Jesús Gilberto Gómez Maza”; "¥Hospital privado, Cd. Juárez, Chihuahua.

Introducción: La fibrosis pulmonar idiopática (FPI) es la más agresiva de las enfermedades intersticiales idiopáticas. En 2014 se aprobó por la FDA el uso de nintedanib como tratamiento específico para disminuir la progresión de la enfermedad, en 2015 se aprobó para su uso en México. Objetivo: Conocer las características de pacientes mexicanos con FPI que ingresaron al programa compasivo (NPU) para tratamiento con nintedanib. Material y métodos: Se invitó a neumólogos del país a ingresar pacientes con diagnóstico de FPI, se revisaron a nivel central para aceptar su ingreso, se inició tratamiento con nintedanib $150 \mathrm{mg}$ cada $12 \mathrm{~h}$ y se registraron características clínicas, pruebas de función respiratoria (PFR) y seguimiento trimestral de los pacientes. Resultados: Se revisaron 77 casos, se aceptaron 37 pacientes que cumplieron con los criterios establecidos, dos fallecieron antes de iniciar tratamiento, uno durante el primer trimestre, dos se eliminaron por indicación médica, el análisis para este resumen se realizó con 28 casos de los que se contaba con toda la información. Distribución por estados: Chiapas 4\%, Chihuahua 4\%, D.F. $67 \%$, Puebla 14\%, Tabasco $7 \%$ y Tamaulipas 4\%. Predominio de género masculino, 2 picos de edad 60-65 y > 80 años; $75 \%$ de los pacientes tenían evolución de al menos dos años, 50\% tuvieron antecedente de tabaquismo, comorbilidades más frecuentes: hipertensión arterial, diabetes mellitus y reflujo gastroesofágico. $65 \%$ tenía capacidad vital forzada $(\mathrm{CVF})>50 \%$, a los tres meses la mayoría de los pacientes mostraron estabilidad de la enfermedad. $50 \%$ de los pacientes habían recibido pirfenidona siendo suspendida 
por falla terapéutica, $11 \%$ tienen síndrome combinado. Los efectos adversos reportados: gastrointestinales, fatiga y alteraciones electrolíticas. Conclusiones: Los pacientes incluidos en el programa NPU tienen una CVF menor a la aceptada en los estudios IMPULSIS, hasta el momento han presentado el mismo comportamiento de estabilidad y efectos adversos reportados.

\section{Comparación de la acústica pulmonar en pacientes con FPI y síndrome combinado}

\section{Bernabe SJC, * Charleston-Villalobos S, González CR, ${ }^{\ddagger}$ Santiago FLM, $\neq$ Mateos $T H,{ }^{*}$ Mejía ÁME, * Buendía RCI*}

*INER Ismael Cosío Villegas; ¥Universidad Autónoma de Metropolitana

Introducción: El enfisema pulmonar y la FPI son entidades definidas por distintos criterios clínicos, funcionales, radiológicos y patológicos. Existe un fenotipo llamado síndrome combinado enfisema fibrosis (SCEF) el cual tiene comportamiento distinto a la FPI. La tomografía computada de alta resolución (TCAR) es un método diagnóstico que permite separar fácilmente los casos de CFPE y FPI; sin embargo, a pesar de ser reproducible no es recomendable para el seguimiento, por lo que utilizar métodos no invasivos e inocuos como los sonidos pulmonares puede ser de utilidad. Métodos: Se incluyeron pacientes con diagnóstico de FPI y SCEF de la cohorte del servicio clínico 1 del INER del 2005 al $2015 \mathrm{n}=$ 20, se les realizaron TACAR pruebas de función respiratoria (PFR) completas así como obtención de sonidos pulmonares. Se describieron las características acústicas cuantitativas en pacientes con FPI y SCEF, se compararon entre ellos y se obtuvo la sensibilidad (s) y especificidad (e) de los sonidos pulmonares. Resultados: Se incluyeron 30 sujetos, 10 con FPI, 10 con SCFE y 10 sanos a los cuales se les realizó acústica pulmonar, de acuerdo con éstas se encontró que las frecuencias percentiles tuvieron una $\mathrm{s}=95.8 \mathrm{y}$ e $=$ 93.02, las frecuencias percentiles más información de potencia incrementaron a una $\mathrm{s}=97.72$ y e $=95.31$. En cuanto a la comparación de las PFR sólo se observó diferencia a nivel del intercambio gaseoso y en la caminata de $6 \mathrm{M}$ con una $\mathrm{p}<0.05$. Conclusiones: Las características acústicas de los pacientes con FPI y SCEF son diferentes a los sujetos sanos y es posible discriminar entre ambas poblaciones. Este estudio logra sentar las bases de la acústica pulmonar como una herramienta en el diagnóstico y seguimiento en estos grupos.

\section{Revisión de 30 casos de enfermedad difusa del parénquima pulmonar}

López ME, Martínez SG, Guzmán VN, Treviño GM,

De la Fuente FL, Sánchez AAA, Zaldívar CG, González CE

IMSS UMAE 34 Monterrey

Introducción: Estudios de prevalencia de enfermedad intersticial difusa en nuestro país no existen, por lo que puede estar subdiagnosticada, tampoco hay registros epidemiológicos pese a que hay centros de referencia especializados y guías para el abordaje y diagnóstico y terapéutico. Material y método: Presentamos una revisión de casos ingresados a neumología de 3er nivel de atención, todos provenientes de neumología, medicina interna o subespecialidades de 2 do nivel de atención de medicina institucional, con sospecha de enfermedad intersticial y que fueron evaluados con radiografía y TACAR de Tórax, espirometría, pletismografía, gasometría arterial, DLCO, ECG, ECOCG, caminata de 6 minutos, perfiles reumatológicos; algunos fueron llevados a biopsia a cielo abierto, otros biopsia trasbronquial por broncoscopia flexible. Se utilizaron criterios ATS/ ERS/JRS/ALAT para diagnóstico. Resultados: De los 30 casos, 21 fueron llevados a biopsia a cielo abierto y en 5 se estableció el diagnóstico histológico por broncoscopia y biopsia transbronquial, en todos se confirmó afección intersticial, y todos fueron estratificados por TACAR, sólo 4 por estadio avanzado de la enfermedad se quedaron con estudios de imagen como método de diagnóstico. Todos los pacientes demostraron patrón restrictivo en estudios de función respiratoria y en el ecocardiograma transtorácico datos de HP. Conclusiones: A pesar del acceso para la realización de una biopsia pulmonar a cielo abierto para el diagnóstico de las enfermedades intersticiales pulmonares, la disparidad de los resultados histopatológicos no permite identificar específicamente aquellos pacientes en los que existe una etiología precisa, por lo que los estudios de imagen, tales como la TACAR, continúan siendo métodos no invasivos de elección para el estudio y seguimiento de la enfermedad intersticial.

\section{Malformaciones y trastornos genéticos}

\section{No todo lo que silba es asma; malformación arteriovenosa pulmonar, una patología poco frecuente}

\section{Barón S, * Real NE, ${ }^{\ddagger}$ Martínez GG, ${ }^{\ddagger}$} Martínez SM, ${ }^{\ddagger}$ Ruiz FJ

*ISSSTE; ${ }^{\star}$ Hospital Regional Centenario de la Revolución Mexicana, ISSSTE, Morelos

Introducción: Las malformaciones arteriovenosas pulmonares (MAVP), son verdaderas fístulas vasculares de alto flujo y baja presión carentes de filtro capilar pulmonar. Congénitas, producidas por el desarrollo incompleto de los septos vasculares (sexto arco y plexo endodérmico venoso). Los síntomas pueden ser insuficiencia respiratoria crónica, cianosis, intolerancia al ejercicio y hemotórax. El diagnóstico de MAVP requiere alto nivel de sospecha debida a la baja incidencia y a diferentes formas clínicas de presentación. Presentación del caso: Femenino de 
7 años de edad originaria de Iguala, Gro., sin antecedentes perinatales de importancia. Antecedentes personales patológicos: desde los cuatro meses de edad con cuadros de dificultad respiratoria, que se acompañan de cianosis y sibilancias, sólo en algunas ocasiones asociados a procesos infecciosos. Es diagnosticada desde edad temprana como asmática y tratada con SABA y ocasionalmente corticoides inhalados. Sin embargo, posterior a NAC presenta evolución insidiosa, llamando la atención disnea persistente e hipoxemia grave, motivo por el cual es referida a nuestro centro hospitalario. A su ingreso cuenta con RxTx con imagen hiperlúcida a nivel de $\mathrm{S} 3$ por lo que se realiza angiotomografía donde hay evidencia de malformación arteriovenosa apical derecha dependiente de la arteria pulmonar. Ecocardiograma: HAP leve PSAP $37 \mathrm{mmHg}$, disfunción sistólica de ventrículo derecho grado leve. Gammagrama perfusorio con datos de hipoperfusión generalizada en segmento apical de lóbulo superior. Se realizó segmentectomía apical derecha y segmentectomía lateral. Reporte de patología: Malformación arteriovenosa. Actualmente seguimiento por neumopediatría; la menor asintomática, con ecocardiograma de control sin datos de HAP y sin crecimiento de cavidades derechas, espirometría simple y con broncodilatador sin datos de obstrucción y sin respuesta a broncodilatador. Conclusión: Es importante un análisis exhaustivo de una patología poco frecuente y con diagnósticos diferenciales que pueden ser confundidos con patologías más frecuentes, nunca olvidando que no todo lo que silba es asma.

\section{Malformación arteriovenosa y poliposis juvenil en paciente con Rendu-Osler-Weber. Presentación de caso}

Martínez MC, Irissont DJA
Introducción: Las malformaciones arteriovenosas (MAV) son estructuras vasculares de baja resistencia y alto flujo que conectan una arteria pulmonar a una vena pulmonar, ocasionando cortocircuito de derecha izquierda. Las consecuencias fisiológicas dependen del grado del cortocircuito dentro de las que se incluyen hipoxemia, disnea y cianosis. Presentación de caso: Paciente de 12 años de edad, enviado a neumología pediátrica por presentar broncoespasmo en tres eventos anestésicos y rinitis. Antecedente de cinco hospitalizaciones por poliposis intestinal y sangrado de tubo digestivo desde los dos años de edad. Refiere respiración oral constante, aunque niega ronquido. Presenta prurito nasal constante y epistaxis frecuente. A la exploración física saturación de $85 \%$, palidez de piel y tegumentos, con líneas de Dennie Morgan, respiración oral; nariz con mucosa pálida, huellas de sangrado y zonas de dilatación vascular, cornetes hipertróficos; encías con telangiectasias; cardiopulmonar sin compromiso; abdomen asignológico, acropaquias grado III. Se realizó angiotomografía encontrando sobredistensión pulmonar, con evidencia de fístula arteriovenosa. El cateterismo demostró múltiples malformaciones arteriovenosas bilaterales, embolizándose la de mayor tamaño ubicada en lóbulo medio. Discusión: La enfermedad de Rendú-Osler-Weber (ROW), es un desorden vascular autosómico dominante. El diagnóstico se realiza cumpliendo tres de los cuatro criterios de Curacao: epistaxis (recurrentes) telangiectasias (múltiples, en labios, cavidad oral) lesiones viscerales (pulmonares, hepáticas) e historia familiar. Este paciente cumple con tres de los criterios mencionados. Destaca, a su vez, que del 1 al 2\% de los pacientes presentan cambios epiteliales precancerosos (poliposis juvenil), como están documentados en este paciente. Conclusiones: Las manifestaciones clínicas de las MAV no son uniformes, por lo que se dificulta su diagnóstico y manejo. Las MAV sin tratamiento y más aún asociadas con ROW, presentan múltiples complicaciones como hemorragia, hipoxemia y enfermedad vascular cerebral. El tratamiento de elección es la embolización percutánea como la realizada en este caso.

\section{Malformación arteriovenosa pulmonar: reporte de un caso}

Lechuga TI, Meza BJH, Hernández RFI, Del Razo RR, Velázquez SR

INER Ismael Cosío Villegas

Introducción: Las malformaciones arteriovenosas pulmonares son comunicaciones anormales entre el sistema arterial y venoso. Su incidencia es de 2 a 3 casos por cada 100,000 habitantes, se observan lesiones múltiples en el 33$50 \%$. Pueden ser congénitas o asociadas con cirugía torácica, traumatismos, actinomicosis, esquistosomiasis, cirrosis y metástasis pulmonares. El tratamiento quirúrgico garantiza la resección de la lesión macroscópica y de lesiones microscópicas vecinas. Presentación del caso: Femenino de 8 años, originaria de Guerrero, inicia su padecimiento un año previo a su ingreso con la presencia de acropaquias, astenia y adinamia, manejada con facultativo con vitaminas, seis meses posteriores se agrega disnea de medianos esfuerzos, valorada en hospital de Chilpancingo en donde realizan radiografía con imagen radiopaca apical derecha y envían a nuestro instituto. A su ingreso con oximetría de $78 \%$ al aire ambiente, FR 28 rpm, FC 120, afebril, cianosis peribucal, sin dificultad respiratoria, tórax simétrico, adecuado murmullo vesicular, sin agregados pulmonares, precordio sin soplos, extremidades con acropaquias, cianosis distal. Se realiza BH con HB 15.8 HTO 48.2, gasometría arterial $\mathrm{PaO}_{2} 45 \%$, ANGIOTAC reporta malformación venosa con múltiples comunicaciones. Ecocardiograma: corazón estructuralmente sano, se realiza cateterismo cardíaco con reporte de fístula arteriovenosa en lóbulo superior derecho. No se procede a embolizar por tamaño de fístula, se realiza lobectomía superior derecha, egresada con 
oxígeno. Control en consulta externa sin oxígeno, sin cianosis y recuperación física. Discusión: La mayoría de los pacientes presentan MAVP múltiples, de tamaño variable, localizadas generalmente en lóbulos inferiores; sin embargo, en nuestra paciente fue única y localizada en lóbulo superior. La tríada clásica de disnea, cianosis y acropaquias aparece sólo en el $30 \%$ de los casos, presentados por la paciente. Conclusión: Las MAVP pueden no ser diagnosticadas fácilmente debido a que los signos y síntomas son subclínicos al principio. Nuestra paciente tuvo excelentes resultados con el tratamiento quirúrgico.

\section{Malformación arteriovenosa pulmonar. Reporte de caso}

Domínguez EMG, Ayala PCG, Narváez FS, Guerrero LM, Hernández MG, Sánchez MML

Hospital Regional de Alta Especialidad del Bajío. León, Gto.

Introducción: Las malformaciones arteriovenosas pulmonares (MAV) son estructuras vasculares anormales que se conectan de una arteria pulmonar a la vena pulmonar, sin pasar por el lecho capilar pulmonar normal y que resulta en un shunt intrapulmonar de derecha a izquierda. Aparecen como anomalías o en asociación con telangiectasia hemorrágica hereditaria. Dependiendo del tamaño debutan con disnea, cianosis, dedos hipocráticos o hemoptisis, puede ser único o múltiple, unilateral o bilateral, simple o compleja. Ante la sospecha debe hacerse una angiotomografía para precisar el tamaño y ubicación de la fístula para determinar el tratamiento que puede ser desde embolización hasta resección quirúrgica. Descripción: Masculino de 2 años con diagnóstico cianosis-probable tetralogía Fallot. No antecedentes de importancia previos. Padecimiento: historia de cianosis desde los seis meses de vida, telangiectasias palpebrales, fatiga de grandes esfuerzos, exploración:
$\mathrm{SO}_{2} 60 \%$ cianosis peribucal, ungueal, telangiectasias palpebrales, soplo en línea axilar media grado II/VI, segundo ruido reforzado, pulsos palpables, campos pulmonares murmullo vesicular presente, hipocratismo digital, se inicia abordaje por sospecha malformación arteriovenosa Rx tórax radiopacidad heterogénea a nivel de lóbulos medio e inferior, Rx lateral de tórax radiopacidad heterogénea supradiafragmática, ecocardiograma: corazón estructuralmente sano, sin cortocircuitos de derecha a izquierda, presión pulmonar $20 \mathrm{mmHg}$, FEVI 56\%, gammagrama pulmonar perfusorio hipoperfusión del lóbulo medio y lóbulo inferior derecho. Angiotomografía fase contrastada imagen hiperdensa hacia área de lóbulos medio e inferior derecho, fase venosa condición parenquimatosa normal, con compresión a nivel de lóbulos medio e inferior derecho. Cateterismo $\mathrm{dx}$ fístula arteriovenosa pulmonar derecha. Se realizó lobectomía inferior derecha, reporte histopatológico malformación arteriovenosa. Evolución clínica actual asintomático. Discusión: Aunque la malformación arteriovenosa pulmonar es rara, su estudio permite identificar tamaño y ubicación de la fístula para decidir la modalidad de tratamiento más adecuada, se considera la escisión quirúrgica necesaria en pacientes en los que la embolización no tuvo resultados óptimos.

\section{Quiste de Hattori, reporte de caso clínico}

Flores MR, Armenta RR

IMSS

Introducción: Los quistes mediastínicos son malformaciones congénitas primarias relativamente raras, representando aproximadamente el 12 a $30 \%$ de todos los tumores de mediastino. El quiste más común es el de intestino anterior (broncogénico) representando aproximadamente la mitad de estas lesiones. Informes recientes han demostrado que varios de estos presuntos quistes del intestino anterior exhiben diferenciación de Müller. Presentación del caso: Mujer 48 años, antecedente de cáncer tiroideo tratado hace siete años con tiroidectomía radical y I 131, hipotiroidismo secundario manejado con levotiroxina $150 \mu \mathrm{g} / \mathrm{día}$. Mastectomía radical derecha hace seis meses por cáncer de mama, en tratamiento con tamoxifeno $20 \mathrm{mg}$ al día. En valoración preoperatoria se observó opacidad torácica con signo cervicotorácico, corroborando tumoración de mediastino posterior por tomografía, paraclínicos normales. Se realizó cirugía para toma de biopsia con reporte de lesión paraaórtica quística de contenido citrino de $6 \times 4 \mathrm{~cm}$, volumen $50 \mathrm{~cm}^{3}$, realizando resección de la misma con reporte histopatológico con tinciones de inmunohistoquímica WT1, AE1/ AE3, RE, RP positivo; concluyendo «quiste de mediastino posterior con revestimiento epitelial con diferenciación mülleriana». Discusión: Clínicamente cursan asintomáticos, generalmente de localización paravertebral (T3T8) en mujeres de mediana edad, se sugiere que este quiste podría representar mesotelio fuera de lugar con características de Müller y que son de una etiología diferente que aquellos situados en el retroperitoneo, dado que este último a menudo tienen la diferenciación endocervical que normalmente no se ve en los quistes mediastínicos, el diagnóstico casi nunca se puede realizar preoperatoriamente y la escisión quirúrgica es el tratamiento de elección. Conclusiones: Los quistes de Müller en lugares fuera de la pelvis femenina son raros. Algunos lugares reportados incluyen la piel y retroperitoneo, existen muy pocos reportes de caso en la literatura a nivel mediastinal, probablemente infradiagnosticados y el examen anatomopatológico del mismo es imperativo para descartar malignidad.

\section{Malformaciones congénitas del árbol traqueobronquial}

Vargas BEE, Castillo LAP, Ruiz GHH, Membrila MJ, Rivera GSY, 
Saucedo TJL, Martínez BMC, de Borbón $A B$, Vargas BEE

IMSS, CMNO, Guadalajara, Jalisco

Introducción: Los errores en la embriogénesis de los órganos que conforman la vía aérea y el parénquima pulmonar, dan lugar a un gran espectro de malformaciones congénitas que pueden ser incompatibles con la vida, potencialmente mortales o casualmente descubiertas hasta la edad adulta. Esta revisión muestra la importancia de la semiología respiratoria para la sospecha de malformaciones broncopulmonares. Objetivo: Establecer la importancia de los signos y síntomas respiratorios recurrentes o persistentes para búsqueda de malformaciones broncopulmonares. Material y métodos: Se describen 10 casos de pacientes con signos y síntomas respiratorios que llevaron al diagnóstico de malformación broncopulmonar congénita. Resultados: La edad de los pacientes fue de tres días hasta siete años de edad, de los cuales seis son masculinos y cuatro femeninos. Tres pacientes que presentaron signos de atragantamiento al nacimiento con dificultad respiratoria su diagnóstico fue fístula traqueoesofágica tipo III. Un caso manifestó dificultad respiratoria desde el nacimiento y se encontró hernia diafragmática congénita izquierda. En dos pacientes el signo principal fue el estridor diagnosticándose estenosis subglótica congénita y hemangioma subglótico. En tres pacientes predominaron las infecciones recurrentes de vías respiratorias inferiores, encontrándose quiste broncogénico en dos casos y malformación adenomatoidea quística en el otro. Un caso presentó múltiples malformaciones como: secuestro pulmonar y enfisema lobar con sintomatología respiratoria crónica como antecedente. Conclusiones: La sintomatología respiratoria recurrente es de vital importancia para la sospecha diagnóstica de malformaciones broncopulmonares.

\section{Linfangioleiomiomatosis, experiencia en el Hospital General de México}

Luis ME, "Hernández SA, * Barragán PG, ${ }^{*}$ Yescas SG, ${ }^{\star}$ Martínez ChRA, ${ }^{*}$ Eliosa AGA, ${ }^{*}$ Landa APDL, * Cicero $S R^{\ddagger}$

*Hospital General de México "Dr. Eduardo Liceaga"; "Facultad de Medicina, UNAM

Introducción: La linfangioleiomiomatosis (LAM) es una enfermedad rara, afecta casi exclusivamente a mujeres en edad fértil, se presenta de forma esporádica o asociada con esclerosis tuberosa (LAM-ET). Se caracteriza por la proliferación de células musculares lisas en el intersticio pulmonar y alrededor de las estructuras broncovasculares con formación de quistes; se presenta con neumotórax recurrente, quilotórax y en muchos casos insuficiencia respiratoria. Es común encontrar linfangioleiomiomas, angiomiolipomas, ascitis quilosa. El curso de la enfermedad es variable. No existe en la actualidad tratamiento curativo de esta patología. Objetivo: Determinar la frecuencia de los pacientes con linfangioleiomiomatosis y sus características. Metodología: Se realizó un estudio retrospectivo, observacional, con pacientes con el diagnóstico de egreso de linfangioleiomiomatosis que acudieron al Hospital General de México del 2010 al 2015. Resultados: Se identificaron cuatro pacientes con LAM esporádica y uno con LAM-ET, sexo femenino: 5 pacientes (100\%), edad promedio de $41 \pm$ 4 años, la sintomatología principal fue disnea en 5 pacientes (100\%), dolor torácico: 3 pacientes $(60 \%)$, tos: 2 pacientes $(40 \%)$; las 5 pacientes presentaban hipoxemia, 1 paciente (20\%) presentó neumotórax recurrente, hipertensión pulmonar: 2 pacientes ( $40 \%$ ), todas contaban con TACAR con múltiples lesiones quísticas, en 1 paciente se encontró neumotórax, biopsia pulmonar: 1 paciente (20\%), 1 paciente falleció (20\%). Conclusión. En nuestro centro hospitalario son pocos los casos que se diagnostican como linfangioleiomiomatosis que coincide con lo reportado en la literatura, sólo en un caso se pudo confirmar el diagnóstico mediante biopsia pulmonar, el resto se clasificó mediante la presentación clínica y los hallazgos tomográficos, consideramos importante sospechar la enfermedad en especial en mujeres en edad fértil, considerar biopsia pulmonar en pacientes que no cumplen criterios compatibles con LAM.

\section{Neumotórax espontáneo como manifestación pulmonar inicial del complejo esclerosis tuberosa- linfangioleiomiomatosis. Presentación de un caso}

\section{Sánchez RCP, Rodríguez RMS}

INER Ismael Cosío Villegas

Introducción: La linfangioleiomiomatosis es una enfermedad que afecta mujeres en edad fértil. Se presenta de forma esporádica (S-LAM) o asociada con el complejo de esclerosis tuberosa (TSC-LAM). Se caracteriza por una proliferación anormal de células musculares lisas inmaduras con crecimiento aberrante en vía aérea, parénquima, linfáticos y vasos sanguíneos pulmonares. Tiene carácter multisistémico. Es una afección de escasa prevalencia, la dificultad diagnóstica temprana y ausencia de un tratamiento curativo. Existe un creciente interés en el estudio de esta enfermedad, lo que ha determinado el establecimiento de registros de pacientes y un crecimiento exponencial en la investigación tanto a nivel clínico como celular. Presentación de caso: Femenino de 44 años con esclerosis tuberosa, antecedente de disnea progresiva y neumotórax espontáneo. Clínicamente angiofibromas faciales, neurofibromas cutáneos y parche de Shagreen. Dentro del abordaje diagnóstico con TCAR patrón de linfangioleiomiomatosis. TC cráneo nódulo subependimarios calcificados. USG abdominal: angiomiolipomas renales y hepáticos. Discusión: Hay mayor prevalencia de nódulos pulmonares no 
calcificados y angiomiolipomas renales y hepáticos en TSC-LA. El curso de la enfermedad es variable y no se conocen factores pronósticos relevantes. En el presente caso las opciones terapéuticas estuvieron limitadas a la rehabilitación como única oferta terapéutica por el retraso en el diagnóstico de la afección pulmonar. Conclusión: Gran parte de esta variabilidad durante el curso de la enfermedad podría explicarse por el polimorfismo genético. En la actualidad no existe ningún tratamiento curativo. El tratamiento con progesterona ha sido cuestionado en los últimos años, dando opción al trasplante pulmonar (TP); sin embargo, la utilidad del TP en la LAM ha sido motivo de controversia por la escasa incidencia de esta enfermedad, el carácter sistémico de la misma y el impacto que la propia enfermedad podría tener en la morbimortalidad perioperatoria.

\section{Síndrome de la cimitarra: reporte de caso y revisión de la literatura}

De Borbón ABK, Aguilar AA, Hernández RR, Ruíz GHH

\section{IMSS}

Introducción: El síndrome de la cimitarra es una anomalía congénita compleja, rara, caracterizada por drenaje venoso pulmonar anómalo, se asocia con hipoplasia del pulmón derecho, secuestro pulmonar, vena cava superior izquierda y dextroposición cardíaca. Sus variantes con hipoplasia de la arteria pulmonar, agenesia del bronquio para lóbulo superior derecho, comunicación interauricular o interventricular, coartación de aorta, tetralogía de Fallot. Hasta $60 \%$ presenta hipertensión arterial pulmonar. Presentación del caso: Masculino de 28 días, madre de 32 años sana, segunda gesta, normoevolutivo, nace de término, sin complicaciones. Referido por ano imperforado. Se inicia abordaje para descartar otras malformaciones. Ecocardiograma reportando hipertensión arterial pulmonar de $40 \mathrm{mmHg}$, iniciando sildenafil.
Derivación intestinal por malformación ano rectal anterior a las 24 horas de vida. A los 14 días presenta dificultad respiratoria y atelectasia superior derecha persistente. Tomografía de tórax con imagen hiperdensa homogénea en segmento anterior de lóbulo superior derecho, ocupación alveolar en lóbulo inferior derecho segmentos posteriores. Broncoscopia a los 18 días con agenesia de bronquio para el lóbulo superior derecho. Gammagrama ventilatorio perfusorio demostró hipoplasia del pulmón derecho con perfusión del 23\%, daño parenquimatoso moderado. Angiotomografía reportando dextrocardia, conexión anómala parcial de las venas pulmonares variedad intracardíaca, defecto interauricular septal, vaso de aorta infradiafragmática que irriga el lóbulo inferior derecho sugerente de secuestro pulmonar. Cateterismo a los 25 días con embolización arterial del vaso aórtico persistiendo disminución de la perfusión e hipertensión pulmonar, se realiza neumonectomía derecha. Durante período posquirúrgico presenta choque séptico, evoluciona a falla orgánica múltiple, fallece. Discusión y conclusiones: El síndrome de la cimitarra con variante acompañada de otras malformaciones en la vía aérea y sistema digestivo es poco descrita en la literatura. Su manejo y pronóstico en ocasiones fatal, depende de la hipertensión arterial pulmonar y severidad de la insuficiencia cardíaca, así como las anomalías asociadas.

\section{Hemolinfangioma quístico torácico como síndrome de lóbulo medio: una rara presentación}

De Borbón ABK, Aguilar AA, Hernández RR, Ruíz GHH

\section{IMSS}

Introducción: Las malformaciones vasculares se observan en el 0.05 al $0.3 \%$ de la población. El hemolinfangioma obedece a lesiones compuestas por elementos linfáticos y sanguíneos. Es un tumor raro, benigno y no invasivo, en cualquier parte del cuerpo, detectado comúnmente antes de los dos años de edad. La localización intratorácica es muy rara, relacionados con datos de compresión de la vía aérea. Reporte clínico: Masculino de 8 años de edad, previamente sano. Inicia el 27 de agosto del 2013 tras sufrir contusión torácica con datos de dificultad respiratoria y dolor. Radiografía de tórax con radio opacidad basal y medial derecha, diagnóstico de derrame pleural encapsulado, manejo conservador. Valorado por primera vez por neumología en abril del 2014 por persistencia de imagen radiográfica, iniciando estudio para síndrome de lóbulo medio. Tórax con murmullo vesicular ligeramente disminuido y mate en región basal y anterior derecha, sin estertores. Tomografía de tórax con imagen homogénea hipodensa, bordes definidos ocupando lóbulo medio, no refuerzamiento, contenido líquido en su interior (20UH). Broncoscopia del 15 de abril sin alteraciones de vía aérea. Lavado broncoalveolar negativo para bacterias, hongos y micobacterias, PCR para Mycobacterium tuberculosis negativa. Sospecha de malformación broncopulmonar con resección quirúrgica el 19 de mayo encontrando tumoración quística, 7 × $8 \mathrm{~cm}$, bordes regulares, contenido líquido aspecto xantocrómico, adherida a lóbulo medio, cultivo del líquido negativo. Estudio histopatológico concluye en hemolinfangioma quístico. Cursa posquirúrgico con neumotórax derecho residual resuelto a las 24 horas. Sonda endopleural retirada a los tres días. Egresado el 26 de mayo en adecuadas condiciones generales. Discusión y conclusiones: Los hemolinfangiomas intratorácicos son tumores muy raros. Este es el primer reporte en la literatura de presentación como síndrome de lóbulo medio tras hallazgo incidental posterior a contusión torácica, descartando otras posibilidades diagnósticas en el abordaje se concluye en malformación y se comprueba tras resección mediante histopatología. 


\section{Reporte de caso de bronquiolitis folicular asociado a discinesia ciliar tipo I}

\section{Urbina MME, Velázquez SJR, Peña ME, Hernández RFI}

INER Ismael Cosío Villegas

Introducción: La bronquiolitis folicular se reconoce por hiperplasia del tejido linfoide a lo largo de la vía aérea, y por el desarrollo de folículos y centros germinales. El pronóstico depende del agente causal. Objetivo: Describir caso de una niña con bronquiolitis folicular asociado con disquinesia ciliar tipo 1 . Presentación de caso: Femenina de 8 años, antecedentes de neumonía recurrente y sibilancias desde los dos meses, se diagnostica asma y rinitis alérgica a los cinco años, con persistencia de sintomatología a pesar de tratamiento con fluticasona/salmeterol 50/500 día y esteroides inhalados con furoato de fluticasona $27.5 \mu \mathrm{g}$ cada 24 horas. Espirometría con obstrucción moderada grave con respuesta significativa a broncodilatador, persistiendo con obstrucción leve, prueba de caminata 346 $\mathrm{m}$ sin presentar desaturación durante el estudio, DLco: con disminución moderada. Pletismografía restricción leve y datos de atrapamiento aéreo. Tomografía de alta resolución: patrón en mosaico y bronquiectasias en segmentos posteriores e imágenes de atelectasia en S5 derecho e izquierdo. Cultivo de expectoración positivo para H. influenza sensible a ceftriaxona/amoxicilina/ ácido clavulánico. Broncoscopia con inflamación generalizada, broncorrea, galactomanano negativo, índice de lipófagos negativo. Baciloscopia negativa, biopsia bronquial: disquinesia ciliar tipo I. IGE alérgeno específica contra Aspergillus fumigatus negativo, electrolitos en sudor conductividad negativa, perfil reumatológico completo negativo. Perfil inmunológico sin datos de inmunodeficiencia. Se sospecha de una neumopatía intersticial, se solicita biopsia pulmonar por toracotomía, reportándose por patología: bronquiolitis folicular. Discusión: Reportamos segundo caso en la literatura de discinesia ciliar primaria asociado con bronquiolitis folicular. Se dio manejo con esteroides en bolo por tres dosis de metilprednisolona, macrólidos durante seis meses y tratamiento con rehabilitación pulmonar. La paciente ha presentado evolución satisfactoria no ha presentado reingresos por patología respiratoria y la sintomatología de la tos ha disminuido. Conclusión: Bronquiolitis folicular asociado con disquinesia ciliar es una entidad poco frecuente.

\section{Manifestaciones pulmonares en pacientes con mucopolisacaridosis}

\section{Moysen SG, Guerra CC, Cruz OF}

UMAE, HG CMN "La Raza”

Introducción: Las mucopolisacaridosis son trastornos genéticos en donde existe un déficit enzimático específico encargado del metabolismo de los glicosaminoglicanos, cuyo déficit desencadena la acumulación de sustratos a nivel intracelular, en los tejidos $u$ órganos. Lo anterior provoca síntomas progresivos en todos los órganos y sistemas, incluyendo nivel respiratorio. Objetivo: Determinar cuáles son las manifestaciones respiratorias más comunes en los pacientes con mucopolisacaridosis, que son atendidos en la UMAE del HG CMN "La Raza" en la Clínica de Enfermedades Lisosomales y son valorados por el Servicio de Neumología Pediátrica. Material y métodos: Se realizó un estudio observacional, epidemiológico, retrospectivo, transversal, serie de casos en el Servicio de Neumología Pediátrica y Clínica de Enfermedades Lisosomales de la UMAE Hospital General Centro Médico Nacional "La Raza", IMSS. Se incluyeron 11 pacientes del género femenino y masculino de 0 a 16 años con diagnóstico confirmado de mucopolisacaridosis y valoración por neumología pediátrica. Resultados: De los 11 pacientes en estudio: $45 \%$ tenía el diagnóstico confirmado de mucopolisacaridosis tipo 1 y el 55\% mucopolisacaridosis tipo 2 . Ocho pacientes contaron con trastorno del sueño, el $100 \%$ presenta apnea-hipoapnea obstructiva del sueño. Cinco de los pacientes cumplían con diagnóstico de hipertensión arterial pulmonar. Al igual cinco pacientes presentaron sintomatología sugestiva de enfermedad intersticial. Conclusión: Las mucopolisacaridosis presentan manifestaciones respiratorias como síntoma inicial, principalmente de causa obstructiva, condicionando SAHOS. El trastorno de sueño más frecuente fue la apnea obstructiva del sueño, encontrándose en el $100 \%$ de los pacientes. La hipertensión pulmonar puede ser multifactorial, tanto por SAHOS como a la enfermedad pulmonar intersticial. Consideramos de suma importancia las valoraciones por el Servicio de Neumología Pediátrica en cuanto se realice el diagnóstico, ya que en promedio tienen dos manifestaciones respiratorias, las cuales de no atenderse, pueden incrementar la morbilidad y posteriormente mortalidad.

\section{Enfermedad de Pompe y sus alteraciones en la función pulmonar: reporte de 3 casos}

Orozco BN, Cobián MA, Frías JS, Loeza JA, Pérez ES, Rodarte ML

IMSS-Centro Médico Nacional de Occidente

La enfermedad de Pompe se caracteriza por acúmulo de glucógeno en los músculos por disfunción de la enzima maltasa ácida lisosomal, condicionando debilidad muscular progresiva, principalmente a nivel respiratorio, que lleva a la muerte. Presentamos el caso de tres hermanas diagnosticadas en el Departamento de Fisiología Pulmonar de nuestro hospital. Caso 1: mujer de 35 años con diagnóstico de distrofia de cinturas desde hace 20 años, hospitalizada por insuficiencia respiratoria 
hipercápnica, egresada con oxígeno y ventilación mecánica no invasiva. En nuestro servicio se documentó restricción pulmonar grave (CVF 21.7\%) y debilidad de músculos respiratorios (Pimax $12.06 \mathrm{cmH}_{2} \mathrm{O}$ ). Dado el cuadro se realizó prueba de actividad enzimática para descartar enfermedad de Pompe, siendo positiva y confirmándose mediante estudio molecular. Recibe terapia de reemplazo enzimático (TRE) a base de alglucosidasa alfa desde hace 18 meses, mejorando sus pruebas de función pulmonar (CVF 26.3\% y Pi$\left.\max 15.75 \mathrm{cmH}_{2} \mathrm{O}\right)$ y la insuficiencia respiratoria. Caso 2: mujer de 25 años con fatiga desde la niñez al caminar y recientemente dificultad para cargar objetos pesados. Espirometría normal con Pimax disminuida (49.9 $\mathrm{cmH}_{2} \mathrm{O}$ ). Caso 3: mujer de 39 años, con imposibilidad para realizar abdominales y disminución de fuerza muscular 3/5 en miembro torácico derecho. Espirometría normal con Pimax normal. Debido a la importante restricción pulmonar por la debilidad de los músculos respiratorios del caso índice, se sospechó y confirmó enfermedad de Pompe. El uso de TRE se ha asociado con evidente mejoría en su función respiratoria, y en forma secundaria en su calidad de vida y pronóstico. El diagnóstico de enfermedad de Pompe pasa desapercibido con frecuencia y debe sospecharse en pacientes que presenten debilidad de los músculos respiratorios. El diagnóstico se hace con una prueba sencilla. En la actualidad se puede detener su progresión con tratamiento específico, mejorando la función pulmonar, calidad y cantidad de vida.

\section{Medicina crítica}

\section{Choque séptico por} neumonía, secundaria a síndrome de ahogamiento por inmersión en agua de mar

\author{
González C
}

Masculino de 29 años, fumador, sin antecedentes patológicos de relevancia. Sufre accidente automovilístico con caída de vehículo a bahía, permanece 30 minutos en inmersión, al rescate se encuentra en paro cardiorrespiratorio por lo que se realizan maniobras de reanimación, intubación orotraqueal y posterior respuesta hemodinámica. Trasladado a UCI de CMNO a nuestro cargo, a su ingreso con SDRA y choque séptico. TAC torácica con neumonía bilateral. Se maneja inicialmente con corticoesteroides y doble esquema antibiótico inicial a base de meropenem y levofloxacino. Hemocultivo positivo para Enterococcus faecium, cultivo de lavado bronquial positivo a Pseudomona aeruginosa y Candida glabrata. Se ajusta esquema antimicrobiano: meropenem, vancomicina y fluconazol. El ahogamiento por inmersión en agua es una entidad relativamente frecuente en nuestro medio, con repercusiones importantes para la víctima por el compromiso multiorgánico. El SDRA y neumonía son frecuentes. Actualmente no existe un consenso acerca de las acciones, más allá de las medidas de soporte ventilatorio, para su manejo. El uso de antibióticos no se encuentra estandarizado ni contamos con un esquema empírico establecido. En este caso nos enfrentamos a la necesidad de implementar tratamiento antimicrobiano precoz y sin cultivos por un cuadro de choque séptico secundario a neumonía por aspiración de agua de mar. Se requiere de mayor experiencia en el manejo de sepsis secundaria a esta entidad, pero por la experiencia en este paciente, así como lo reportado por la literatura consideramos en nuestro servicio que todo paciente con neumonía secundaria a inmersión en agua salada o dulce debe de ser cubierto con el siguiente esquema: levofloxacino, meropenem y fluconazol. Queda a consideración situaciones especiales en las que la probabilidad de Staphylococcus aureus sean altas, el cual escapa de este esquema.

\section{Utilidad de la ultrasonografía}

\section{pulmonar realizada por neumólogos en el Servicio de Urgencias Respiratorias}

Sánchez GJA, Sandoval GJL, Guerrero Z, López GB

INER Ismael Cosío Villegas

Antecedentes: Tradicionalmente, el abordaje diagnóstico del paciente respiratorio en urgencias se basa en la radiografía de tórax, a pesar de sus limitaciones en la precisión diagnóstica de patología pleuropulmonar. La tomografía de tórax resuelve en gran medida este problema, con el inconveniente de radiación, costo y disponibilidad. La ultrasonología pulmonar, definida como el ultrasonido realizado por clínicos, es una herramienta para el diagnóstico preciso de enfermedad pleuropulmonar, permitiendo establecer protocolos de tratamiento urgencias. Presentación de casos: 1 . Masculino de 24 años sin antecedentes, $\mathrm{SpO}_{2}>90 \%$, sin síndrome pleuropulmonar a la exploración. USG pulmonar con patrón A, sin deslizamiento y punto pulmonar, concluye neumotórax espontáneo; 2. Masculino de 59 años, VIH sida con neumonía por PCP con VM y sedación de 38 días se realiza incursión diafragmática, la cual es de $2.2 \mathrm{~cm}$ con éxito a la extubación; 3. Femenino de 65 años, con tumor pulmonar derecho, programada para biopsia transtorácica, el USG muestra aumento de vascularidad del tumor, decidimos abordaje por broncoscopia; 4. Femenino de 65 años, parapléjica por accidente automovilístico hace $>25$ años, neumonías de repetición, referida tumor endobronquial. La broncoscopia muestra únicamente abundantes secreciones. Se realizó USG pulmonar que diagnostica parálisis diafragmática derecha; 5. Masculino de 57 años que ingresa por disnea PA de tórax con derrame pleural derecho, sospecha de $\mathrm{Ca}$. Rastreo USG encontrando derrame y atelectasia. Se punciona derrame guiado por USG. Exudado linfocítico. Biopsia por FBC con diagnóstico de linfoma no Hodgkin. Discusión: La 
ultrasonología pulmonar es una herramienta rápida, inocua y de bajo coste que permite exploración en tiempo real y a la cabecera del paciente. Ha demostrado utilidad para evaluar pulmón, pleura y mediastino, con precisión diagnóstica de $90.5 \%$ para insuficiencia respiratoria aguda (protocolo BLUE). Está en manos de neumólogos avanzar en el conocimiento e integración de esta técnica en la práctica diaria.

\section{Caracterización de} los pacientes con síndrome de insuficiencia respiratoria aguda en una Unidad de Cuidados Intensivos Respiratorios

Yescas G, Álvarez MP, Luis ME, Saavedra de RSI, Martínez ChRA, Landa APD, Cicero SR

Secretaría de Salud

Antecedentes: El síndrome de insuficiencia respiratoria aguda (SIRA) es una patología de base inflamatoria, producida por lesión directa endotelial y del epitelio pulmonar, acompañado de activación de citocinas, de origen pulmonar o extrapulmonar. La lesión endotelial es activada de manera local y sistémica, generando aumento de la permeabilidad vascular y expresión de moléculas de adhesión. Objetivo: Determinar las características de los pacientes que ingresaron a la Unidad de Cuidados Intensivos Respiratorios con diagnóstico de SIRA de acuerdo con los criterios de Berlín. Material y métodos: Estudio descriptivo, retrospectivo en pacientes que ingresaron a UCIR del Servicio de Neumología del Hospital General de México del $1^{\circ}$ de marzo de 2010 a $1^{\circ}$ de marzo de 2015. Resultados: Se revisaron 57 expedientes clínicos. La edad promedio de los pacientes que ingresaron con el diagnóstico de SIRA fue de 43 años, se observó mayor incidencia en el género masculino $(61 \%)$, la causa más frecuente fue neumonía adquirida en la comunidad (73.6\%), de acuerdo con la clasificación de gravedad de los criterios de Berlín, 48 pacientes se ubicaron en la forma grave del SIRA $(84 \%)$, el score de ingreso para SAPS III fue de $56.9 \pm 19.1$ y para SOFA $8.5 \pm 2.75$, con una mortalidad esperada del $52 \%$, la mortalidad fue de $63 \% .26$ pacientes requirieron traqueotomía, 18 pacientes intubación prolongada y 7 pacientes por deterioro neurológico. Los días de estancia en la UCIR fueron en promedio de 13.7 días con estancia hospitalaria de 19.3 días. Discusión y conclusiones: El SIRA es una patología de diversa etiología con una mortalidad elevada, por lo que es importante implementar estrategias para mejorar los resultados. Es prioritario detectar a las poblaciones con riesgo de complicaciones. Este estudio fue de carácter epidemiológico retrospectivo y está sujeto a sesgos, lo que representa una limitación para su generalización.

\section{Manejo complejo del paciente con politrauma y tumor fibroso solitario. Reporte de un caso}

\section{Moreno JA, Martínez AM,} Farah OS

Centro Médico ISSEMYM, Toluca

Introducción: El paciente con trauma torácico requiere un manejo complejo. Presentamos el caso de un paciente con fracturas costales y hernia diafragmática, con hallazgo transquirúrgico de un tumor fibroso solitario. Presentación del caso: Politraumatizado de 61 años, con fracturas costales anteriores derechas de 3 a $6^{\circ}$ y posteriores 6 y $7^{\circ}$, izquierdas 2 a $5^{\circ}$. En primer acto quirúrgico se fijaron arcos derechos anteriores 3 a $5^{\circ}$ y posteriores 6 y $7^{\circ}$, izquierdos 2 a $5^{\circ}$ con clips de seis puentes de titanio. Como hallazgo tumoración de hemitórax derecho de $5 \mathrm{~cm}$ de diámetro, en lóbulo medio, indurada, con vascularidad y vaso nutricio. En segundo acto quirúrgico se realizó toracotomía izquierda, encontrándose hernia diafragmática de $25 \times 15 \mathrm{~cm}$, con contenido de colon transverso y descendente, se realizó cierre primario del defecto y colocación malla de polipropileno supradiafragmática; en mismo tiempo se realizó traqueostomía por intubación prolongada. Diez días después se retiró ventilación mecánica, se decanuló con egreso y seguimiento por consulta externa. Al año, el paciente se encuentra sin secuelas posquirúrgicas, con estoma de traqueostomía cerrado y fonación adecuada; con reporte histopatológico de tumor fibroso solitario. Discusión: Las fracturas costales están en 35 a $40 \%$ de los traumatismos de tórax, siendo la causa más frecuente los accidentes de tráfico. Las lesiones diafragmáticas ocurren entre el 1 y $5 \%$ de accidentes automovilísticos, hasta $60 \%$ pasan inadvertidos. El tumor fibroso representa el $8 \%$ de las neoplasias benignas del tórax y el $10 \%$ de los tumores pleurales, generalmente detectado como un hallazgo incidental. Conclusiones: Hasta hoy no existe reporte de algún caso en el que en un mismo paciente encontremos múltiples fracturas costales, hernia diafragmática postraumática y tumor fibroso solitario. En nuestro caso encontramos situaciones secundarias a trauma de tórax de baja incidencia que requirieron tratamiento quirúrgico, que se acompañó de la resección de una tumoración poco común.

\section{Misceláneos}

\section{Síndrome \\ pulmón-riñón, presentación de caso}

Martínez LF, Leal AT, Alemán ZJE, Velázquez SJR, Del Razo RR

INER Ismael Cosío Villegas

Introducción: El síndrome pulmónriñón (SPR) se caracteriza por la 
combinación de hemorragia alveolar difusa (HAD) y glomerulonefritis (GN). Presentación de caso: Femenino de 13 años, previamente sana, originaria del Estado de México. Inició su padecimiento con fiebre, acudiendo con facultativo sin mejoría, se agregó tos, estornudos, rinorrea, malestar general y sensación de opresión torácica, la tos se vuelve hemoptoica, ingresando a centro hospitalario con diagnósticos de neumonía y síndrome anémico, durante su estancia con mala evolución, dependencia de oxígeno suplementario y persistencia de datos de respuesta inflamatoria sistémica. Radiografía con patrón micro/macronodular, patrón de crazy paving en tomografía, es derivada a nuestra institución. Ingresa inestable, con datos de dificultad respiratoria y apoyo suplementario de oxígeno con mascarilla reservorio a $10 \mathrm{~L} / \mathrm{min}$. A la exploración física con disminución de los ruidos respiratorios, crepitantes bilaterales. Amerita VMNI con BIPAP durante cinco días. Se realiza LBA con presencia de hemosiderófagos tipo III. Se interconsulta al Servicio de Infectología, Reumatología y Nefrología por la presencia de hematuria, proteinuria, resultados de abordaje negativos (urocultivo, cultivo de LBA, perfil reumatológico negativos) y evolución insidiosa. Se realiza biopsia renal con reporte de glomerulonefritis proliferativa extracapilar activa focal, con necrosis fibrinoide segmentaria de tipo pauciinmune. Se otorga tratamiento sistémico con esteroide con evolución favorable, remisión de sintomatología así como dependencia de oxígeno. Discusión: El SPR predomina en adultos y es de mal pronóstico. El $90 \%$ de los pacientes con GN pauciinmune son ANCA positivos. La literatura contrasta con el caso expuesto, tanto en el grupo etario como en la serología. Conclusiones: El diagnóstico precoz y el adecuado tratamiento mejoran la función renal y disminuyen la mortalidad. Es imprescindible lograr la asociación entre los hallazgos clínicos, radiológicos, de laboratorio e histológicos para la identificación de la patología y así brindar el tratamiento específico para su resolución.
Prevalencia de caquexia cardíaca y fibrilación auricular en pacientes con insuficiencia cardíaca

Arámbula E, González ID, Orea $T A$, Santellano JB, Hernández ZR, Cintora MC, Pineda JJA, Peláez HV, Espinosa de los Monteros C, Pablo $S R$, Contreras RE, Herrera SR, Velázquez MA, Flores TF, Sansores $R$, Ramírez VA, Sánchez SRN

INER Ismael Cosío Villegas

Antecedentes: La caquexia es una complicación común en pacientes con insuficiencia cardíaca (IC) avanzada, caracterizándose por una notable desgaste musculoesquelético y activación en las vías de la respuesta inflamatoria. La fibrilación auricular (FA) es la arritmia más frecuente $(26 \%)$ en la IC probablemente favorecida por la activación de mecanismos de remodelamiento a cardíaco, así como la implicación de otras manifestaciones que exacerban el estado de caquexia cardíaca (CC). Objetivos: Evaluar la asociación de fibrilación auricular y caquexia en pacientes con insuficiencia cardíaca. Material y métodos: En un estudio de casos y controles se identificó la proporción de sujetos con y sin CC estudiados mediante bioimpedancia eléctrica con análisis vectorial (BIVA). Se excluyeron sujetos con IC congénita, cáncer, VIH, uso de drogas y aquellos con CC de etiología diferente a la IC. Resultados: Se analizaron 359 sujetos, $52.92 \%$ fueron hombres, la mediana de edad 65 (55-74). El 47.8\% de los sujetos desarrollaron caquexia cardíaca, $17.27 \%$ tenían fibrilación auricular (FA) de éstos el 23\% tenían caquexia cardíaca vs. $12.11 \%$ en sujetos sin caquexia ( $p=0.006)$. En $50.6 \%$ la clase funcional (NYHA) fue: I, en aquellos en clase III el $22.95 \%$ tenían FA y $12.10 \%(\mathrm{p}=0.027)$ no. El $56.6 \%$ el tipo de IC fue: izquierda con fracción de expulsión preservada (VlpEF), 41.7\%, reducida (VlrEF), $40.6 \%$ y con falla derecha $41.7 \%$. Los sujetos con caquexia $v s$. sin caquexia, hubo mayor frecuencia en edema $62.7 \%$ vs. $(\mathrm{p}<0.01)$, menor frecuencia en dislipidemia $47.02 \%$ ( $\mathrm{p}=$ 0.001 ), niveles más bajos de colesterol $(\mathrm{p}=0.021)$ y triglicéridos $(\mathrm{p}=0.009)$. En aquellos con CC y FA fue menor el peso ( $p=0.018$ ) y el IMC (normopeso y obesidad $(\mathrm{p}=0.013)$ y más frecuente el edema ( $p=0.027)$. Conclusión: La caquexia cardíaca y la FA son complicaciones frecuentes de la IC, cuando coexisten son indicadores de mayor severidad de la IC, independientemente del tipo de ésta.

\section{Poliangeítis granulomatosa (granulomatosis de Wegener) no asociada con anticuerpos anticitoplasma de neutrófilos (ANCA) y de evolución fulminante. Reporte de caso}

Tinoco LE, Espeso RMF

IMSS

Introducción: La poliangeítis granulomatosa (PG) es una enfermedad autoinmune relacionada con anticuerpos anticitoplasma de neutrófilos (ANCA) que presenta múltiples manifestaciones sistémicas, vasculitis necrotizante, inflamación granulomatosa y glomerulonefritis. Caso clínico: Mujer de 59 años que inició en marzo 2015 con tos y esputo purulento, rinorrea, descarga retronasal, úlceras orales indoloras y cefalea holocraneana. Recibió múltiples tratamientos antibióticos sin mejoría de los síntomas. A los dos meses, por hallazgos de neumonía necrotizante se sometió a broncoscopia con reporte de compresión extrínseca de bronquio principal derecho, y la biopsia pulmonar a cielo abierto indicó la presencia de granulomatosis no caseificante y necrosis. Se hospitalizó en tercer nivel de atención observándose destrucción de puente nasal de dos meses de evolución, 
queratitis y conjuntivitis de repetición, úlceras orales indoloras, caquexia, hipoxemia grave, proteinuria y hematuria microscópica. Segunda broncoscopia con hallazgo de granulomas traqueales y en lóbulo superior derecho, estenosis de bronquio del lóbulo medio; reporte histopatológico con inflamación granulomatosa; cultivos sin desarrollo. Cultivo de aspirado traqueal con Staphylococcus aureus; la tomografía de tórax (TC) evidenció nódulos pulmonares cavitados y neumonía necrotizante; TC de senos paranasales con hipertrofia de cornetes, sinusitis maxilar y destrucción de celdillas mastoideas; Gene Xpert, galactomanano sérico, ANCA negativos; IgE sérica $180 \mathrm{U} /$ mL; complemento normal; IgA $688 \mathrm{mg} /$ dL. Persistió empeoramiento clínico progresivo pese a tratamiento de amplio espectro e, incluso, antituberculoso, finalmente falleció por choque séptico en noviembre de 2015. Discusión: La PG es una enfermedad de difícil diagnóstico y de baja sospecha. Esta paciente cursó con evolución tórpida y progresiva, cuyo diagnóstico tuvo retraso de ocho meses. Finalmente, por la presencia de $>2$ criterios con sensibilidad de $88 \%$ y especificidad de $92 \%$ se realizó diagnóstico. Conclusiones: El $10 \%$ de $\mathrm{PG}$ puede ser ANCA negativo, por lo que la Universidad Americana de Reumatología creó los nuevos criterios para su diagnóstico, mismos que cumplía la paciente.

\section{Neumonía intersticial idiopática en un paciente con vasculitis asociada a anticuerpos anticitoplasma de neutrófilos (ANCA)}

Urdiales MN, Hernández VD, Medina RE, Rivero MP

Hospital Ángeles del Carmen

Introducción: La neumonía intersticial idiopática secundaria a vasculitis asociada a ANCA (VAA), es una entidad poco frecuente, pero de pronóstico pobre, debido a la rápida progresión y detección tardía. La poliangitis microscópica asociada MPO-ANCA, es la más asociada a neumonía intersticial idiopática. El tratamiento indicado son esteroides asociados con ciclofosfamida o rituximab. Presentación del caso: Masculino 84 años, sin antecedente de tabaquismo, hipertenso controlado. Inició padecimiento siete meses previos con disnea de moderados esfuerzos, tos no productiva, síndrome constitucional con pérdida de peso $7 \mathrm{~kg}$ en siete meses. Posteriormente presenta LRA kdigo 3 , trombocitopenia severa, anemia moderada normocítica-normocrómica. TACAR tórax con patrón intersticial bilateral, nódulos pulmonares en hemitórax derecho, atelectasias pasivas, derrame bilateral loculado y derrame pericárdico. En broncoscopia se observó edema del árbol traqueobronquial bilateral, tinción Gram con leucocitos (6-8) predominio polimorfonuclear; cultivos bacterias, hongos y micobacterias negativos; citología negativo para malignidad. Se realizó toracocentesis, citoquímico con leucocitos (39) predominio mononuclear; ADA 4.3; cultivos bacterias, hongos y micobacterias negativos. Hemocultivos periféricos y centrales negativos. MPO-ANCA positivo (1:10,000), PR3-ANCA negativo. Discusión: La vasculitis asociada con MPO-ANCA, European Respiratory Society (ERS), es una vasculitis necrosante con escasos complejos inmunitarios que afecta vasos de pequeño calibre. Esta enfermedad se acompaña de glomerulonefritis y capilaritis pulmonar, en ausencia de inflamación granulomatosa. Los infiltrados parenquimatosos y nódulos pulmonares son los hallazgos radiológicos en las VAA. Según el consenso de la ERS, al tener alta sospecha diagnóstica de vasculitis sistémica con MPO-ANCA positivos, se recomienda iniciar terapia empírica con corticoesteroides asociado con ciclofosfamida. Conclusiones: La VAA es una enfermedad de mal pronóstico por su rápida progresión, es importante sospecharlo ante un paciente con neumonía intersticial idiopática, afección renal, anticuerpos ANCAs positivos y especificidades antigénicas. El inicio temprano del tratamiento es esencial para mejorar el pronóstico.

\section{Utilidad del modelo de Wallston para predecir la adherencia terapéutica en pacientes con enfermedad respiratoria crónica}

Leija AG, * Peláez HV, ${ }^{\ddagger}$ Pérez CE, Pablo SR, ${ }^{\ddagger}$ Orea TA, ${ }^{\neq}$Pineda JJA, ${ }^{\ddagger}$ González ID, $\neq$ Cintora MC, $\neq$ Contreras $R E, \neq$ Ramírez-Venegas $A,{ }^{\neq}$HernándezZenteno $R, \neq$ Espinosa de los Monteros

$C, \neq$ Velázquez-Montero $A,{ }^{\ddagger}$ FloresTrujillo F,, Sansores $M R^{\ddagger}$

*IPN; ₹ INER Ismael Cosío Villegas

Introducción: Las estrategias de tratamiento para los pacientes con enfermedades respiratorias crónicas consisten en fármacos y cambios en el estilo de vida. Sin embargo, 40-70\% de los pacientes no son adherentes, lo cual afecta la efectividad del tratamiento $y$, por ende, la calidad de vida del enfermo. Diversos estudios muestran que el modelo de Wallston ayuda a predecir la adherencia terapéutica, explicando cómo ésta depende de creencias de control sobre la enfermedad, el valor dado a la salud y la autoeficacia para seguir el tratamiento. Objetivo: Evaluar la utilidad de los factores del modelo de Wallston para predecir la adherencia terapéutica de personas con enfermedad respiratoria crónica. Método: Se realizó un estudio descriptivo transversal. Participaron 134 pacientes ( $74 \%$ mujeres, edad media 47 años), evaluados con la escala del modelo de Wallston para la adherencia terapéutica $(\alpha=0.766)$ y el cuestionario de adherencia terapéutica MGB ( $\alpha=0.770)$. Resultados: Mediante una regresión lineal múltiple por pasos sucesivos se obtuvo que sólo uno los factores del modelo predice de manera significativa la adherencia al tratamiento: autoeficacia $(\mathrm{t}=3.845, \beta$ $=0.317, \mathrm{p}<0.01)$. El modelo obtenido obtuvo un nivel bajo de explicación del constructo de adherencia terapéu- 
tica $\left(\mathrm{r}^{2}=0.101, \mathrm{~F}=14.784, \mathrm{p}<0.01\right.$, constante 7.215). Conclusión: Los resultados muestran que el modelo no es de utilidad para explicar la adherencia en esta población. Sólo la autoeficacia explica una parte del constructo; sin embargo, esta variable está incluida en otros modelos como la teoría de la conducta planeada, que podría ser de mayor utilidad al evaluar a los pacientes y proponer programas de intervención. Se recomienda estudiar otros modelos que puedan adaptarse mejor a las características de la población. Agradecimiento: El presente trabajo fue apoyado por el proyecto aprobado por la SIP con registro 20151036. Se agradece el apoyo del IPN para la presentación de esta ponencia.

\section{Proteinosis alveolar}

\section{Castillo MC, Martínez LF, Varela LA, Cortés BP}

INER Ismael Cosío Villegas

Introducción: Trastorno poco común caracterizado por acumulación de material lipoproteico en la superficie alveolar. Clínicamente varía desde insuficiencia respiratoria en el período neonatal a síntomas más insidiosos en niños mayores, así como cambios radiológicos. Diagnóstico por broncoscopia y/o biopsia pulmonar. Presentación de caso: Paciente femenino, 12 años, consulta por dificultad respiratoria, 24 h de evolución, se encontraba realizando educación física cuando lo notó, acompañándose de tos productiva predominantemente matutina, cefalea, al caminar una cuadra presentó disnea, recibiendo fluticasona/salmeterol $1,000 \mu \mathrm{g} /$ día sin mejoría con oximetría de pulso $88 \%$, sin mostrar disnea en reposo. Los ruidos respiratorios disminuidos, estertores finos subescapulares bilaterales, no acropaquia. Biometría hemática normal, gasometría venosa: equilibrio ácido base. Espirometría: FEV1/FVC: $76.71 \%$ FEV1 52\% FVC $58 \%$, obstrucción moderadamente grave. Espirometría posterior, sin respuesta al broncodilatador. DLco disminución moderada (corregida por altitud 42\%), pletismografía: restricción pulmonar leve, atrapamiento aéreo grave. Radiografía torácica: borramiento de ángulos costofrénicos y costodiafragmáticos, combinación de imágenes radiopacas difusas de bordes mal definidos, imágenes «en riel», sugestivas de bronquiectasias, así como imágenes radiopacas paracardíacas con signo de silueta con broncograma aéreo. TACAR engrosamiento de tabiques interlobulillares (crazypaving). Broncoscopia: cambios inflamatorios en mucosa, secreciones mucohialinas, líquido blanquecino. Frotis: abundantes cúmulos de material proteináceo, cambios inflamatorios y células con metaplasia epidermoide. Citológico: material blanquecino, aspecto grumoso y granular eosinófilo. Discusión: Es una alteración poco común con acumulación del material lipoproteináceo. La patogénesis no es clara. Se sabe que los anticuerpos contra factor estimulante de granulocitos-macrófagos cumplen una función produciendo una sustancia de factor de transcripción. Caminata de seis minutos positiva desaturación $86 \%$. Actualmente se encuentra con tratamiento oxigenoterapia, rehabilitación pulmonar, se evalúa la necesidad de nuevos lavados bronquioalveolares. Conclusión: En el presente caso, tanto el comportamiento clínico como estudios de imagenología resultaron muy inespecíficos. Aunque el diagnóstico se planteó inicialmente, lo fue dentro de una amplia lista neumopatías crónicas.

\section{Una alternativa para el diagnóstico de la microlitiasis alveolar}

\section{Rodríguez BH, Rodríguez LIS, Sánchez HM}

INER Ismael Cosío Villegas

Caso clínico: Hombre de 38 años, con exposición al humo de leña (150 horas/ año) y tabaquismo (1 paquete/año) suspendido hace cuatro años. Inició con disnea mMRC 2 y tos seca que a lo largo de seis meses, progresó a mMRC3 y tos productiva de expectoración verdosa con cianosis peribucal. Por ello, acudió a clínica privada donde tras tratamiento con claritromicina obtuvo mejoría parcial. Debido a la persistencia del cuadro, acudió al Instituto Nacional de Enfermedades Respiratorias. A su ingreso con saturación de oxígeno menor a $75 \%$, corrigió junto con la disnea tras la colocación de oxígeno suplementario a 3 litros/minuto. Tras esta medida, el paciente se mantuvo clínicamente estable durante todo su internamiento y egresó cinco días después. Abordaje: La radiografía de tórax mostró opacidades micronodulares heterogéneas diseminadas bilaterales con gradiente ápico-basal en patrón de «tormenta de arena». La tomografía computada de alta resolución reveló patrón en vidrio deslustrado con micronodulaciones subpleurales con densidad equivalente a la ósea. El gammagrama óseo mostró biodistribución de 99-mTc-HDP en ambos parénquimas pulmonares de predominio basal y posterior. El SPEC-CT corroboró que dicha captación correlacionaba con las áreas de mayor densidad. Discusión: Pese a una imagen radiológica florida y consistente con otras enfermedades intersticiales, la característica principal de la microlitiasis alveolar es la disociación clínico-radiológica. Causada por la mutación del gen codificador del cotransportador sodio-fosfato tipo IIb (SLC34A2), el estándar de diagnóstico actual requiere la realización de broncoscopia para análisis histopatológico del lavado bronquioloalveolar y/o biopsia transbronquial. Sin embargo, los estudios de medicina nuclear han demostrado poder confirmar la naturaleza cálcica de las lesiones a través de un procedimiento mucho menos invasivo $y$, a diferencia de los estudios de radiología convencional, simultáneamente descartar otros posibles focos de calcificación extrapulmonar. Hasta el día de hoy, no existe tratamiento útil para la microlitiasis alveolar.

\section{Pleura}

\section{Quilotórax}


Badillo AJI, ${ }^{\star}$ Martínez FM,, Garza VI, ${ }^{\ddagger}$ García $A H^{\S}$

*Hospital General Zacatecas, Servicios de Salud de Zacatecas y Medicina Humana

U.A.Z; ¥ Medicina Humana U.A.Z.; \$ \$ Hospital General Zacatecas

Introducción: El quilotórax designa derrame pleural frecuentemente lechoso, opalescente, con alta concentración de grasas neutras y bajo contenido de colesterol, el análisis de lipoproteínas para demostrar la presencia de quilomicrones es el estándar de oro. La concentración de triglicéridos es superior a $110 \mathrm{mg} \%$ (> $1.2 \mathrm{mmol} / \mathrm{L})$ mientras que la del colesterol es menor o igual a $200 \mathrm{mg} \%$ con un índice colesterol/ triglicéridos $<1$. Existe linfocitosis y concentración de inmunoglobulinas. Serie de casos (3): 2 masculinos de 84 y 69 años, diagnosticados con linfoma no Hodgkin y derrame pleural derecho que a la toracocentesis presentan apariencia lechosa; y un paciente del sexo femenino de cinco años posquirúrgica por cierre de conducto arteriovenoso con derrame izquierdo. El examen citoquímico reportó triglicéridos en rangos desde 161 a $941 \mathrm{mg} \%$ y colesterol de 55 a $86 \mathrm{mg} \%$, un índice $\mathrm{C} / \mathrm{T}<\mathrm{a}$ 1. Con linfocitosis del $84 \%$ en líquido pleural. No realizamos determinación de quilomicrones. Discusión: Se produce un quilotórax cuando el conducto torácico se rompe y se acumula quilo en el espacio pleural. Las causas frecuentes comprenden trauma cerrado de tórax, poscirugía, infecciosas, neoplasias torácicas y menos frecuentes el espontáneo, por filariasis o por bostezo. El quilotórax izquierdo obedece a obstrucción/ruptura de la parte superior del conducto, en el derecho la lesión es en la parte inferior del conducto. La resolución del quilotórax en nuestros pacientes con linfoma fue mediante pleurodesis, en la pediátrica mediante ligamiento del conducto torácico. Diagnóstico diferencial con patologías que causan pseudoquilotórax como artritis reumatoide o la tuberculosis. Conclusiones: El quilotórax en nuestros pacientes obedeció a las causas frecuentes descritas en la literatura, las traumáticas (cirugía) y neoplásicas.

\section{Quilotórax primario infectado de etiología idiopática}

\section{Preciado AN, * López TJG, * Otazu \\ AMR,${ }^{*}$ Ramírez SCh, ${ }^{*}$ Ruvalcaba COG, ${ }^{\ddagger}$ Mojica $R C E^{\star}$}

*Hospital Civil de Guadalajara "Fray Antonio Alcalde"; " IMSS

Se trata de paciente femenina de 61 años quien presenta tos y disnea progresiva de medianos a pequeños esfuerzos. A la exploración física paciente con ortopnea y disnea, campos pulmonares con hipoventilación derecha, hemitórax izquierdo bien ventilado sin crépitos, estertores ni sibilancias. Radiografía de tórax con velamiento del hemitórax derecho por derrame pleural de etiología a determinar. Dados los hallazgos en la radiografía de tórax se decidió colocar drenaje cerrado de tórax con tubo endopleural obteniendo $800 \mathrm{~cm}^{3}$ de material de aspecto purulento. Al análisis del líquido pleural se obtuvieron los siguientes resultados: Leu 10,300 con predominio de PLMN de 94\%, glucosa, 97 microproteínas 626 y DHL 441, catalogándose como derrame pleural complicado. Posteriormente llama la atención el aumento significativo del drenaje a través del tubo de $1,000 \mathrm{~cm}^{3}$ en $24 \mathrm{~h}$ por lo que se sospechó de un quilotórax infectado y se realizó determinación de colesterol y triglicéridos obteniendo TGL 2,585 mg/dL, Col. 197 $\mathrm{mg} / \mathrm{d}$. Iniciamos tratamiento antibiótico con meropenem y clindamicina además de dieta a base de triglicéridos de cadena media y nutrición parenteral total descendiendo de manera considerable el gasto del líquido a través del drenaje. TAC sin evidencia de lesiones neoplásicas descartando, además, infección por tuberculosis mediante PCR de líquido pleural y ADA negativos. Posterior a completar esquema de antibiótico y 15 días con NPT el paciente continúa con mejoría del cuadro clínico y descenso del drenaje a través de la sonda endopleural, por lo que posterior a tres sesiones de pleurodesis con bleomicina es dada de alta sin complicaciones.

\section{Quilotórax asociado con linfoma. Presentación de un caso}

\section{Sandoval VF, Tapia JSR, González OC, Gutiérrez MA, Sandoval CA}

Hospital México Americano Guadalajara

Introducción: El diagnóstico del quilotórax se realiza demostrando en líquido pleural: triglicéridos > $110 \mathrm{mg} / \mathrm{dL}$, relación: triglicéridos líquido pleural/ sérico: > 1 y relación: colesterol-líquido pleural/sérico: < 16. El linfoma asociado con quilotórax no traumático tiene actualmente un pronóstico de vida de entre cinco a diez años, siempre que se añada terapia biológica a la quimioterapia convencional. Los linfomas que desarrollan quilotórax recurrentes requieren aspiraciones pleurales repetidas y pleurodesis con talco. Presentación de caso: Paciente femenina de 64 años de edad, soltera, fumadora crónica 20 cigarrillos diarios quien inició su padecimiento hace 45 días con dificultad respiratoria de medianos a mínimos esfuerzos, dolor retroesternal. Al ingreso FC 110 FR 18 TA 110/70 ausencia de ruidos respiratorios en todo hemitórax derecho, disminución de frémito vocal y matidez a la digito percusión. $\mathrm{Rx}$ derrame pleural derecho. TAC de tórax con lesión tumoral en tórax posterior e nivel de D10 D11, se realiza toracocentesis demostrando analítica quilotórax, por tanto es sometida a toracotomía derecha para biopsia y ligadura de conducto torácico, se deja tubo de drenaje torácico con nutrición parenteral total drenando $300 \mathrm{~mL}$ líquido lechoso, el cual posterior a 15 días cede y es retirado reportando linfoma no Hodgkin difuso de linfocitos pequeños de bajo grado tipo B, por lo que se continúa manejo por oncología. Conclusiones: El quilotórax puede ser el principal hallazgo de un linfoma, por ello el interés de presentar este caso. Es importante determinar estrategias rutinarias de diagnóstico de manera oportuna, ya que en el caso de ser no traumático, la principal causa es linfoma no Hodgkin. 
Así ofrecer un tratamiento adecuado, con mejor pronóstico.

\section{Quilotórax y ascitis quilosa: Asociación infrecuente de enfermedades infrecuentes}

\section{Contreras FJ, Mendoza TLA, Hernández GD, Ibarra IR, Martínez SG}

\section{Centro Médico Nacional de} Occidente-IMSS

Antecedentes: La acumulación de quilo en el espacio pleural tiene prevalencia de $2.5-5.3 \%$ de los derrames pleurales. La ascitis quilosa es un problema cínico raro, en ambos al excluir etiología traumática y quirúrgica los linfomas son la principal etiología. El colangiocarcinoma tiene frecuencia del $3 \%$ entre los tumores gastrointestinales, la forma intrahepática da cuenta de apenas el $10 \%$ de los casos de este tipo de tumor. Presentación de caso: Hombre de 81 años, índice tabáquico 25 paquetes-año, alcoholismo crónico intenso, con síndrome consuntivo, aumento del diámetro abdominal y disnea progresiva, se documentó derrame pleural izquierdo masivo y ascitis, se demostró quilotórax y ascitis quilosa. Los estudios de gabinete evidenciaron múltiples nódulos hepáticos con probable relación a metástasis. Se colocó drenaje pleural izquierdo con evacuación persistente de líquido lechoso, evoluciona con deterioro clínico progresivo hasta su muerte al quinto día de estancia hospitalaria. La necropsia confirmó carcinoma de ductos biliares intrahepático, moderadamente diferenciado, invasor, que afectó el $70 \%$ del parénquima hepático, con extensión a páncreas, duodeno y metástasis a ganglios paraaórticos. Discusión: El quilotórax obedece a la fuga de quilo del conducto torácico por trauma, debilidad de la pared u obstrucción, tanto por efecto de masa como por diseminación metastásica. Otros mecanismos son extremadamente raros como el paso transdiafragmático por ascitis quilosa, de los cuales sólo existen casos-reportes aislados. La asociación de quilotórax con ascitis es extremadamente rara, generalmente la causa es traumática o quirúrgica, además de neoplasias, principalmente linfoma, se han reportado otras como lupus, tuberculosis y falla cardíaca. Conclusiones: Presentamos un caso de la asociación infrecuente de quilotórax secundario a ascitis quilosa, atribuido a colangiocarcinoma. Ambas entidades tienen baja incidencia y presentan un reto diagnóstico. Deben de considerarse las causa neoplásicas como la principal etiología.

\section{Quilotórax asociado a trauma torácico indirecto en paciente pediátrico}

\section{Urbina ME, Del Razo $R$, Varela $L A$, Vázquez MME, Sánchez UMG, Topete MLE, Castillo VMC}

INER Ismael Cosío Villegas

Antecedentes: El quilotórax es un derrame pleural causado por extravasación de quilo en el espacio pleural debido a la obstrucción o lesión del conducto torácico; son criterios para confirmar su presencia triglicéridos $>110 \mathrm{mg} / \mathrm{dL}$ o presencia de quilomicrones en el líquido pleural. Objetivo: Describir el caso de un niño con quilotórax secundario a traumatismo torácico. Presentación de caso: Masculino de 1 año 11 meses previamente sano, 30 días antes de su ingreso presenta caída de su propia altura con contusión en tórax anterior, presentando disnea de medianos esfuerzos, sin tos ni fiebre, primera valoración médica, solicitan radiografía de tórax detectan derrame pleural derecho, y se da manejo médico con antibioticoterapia, nueve días de tratamiento y persiste con la misma imagen por lo que es referido a tercer nivel. Clínicamente con dificultad respiratoria, tórax asimétrico, sin datos de respuesta inflamatoria sistémica. Radiografía de tórax y USG: derrame pleural derecho del 90\%. Toracoscopia y toma de biopsia: derrame pleural quiloso (800 mL), engrosamiento marginal a nivel basal y lateral posterior. Análisis de líquido pleural: color blanco lechoso, triglicéridos: 2,994, linfocitos: 85, pH: 7.6, ADA 10, glucosa: 82, colesterol: 18, LDH: 175, leucocitos: 3,190, albúmina 3.36, proteínas totales: 4.93. Patología: infiltrado linfocitario policlonal, linfangiectasias en pared pleural. Linfogammagrafía: ganglios centinela axilares. Segunda intervención: pleurectomía total de la cara lateral y pleurodesis abrasiva de ápex y química. Tercera intervención: ligadura de conducto torácico dos meses posterior, por recurrencia del derrame, seguimiento por consulta externa con evolución satisfactoria. Discusión: El $79 \%$ de los casos se debe a lesiones provocadas por cirugía cardíaca, reportamos segundo caso debido a un traumatismo torácico indirecto sin datos de fractura costal, el cual puede ser por un mecanismo de aceleración y desaceleración. Conclusión: El quilotórax asociado con traumatismo torácico en los niños es muy raro reportamos segundo caso.

\section{Quilotórax por tuberculosis. Presentación de dos casos y revisión de la literatura}

\section{Valencia J, Alonso MD, Carrillo RG, Suárez LTJ, Quiñones FF, Salazar LMÁL}

INER Ismael Cosío Villegas

Introducción: La tuberculosis pleural es la forma de tuberculosis extrapulmonar más frecuente. Se manifiesta con derrame siendo un exudado linfocítico con adenosindesaminasa $($ ADA) $\geq$ 30 U. El diagnóstico de tuberculosis pleural precisa de la demostración del bacilo en la biopsia pleural con la visualización de granulomas. El análisis del líquido pleural es muy útil para sospecharlo. Caso clínico 1: Hombre de 34 años con dolor pleu- 
rítico derecho, tos y fiebre de $39{ }^{\circ} \mathrm{C}$ intermitente. Radiografía de tórax con derrame pleural derecho. Se le realizó toracocentesis obteniéndose líquido anaranjado, exudado, linfocitos $98 \%$, ADA de $48 \mathrm{U}$, colesterol 79, triglicéridos 124. BAAR y gene Xpert en líquido pleural negativos. En la biopsia pleural por toracoscopia con reporte de lesión granulomatosa caseificante con células epitelioides y células gigantes multinucleadas de tipo Langerhans, secundaria a micobacterias. En la fluorescencia para auramina-rodamina positiva para micobacterias. El cultivo de líquido pleural con crecimiento de M. tuberculosis. Caso clínico 2: Hombre de 43 años con fiebre de hasta $39{ }^{\circ} \mathrm{C}$ de predominio vespertino, diaforesis y disnea. En la radiografía de tórax con derrame pleural izquierdo. En la toracocentesis se obtuvo líquido serohemático, exudado, linfocitos $80 \%$, ADA 34 U, colesterol 104, triglicéridos 162. BAAR y gene Xpert negativos en líquido pleural. En la biopsia pleural por toracoscopia se reportó lesión granulomatosa caseificante con células epitelioides y células gigantes multinucleadas de tipo Langerhans. Discusión: Las causas más frecuentes de quilotórax (QT) son los secundarios a enfermedad tumoral. El diagnóstico se establece por la determinación en líquido pleural de una concentración de triglicéridos mayor de $110 \mathrm{mg} / \mathrm{dL}$. Existen casos reportados de tuberculosis pleural que se manifiestan como quilotórax. Se encontraron 10 reportes de caso. Conclusión: La presencia de ADA mayor a 30 y con perfil celular linfocítico aun en quilotórax obliga a descartar tuberculosis pleural.

\section{Rentabilidad}

diagnóstica de la biopsia pleural con aguja de tru-cut $v s$. aguja de cope en pacientes con patología pleural

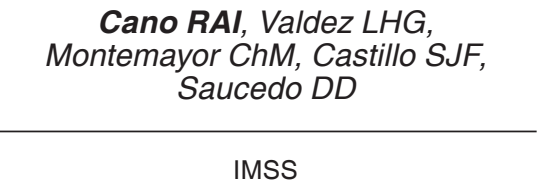

Introducción: La prevalencia del derrame pleural en México es superior a 400 por 100,000 habitantes, siendo de etiología infecciosa en $45.7 \%$ y neoplásica en $32.6 \%$. La biopsia pleural tiene una sensibilidad de $48-70 \%$ en cáncer y $50-90 \%$ en tuberculosis utilizando aguja de Cope o Abrams. En 1989 se describió inicialmente la biopsia con aguja cortante (tru-cut), como alternativa en derrames pleurales grandes con una sensibilidad de $86 \%$, sin embargo, su empleo es controversial. En nuestro hospital se cuenta con amplia experiencia en el uso de la biopsia pleural con tru-cut con buenos resultados, pero es importante corroborar su rentabilidad. Objetivo: Comparar la rentabilidad diagnóstica de las biopsias pleurales con aguja de tru-cut contra aguja de Cope en pacientes con patología pleural. Material y métodos: Estudio cuasiexperimental, no ciego, analítico y transversal en el que se incluyeron adultos con patología pleural crónica, a cada paciente se le realizaron cuatro biopsias pleurales con aguja de trucut y cuatro con aguja de Cope para comparar rentabilidad diagnóstica por ambos procedimientos. Los resultados se analizaron mediante estadística descriptiva e inferencial con el paquete estadístico SPPSS 20.0. Resultados: Se incluyeron 44 pacientes; 24 (55\%) hombres y $20(45 \%)$ mujeres, con un promedio de edad de $61.4 \pm 12.2$ años. La rentabilidad diagnóstica con la agua de tru-cut fue de 57\% y con Cope de 50\%. Los diagnósticos más frecuentes fueron adenocarcinoma $(20.5 \%)$, mesotelioma (15.9\%) y tuberculosis (15.9\%). Conclusiones: La rentabilidad diagnóstica de las biopsias pleurales cerradas con aguja de tru-cut es ligeramente mayor a la obtenida con aguja de Cope, muy semejante a lo que se reporta en la literatura, siendo este procedimiento una fortaleza en nuestra práctica clínica.

\section{Rendimiento diagnóstico de la biopsia pleural cerrada en derrame pleural}

Contreras RFJ, Mendoza TLA, Hernández GD, Guerrero RA

Centro Médico Nacional de Occidente, IMSS

Antecedentes: La biopsia pleural está indicada en pacientes con derrame pleural de tipo exudado de etiología desconocida, cuando se sospecha neoplasia o tuberculosis. Su rendimiento diagnóstico varía dependiendo la etiología, de 70-80\% en tuberculosis y 45$56 \%$ en neoplasia. Se recomiendan tres a cinco muestras para histopatológico y una para cultivo de micobacterias. Las agujas de Cope y Abrams tienen similar rendimiento. Objetivos: Evaluar el rendimiento diagnóstico de la biopsia pleural cerrada con aguja de Cope en pacientes con derrame pleural de etiología desconocida. Métodos: Estudio descriptivo, retrospectivo, que incluyó a todos los pacientes con derrame pleural a quienes se les realizó biopsia pleural cerrada para establecer etiología durante nueve meses del 2015, en el Departamento de Neumología del CMNO-IMSS. La información fue obtenida del expediente clínico y de los registros anatomopatológicos. El sitio de toma de muestra fue elegido según la exploración física y estudios de imagen. Se utilizó estadística descriptiva. Resultados: Se incluyeron 40 pacientes, $55 \%$ masculinos, con una mediana de edad de 61 años. Todas las muestras tenían tejido pleural, la mediana del número de fragmentos fue de cuatro. Se obtuvo diagnóstico en el $47.5 \%$ de los casos (19/40). El 89.5\% (17/19) fueron positivos para malignidad y $10.5 \%$ (2/19) para tuberculosis pleural. Adenocarcinoma pulmonar primario fue lo más frecuente con $82 \%$ de las neoplasias (14/17). No hubo complicaciones asociadas con el procedimiento. Conclusiones: El procedimiento con aguja de Cope es útil en ausencia de toracoscopia. En nuestro centro se considera un procedimiento seguro. 
Practicarla mediante ultrasonido puede aumentar su rendimiento.

\section{Ventana torácica abierta. Experiencia de 4 años en CMN "La Raza"}

Lemus-Rangel R, Soto-Vidal G, Armenta-Reyes RM, Suárez-Suárez JP, Payró-Hernández LE, OchoaVázquez $M D$

\section{IMSS}

Antecedentes: La ventana torácica abierta (VTA) fue descrita por Eloesser en 1935 para el manejo del empiema tuberculoso en pacientes crónicamente debilitados. Actualmente con mayor entendimiento de la fisiopatología de las infecciones pleuropulmonares, el advenimiento de mejores antibióticos y avances en las técnicas quirúrgicas, se ha observado una disminución de este procedimiento. Objetivos: Describir las características clínicas y epidemiológicas de pacientes sometidos a VTA. Métodos: Estudio descriptivo, retrospectivo y transversal. Se incluyeron pacientes sometidos a VTA de enero 2012 a diciembre 2015 en CMN "La Raza" a los cuales se pudo tener acceso al expediente clínico. Se identificaron 19 pacientes y se obtuvo acceso en 15 , de los cuales 12 fueron varones $(80 \%)$, con edad promedio de 63 años (rango 19-75). Resultados: Las principales comorbilidades fueron: diabetes $46 \%$, HAS $33 \%$, cáncer (mama, renal y próstata) $20 \%$, ERC terminal $20 \%$. El IMC promedio fue $24.5 \mathrm{~kg} / \mathrm{m}^{2} \mathrm{y}$ de albumina $2.26 \mathrm{~g} / \mathrm{dL}$. La indicación principal fue empiema en 11 pacientes (73\%) (6 paraneumónico, 3 tuberculoso, 1 por mediastinitis y 1 poslobectomía) y cavidad pleural residual en cuatro pacientes $(26 \%) .80 \%$ fueron tratados previamente con sonda endopleural y $40 \%$ con lavado-decorticación. La VTA fue derecha en ocho casos (53\%), en siete se encontró fístula broncopleural, el promedio de costillas resecadas fue de 1.8 (rango 1-3), en cinco pacientes se realizó VTA modificada, la mortalidad hospitalaria fue de $13 \%$ asociada a sepsis y $0 \%$ relacionada con el procedimiento, el promedio de estancia posquirúrgica fue de 29.3 días, ocho pacientes se colonizaron (pseudomonas, S. aureus, Acinetobacter) y en cinco se logró el cierre en un promedio de 13.6 meses. Conclusiones: Comorbilidades e hipoalbuminemia son comunes en pacientes sometidos a VTA. El empiema paraneumónico es la principal causa para VTA y ésta sigue siendo un procedimiento vigente en pacientes severamente comprometidos. No se encontró mortalidad asociada con el procedimiento.

\section{Sueño}

\section{Diferencias en el} cuadro clínico entre pacientes preescolares y escolares con diagnóstico de síndrome de apnea obstructiva del sueñoa

Torres VRA, Carrillo AJL, Torres FMG INER Ismael Cosío Villegas

Antecedentes: El síndrome de apnea obstructiva del sueño (SAOS) en edad pediátrica es muy frecuente; sin embargo, sus manifestaciones clínicas están poco reportadas y la edad de los pacientes podría influir sobre su cuadro clínico. Objetivo: Comparar el cuadro clínico, comorbilidades y hallazgos poligráficos entre niños preescolares y escolares con SAOS. Material y método: Revisión de expedientes, se incluyeron niños de 2 a 12 años de edad, que acudieron a la Clínica de Trastornos Respiratorios del Sueño durante el 2014 con diagnóstico de SAOS confirmado por estudio de sueño. Resultados: Se incluyeron 244 pacientes (108 preescolares y 136 escolares). Los pacientes preescolares tuvieron mayor crecimiento amigdalino en comparación con los niños escolares. Las manifestaciones nocturnas fueron muy frecuentes y los síntomas diurnos fueron poco reportados en ambos grupos, excepto la intensidad del ronquido que fue mayor en el grupo de preescolares, no se encontraron diferencias en el cuadro clínico y en los antecedentes familiares. En SAOS fue más grave en los preescolares (RDI 26 vs. 19, TC90 19 vs. 13, $\mathrm{SpO}_{2}$ mínima 73 vs. 79, $\mathrm{p}<$ 0.05). La frecuencia por enfermedad por reflujo gastroesofágico (ERGE) fue mayor en preescolares mientras que los escolares presentaron mayor frecuencia de obesidad. Conclusiones: No existen diferencias significativas en el cuadro clínico y antecedentes familiares de los niños preescolares y escolares con SAOS. Los niños preescolares presentan índices más graves que los escolares. La comorbilidad más importante en escolares es la ERGE y en los escolares la obesidad.

a Trabajo seleccionado para ser presentado de forma oral.

\section{Prevalencia de apnea obstructiva del sueño en síndromes coronarios agudos $^{a}$}

Hernández-Gordillo D, Castañeda BEA, Guzmán SCM, Mendoza TLA

Hospital de Especialidades, Centro Médico Nacional de Occidente

Introducción: Existe evidencia suficiente para considerar a la apnea obstructiva del sueño (AOS) como un factor de riesgo independiente cardiovascular. Objetivo: Describir la asociación entre el AOS y el síndrome coronario agudo (SICA), y evaluar algunos parámetros ecocardiográficos como indicadores de riesgo para AOS. Metodología: Estudio transversal que incluyó pacientes mayores de 18 años de edad, con síndrome coronario agudo no complicado, a los cuales se les realizó estudio de poligrafía con equipo ALICE-PDX y ecocardiograma transtorácico entre 5 y 60 días posteriores al SICA. Resultados: Se incluyeron 33 pacientes, $70 \%$ fueron hombres, edad de $64 \pm 10$ años. 
Con IMC $27.5 \pm 3.3$, la circunferencia de cuello Iq25-75 34.5 - 39 cm, 88\% roncadores habituales, tabaquismo $67 \%$, hipertensos $67 \%$, diabéticos $55 \%$, Epworth $\geq 10$ puntos el $12 \%$. El $67 \%$ presentó SICA tipo IAM con elevación ST, $18 \%$ IAM sin elevación ST y el resto angina inestable de riesgo alto. De éstos el $36 \%$ fue de riesgo alto estratificado mediante el modelo de riesgo GRACE, el $43 \%$ de riesgo intermedio y el $21 \%$ riesgo bajo. La prevalencia de AOS en SICA fue $60 \%$. El $37 \%$ con RDI $>30$, $18 \%$ en grado moderado y $27 \%$ con RDI entre 5-15 eventos por hora. Se observó respiración tipo Cheyne-Stokes en $30 \%$. Las variables ecocardiográficas asociadas con AOS fueron volumen auricular izquierdo (VoIA) incrementado RR 1.35 (IQ 95 0.78-2.27) y dilatación del ventrículo derecho RR 1.33 (IQ 95 0.78-2.25). Conclusiones: En pacientes con SICA la prevalencia de AOS fue de $60 \%$. El VoIA incrementado como la dilatación del ventrículo derecho aumenta el riesgo de presentar AOS. Los síntomas clásicos de AOS pueden no estar presentes en esta población; sin embargo, la alta prevalencia de AOS en este grupo de pacientes justifica el tamiz de forma sistemática.

a Trabajo seleccionado para ser presentado de forma oral.

\section{Calidad de sueño y trastornos respiratorios del dormir en niños asmáticos}

García ER, Vázquez GJC, Carrillo-Alduenda JL, Torres FMG

INER Ismael Cosío Villegas

Introducción: El asma es una enfermedad crónica frecuente en la infancia; aquellos descontrolados experimentan síntomas nocturnos y mala calidad de sueño. Justificación: Mala calidad de sueño, asma y AOS causan alteraciones neurocognitivas graves; describir cuadro clínico, medir prevalencia y evaluar asociación podría generar estrategias para diagnóstico y tratamiento opor- tunos. Objetivo principal: Describir calidad de sueño en niños asmáticos. Secundarios: Medir prevalencia de AOS, evaluar asociación entre gravedad del asma y ronquidos/apnea del sueño. Metodología: Niños 2-12 años de edad, diagnóstico de asma. Etapa 1: cuestionario salud general, síntomas de asma, hábitos de sueño, antecedentes generales. Se realizó espirometría y exploración física. Etapa 2: polisomnografía. Las variables se expresaron de acuerdo con tipo y distribución. Para valorar diferencias entre grupos de acuerdo con la gravedad del asma: prueba de Kruskal-Wallis; análisis multivariado para evaluar asociación de gravedad del asma y síntomas de sueño. Resultados: 222 niños con edad promedio de 7 años; 133 hombres $(60 \%)$ y 89 mujeres (40\%), 34\% preescolares y $66 \%$ escolares. Ronquido habitual en 37 $(16.7 \%)$ y ocasional en 74 (34.2\%). Frecuencia de asociación RH más apneas presenciadas fue $5.4 \%$. Sin diferencias entre género. En análisis multivariado, predictores independientes de $\mathrm{RH}$ : respiración oral (OR: 10.7, 95\% IC: 4.2-26.9), asma grave persistente (OR: 8.6, 95\% CI: 1.29-57.7), apneas presenciadas (OR: 5.5, 95\% CI: 1.7-17.7) y amígdalas crecidas (OR: 5.4, 95\% CI: $1.5-19.1)$, a 25 de los 37 niños (67.6\%) con RH se les realizó PSG. Mayor gravedad del asma, mayor resistencia para levantarse $(\mathrm{p}=0.02)$, peor calidad de sueño $(\mathrm{p}=0.0002)$, despertares nocturnos $(p=0.009)$ e irritabilidad diurna ( $\mathrm{p}=0.002)$; asociación entre gravedad del asma y siestas durante clases, somnolencia diurna, fatiga e irritabilidad ( $p<0.05)$. PSG: incremento del tiempo de vigilia después de iniciado sueño y despertares, IAH aumentado. No diferencias en valores reportados de $\mathrm{SpO}_{2}$ promedio, o tiempo de $\mathrm{SpO}_{2} 90-99 \%, 80-89 \%$ y $70-79 \%$. Frecuencia de AOS en pacientes con RH $(\mathrm{IAH}>1 / \mathrm{h})$ de $60 \%$. Gravedad del asma y AOS tendencia a asociarse, sin significancia estadística. Conclusiones: La gravedad del asma afecta la calidad de sueño referida por los padres. Niños con asma grave aumentan el tiempo de vigila después de haberse dormido, latencia corta a sueño. $\mathrm{SpO}_{2}$ durante el dormir no se modifica con la gravedad del asma. Elevada prevalencia de RH y AOS.

\section{Beneficios y \\ efectos adversos \\ relacionados con el \\ uso del CPAP en \\ síndrome de apnea \\ obstructiva del sueño}

\section{Hernández-Gordillo $D,{ }^{\star}$ Álvarez PJ, ${ }^{\ddagger}$ Carrasco $C A^{\S}$}

\footnotetext{
*Somnox Laboratorio del Sueño y Función Pulmonar; ${ }^{+}$Hospital de Especialidades Centro Médico Nacional de Occidente; \$Hospital Regional "Dr. Valentín Gómez Farías"
}

Antecedentes: La prevalencia del síndrome de apnea obstructiva del sueño (SAOS) aumentó al menos 10 veces en los últimos años y la terapia con presión positiva continúa en la vía aérea (CPAP), es la que mayores beneficios ha demostrado. Objetivo: Informar los beneficios y efectos adversos asociados con el uso de CPAP en el tratamiento del SAOS. Métodos: Estudio trasversal. Derechohabientes del ISSSTE, referidos a poligrafía con equipo ALICE PDX previa valoración por neumología y titulación automática de CPAP tres a siete noches, con humidificador y mascarillas nasales. Se interrogó sobre calidad de sueño y 10 efectos adversos. Resultados: Se estudiaron 151 pacientes en dos años. La edad fue $56 \pm 13$ años, $63 \%$ hombres, en $73 \%$ el IMC fue $\geq 30$. El $83 \%$ tenía riesgo clínico alto y el $3.5 \%$ en riesgo bajo, $60 \%$ con Epworth $\geq 10$ puntos, en el $91 \%$ se documentó un $\mathrm{RDI}>10$. Y $61 \%$ con RDI $>30$. La presión terapéutica de CPAP fue $10 \pm 2$ $\mathrm{cmH}_{2} \mathrm{O} .65 \%$ de los pacientes se sintió mejor que antes de usar CPAP y los efectos adversos más frecuentemente informados durante la prueba de CPAP fueron despertares $61 \%$, resequedad de boca y garganta 53\%, fugas $37 \%$ e irritación de la piel (32\%) y no influyó el gradiente de presión. Sólo el 6\% requirió presiones $\geq 16 \mathrm{cmH}_{2} \mathrm{O}$. En $6(4 \%)$ pacientes la titulación fue inadecuada 
(IAH residual mayor a 10/h) o tenían apnea de tipo central y se recomendó realizar polisomnografía. La mejoría en la calidad del sueño se presentó en $65 \%$ posterior al uso de CPAP. Conclusiones: Los efectos adversos son leves y el conocerlos puede mejorar el entrenamiento del paciente para lograr mejor apego. En centros donde no se cuente con polisomnografía el abordaje simplificado es una alternativa válida ante la creciente prevalencia del SAOS.

\section{Cuadro clínico y comorbilidades en mujeres con apnea obstructiva del sueño, diferencias de género}

\section{Marte A, Taniyama N, Carrillo JL}

INER Ismael Cosío Villegas

Introducción: La apnea obstructiva del sueño es un problema de salud pública mundial; existen diferencias anatómicas y fisiológicas secundarias al género que podría explicar las diferencias epidemiológicas existentes, esta disparidad podría generar divergencias en el cuadro clínico y comorbilidades entre mujeres y hombres. Objetivo primario del estudio: Comparar el cuadro clínico, comorbilidades y hallazgos polisomnográficos entre hombres y mujeres con apnea obstructiva del sueño. Materiales y métodos: Revisión de registros de la Clínica de Sueño del INER del 1 enero al 31 diciembre 2015. Resultados: Se incluyeron 237 pacientes, 92 mujeres y 145 hombres, con promedio de edad de $51.6 \pm 12.6$ años, las mujeres son más obesas, existen diferencias que impactan sobre el intercambio gaseoso diurno, así las mujeres tienen menor $\mathrm{SpO}_{2}$ y mayor $\mathrm{EtCO}_{2}(\mathrm{p}<$ $0.05)$. Las mujeres manifestaron mayor consumo de medicamentos hipnóticos, menor frecuencia de apneas presenciadas y sensación de no descanso, menor somnolencia excesiva diurna medida por cuestionario de Epworth y mayor prevalencia de cefalea matutina con respecto a los hombres. Las mujeres presentaron mayor frecuencia de comorbilidades especialmente cardiovasculares, neumológicas y metabólicas ( $\mathrm{p}$ $<0.05$ ). Las mujeres presentaron menor eficiencia de sueño. No se encontró diferencia en los eventos respiratorios, pero al igual que en el estado de vigilia, el $\mathrm{EtCO}_{2}$ nocturno es mayor en mujeres en comparación con los hombres ( $\mathrm{p}<$ 0.05). En mujeres, a diferencia de los hombres, no se encontró correlación entre marcadores de obesidad como circunferencia de cuello (CC) e IMC y el índice de apnea hipopnea (IAH) como indicador de gravedad del SAOS. Conclusiones: Existen diferencias significativas atribuibles al género en cuadro clínico y comorbilidades entre los pacientes con apnea obstructiva del sueño que acuden al INER, en las mujeres no hay asociación entre la obesidad y el índice de apnea hipopnea.

\section{Cambios \\ cardiorrespiratorios registrados en \\ poligrafía respiratoria \\ como sustituto de microdespertar en \\ pacientes con \\ síndrome de apnea-hipopnea de sueño (SAHS)}

Millán RG, ${ }^{*}$ Luis ME, ${ }^{\ddagger}$ Santana $V, \neq$ Gutiérrez ER, ${ }^{\star}$ Jiménez $C J L^{\star}$

*UNAM; 怙ospital General de México

Antecedentes: El SAHS es una enfermedad prevalente que acompaña a la epidemia creciente de obesidad, por lo que su diagnóstico y tratamiento constituye un problema de salud pública. $\mathrm{La}$ polisomnografía (PSG) se considera el «estándar de oro» para el diagnóstico; sin embargo, la poligrafía respiratoria (PR) es un método alternativo aceptado, aunque se subestima el índice de apneahipopnea (IAH) debido a que ésta no puede identificar microdespertares. Objetivos: Determinar el grado de concordancia entre microdespertares de la PSG, comparado con los cambios cardiorrespiratorios de la PR con la finalidad de que pudieran considerarse como sustituto de microdespertar. Método: Estudio prospectivo transversal, se incluyeron pacientes de entre 18 a 65 años de edad con sospecha clínica de SAHS que acudieron a la Clínica de Trastornos del Sueño de la Facultad de Medicina de la UNAM, a los cuales se les realizó PSG y PR durante una noche de estudio (simultáneo). Se analizó mediante el programa SPSS comparando el IAH de ambos estudios (considerando los cambios cardiorrespiratorios como microdespertares), por medio de prueba T, método de Bland Altman y regresión lineal. Resultados: Se analizaron estudios de ocho pacientes, siete hombres y una mujer, con edad media de 38 años, IAH media en PSG $=52$, $\mathrm{PR}=39$, PR considerando cambios cardiorrespiratorios $=49$, al analizar el IAH de PSG con la PR con cambios cardiorrespiratorios, obtuvimos una $\mathrm{t}$ $=1.62, \mathrm{p}=.773$ y r $=208.23, \mathrm{p}=.269$. Conclusión: No se observaron diferencias significativas en la puntuación de IAH entre el estudio «estándar de oro» y el estudio simplificado; además, se observó concordancia entre ambos métodos, por lo cual los cambios cardiorrespiratorios pudieran considerarse como sustituto de microdespertares; sin embargo, se requiere aumentar el número de sujetos a estudiar.

\section{Tuberculosis}

\section{Derrame pericárdico por tuberculosis, una entidad compleja} Trejo DA, Gordillo MJA, Ambríz MJC,
Cicero SR, Vargas ÁB

Hospital General de México

Femenino de 56 años de edad con exposición a biomasa de 90 horas año. Se presenta al Servicio de Urgencias con cuadro de tres meses de evolución con disnea de medianos esfuerzos, ortopnea y disnea paroxística nocturna, astenia, 
adinamia y pérdida de peso de seis kilogramos, posteriormente un mes con tos seca en accesos cortos y disnea, dolor precordial opresivo intensidad 3/10 exacerbado al decúbito dorsal; radiografía con derrame pericárdico de casi la totalidad del hemitórax izquierdo, electrocardiograma normal, ecocardiograma con compresión severa del ventrículo y aurícula derecha, derrame pericárdico severo y separación máxima de hojas pericárdicas de 73 $\mathrm{mm}$, fracción de eyección del ventrículo izquierdo del $60 \%$, clínicamente sin datos de tamponade. Glucosa en ayuno de $138 \mathrm{mg} / \mathrm{dL}$, hemoglobina glucosilada de $6.8 \mathrm{mg} / \mathrm{dL}$, Pro-BNP 38.1 , procalcitonina 0.05 , marcadores tumorales normales, complemento normal. Se decide manejo inicial con catéter pericárdico de $14 \mathrm{fr}$ evacuando $3,500 \mathrm{~cm}^{3}$ en $72 \mathrm{~h}$; obteniendo líquido serohemático con características de exudado con proteínas fuera de rango alto, celularidad de 1678, predominio linfocítico del $70 \%$, toracoscopia con hallazgo de derrame pleural y adherencias laxas, engrosamiento pericárdico; vía toracoscópica, se evacua $3,000 \mathrm{~cm}^{3}$ de líquido serohemático realizando dos ventanas pericárdicas y colocación de catéter $30 \mathrm{fr}$, líquido pericárdico con determinación de ADA de 47, BAAR negativo, cultivo de Lownenstein-Jensen negativo, determinación de GeneXper negativo, PCR para Mycobacterium tuberculosis negativo, tinción con de Ziehl-Neelsen negativo. Estudio actual de imagen muestra resolución de derrame y pericardio con discreto engrosamiento; se decide retiro de sistema de drenaje y se egresa con tratamiento antituberculoso de prueba y radiografía de tórax normal. Punto de corte de ADA para tuberculosis pericárdica es 40 U/L con sensibilidad $88 \%$ y especificidad de $83 \%$, incidencia de 1 al $8 \%$; el diagnóstico definitivo es difícil al tratarse de enfermedad paucibacilar y el largo tiempo para el crecimiento del bacilo.

\section{Falla ventilatoria} secundaria a tuberculosis
ganglionar mediastinal asociada con miopatía inflamatoria autoinmune

Padua J, Guzmán de Alba E

Centro Médico ABC

Introducción: La linfadenitis tuberculosa es la más frecuente de las presentaciones de la tuberculosis extrapulmonar. La tuberculosis es responsable de más del $43 \%$ de la linfadenopatía periférica en países en vías de desarrollo, en donde la tuberculosis es endémica. La variedad extrapulmonar ocurre en $60 \%$ de pacientes coinfectados con VIH. El diagnóstico diferencial de la linfadenopatía periférica es extenso e incluye malignidad (linfoma Hodgkin, no Hodgkin) y otras infecciones (micobacterias no tuberculosas: $[M$. scrofulaceum, M. avium complex, $M$. kansasii], enfermedad por arañazo de gato, infecciones fúngicas, sarcoidosis y otras adenitis bacterianas). La miositis necrozante inducida por estatinas ha sido reconocida como parte del espectro de «miopatía inducida por estatinas», y está caracterizada por debilidad muscular proximal con una marcada elevación de creatin fosfokinasa (CPK) y evidencia histológica de mionecrosis, con poco o ningún infiltrado inflamatorio. Presentación del caso clínico: Mujer de 28 años, enfermera, quien se presenta con historia de seis meses de pérdida ponderal de $8 \mathrm{~kg}$ sin hiporexia, asociada a diaforesis, cansancio y fatiga fácil, debilidad muscular proximal para deambular, subir escaleras y ponerse de pie. Lo anterior coincide con el inicio de simvastatina/ezetimiba por dislipidemia. Se encuentra elevación de enzimas musculares (CPK, mioglobina, TGO, DHL), linfadenopatía mediastinal (subcarinal, paratraqueal) e insuficiencia ventilatoria ( $\mathrm{PH} \mathrm{7.1,}$ $\mathrm{PaCO}_{2}$ 104). Se confirma tuberculosis ganglionar por toma de biopsia a través de mediastinoscopia y mionecrosis en biopsia de cuadriceps. Discusión: La reactivación de la tuberculosis en personal de alto riesgo (enfermera), provocó un síndrome consuntivo, que aunado a la mionecrosis mediada por estatinas determinó el escenario de falla muscular esquelética y diafragmática ocasionando insuficiencia ventilatoria crónica agudizada. No existen casos clínicos similares reportados en la literatura mundial. El manejo fue a expensas de suspensión de estatinas, antituberculosos, esteroides e inmunosupresores, logrando la recuperación total de la paciente.

\section{Tuberculosis diseminada con afección pulmonar, meníngea, ganglionar, renal, en pacientes reumatológicos que recibieron terapia inmunomoduladora con esteroides y biológicos}

\author{
Escobedo-Jaimes L, \\ López-Ruiz M, Amezcua-Herrera C, \\ Velázquez-Fonseca LK, \\ Moreira-Meyer $A$, Iñarra-Hiriart $A$, \\ Rosas-Rendón AM, \\ Vázquez-Bautista MC, González- \\ González H, \\ Ramírez-Casanova E
}

Hospital General de México

Introducción: Las enfermedades reumáticas constituyen una causa importante de morbilidad, tienen riesgo de tuberculosis por la terapia con esteroides y biológicos que bloquean el factor de necrosis tumoral produciendo respuesta inmune inadecuada. Serie de casos: Femenino de 22 años con artritis reumatoide (AR), tratada con ciclofosfamida, metilprednisolona y adalimumab, infiltrado miliar en radiografía de tórax, hematuria, Lowenstein positivo en orina, crisis convulsivas, resonancia de cráneo ( $\mathrm{RMN}$ ) con tuberculomas. Masculino de 19 años con espondilitis anquilosante (EA) tratado con adalimumab, infiltrado miliar en radiografía de tórax, Xpert positivo en lavado bronquial, ADA (adenosindesaminasa) de LCR 14, resonancia 
con tuberculoma. Femenino de 24 años con lupus y dermatopolimiositis, tratada con metilprednisolona, ciclofosfamida, crisis convulsivas, ADA de LCR 12, derrame pericárdico con ADA 38, RMN con meningitis. Femenino de 33 años, con lupus tratada con ciclofosfamida/metilprednisolona, ADA de LCR 6, BAAR en expectoración y ganglio positivos, $\mathrm{RMN}$ con tuberculomas. Femenino de 59 años con lupus tratada con hidroxicloroquina, adenopatías diseminadas, lesiones hepáticas, biopsia con inflamación crónica granulomatosa, Xpert positivo. Femenino 27 con lupus tratamiento con metilprednisolona y ciclofosfamida, adenopatías axilares, radiografía de tórax con infiltrado miliar, alteración neurológica, ADA de LCR 17, RMN cráneo tuberculomas. Femenino de 36 años con AR tratada con metotrexate, hidroxicloroquina, padre fallecido por tuberculosis, adenopatías cervicales, biopsia ganglionar y PCR positivos para tuberculosis, TAC con tuberculoma pulmonar y lesiones en hígado. Femenino de 56 años con EA tratada con adalimumab, TAC tórax con infiltrado miliar, adenopatía ganglionares diseminadas, biopsia pulmonar y ganglionar con auramina rodamina y Xpert positivos. Discusión: Todos presentaron afección extrapulmonar de difícil diagnóstico, es útil el Xpert y las biopsias, los síntomas se enmascaran por la enfermedad de base. Conclusiones: El uso de biológicos y esteroides producen tuberculosis diseminada siendo de alta morbimortalidad, estos pacientes requieren quimioprofilaxis si se descarta tuberculosis activa.

\section{Síndrome de DRESS por tratamiento antituberculoso en pacientes con tuberculosis pulmonar, pleural y tuberculosis ganglionar}

Escobedo-Jaimes L, Rosas-Rendón AM, Iñarra-Hiriart $A$, Vázquez-Bautista MC, Villegas-

\section{Martínez LA, Cruz-Flores SP, González-González H, Ramírez-Casanova $E$}

Hospital General de México

Introducción: El síndrome de DRESS (del inglés Drug Reaction with Eosinophilia and Systemic Symptom), es una reacción adversa inducida por drogas, con una incidencia 1 en 10,000, es más frecuente a anticonvulsivantes, es raro a antituberculosos, se caracteriza por rash maculopapular pruriginoso con evolución a eritrodermia, descamación, fiebre, eosinofilia linfocitosis atípica, afectación visceral principalmente hígado. El tratamiento consiste en suspender el fármaco implicado y administrar corticoides. Presentación de casos: Caso (1): masculino de 52 años, con tuberculosis pulmonar y pleural, lavado bronquial (LB) con BAAR (+), Lowenstein (+). A $24 \mathrm{~h}$ de inicio de tratamiento con DOTBAL ${ }^{\circledR}$ presenta fiebre, ictericia, eritrodermia, prurito, edema facial, mucosas y genitales, descamación, hepatomegalia y transaminasemia. Caso (2): femenino de 19 años, con tuberculosis ganglionar y pulmonar, biopsia con linfadenitis granulomatosa, Lowenstein (+) en LB. A $48 \mathrm{~h}$ de inicio de tratamiento antituberculoso presenta eritrodermia, rash, transaminasemia. Caso (3): femenino de 47 años, con tuberculosis pulmonar, LB con BAAR (+), Lowenstein $(+)$, a la dosis 20 de antituberculosos presenta eritrodermia, edema palpebral y transaminasemia. Caso (4): femenino de 22 años con tuberculosis ganglionar, biopsia con inflamación crónica granulomatosa. A la dosis 22 de antituberculosos, presenta eritrodermia, fiebre, ictericia, hepatomegalia y transaminasemia. Discusión: Todos los pacientes eran HIV negativos, dos con antecedente de atopia. En estos pacientes era fundamental continuar con el tratamiento antituberculoso, a todos se les hizo prueba de reto para identificar el fármaco implicado y se les realizó desensibilización además de esteroides a dosis altas. Todos curaron de tuberculosis. Conclusiones: El síndrome de DRESS es una reacción a fár- macos severa, potencialmente fatal. El diagnóstico diferencial incluye eritema pigmentado fijo, eritema multiforme, dermatitis exfoliativa, erupción liquenoide, vasculitis, síndrome de StevensJohnson y necrólisis epidérmica tóxica. El reconocimiento rápido de estas reacciones es necesario para la suspensión inmediata de la droga implicada y así minimizar la morbimortalidad.

\section{Tuberculosis meníngea en pacientes con diabetes mellitus}

Escobedo-Jaimes L,
López-Ruiz M, Yescas-Sosa G,
Hernández-Romero J,
Iñarra-Hiriart A, Rosas-Rendón AM,
Velázquez-Fonseca LK,
Herrera-Arroyo A, Vázquez-Bautista
MC, González-González H,
Ramírez-Casanova E

Hospital General de México

Antecedentes: La tuberculosis meníngea es la forma más grave de la enfermedad. Tiene una incidencia en México del 1.6\%. El 21.2\% de los casos de tuberculosis se asocian con diabetes mellitus (DM), siendo un importante factor de riesgo para tuberculosis, produciendo presentaciones atípicas de la enfermedad y afectando la respuesta al tratamiento. Caso 1: femenino de 48 años, diabética, COMBE positivo. Presenta afección neurológica, RMN (resonancia magnética nuclear) con leptomeningitis, LCR (líquido cefalorraquídeo), ADA (adenosindesaminasa) $16.3 \mathrm{u} / \mathrm{L}$, Ziehl-Neelsen $(\mathrm{Z} / \mathrm{N})$ y Xpert negativo, Lowenstein positivo. RMN de columna con mal de Pott. Caso 2: masculino de 44 años, diabético, tuberculosis miliar, lavado bronquial Lowenstein positivo, afección neurológica, LCR ADA de 15.8, $\mathrm{Z} / \mathrm{N}$ negativo, Xpert y Lowenstein positivos. Caso 3: masculino de 40 años, combe positivo, tuberculosis miliar y pleural, afección neurológica, LCR con ADA 5.5, BAAR y Lowenstein negativos, RMN con múltiples tuber- 
culomas. Reporte de biopsia pleural inflamación crónica granulomatosa, ADA líquido pleural 111. Caso 4: masculino de 59 años, diabético, mieloma múltiple, deterioro neurológico, ADA 4.1, RMN y espectroscopia con absceso cerebral. Caso 5: femenina de 72 años con DM2, con hemiplejia izquierda, TAC con tumoración cerebral, se realiza biopsia reportando tuberculoma talámico, Ziehl-Neelsen positivo. Discusión: La DM se asocia con mayor riesgo de tuberculosis porque diversos aspectos de la inmunidad están alterados. El diagnóstico de la tuberculosis meníngea es un reto médico. El Lowenstein-Jensen es el estándar de oro, pero tiene poca sensibilidad, son de gran utilidad en el LCR el Xpert, ADA y los estudios de imagen. Conclusiones: La tuberculosis meníngea debe ser sospechada en pacientes diabéticos que cursen con meningitis. La tuberculosis tiene alta prevalencia en nuestro medio, por lo que se debe considerar a los diabéticos como un grupo vulnerable por su estado de inmunosupresión, el diagnóstico tiene que ser oportuno para evitar la morbimortalidad.

\section{Tuberculosis de mama diagnóstico diferencial obligado de procesos neoplásicos}

\section{Escobedo-Jaimes L, Iñarra-Hiriart $A$, Rosas-Rendón AM, Velázquez- Fonseca LK, Ríos-Rodríguez N, Tenorio-Flores E, Vázquez-Bautista MC, González-González H, Ramírez-Casanova E}

Hospital General de México

Introducción: La tuberculosis de glándula mamaria es una localización rara de tuberculosis extrapulmonar, siendo el 0.1 a $0.5 \%$ de todos los casos. El origen puede ser primario o secundario a foco tuberculoso con diseminación hematógena o linfática. Se manifiesta como un tumor e inflamación, generalmente en cuadrantes inferiores de la mama. Existen tres variedades clínicas: nodular, diseminada y esclerosante. El diagnóstico es por biopsia, fundamentado en inflamación crónica granulomatosa, Ziehl-Neelsen (ZN) Lowenstein, PCR y se confirma con la respuesta al tratamiento antituberculoso. Serie de casos: Caso (1): femenino 39 años de edad, VIH (-), con tumoración en mama izquierda, mastografía con BIRADS 3, biopsia con mastitis crónica granulomatosa, PAS, ZN y Grocott negativas. Caso (2): femenino 39 años VIH (-), con dos tumoraciones en mama izquierda dolor y eritema, biopsia con mastitis crónica granulomatosa, mastografía BIRADS 2, ZN negativo. Caso (3): femenino 35 años, VIH (+), con tumoración en región axilar derecha y mama derecha, dolorosa, mastografía BIRADS 2, biopsia con mastitis crónica granulomatosa, ZN negativo. Caso (4): femenina 59 años, VIH (-), lupus eritematoso sistémico y enfermedad de Chagas, con adenopatías cervicales, supraclaviculares, axilares y en mama izquierda, biopsia con mastitis crónica granulomatosa, ZN (+), Gene Xpert (+), mastografía BIRADS 4. Caso (5): femenina 34 años VIH (-), con tumoración en mama derecha, biopsia con mastitis crónica granulomatosa, PCR (-), ZN (-), mastografía BIRADS 3. Discusión y conclusiones: Sólo dos pacientes tenían inmunocompromiso. La tuberculosis mamaria es un tipo de mastitis crónica secundaria a proceso inflamatorio granulomatoso, su diagnóstico es difícil, ya que puede ser confundida tanto por la clínica como por hallazgos en imagen con procesos neoplásicos y otras lesiones granulomatosas con necesidad de realizar biopsia, biología molecular, tinciones y cultivos especiales para el diagnóstico diferencial. Todas las pacientes recibieron Dot $\mathrm{Bal}^{\circledR}$ y curaron con el tratamiento.

\section{Tuberculosis}

musculoesquelética

en pacientes HIV

negativos

Escobedo-Jaimes L,

Hernández-Romero J, Iñarra-Hiriart A,
Rosas-Rendón AM, Peláez-González HE, Velázquez-Fonseca LK, Vázquez-Bautista MC, GonzálezGonzález H, Ramírez-Casanova E

Hospital General de México

Introducción: La afección del sistema musculoesquelético por tuberculosis representa menos del $1 \%$ de los casos, ocurre por vía hematógena y por contigüidad, son necesarios estudios de imagen y biopsias para su diagnóstico. Los sitios más afectados son la columna, cadera y rodilla. Caso 1: femenino de 51 años con tumoración supraclavicular derecha TAC destrucción de la articulación esternoclavicular, biopsia con BAAR positivo. Caso 2: femenino de 47 años de edad, con tuberculosis pulmonar con BAAR y cultivo positivos, destrucción de cadera derecha, pérdida del acetábulo, fístula con drenaje purulento con BAAR y Xpert positivos. Caso 3: masculino de 34 años, con mal de Pott RMN detectando destrucción ósea, espondilodiscitis, deformidad de rodilla derecha con ADA (adenosindesaminasa) 76.9. Caso 4: masculino de 24 años, con tuberculosis pulmonar, con absceso y fístula en hombro derecho RNM con destrucción de articulación glenohumeral derecha, Lowenstein positivo. Caso 5: femenino de 42 años, absceso en codo izquierdo y osteomielitis en clavícula izquierda con fístula drenaje purulento con cultivo Lowenstein y biopsia positivos. Caso 6: masculino de 32 años, con tuberculosis pleural PCR positivo y lesiones cutáneas en tórax región submamaria bilateral $1 \mathrm{~cm}$ con material purulento, lesión escrofulosa en región torácica lateral derecha, absceso en mesogastrio en tejido subcutáneo de 4 x $6 \mathrm{~cm}$ con biopsia, BAAR y Lowenstein positivos. Discusión: Cualquier hueso, bursa o articulación pueden ser afectados por tuberculosis, estos pacientes presentaron en hombro, clavícula, codo y tejido subcutáneo que son presentaciones muy raras, como antecedente importante encontramos uso de drogas y alcohol. Todos los pacientes curaron con el tratamiento. Conclusiones: La tuberculosis tiene innumerables presentaciones en nues- 
tro entorno clínico y sigue siendo un diagnóstico diferencial fundamental. Este tipo de presentación clínica cursa con pocos bacilos dificultando su diagnóstico, son primordiales los hallazgos en la biopsia, ADA, cultivos y biología molecular.

\section{Pericarditis tuberculosa en pacientes con tuberculosis miliar}

\section{Escobedo-Jaimes L, Gordillo-Mena J, Trejo-Osornio D, Aguilar-Maciel S, Iñarra-Hiriart A, Rosas-Rendón AM, Velázquez-Fonseca $L K$, \\ Peláez-González HE, Vargas-Abrego $B$, Fierro-Chávez EM, Vázquez-Bautista $M C$, González-González H, Ramírez-Casanova E, Heredia-Arroyo $A$}

Hospital General de México

Introducción: La pericarditis por tuberculosis corresponde al $1 \%$ de todos los casos de tuberculosis. Se presenta por diseminación linfática o hematógena de una infección tuberculosa primaria. Tiene cuatro estadíos: exudado fibrinoso, derrame serosanguinolento, absorción del derrame con organización caseificación granulomatosa y cicatrización constrictiva. El diagnóstico se basa en determinación de ADA mayor de 30, Lowenstein, BAAR, biopsias y biología molecular. Presentación de casos: Masculino 32 años, VIH (-), enfermedad renal crónica (ERC) en hemodiálisis, tuberculosis miliar (TBM); tomografía computarizada (TAC) con derrame pleural, derrame pericárdico, pericardiocentesis con ADA 38, Xpert (+). Femenino 24 años con lupus, dermatopolimiositis, tratada con metilprednisolona/ciclofosfamida, crisis convulsivas, ADA (adenosindesaminasa) de LCR 12, TAC derrame pericárdico, pericardiocentesis con ADA 38 U/L, RMN con tuberculomas. Masculino 26 años, ERC en hemodiálisis, con TBM, TAC con derrame pleural unilateral y derrame pericárdico; pericardiocentesis con BAAR (+).
Masculino de 18 años, VIH (+), con TBM, lavado bronquial BAAR y Xpert $(+)$, Lowenstein $(+)$, pericardiocentesis con ADA de 138 U/L, Lowenstein (+). Femenino 56 años, con diabetes mellitus, ecocardiograma con derrame pericárdico de $3,000 \mathrm{~cm}^{3}$, TAC con derrame pleural. Pericardiocentesis con ADA de 48. Biopsia pleural con pleuritis aguda y crónica. Femenino de 55 años con ERC, diabética, derrame pericárdico, pericardiocentesis ADA 49.8, biopsia pericarditis por TB. Discusión: Todos tenían inmunocompromiso, cuatro pacientes con TBM, a todos se les realizó pericardiocentesis para el diagnóstico. A pesar del inicio del tratamiento fallecieron tres pacientes debido a la diseminación de la tuberculosis, a las comorbilidades y al diagnóstico tardío. Conclusión: La principal causa de pericarditis en países subdesarrollados es por tuberculosis. Se debe sospechar en pacientes de riesgo. Se presenta como derrame pericárdico, pericarditis constrictiva o ambos, se asocia con derrame pleural y TBM. El diagnóstico y tratamiento oportuno, con antituberculosos y esteroides son primordiales para prevenir el taponamiento cardíaco o la pericarditis constrictiva.

\section{Tuberculosis suprarrenal en pacientes sin hiperpigmentación con tuberculosis miliar y renal}

\section{Escobedo-Jaimes L, Moreira-Meyer A, López-Ruiz M, Iñarra-Hiriart A, Rosas-Rendón AM, Velázquez- Fonseca LK, Vázquez-Bautista MC, González-González H, Ramírez-Casanova $E$ \\ Hospital General de México}

Introducción: La causa más frecuente de la insuficiencia suprarrenal primaria es la tuberculosis (TB) se debe a diseminación linfohematógena, se relaciona con TB pulmonar y genitourinaria. Es necesaria una destrucción del
90\% de la glándula para que ocurran las manifestaciones clínicas, hiperpigmentación, hipotensión, alteraciones electrolíticas. Serie de casos: Femenino de 25 años, COMBE positivo madre con tuberculosis pulmonar. Presenta deterioro neurológico, con tuberculosis meníngea, ADA 21 y Lowenstein positivo, sodio 124 , cortisol urinario 58, ultrasonido y TAC de abdomen con crecimiento de suprarrenales, hepatoesplenomegalia, adenomegalias en páncreas, paraaórticas, pericavales, conglomerado retroperitoneal, biopsia positiva para TB. Masculino de 27 años, VIH positivo, con TB miliar y ganglionar diseminada. TAC toracoabdominal-pélvica con patrón micronodular pulmonar, infiltración en glándulas suprarrenal, derrame pleural, adenomegalias mediastinales necróticas y retroperitoneales con biopsia positiva para TB. Masculino de 55 años, con EPOC, en tres ocasiones presenta estado de choque requiriendo marcapaso por bloqueo completo por hipercalemia, hiponatremia de 109 у АCТH 353, cortisol 4.89 TAC toracoabdominal con calcificaciones en suprarrenales, TB renal con cultivo de Lowenstein positivo en orina. Discusión: La hiperpigmentación se encuentra en el 94\%; sin embargo, estos pacientes no presentaban hiperpigmentación, pero tenían alteraciones clínicas y electrolíticas que hicieron sospechar insuficiencia suprarrenal, documentándose TB en otros sitios. Conclusiones: La biopsia de glándula suprarrenal no es necesaria en un paciente que ya se documentó TB en otro sitio. Es suficiente los hallazgos en TAC con crecimiento difuso adrenal en la forma activa y en la forma crónica atrofia y calcificaciones. El diagnóstico se confirma por cortisol sérico bajo y ACTH alta. Cuando la TB afecta las glándulas suprarrenales, el tratamiento antituberculoso no restaura la función adrenal, es necesario agregar esteroides. La TB suprarrenal es una enfermedad de difícil diagnóstico, es necesario tener alta sospecha en los pacientes con hiperpigmentación y tendencia a la hipotensión. 


\section{Enfermedades neoplásicas asociadas a diferentes formas de tuberculosis}

\section{Escobedo-Jaimes L, Saavedra-De Rosas I, Casillas-Suárez C, Luna-Rojas $C$, Iñarra-Hiriart $A$, Rosas-Rendón AM, Velázquez- Fonseca LK, Peláez-González HE, Vázquez-Bautista MC, González- González H, Ramírez-Casanova E}

Hospital General de México

Introducción: La coexistencia de cáncer y tuberculosis (TB) se observa con mayor frecuencia. Son problemas de salud pública que conllevan alta morbimortalidad. Un tercio de la población mundial cursa con TB latente y al padecer cáncer ocurre deterioro de la inmunidad debido a los efectos locales o sistémicos del tumor o al tratamiento administrado (quimioterapia, radioterapia), produciendo reactivación o adquisición de la TB. Serie de casos: Masculino de 29 años, fiebre, pérdida de peso, reacción leucemoide, múltiples adenopatías cervicales, inguinales, biopsia con TB ganglionar, Ziehl-Neelsen (ZN) y Lowenstein positivos, además, linfoma Hodgkin (LH). Femenino de 70 años operada por TB ósea que durante la cirugía se reseca nódulo pulmonar con reporte de adenocarcinoma. Femenino de 61 años con historia de cáncer de mama (CAM), carcinoma papilar de tiroides, con LH, PET de control con hipercaptación en endometrio, la biopsia reporta TB de endometrio. Femenino 71 años, antecedente de tabaquismo, resección de nódulo pulmonar con reporte de tumor carcinoide y TB pulmonar con ZN y auramina-rodamina positivos. Femenino de 32 años, antecedente de CAM, con tumoración en lóbulo superior derecho, sometida a lobectomía con reporte de TB pulmonar y cáncer broncogénico epidermoide. Masculino de 14 años disminución de $20 \mathrm{~kg}$, fiebre, TAC masa abdominal de $15 \mathrm{~cm}$, biopsia de ganglio inguinal reportando LH y TB ganglionar con auramina-rodamina po- sitiva. Masculino de 59 años, diabético, con mieloma múltiple, deterioro neurológico, RMN y espectroscopia con absceso cerebral por TB. Discusión: Ningún paciente fue combe positivo, tres pacientes tenían diagnóstico de cáncer previamente, cuatro pacientes se diagnosticaron de forma simultánea de cáncer y TB. Todos curaron de TB. Conclusión: El carácter inmunosupresor del tratamiento del cáncer facilita la adquisición de TB. La ocurrencia simultánea de TB y cáncer provoca un dilema diagnóstico, ya que los síntomas de ambas enfermedades dificultan el diagnóstico y el tratamiento.

\section{Tuberculosis espinal «mal de Pott» causa frecuente de paraplejia no traumática y su asociación con tuberculosis en otros sitios. Utilidad de la resonancia magnética para su diagnóstico}

\section{Escobedo-Jaimes L, López-Ruiz M, Vargas-Abrego $B$, Méndez-Viveros A, Camarillo-Juárez $F$, Amezcua-Herrera $C$, Velázquez-Fonseca $L K$, \\ Iñarra-Hiriart $A$, Rosas-Rendón AM, Vázquez-Bautista MC Ramírez-Casanova E}

Hospital General de México

Introducción: La tuberculosis (TB) ósea representa $1-3 \%$ de las formas extrapulmonares, se debe a diseminación hematógena o linfática al hueso, proveniente de otra región con TB. La espondilodiscitis por TB es una combinación de abscesos, osteomielitis y discitis que compromete al disco y cuerpo vertebral, tejidos adyacentes, meninges, médula espinal y raíces nerviosas. Objetivos: 1. Establecer flujograma diagnóstico para tratamiento oportuno; 2. determinar su asociación con otros tipos de TB; 3. determinar la utilidad de la resonancia magnética (RMN); 4. establecer el drenaje del absceso para el diagnóstico y mejor evolución. Métodos: Estudio de casos consecutivos del 2103-2015. Criterios de inclusión: dolor torácico o lumbar, parestesias, absceso paravertebral, espondilodiscitis, destrucción ósea, fiebre, pérdida de peso. Resultados: Se estudiaron 35 pacientes, $62.8 \%$ hombres, $37.2 \%$ mujeres, de 18 a 70 años, con una media de 42 . El 50\% pérdida de peso, $32.1 \%$ fiebre. El $75 \%$ lumbalgia, $53.5 \%$ pérdida de fuerza en miembros pélvicos, paraparesia $89.2 \%$, paraplejia $35.7 \%$. En RMN absceso paravertebral el $71.4 \%$, espondilodiscitis $64.2 \%$, destrucción ósea $50 \%$. Se operó $50 \%$, drenaje de abscesos y toma de biopsia $46.4 \%$, malla $13.5 \%$, autoinjerto $10.7 \%$. Factores asociados: diabetes $21.4 \%, 10.7 \%$ enfermedad reumática, $7.1 \%$ HIV, cáncer (próstata y pulmón) $7.1 \%$, tabaquismo $25 \%$, alcoholismo $35.7 \%$, drogas $7.1 \%$. TB en otros sitios: TB miliar $28.5 \%$, meníngea $20 \%$, TB renal $14.2 \%$, TB ganglionar $10.7 \%$, TB pleural $7.1 \%$. Recibieron tratamiento un año con Dot $\mathrm{Bal}^{\circledast}$. Conclusiones: La TB espinal es causa frecuente de déficit neurológico, se asocia con TB en otros sitios, lo que contribuye al diagnóstico. La población estudiada tiene un alto porcentaje de factores de riesgo debido a la transición epidemiológica que está ocurriendo en las grandes ciudades, las enfermedades crónico-degenerativas y las toxicomanías son determinantes. La RMN es el método de elección para el diagnóstico de la localización y extensión del proceso.

¿Es útil la prueba de GeneXpert en pacientes con diagnóstico de derrame pleural por tuberculosis?

Ruiz F, Carrillo G, Alonso D, Suárez T, Jaime T, Alvear G, Valencia J, Salazar MÁ

INER Ismael Cosío Villegas 
Introducción: El diagnóstico de tuberculosis pulmonar y extra pulmonar en ocasiones requiere pruebas de laboratorio particulares. Actualmente se utiliza el ensayo del GeneXpert, que identifica al bacilo de la tuberculosis y resistencia a la rifampicina (RMP), prueba automatizada de una reacción en cadena de la polimerasa en tiempo real (RT-PCR) que amplifica el ácido nucleico en 2-3 h, detecta 81 pares de bases del gene rpoB. Sin embargo, no existen datos contundentes del beneficio de la prueba en pacientes con derrame pleural de tipo exudado linfocítico por tuberculosis. Objetivo: Determinar la sensibilidad de la prueba GeneXpert en derrame pleural de tipo exudado linfocítico por tuberculosis. Material y métodos: 24 pacientes con derrame pleural fueron estudiados en el INER, se estableció el diagnóstico de tuberculosis pleural en 10 paciente por biopsia pleural, 10 pacientes con baciloscopia en expectoración y cuatro pacientes con tratamiento y seguidos al mes con mejoría, el estudio del líquido pleural fue exudado linfocítico con ADA mayor a 34 U. Se les realizó la prueba GeneXpert en muestras de líquido pleural y se analizó la sensibilidad de la misma. Resultados: Los 24 pacientes con criterios de exudado linfocítico y mediana de la adenosindesaminasa (ADA) de 48 U (34-73), con diagnóstico confirmado de tuberculosis pleural mostraron la prueba GeneXpert negativa.

\section{Síndrome de Down y tuberculosis miliar}

\section{Escobedo-Jaimes L, Rosas-Rendón $A M$, Iñarra-Hiriart $A$, Velázquez- Fonseca LK, Peláez-González HE, Vázquez-Bautista MC, Niezen-Lugo SF, Esquerra-Alvarado PS, Baley- Amiga I, González-González H,} Ramírez-Casanova E

Hospital General de México

Introducción: El síndrome de Down es la anormalidad cromosómica más frecuente, se presenta en 1 de 800 nacidos vivos. El $40 \%$ tiene alguna malformación cardíaca congénita, como la tetralogía de Fallot (comunicación interventricular, destraposición de la aorta, hipertrofia ventricular derecha, estenosis pulmonar). Cursan con anomalías inmunológicas, el $90 \%$ tiene cifras disminuidas de linfocitos $\mathrm{T}$ y B que los predisponen a procesos infecciosos, entre ellos y poco descrito en estos pacientes la tuberculosis miliar, que ocurre por diseminación linfohematógena. Caso 1: masculino de 18 años, Combe negativo, con síndrome de Down, antecedente de cirugía por tetralogía de Fallot, HIV negativo, reciente diagnóstico de epilepsia tratada con anticonvulsivantes, cursa con fiebre, tos, expectoración, crecimiento ganglionar cervical bilateral, pérdida de $9 \mathrm{~kg}$, radiografía de tórax con infiltrado miliar, tomografía (TAC) caverna apical, múltiples adenopatías cervicales, paratraqueales, abdominales, lavado bronquial con Ziehl-Neelsen (ZN) y Lowenstein positivo. Resonancia magnética ( $\mathrm{RMN})$ de cráneo con tuberculomas y leptomeningitis. Caso 2: masculino de 32 años, con síndrome de Down, Combe negativo, HIV negativo, con antecedente de tuberculosis a los cuatro años con tratamiento por un año con curación. Con padecimiento actual de un mes con tos, expectoración, fiebre, pérdida de peso, radiografía de tórax con infiltrado miliar y derrame pleural con ADA (adenosindesaminasa) de 100 , lavado bronquial $\mathrm{ZN}$ y Lowenstein negativo. Discusión y conclusiones: Los pacientes recibieron tratamiento antituberculoso un año y curaron. Tenían tuberculosis miliar con alta morbimortalidad y de difícil diagnóstico, $25 \%$ pueden tener diseminación meníngea, $70 \%$ tienen ZN y Lowenstein negativos en expectoración, se pueden encontrar sitios extrapulmonares afectados. Son útiles para el diagnóstico el ZN, Lowenstein, biología molecular y biopsias. Debido a las anormalidades inmunológicas que tienen estos pacientes, deben de ser considerados un grupo de riesgo para desarrollar tuberculosis, son candidatos a quimioprofilaxis con isoniacida como prevención, si se les descarta tuberculosis activa.
Frecuencia de genes de resistencia por el método de genotipificación (HAIN) a fármacos antituberculosis de primera línea en el Instituto Nacional de Enfermedades Respiratorias en el período 2010-2014 y su asociación con la severidad en la presentación radiológica

\section{Núñez LBA, Martínez OJA, Salazar LMÁ, Juárez HF, Narváez DLA, Mireles DChD}

INER Ismael Cosío Villegas

Antecedentes: La tuberculosis continúa siendo el principal problema de salud pública a nivel global. En México la TB es endémica. La propagación de TB MDR y TB XDR amenaza los esfuerzos mundiales para controlar la TB. Objetivos: Conocer la frecuencia de genes de resistencia a isoniacida, rifampicina, etambutol y estreptomicina por el método de genotipificación HAIN de las muestras obtenidas en el período 20102014. Métodos: Se obtuvo la frecuencia a los diferentes genes de resistencia a fármacos antituberculosos de primera línea. Se correlacionó la frecuencia de genes de resistencia a fármacos con los hallazgos radiológicos. Resultados: Se analizaron 332 cepas de MTb con resistencia a fármacos de primera línea. La genotipificación se realizó utilizando Genotype MTBDRplus y MTBDR SL. Encontrando resistencia a rifampicina mediante el gen rpoB se genotipificó 52 muestras, las más frecuentes asociadas fueron: ausencia de WT (Wild Type) 7; 16 (4.8\%), ausencia de WT 8; 30 (9\%). La resistencia a isoniazida mediante los genes katG e inhA en 52 muestras, encontrando: ausencia WT katG; 7 (2.1\%) MUT (mutación) katG1; 7 (2.1\%) 
ausencia WT1 inhA; 10 (3\%), ausencia WT2 inhA; 24 (7.2\%), las mutaciones en katG e inhA en cinco muestras (1.5\%). Etambutol por genotipificación en 32 muestras encontrando ausencia de WT emb1; 16 (4.1\%) MUT emb1b; 2 (0.6\%). Estreptomicina se realizaron 33 pruebas para genotipificación presentaron ausencia de WT rrs1; 10 (3\%) y ausencia de WT rrs2 7 (2.1\%). En imágenes tomográficas no se encontró asociación estadísticamente significativa entre los genes de resistencia y los patrones tomográficos; sin embargo, predominaron cavidades múltiples (68\%), lesión nodular múltiple $(62.5 \%)$ y árbol en gemación (25\%). Conclusiones: Es el primer estudio reportado en México de genes de resistencia $\mathrm{MTb}$ por el método de genotipificación. En el futuro se debe valorar al impacto de la genómica en la atención clínica, auxiliares de diagnóstico y tratamiento del paciente.

\section{Reporte de un caso concomitante de tuberculosis pulmonar ATS III-linfangioleiomiomatosis}

\section{Escobedo JL, Saavedra de RSI, Peláez GHE, Velázquez FLK, Ramírez CME}

Hospital General de México

Introducción: La tuberculosis en México es un problema de salud pública, al año se registran 15 mil casos nuevos y 2,000 defunciones, esta enfermedad se adquiere por la inhalación de secreciones respiratorias que contienen algún microorganismo del complejo Mycobacterium tuberculosis. Los casos de tuberculosis frecuentemente son el resultado de una infección oportunista en pacientes que tienen los mecanismos inmunitarios comprometidos, entre la población vulnerable son los niños y adultos mayores, padecer enfermedades crónicas como diabetes mellitus e insuficiencia renal, VIH, tratamiento prolongado con esteroides, y quimioterapia. Descripción del caso: Femenino de 42 años de edad con exposición a humo de leña 120 h/año, Combe positivo, diabetes mellitus 2 , acidosis tubular renal tipo II, cuadro clínico caracterizado por tos productiva, fiebre, diaforesis y pérdida de peso, BAAR de expectoración positivo, se inició tratamiento antituberculoso prolongándose un año por sospecha de tuberculosis miliar, durante el seguimiento la paciente cursa con disnea MMRC2, se hospitaliza y se realiza nueva tomografía observándose lesiones micro nodulares de localización centrolobulillar y quistes dispersos, biopsia de pulmón con proliferación focal de músculo liso que se hace evidente con tinción tricrómica de Masson, compatible con linfangioleiomiomatosis. Espirometría sugerente de restricción leve, DLCO. Restricción moderada. Caminata de seis minutos. Distancia recorrida 391 metros. Ecocardiograma: PSAP. $35 \mathrm{mmHg}$. Ultrasonido de útero y anexos con leiomiomas. Conclusión: La paciente presenta factores de riesgo para tuberculosis y durante el seguimiento se realizó tomografía de alta resolución, la cual permitió descartar el diagnóstico diferencial confirmado por biopsia de una enfermedad rara linfangioleiomiomatosis; por lo tanto, se correlaciona lo referido en la literatura, la tuberculosis debería ser considerada como una posibilidad diagnóstica en pacientes con diabetes mellitus 2 , y si se encuentra disponible se debería efectuar estudios de imagen como tomografía de alta resolución.

\section{Tumores}

\section{Carcinoma} adenoescamoso de pulmón. Presentación de

Ríos MÁ, * Vargas MÁD, ${ }^{\ddagger}$ García RJR

*Universidad de Guanajuato; ${ }^{*}$ Hospital General Regional de León

Introducción: El carcinoma adenoescamoso de pulmón es una variable histopatológica rara que muestra los componentes, tanto del carcinoma de células escamosas como del adenocarcinoma con cada uno en al menos $10 \%$ del tumor, tiene una frecuencia entre $0.4-4 \%$ entre los carcinomas de pulmón. Se encuentran comúnmente en hombres, en la séptima década de la vida y con historial de tabaquismo. Presentación del caso: Masculino de 23 años, sin antecedentes de importancia, inició su padecimiento ocho meses previos con dolor sordo en hombro izquierdo que aumento de intensidad paulatinamente, un mes antes presentó tos productiva. En interrogatorio refirió disnea progresiva, fiebre de predominio nocturno, pérdida de peso de $6 \mathrm{~kg}$ en un mes, niega toxicomanías. Exploración física se encontró síndrome de Horner completo. La TAC de tórax reportó una masa en la región apical pulmonar izquierda. Se realizó toracocentesis que no se reportó evidencia de células malignas. Posteriormente se realizó biopsia guiada por TAC, el resultado del estudio histopatológico reportó el diagnóstico de carcinoma adenoescamoso poco diferenciado infiltrante. El paciente evolucionó sin mostrar mejoría, fallece 27 días después de su ingreso. Discusión: El paciente se encontraba en la segunda década de la vida, mostrando así una aparición temprana de esta neoplasia además de no contar con un historial de tabaquismo, el cual es un factor de riesgo importante en las neoplasias pulmonares. Debido a la localización del tumor en el vértice pulmonar la clínica mostró un Horner completo. El estudio histopatológico reportó la presencia tanto del carcinoma de células escamosas como del adenocarcinoma. Conclusión: Dentro de las extirpes de carcinoma de pulmón, el carcinoma adenoescamoso es una entidad además de rara poco frecuente a edades tempranas. La complejidad del diagnóstico se fundamentó en el cuadro clínico; el diagnóstico histopatológico es fundamental para el diagnóstico, clasificación y posible tratamiento.

\section{Linfoma no Hodgkin de}




\section{pared torácica. Reporte de un caso}

Estrella SJA, ${ }^{*}$ González LR, ${ }^{\neq}$ Rodríguez LMP¥

${ }^{*}$ Centro Médico Puerta de Hierro, Colima; ‡Hospital Civil Antiguo de Guadalajara

Masculino de 31 años, inició hace un año con tumoración costal de 1-2 $\mathrm{cm}$ en pared anterior de tórax, lado derecho, en topografía de pectoral, asintomática; hace dos meses presentó aumento de tamaño importante, con dolor intenso, mejoría parcial con analgésicos comunes, exploración con tumoración de 15 x $10 \mathrm{~cm}$, llegando a región paraesternal derecha, bordes irregulares, lobulada, adherida a planos profundos, consistencia pétrea, zonas con coloración violácea de piel, acudió a valoración médica donde se solicita radiografía de tórax, ultrasonido de pared y tomografía de tórax, reportándose tumoración de pared costal, con infiltración a mediastino anterior, se realiza biopsia incisional y el estudio de patología reporta linfoma difuso de células grandes. Se envió paciente a valoración y manejo por hemato/oncología. El linfoma que se presenta como una masa única de pared torácica no es frecuente, se han reportado sólo pocos casos en la literatura, comprende el $2 \%$ de todos los tumores de pared torácica y en la mayoría es extensión de enfermedad mediastinal, enfermedad nodal de la cadena mamaria interna es lo más común, pero también puede diseminar del nodo axilar o subclavio. Un estudio de 324 pacientes con linfoma en estadío 1 y 2 , refiere 22 pacientes $(6.7 \%)$ con invasión de la pared torácica; Press et al. refieren estudio donde 4 de 250 pacientes con linfoma tienen pared torácica como único sitio afectado (1.6\%). El linfoma primario de la pared torácica como tumor aislado no es común; la biopsia tiene una ventaja importante sobre la punción aspiración con aguja fina ya esta última tiene alto índice de falsos negativos, se sugiere que a tumores pequeños se les realice biopsia excisional y a tumores grandes, biopsia incisional; la quimiorradioterapia es el manejo principal de estos tumores. La resección quirúrgica seguida de quimioterapia se considera subóptima, pero puede contemplarse en situaciones inusuales.

\section{Adenocarcinoma de pulmón simulando enfermedad pulmonar intersticial en mujer de 59 años}

\section{Alemán MÁ, California $R C$}

\section{IMSS}

Introducción: Cáncer de pulmón, primera causa de muerte por cáncer en el occidente y principal causa de mortalidad por cáncer en México. $\mathrm{Su}$ incidencia está relacionada con tabaquismo en el $10 \%$ de los fumadores, desarrollándose en el $10-15 \%$ de pacientes no fumadores. Ocasionalmente el adenocarcinoma pulmonar tiene presentación histológica con predominio de inflamación y fibrosis, siendo difícil diferenciarlo de enfermedad pulmonar intersticial difusa (EPID). Presentación del caso: Mujer de 59 años de edad, sin antecedentes de cáncer, tabaquismo y exposición al humo de leña, padecimiento de seis meses de evolución con tos no productiva, fiebre ocasional, disnea en reposo, agregándose pérdida ponderal de $5 \mathrm{~kg}$ y esputo purulento, recibiendo tratamiento con antibióticos, esteroides y broncodilatadores, al no presentar mejoría es referida al IMSS. Orointubada e ingresada en la UCIR, presenta ruido respiratorio disminuido bilateral, estertores crepitantes bilaterales, hipoxemia grave, $\mathrm{FiO}_{2} 40 \%$, radiografía de tórax con patrón reticulonodular difuso bibasal, TACAR con patrón reticular, engrosamiento septal, áreas de consolidación en parches en lóbulos inferiores, se realiza biopsia reportando adenocarcinoma pulmonar bien diferenciado predominantemente lepídico. Discusión: El adenocarcinoma lepídico, subtipo de adenocarcinoma poco frecuente, representa el $4 \%$ de los cánceres de células no pequeñas, puede manifestarse como EPID en la radiografía de tórax, que pueden imitar etiologías infecciosas. Su presentación puede ser confundida con neumonía y; sólo después de que un paciente no mejora con antibióticos o esteroides se puede pensar en adenocarcinoma pulmonar. Conclusión: El adenocarcinoma de pulmón debe mantenerse en el diagnóstico diferencial en paciente con EPID con distorsión de la arquitectura si no responde a esteroides y antibióticos. Este caso pone de manifiesto las dificultades en el diagnóstico de adenocarcinoma pulmonar en presencia de inflamación y fibrosis y refuerza la importancia del diagnóstico tisular en pacientes con EPID.

\section{Micropartículas circulantes como biomarcadores de respuesta a tratamiento en cáncer pulmonar}

\section{Arroyo M, Rodríguez CJ, Sada OI}

INER Ismael Cosío Villegas

Actualmente, el tratamiento más efectivo y utilizado para tratar el cáncer pulmonar es la quimioterapia (QT), respondiendo sólo el $40 \%$ de los pacientes. La primera valoración de respuesta se realiza tres meses después del inicio del tratamiento, por lo que se puede concluir que el $60 \%$ de los pacientes recibieron una QT poco útil durante este tiempo y es aún más relevante si se considera que en México $85 \%$ de los pacientes con cáncer pulmonar se encuentran en estadío avanzado de la enfermedad al momento de la detección. ¿Podemos predecir qué pacientes están respondiendo a la QT antes de los tres meses? Las células eucariotas sujetas a alteraciones físicoquímicas, estimulación isquémica, transformación neoplásica o apoptosis liberan al espacio extracelular fragmentos de su membrana, llamadas microvesículas. Estas estructuras se encuentran presentes en neoplasia y su 
medición podría ser un biomarcador de respuesta a tratamiento. Metodología: El trabajo se llevó a cabo en el Laboratorio de Inmunología Integrativa del INER. Se obtuvieron micropartículas circulantes de muestras de sangre periférica de 10 pacientes con diagnóstico de carcinoma de células no pequeñas EC IV. El muestreo se realizó previo al inicio de la QT al segundo ciclo y al finalizar el tratamiento. Resultados: Se identificaron marcadores circulantes en sangre periférica de pacientes con diagnóstico de cáncer pulmonar; sin embargo, no se pudo realizar una correlación directa entre el número de micropartículas y la respuesta al tratamiento. Conclusiones: Los resultados del estudio demuestran que la medición de micropartículas puede ser un biomarcador útil que represente la respuesta al tratamiento de forma temprana y considerarse un factor predictivo de la enfermedad que permita decidir si se continúa con el mismo tratamiento o se redirija el manejo. No obstante, se requiere una muestra representativa que permita extrapolar los resultados obtenidos a una población mayor y reforzar la validez del estudio.

\section{Obstrucción maligna traqueobronquial, eficacia diagnóstica de la broncoscopia en un hospital de tercer nivel}

\section{Moreira A, * Núñez PRC, ${ }^{\star *}$ Cicero SR ${ }^{\star *}$}

*Hospital General de México; łFacultad de Medicina, UNAM

Antecedentes: La obstrucción maligna traqueobronquial puede ser: endoluminal, extraluminal o mixta. El cáncer pulmonar epidermoide es la principal causa de obstrucción de origen neoplásico. La broncoscopia flexible o rígida permite una visión directa del tumor para evaluar el grado de estrechamiento de la luz traqueal y bronquial, la extensión y la distancia con respecto a la carina principal para la estadificación del cáncer; además, permite tomar

muestras para estudio citopatológico con una eficacia diagnóstica de $85 \%$. Justificación: El cáncer pulmonar es la primera causa de muerte por cáncer a nivel mundial, con una mortalidad anual de 1.59 millones. Del 20 a 30\% de los pacientes con cáncer pulmonar presentan obstrucción traqueobronquial. Objetivos: Determinar la eficacia diagnóstica de la broncoscopia en obstrucción maligna traqueobronquial. Material y métodos: Estudio observacional, descriptivo, prospectivo en pacientes a quienes se realizó broncoscopia por diversas indicaciones, con evidencia de obstrucción maligna traqueobronquial de tipo endoluminal por tumor exclusivamente. De marzo a octubre de 2015. Resultados: Se estudiaron 40 pacientes, en 35 se obtuvo diagnóstico definitivo y en cinco casos sólo hallazgos inespecíficos por pérdida en el seguimiento. De los 35 casos en 23 se obtuvo el diagnóstico por fibrobroncoscopia. Los diagnósticos histopatológicos fueron: adenocarcinoma pulmonar (13 casos, 32\%), carcinoma epidermoide pulmonar (8 casos, 20\%), carcinoma metastásico (4 casos, 10\%), tumor benigno (3 casos, 7\%). El sitio anatómico más afectado fue el lóbulo superior derecho (11 casos, 27.5\%). El grado de obstrucción promedio fue $90 \%$ del bronquio afectado. Discusión y conclusiones: La broncoscopia fue diagnóstica en el $57 \%$ de los casos (23/40) para malignidad, con una sensibilidad de $63.6 \%$, y una especificidad de $71.4 \%$, valor predictivo positivo alto de $91.3 \%$ y un valor predictivo negativo de $29.4 \%$. Con un índice kappa de concordancia débil de 0.22 . La principal causa de obstrucción fue el adenocarcinoma (32\%).

\section{Linfoma primario de pleura: a propósito de un caso}

Morett $F,{ }^{*}$ Ibarra $R,{ }^{\star}$ Sánchez $F,{ }^{*}$ Hernández $D,{ }^{*}$ Contreras $F,{ }^{*}$ Plascencia $T,{ }^{*}$ Villanueva $A,{ }^{\star}$ Padilla $A,{ }^{\neq}$ Arellano-Arteaga $J,{ }^{\S}$ Mendoza $A^{*}$

*IMSS, Centro Médico Nacional de Occidente; ${ }^{\ddagger}$ Antiguo Hospital Civil de Guadalajara Fray
Antonio Alcalde; §Nuevo Hospital Civil de Guadalajara Juan I. Menchaca

Introducción: Menos del 1\% del total de las neoplasias pleurales corresponden a linfoma primario de pleura, éste comparte características clínicas y radiológicas con el resto de los tumores pleurales, tiene su origen en el centro de Kampmeier que es un agregado de células rodeado de vasos linfáticos que tiende a aumentar su tamaño ante infecciones pleurales como tuberculosis, piotórax, infección por virus de Epstein Barr, lo que condiciona una neoplasia linfoproliferativa. Presentación: Es el caso de un femenino de 86 años, antecedente de tabaquismo y biomasa no significativos, nódulo pulmonar izquierdo intervenido por videotoracoscopia con reporte negativo a malignidad. Inició padecimiento seis meses previos con astenia, adinamia, pérdida de peso, disnea progresiva de grandes a pequeños esfuerzos. Los estudios radiológicos muestran opacidad de bordes obtusos e irregulares, heterogénea, 8 × 6 × 10 $\mathrm{cm}$, a la altura de carina principal que no realza al contraste intravenoso. $\mathrm{La}$ biopsia reporta linfoma no Hodgkin de células B del margen, inmunotinciones positivas: CD20, CD43 e IQM. Clasificándose como un Ann Harbor IIE e iniciando tratamiento con RCHOP por el Servicio de Hematología. Discusión: Los linfomas muy rara vez afectan las cavidades corporales pero cuando se presentan se tiene un factor predisponente que en la mayoría de los casos corresponde a infecciones. En la literatura internacional hasta el 2012 existen reportados sólo siete casos de este raro tumor pleura; en México no existe registro epidemiológico, sin embargo, en los últimos tres años en nuestra unidad hospitalaria se han reportado dos casos. El pronóstico es bueno cuando no se tiene enfermedad sistémica. Conclusión: En el contexto de un paciente con piotórax es fundamental la sospecha de esta entidad que aunque rara puede presentarse; asimismo, debe buscarse la biopsia quirúrgica para un mayor rendimiento diagnóstico. 


\section{Pseudotumor inflamatorio traqueal, reporte de un caso}

Hernández RFI, Meza BJH, Lechuga
TI, Alejandre GA, Velázquez SR

INER Ismael Cosío Villegas

Introducción: El pseudotumor inflamatorio de tráquea son lesiones que se consideran como sarcomatosas de bajo grado. Afecta predominantemente a niños y adultos jóvenes. La etiología es desconocida. La resección quirúrgica es la mejor opción de tratamiento. Objetivo: Describir caso de paciente femenino con estenosis traqueal debido a pseudotumor inflamatorio en el INER. Presentación de caso: Inició padecimiento un mes previo a su ingreso con tos persistente continua sin manejo médico, somnolencia diurna. Dos semanas previas persiste con tos no productiva, disneizante con sibilancias a distancia acude a valoración en hospital pediátrico, se inicia manejo para neumonía adquirida en la comunidad, egresada con B2 de acción corta, persistiendo con tos sin predominio de horario y se agrega disnea de pequeños esfuerzos. Debido a que persiste con sintomatología y dificultad respiratoria reacude a valoración, donde es manejada con b2 de acción corta y se decide envío a INER. En urgencias se realiza espirometría observándose amputación de flujo y curva morfológica en meseta. Se realizó tomografía observando estrechamiento traqueal extrínseco, también una broncoscopia donde hay una disminución de la luz en $70 \%$ por compresión extrínseca. La pacientes es sometida a abordaje quirúrgico con resección de cuatro anillos traqueales, traqueoplastía más traqueostomía. Se mantiene con ventilación mecánica asistida, con posterior retiro de la misma y decanulación por fibrobroncoscopia, es egresa del servicio y continúa control por consulta externa. Discusión: El pseudotumor inflamatorio representa un reto diagnóstico así como de clasificación y tratamiento, debido a lo infrecuente de su presentación. El pseudotumor inflamatorio puede presentar recidivas en el 3-24\% de los casos, generalmente en el contexto de resección incompleta. Sin embargo, el estándar de tratamiento actual es la resección quirúrgica completa. Conclusión: El pseudotumor inflamatorio de tráquea representa un reto clínico y diagnóstico, la resección quirúrgica completa es el estándar de tratamiento actual.

\section{Obstrucción grave de la vía aérea central debida a invasión de tumor germinal primario de mediastino (manejo broncoscópico)}

\section{Moreira MA, Álvarez MP, Cicero SR, Núñez PRC}

Hospital General de México, SSA

Introducción: La obstrucción maligna traqueobronquial puede ser: endoluminal por tumor endobronquial, extraluminal por compresión extrínseca y mixta. La principal causa es el cáncer pulmonar, le siguen el de esófago, tiroides, laringe, las metástasis y los tumores de mediastino. Las manifestaciones clínicas de las vías aéreas son: las obstructivas y el sangrado. Por regla, la obstrucción produce disnea, sibilancias y/o estridor cuando la oclusión es del 50\% o más. Presentación de caso: Masculino de 27 años, ingresa por insuficiencia respiratoria aguda. La tomografía muestra tumor mediastinal que ocupa todo el hemitórax izquierdo. Hallazgos broncoscópicos: tumor endobronquial que ocluye $100 \%$ del bronquio principal izquierdo (BPI), 60\% del bronquio principal derecho (BPD), infiltra carina principal. Para asegurar la ventilación se intuba selectivamente el bronquio principal derecho con dos cánulas adaptadas delgadas. Se introduce videobroncoscopio paralelamente a lo largo de las cánulas acopladas y se inicia resección tumoral con el balón Karakoca mediante un efecto de «legrado», se controla el sangrado con argón plasma y se completa resección con pinza de biopsia obteniendo $50 \%$ de luz del BPI. Reporte histopatológico: tumor germinal de tipo carcinoma embrionario El tratamiento con quimioterapia (etoposido, cisplatino, bleomicina) dio buena respuesta. La broncoscopia de revisión 15 días después muestra ambos bronquios principales permeables al $100 \%$. Discusión: El tratamiento endoscópico fue exitoso, mediante la combinación de broncoscopia paralela a intubación selectiva, balón de resección Karakoca, argón plasma, y pinza. Por regla, los tumores de mediastino causan obstrucción de la vía aérea por compresión extrínseca, los tumores germinales no seminomatosos del mediastino, específicamente los carcinoembrionarios, los menos frecuentes (1.8\%) dentro de este grupo son los que muestran un comportamiento más agresivo, invaden estructuras adyacentes. No encontramos ningún reporte de invasión endoluminal traqueobronquial por esta causa, éste es el primer caso en un adulto con obstrucción crítica de la vía aérea.

\section{Leiomioma vascular tímico y quilotórax secundario. Abordaje y ligadura del conducto torácico por videotoracoscopia}

\section{Gordillo MJA, Fierro ChEM, Ambriz MJC, Vargas ÁB}

Hospital General de México

Mujer de 41 años con leiomioma vascular tímico que desarrolló quilotórax tras resección quirúrgica videotoracoscópica y ligadura del conducto torácico toracoscópico. Antecedente familiar de linfoma. Inició hace nueve meses con disnea mMRC 1 agregándose un mes después dolor torácico opresivo. Radiografía y tomografía computada de tórax evidenciaron lesión tumoral en mediastino anterior, atenuación oscilando entre 13 y 25 U.H; adyacente al arco aórtico, tronco de arteria pulmonar y 
contactando pericardio con posibilidades diagnósticas de hiperplasia tímica $v s$. actividad linfoproliferativa. Marcadores tumorales con incremento de CA 125. Se sometió a videotoracoscopia para resección tumoral, encontrando tumor mediastinal anterior amarillo bien delimitada blando de aproximadamente $8 \times 6 \mathrm{~cm}$, se resecó $80 \%$, con salida mínima de material quiloso del lecho tumoral confirmándose quilotórax, manejado de manera conservadora, egresando por resolución del cuadro; reingresa una semana después por derrame pleural izquierdo-quilotórax del 90\% tratándose con sonda endopleural y videotoracoscopia derecha, ligando conducto torácico con grapas de titanio resolviendo el cuadro. Reporte patológico e inmunohistoquímica de tumoración reportó leiomioma vascular sin datos de malignidad, timo residual sin alteraciones histológicas. El leiomioma vascular o angioleiomioma es la proliferación de células de músculo liso en pared vascular; $90 \%$ son subcutáneos o aparecen como nódulos cutáneos en extremidades; su desarrollo en hígado y riñón ha sido reportado pero es raro. Los leiomiomas mediastinales primarios son muy raros con reporte de aproximadamente 20 casos en la literatura. Son más comunes en mujeres y normalmente se observan en mediastino posterior. Pueden ser asintomáticos o presentan dolor torácico y disnea. $\mathrm{Su}$ resección es curativa sin descripción de muerte o recurrencia en reportes de seguimiento. La ligadura del conducto torácico vía toracoscópica es la mejor opción para tratamiento quirúrgico del quilotórax. No existen casos reportados de angioleiomioma localizado en timo, siendo este caso extremadamente raro, eligiéndose el abordaje correcto para el quilotórax secundario.

\section{Tumores gigantes de tórax. Reporte de casos clínicos}

\section{Márquez C, Flores MR, Navarro DI, Armenta $R$}

IMSS, CMN "La Raza”
Introducción: Los tumores gigantes de tórax más frecuentes son de origen mediastinal (principalmente teratoma, timoma) y de naturaleza sarcomatoide. No se conoce la epidemiología de este tipo de tumores, se estima que son infrecuentes. En este trabajo presentamos cinco casos que se presentaron en nuestro servicio en un lapso de 10 meses. Serie de casos: Se revisaron cinco casos entre marzo y diciembre de 2015. Dos mujeres y tres hombres. La edad media fue 65 años. Los síntomas característicos fueron disnea, disfonía, disfagia y datos de síndrome de vena cava superior (3 casos). El abordaje diagnóstico fue clínico, radiológico e histopatológico. En cuatro de los casos se realizó biopsia percutánea, en tres casos obteniéndose el diagnóstico definitivo por dicho método. Tres casos ameritaron manejo quirúrgico, resección completa en dos de ellos, el restante no fue posible por invasión torácica de alto grado. Los diagnósticos histopatológicos fueron: tumor fibroso solitario de pleura (2 casos), carcinoma papilar de tiroides (1 caso), seminoma (1 caso), metástasis de hepatocarcinoma (1 caso). Las complicaciones incluyeron obstrucción de la vía aérea y muerte (1 caso), choque hipovolémico (1 caso), hematoma retroperitoneal (1 caso). Discusión: Los tumores gigantes de tórax generalmente son de naturaleza mesenquimatosa, pueden ser malignos o benignos. Suelen comprometer diversos órganos y estructuras por vecindad, bien por infiltración o compresión; en general, se describen con baja capacidad metastásica. La resección quirúrgica constituye la mejor posibilidad de curación y/o sobrevida en su mayoría con el fin de mejorar la sintomatología, la cual depende de una intervención oportuna. Conclusiones: Si bien los tumores gigantes de tórax son en la mayoría de los casos de mediastino y sarcomas, en nuestro centro no fue así; en el período descrito sólo uno correspondió a tumor mediastinal y el resto a tumores descritos como infrecuentes en la literatura.

\section{Neumonitis por} taxanos en

\section{pacientes con cáncer de mama: reporte de casos}

\author{
Abundis CR \\ UMAE No. 34, IMSS, Monterrey, \\ Nuevo León
}

Los taxanos han demostrado detener la progresión de enfermedad y aumentar la supervivencia, se ha empleado en pacientes con cáncer de mama como citotóxico. La neumonitis por taxanos tiene una incidencia entre el 1-4\%, aumentando esta cifra cuando se asocia con otros fármacos citotóxicos o a radioterapia. En nuestro hospital, en tres meses se presentaron nueve casos de pacientes compatibles con este cuadro. Se presentaron nueve casos en estadíos temprano. El cuadro clínico se inició entre una semana y 15 días después de la aplicación del taxano con deterioro del estado general, disnea progresiva hasta hacerse de repos, tos y fiebre de $39^{\circ} \mathrm{C}$. En todos los casos se recogieron muestras para microbiología, siendo todas negativas y se instauró tratamiento con antibioticoterapia de amplio espectro sin clara mejoría. Por este motivo se realizó tomografía de tórax, donde se describió afectación difusa de parénquima pulmonar en forma de vidrio deslustrado, con engrosamiento de septos interlobulillares y múltiples áreas de consolidación de forma bilateral de predominio lóbulo superior y medio. Se inició tratamiento con corticoides con rápida mejoría clínica de las pacientes $\mathrm{y}$, posteriormente, radiológica con resolución de las lesiones, dos pacientes fallecieron durante hospitalización y dos más con secuelas de hipoxemia crónica. Es una complicación infrecuente y de suma importancia conocer ya que cobra especial trascendencia en tratamientos de índole adyuvante, puesto que éstos se aplican a pacientes potencialmente curados del tumor de base. El diagnóstico de sospecha y el inicio temprano del tratamiento con corticoides son fundamentales para 
garantizar una adecuada evolución clínica. Ante la sospecha del cuadro debe iniciarse empíricamente corticoides.

\section{Hiperplasia difusa idiopática de células neuroendocrinas pulmonar (enfermedad de Aguayo-Miller), presentación de un caso y breve revisión de la literatura}

\section{Briseño HAA, Peña MES, Luna RC, de León FJP}

Instituto Nacional de Enfermedades Respiratorias

Introducción: La hiperplasia difusa idiopática de células neuroendocrinas pulmonar es una condición rara, considerada como una lesión pulmonar precursora o pre-neoplásica de tumores pulmonares neuroendocrinos, fue descrita en 1992 por Aguayo y colaboradores como una enfermedad obstructiva severa de la vía área que se acompaña de hiperplasia de células neuroendocrinas. En 1999 fue incorporada por la Organización Mundial de la Salud como una lesión precursora de potenciales tumores; en la literatura se cuenta con poco más de 100 casos individuales y sólo pequeñas series, la mayor con 30 pacientes. Caso clínico: Femenina de 64 años, trabajó durante 8 años en fábrica textil, inicia padecimiento actual 5 años previos con tos seca ocasionalmente con accesos, tratada en múltiples ocasiones como infección respiratoria sin mejoría, acude a este instituto en donde se realiza tomografía de alta resolución, que evidencia un patrón nodular múltiple, bilateral, la espirometría mostró un patrón restrictivo con persistencia a broncodilatador, se realizo broncoscopia con lavado bronquial que reportó alteraciones inflamatorias, por lo cual se programa para biopsia en cuña, espécimen de forma piramidal que al corte presenta múltiples nódulos, el mayor de $0.4 \mathrm{~cm}$ de eje mayor, los cortes histológicos muestran células poligonales, redondas, algunas fusiformes, de escaso citoplasma, dispuestas en patrón trabecular, organoide y sólido, se observan también múltiples bronquiolos respiratorios que presentan cúmulos de células poligonales con las mismas características ya descritas, la inmunohistoquímica evidencia positividad para cromogranina, sinaptofisina y CD56, llegando al diagnóstico de hiperplasia difusa idiopática de células neuroendocrinas pulmonar, la paciente cursó un posoperatorio favorable, fue egresada con sintomáticos, vigilancia y octreotide, actualmente persisten episodios de exacerbación de tos. Conclusión: La hiperplasia difusa idiopática de células neuroendocrinal pulmonar es una enfermedad poco frecuente, crónica y que puede simular cuadros infecciosos, cuyo diagnóstico oportuno es importante debido a que los pacientes pueden progresar por dos caminos, uno de ellos es el desarrollo de tumores neuroendocrinos y, el otro, evolucionar a un cuadro obstructivo con fibrosis pulmonar.

\section{Meningoteliomatosis difusa pulmonar, correlación clínica, radiológica e histopatológica. Presentación de un caso}

Briseño HAA, Luna $R C$, León-Fajardo JP, Islas RAI

INER Ismael Cosío Villegas

La meningoteliomatosis pulmonar es una identidad descrita por Korn et al. en 1960, originalmente denominado como «quimiodectomas pulmonares», la mayoría de los casos se presenta de forma solitaria y como lesión única, la presentación de forma difusa corresponde al $32 \%$ de los casos y pocos se presentan con sintomatología restrictiva. Femenina de 51 años de edad sin antecedentes de importancia con padecimiento de cinco años de evolución caracterizado por tos intermitente, no productiva, previo a su ingreso con expectoración amarillenta, disnea de pequeños esfuerzos en el último mes, espirometría con patrón restrictivo (FEV1, 1.96 [2.58] 67-85\%, FVC, 2.53 [3.30] 74-85\%). La tomografía computada de alta resolución evidenció múltiple nodularidad, de baja densidad, difuso y con predominio en lóbulos inferiores; se realizó biopsia en cuña que mostró microscópicamente una lesión nodular con pequeños nidos de células poligonales, de núcleo redondo y oval con seudoinclusiones nucleares, la inmunohistoquímica fue positivo para antígeno epitelial de membrana, vimentina y receptores de progesterona, por lo que se realizó el diagnóstico de meningoteliomatosis pulmonar difusa. La paciente actualmente se encuentra asintomática y en vigilancia.

\section{Incidencia de tumores pulmonares primarios tipo glándula salival hallazgos histológicos y radiológicos en el Instituto Nacional de Enfermedades Respiratorias Ismael Cosío Villegas}

\section{Briseño HAA, Peña MES, Luna RC, de León FJP \\ Instituto Nacional de Enfermedades Respiratorias}

Introducción: Los tumores pulmonares primarios tipo glándula salival, representan menos del $1 \%$ de todos los tumores pulmonares. Las glándulas seromucinosas que se localizan en tráquea y bronquios principales son similares a las glándulas salivales menores, por esto, de ellas se pueden originar tumores histológicamente idénticos. La OMS en su clasificación de 2015 sólo comprende tres neoplasias, el carcinoma mucoepidermoide, carcinoma adenoideo quístico y carcinoma epitelial-mioepitelial. Objetivos: Conocer la incidencia, hallazgos clínicos, histológicos, radiológicos, respuesta a tratamiento y sobrevida de 
los tumores primarios pulmonares tipo glándula salival en el Instituto Nacional de Enfermedades Respiratorias Ismael Cosío Villegas. Material y métodos: Se revisó el archivo del servicio de Anatomía Patológica del INER y se elaboró base de datos con pacientes con diagnóstico de tumor pulmonar primario tipo glándula salival acorde a la OMS en un periodo de enero 2010 a diciembre 2015. Se reevaluaron los casos por dos patólogos expertos. Resultado: Se revisaron 12,118 quirúrgicos en un periodo de cinco años; 3,271 correspondió a neoplasias malignas (27\%), sólo 24 casos fueron tumores primarios pulmonares tipo glándula salival $(0.6 \%)$, se excluyeron cuatro casos, tres por no contar con expediente clínico, uno por no contar con bloque ni laminillas. El $65 \%$ de los pacientes negó tabaquismo, clínicamente el $85 \%$ presentó dolor de tórax no incapacitante, disnea de pequeños esfuerzos $70 \%$ $\mathrm{y}$ tos $15 \%$. Tipo de neoplasia, el $60 \%$ del total correspondió a carcinomas mucoepidermoides (58\% de bajo grado, $17 \%$ grado intermedio, $25 \%$ alto grado), $30 \%$ carcinomas adenoideoquístico, $10 \%$ carcinoma epitelial-mioepitelial. El seguimiento general fue de 17.3 meses (1-85); al cierre del estudio el $75 \%$ de los pacientes se encontraba vivo y libre de enfermedad, $10 \%$ vivo con enfermedad estable, sólo se reportaron tres defunciones, histológicamente con carcinomas mucoepidermoides de alto grado. Conclusión: Los tumores primarios tipo glándula salival son poco frecuentes; sin embargo es importante hacer un diagnóstico certero ya que presentan un mejor pronóstico que el resto de neoplasias primarias pulmonares, afecta pacientes de la tercer década de vida, son de crecimiento lento y la mayoría son centrales.

\section{Manifestación infrecuente de neoplasia de células plasmáticas, extensión más allá de la médula ósea y del sistema linfático. Presentación}

\section{de caso y revisión de la literatura}

Rodríguez BH, Rodríguez LIS, Rumbo NU, Castillo GP

INER Ismael Cosío Villegas

Introducción: Las neoplasias de células plasmáticas son un grupo de enfermedades que representan un espectro formado por mieloma múltiple (MM), plasmocitoma solitario óseo, plasmocitoma extramedular (PEM) y leucemia de células plasmáticas. Se originan de células B y son consideradas manifestaciones diferentes de la misma enfermedad. Sus manifestaciones se solapan y no existen límites claramente establecidos entre ellas. El MM está mayoritariamente confinado, la médula ósea y sus manifestaciones están relacionadas con la infiltración medular y la destrucción ósea. Sin embargo, la afectación extramedular (sin continuidad ósea) en el MM es frecuente. El plasmocitoma extramedular difiere de otras formas del mieloma en que las lesiones primarias surgen fuera de la médula ósea. Caso clínico: Comunicamos el caso de un hombre de 75 años, con tabaquismo de 3.75 paq/año. Inició hace cuatro meses con pérdida de $20 \mathrm{~kg}$, dolor torácico transfictivo y en cadera derecha con disminución de fuerza de miembro pélvico ipsilateral. En la radiografía de tórax se presenta una radiopacidad homogénea izquierda de bordes bien definidos de $6 \times 5 \mathrm{~cm}$, TAC de tórax con hiperdensidad de 67 UH. Se realizó biopsia transtorácica con abundantes láminas de células plasmáticas y cuerpos de Russel con IHQ Kappa positivo, lambda negativa, con CD 138 positivo. El diagnóstico histopatológico reveló neoplasia de células plasmáticas con restricción de cadenas ligeras. Discusión: Ante un paciente con dolor torácico transfictivo con hallazgos radiológicos inusuales, conviene recordar que las enfermedades hematológicas pueden dar lugar a manifestaciones radiológicas atípicas, como la descrita previamente. Por ello, el diagnóstico de este tipo de neopla- sias requiere un alto nivel de sospecha alcanzado gracias a una adecuada anamnesis.

Diferencias clínicas,
patológicas, biológicas
y terapéuticas en
pacientes con cáncer
de pulmón con y sin
enfermedad pulmonar
obstructiva crónica
(EPOC)

Díaz A, Rodríguez CJR

INER Ismael Cosío Villegas

Antecedentes: El cáncer de pulmón (CP) al igual que la enfermedad pulmonar obstructiva crónica (EPOC) representa un problema de salud pública a nivel mundial. El CP y EPOC tienen factores de riesgo comunes y se considera que también pueden compartir mecanismos patogénicos. Se desconoce si el cáncer relacionado con EPOC tiene diferentes características de tumores en pacientes sin EPOC. Objetivos: Identificar si existen diferencias en características clínicas, histopatológicas, de expresión molecular y terapéuticas en pacientes con CP con y sin EPOC. Comparar si la EPOC en pacientes con $\mathrm{CP}$ influye negativamente en el estado de nutrición, calidad de vida (CV), repuesta al tratamiento y supervivencia. Metodología: Se incluyeron pacientes con CP estadío clínico III y IV de la Clínica de Cáncer de Tórax del Instituto Nacional de Enfermedades Respiratorias y se dividieron en dos grupos: pacientes con CP y EPOC y pacientes con CP sin EPOC. Se analizó el tipo histológico, mutación EGFR, ACE inicial, $\mathrm{CV}$, estado de nutrición, tasa de respuesta a tratamiento, supervivencia libre de progresión (SLP) y supervivencia global (SG). Resultados: Se encontró una asociación inversa entre los pacientes con $\mathrm{CP}$ y EPOC a la expresión de EGFR $\left(\mathrm{r}^{2}-0.20, \mathrm{p}<0.05\right)$, además una asociación de $1.61(\mathrm{p}=0.006) \mathrm{del}$ grupo de CP y EPOC a presentar un 
mejor estado de nutrición que el grupo control, pero peor CV. Al realizar el análisis multivariado de EPOC con CV se observó una intervención significativa en la $\mathrm{SG}(\mathrm{p} \leq 0.028)$ pero no en la SLP ( $p=0.13$ ). Conclusiones: La SG en pacientes con CP y EPOC es similar a los sujetos con CP sin EPOC cuando la $\mathrm{CV}$ no se encuentra deteriorada, pero cuando ésta es mala, la SG disminuye hasta una media de 10 meses. Existe menor expresión de EGFR y ACE en pacientes con CP y EPOC.

\section{Enfermedad de}

\section{Castleman localizada en mediastino.} Caso clínico

\section{Pérez KN, Landa APD, Cicero SR}

Hospital General de México

Introducción: La enfermedad de Castleman es una entidad rara. Fue descrita en 1954 y luego definida por el Dr. Benjamín Castleman en 1956, en una serie de casos con adenomegalias mediastinales. Caso clínico: Masculino de 59 años de edad, con exposición a polvos inorgánicos y solventes referido a nuestra unidad por cuadro de seis meses de evolución con accesos de tos cortos, expectoración en cantidad moderada de coloración blanquecina, evoluciona con disnea progresiva hasta ortopnea y dolor torácico opresivo en hemitórax derecho, EVA 9/10, y derrame pleural derecho y adenomegalia submandibular derecha. Se colocó drenaje pleural derecho obteniendo líquido pleural con características de trasudado. En TAC contrastada se evidencia tumoración en mediastino medio paracardíaca derecha en relación íntima con grandes vasos. Se realizó biopsia por toracotomía, el estudio histopatológico se informó como enfermedad de Castleman con degeneración hialino-vascular. Discusión y conclusiones: La enfermedad de Castleman es una patología benigna incluida en la categoría de «trastornos linfoproliferativos atípicos», su incidencia en la literatura consultada fue reportada en 1 por cada 100,000 habitantes. La etiología de la enfermedad de Castleman aún no está bien definida. Sin embargo, se ha asociado con la infección por VIH y herpes virus tipo 8 del humano, específicamente con la variante de células plasmáticas. Debido a su rareza y el escaso material bibliográfico que existe, es difícil extraer conclusiones definitivas sobre el manejo clínico y el pronóstico. En casos localizados la resección está indicada y parece ser el pilar del tratamiento; sin embargo, aún queda pendiente dislumbrar el papel de la quimioterapia para la evolución de la enfermedad.

\section{Tumor fibroso de pulmón, caso clínico}

\section{Pérez KN, Landa APD, Cicero SR}

Hospital General de México

Introducción: El tumor fibroso solitario es una neoplasia mesenquimatosa, fue descrita inicialmente en la pleura; sin embargo, se origina en cualquier órgano o tejido a expensas de una célula estromal. Caso clínico: Paciente femenino de 42 años, el cual presenta disnea de grandes esfuerzos que se exacerbaba con la actividad física, así como también refiere ortopnea y tos disneizante, en radiografía radiopacidad basal interna y externa izquierda, en la tomografía de tórax se encuentra lesión homogénea en región basal externa de pulmón izquierdo que ocasiona atelectasia pasiva del segmento 9 y 10. Se realizó toracotomía izquierda con resección tumor de 12 x $10 \mathrm{~cm}$ en los segmentos 9 y 10 , engrosamiento pleural aleatorio, en los controles a dos años por imagen no ha presentado recurrencia de actividad neoplásica. Discusión: Los pacientes por lo regular son asintomáticos y el tumor fibroso generalmente se descubre en las radiografías de tórax de rutina; otros pacientes reportan síntomas pulmonares atípicos como tos seca, dolor de pecho y dificultad para respirar. El tumor fibroso solitario de pleura puede presentar recurrencia local y metástasis a distancia, puede ocurrir sobre todo en tumores que tienen características histológicas de malignidad, por lo tanto, el seguimiento del paciente es esencial. Alrededor del 10-20\% de los casos reportados en la literatura son malignos. Por lo general, la resección del tumor se correlaciona con resultado favorable y los pacientes tienen una tasa de supervivencia libre de enfermedad a los cinco años del 84\%. Conclusiones: El tumor fibroso solitario es una patología rara, el tratamiento quirúrgico es una opción curativa en la mayoría de los casos.

\section{Tumor maligno de células germinales en mediastino: reporte de caso poco frecuente}

Contreras FJ, Mendoza TLA, Hernández-Gordillo D, González ACl, Gardea de la OEE

Centro Médico Nacional de Occidente-IMSS

Introducción: Los tumores de mediastino anterior por frecuencia: malignidad del timo (35\%), linfoma (25\%), tiroides y otros tumores endocrinos $(15 \%)$, teratoma benigno $(15 \%)$ y tumores germinales malignos $(10 \%)$, estos últimos clasificados como seminomatosos (4\%) y no seminomatosos (6\%). Los seminomatosos suelen requerir de biopsia percutánea o quirúrgica para el diagnóstico. En no seminomatosos la presencia de niveles séricos elevados de $\beta$-HCG o $\alpha$-FP se consideran patognomónicos en el diagnóstico. Son neoplasias de crecimiento rápido, la mayoría sintomáticos, causados por afección de las estructuras mediastínicas, desarrollan metástasis a pulmones, pleura, ganglios e hígado. Presentación del caso: Mujer de 46 años de edad, previamente sana, con historia de disnea de dos semanas de evolución, tos, dolor torácico y pérdida de peso, se presenta con tumor mediastinal anterior y tamponade cardíaco, además de neumonía posobstructiva que evoluciona a estado de choque séptico, coagulación intravascular diseminada y muerte. La necropsia 
reporta tumor de células germinales no seminomatoso (teratoma quístico de elementos maduros con transformación maligna mixta tipo somático: $80 \%$ carcinoma neuroendocrino pobremente diferenciado, $20 \%$ adenocarcinoma tipo intestinal). Discusión: Los tumores germinales extragonadales constituyen el 2-5\% de los tumores de células germinales, localizados en estructuras de la línea media corporal, predominio en mediastino y retroperitoneo. En no seminomatosos relación hombre mujer (20:1), con una edad promedio 28.5 años, aunque la variedad teratoma con transformación maligna, en reportes de caso, se observa un pico de incidencia en pacientes de 40 a 60 años de edad. Conclusión: Los tumores de mediastino de células germinales en mujeres y de edad mayores 40 años son extremadamente raros, pero se debe de considerar como diagnóstico diferencial en los tumores de mediastino anterior, tomando importancia de la determinación de niveles séricos de $\beta$-HCG o $\alpha$-FP, con tratamiento oportuno tienen sobrevida a cinco años de $60-95 \%$ en seminomatosos y $30-50 \%$ no seminomatosos.

\section{Mesotelioma sarcomatoide diagnosticado por ultrasonido endobronquial: la utilidad de una evaluación sistemática por EBIS}

Folch SA, Cárdenas GJL, VanderLaan PA, Kent MS, Majid A, Cheng GZ, Alape DE, Folch E

Division of Thoracic Surgery and Interventional Pulmonology, Beth Israel Deaconess Medical Center, Harvard Medical School

El mesotelioma pleural es una entidad poco común, cuyo principal factor de riesgo es la exposición a asbestos. Los pacientes usualmente presentan derrame pleural unilateral y disnea. $\mathrm{Su}$ pronóstico es poco alentador debido a que con frecuencia es diagnosticado en estadíos avanzados. El patrón sarcomatoide se considera el de peor pronóstico. Paciente masculino de 76 años con antecedente de tabaquismo (30 paquetes-año) y adenocarcinoma salival sometido a resección y quimioterapia, fue referido al Servicio de Intervencionismo por opacidad en vidrio esmerilado en lóbulo superior izquierdo en tomografía de control. El PET evidenció captación intensa de FDG en linfadenopatía mediastinal, lóbulo superior y en pleura ipsilateral. Al reinterrogar al paciente, éste refiere exposición laboral a asbesto. Se realizó broncoscopia flexible y aspiración transbronquial con aguja guiada por ultrasonografía (EBUS-TBNA) en las estaciones 4R, 7 y del engrosamiento pleural en área paraaórtica (11L). La citología tomada de $11 \mathrm{~L}$ reveló proliferación de células fusiformes atípicas, infiltrando el tejido fibroso e inmunohistoquímica positiva para AE1/AE3, WT-1 y D2-40 y negativa para calretinina, p63, TTF-1, CEA(m), MOC-31 y S100 sugiriendo el diagnóstico de mesotelioma sarcomatoide. Muestras adecuadas de la estación siete resultaron negativas; sin embargo, el resultado de la estación cuatro fue positivo para células malignas que por morfología e inmunohistoquímica (positivo para CK7 y GCDFP-15 y negativos para TTF-1, napsina A, WT-1, calretinina, mamaglobina y CD68) fue consistente con adenocarcinoma salival metastásico. Finalmente, el paciente fue sometido a VATS confirmando el diagnóstico de mesotelioma sarcomatoide. Este caso resalta la importancia de una evaluación sistemática al momento de realizar EBUS-TBNA. Si sólo se hubieran tomado muestras de 4R, el segundo tumor se hubiera obviado. A pesar de que los hallazgos citológicos del EBUS-TBNA sugirieron el diagnóstico, este método continúa siendo una práctica anecdótica que no sustituye al VATS como el estándar de oro para el diagnóstico de mesotelioma pleural.

\section{Mesotelioma pleural secundario a tratamiento de}

\section{radioterapia por cáncer de mama}

Estrella HM, Ávila HJI IMSS

Presentación de caso: Motivo de consulta: derrame pleural recidivante. Originaria y residente de Monterrey, Nuevo León, casada, licenciatura en enfermería. Combe positivo por actividad laboral. Niega biomasa, tabaquismo, alcoholismo, así como uso de otro tipo de drogas. Antecedente de cáncer de mama izquierdo de tipo carcinoma ductal infiltrante en 2014 T3N2M0 estadío clínico IIIA manejado con cuadrantectomía superior izquierda con vaciamiento ganglionar, posterior a esto recibe seis sesiones de quimioterapia a base de ciclofosfamida, 5 fluorouracilo, epirrubicina y trastuzumab por un año, así como 25 sesiones de radioterapia. Inició padecimiento actual en diciembre 2014 con dolor tipo pleurítico en hemitórax izquierdo, el cual aumenta de manera progresiva, acudiendo a valoración detectándose derrame pleural izquierdo de aproximadamente $10 \%$, realizándose toracocentesis diagnóstica, con citológico, BAAR, $\mathrm{KOH}$ y cultivos negativos. Al persistir con dolor se realiza tomografía de tórax y abdomen encontrando aparentemente lesión nodular en lóbulo hepático derecho, afección de cuerpos vertebrales, así como derrame pleural izquierdo. Dicho derrame recidivó en dos ocasiones, por lo que se realiza toma de biopsia pleural cerrada con aguja tru-cut y cope con resultado: neoplasia maligna poco diferenciada de aspecto epitelial con inmunofenotipo de mesotelioma maligno con inmunohistoquímica $\mathrm{Ck}$ - coctel positivo $\mathrm{Ck} 7$ positivo calretinina positivo TTF1 negativo mesotelina negativo trombomodulina negativo. Conclusiones: Existe una asociación entre exposición a radioterapia y desarrollo de mesotelioma, aunque existen muy pocos reportes de casos descritos que presentan algunas características en común como factores genéticos, radioterapia con intervalo 
de exposición entre 7 a 30 años con dosis de radiación entre 1,500 a 5,000 cGy en áreas cercanas a tórax y alguna patología maligna. En nuestro caso, la paciente cuenta con varias de estas características aunque por probabilidad se intentó descartar progresión del cáncer de mama en pleura, se diagnosticó por inmunohistoquímica mesotelioma.

\section{Tumor miofibroblástico inflamatorio como causa de hemoptisis en pediatría: a propósito de un caso}

\begin{tabular}{c} 
Aguilar A, Campos THH, \\
Quezada RJJ, Ruiz GHH, \\
Hernández RR, Saucedo TJL, \\
Martínez BM, Vargas BE \\
\hline IMSS
\end{tabular}

Introducción: El tumor mioinflamatorio constituye la primera causa de lesiones benignas torácicas en la edad pediátrica, se caracteriza por una proliferación localizada de células inflamatorias monoclonales generalmente células plasmáticas, linfocitos, eosinófilos y células mesenquimales en forma de huso y miofibroblastos. La clínica es variada, el $70 \%$ es asintomático, el resto pueden presentar síntomas como disnea, dolor torácico, tos, hemoptisis, fiebre o pérdida de peso. Objetivo: Analizar las características clínicas y radiológicas del tumor miofibroblástico y su incidencia en la edad pediátrica como causa de hemoptisis. Caso clínico: Masculino de 7 años de edad con cuadro de dos meses de evolución con accesos de tos húmeda, no cianosante, no disneisante, con presencia de hemoptisis hasta en tres ocasiones al día con sangre roja, fresca, no coágulos ni sangre digerida, no secreción purulenta. Paraclínicos reportan: basciloscopias y PCR para micobacterias típicas y atípicas negativas, quantiferon negativo, TAC de tórax con una lesión intraparenquimatosa hiperdensa heterogénea a nivel de língula, adherida a la pared, con calcificaciones en su interior. Se realizó broncoscopia localizando sangrado a nivel de língula sin compresiones ni lesiones endobronquiales, por lo que se decidió toracotomía exploratoria encontrando un quiste broncogénico de $5 \mathrm{~cm}$ de diámetro cuyo reporte histopatológico refiere tumor miofibroblástico inflamatorio de $5.8 \mathrm{~cm}$ de diámetro de consistencia sólido-quística, con hemorragia extensa, bien delimitado con atipia focal y una mitosis por 50 campos. Conclusión: La hemoptisis es un síntoma raro en pediatría, originado por múltiples etiologías, algunas de las cuales pueden ser graves y poner en riesgo la vida del paciente. Las causas tumorales son poco comunes, dado su carácter destructivo e invasor deben tenerse en cuenta, sobre todo el tumor miofibroblástico, principal causa de tumores primarios pulmonares en la infancia.

\section{Importancia del estudio molecular en el diagnóstico actual del cáncer pulmonar}

\section{López ME, Sáenz FJA, Guzmán DN, Martínez SG, Sauceda D}

IMSS, UMAE 34, Monterrey

Introducción: El cáncer pulmonar muestra una tendencia progresiva como causa de morbimortalidad en los últimos años, por lo que la única esperanza en modificarlo es promover que en el estudio inicial en sospecha de cáncer, las muestras lleguen a estudio molecular, ya que las terapias dirigidas muestran respuestas alentadoras en sobrevida aun en etapas avanzadas. Objetivo: Demostrar que biopsias de adenocarcinoma pulmonar primario realizadas por neumólogos intervencionistas de la seguridad social en hospitales de alta especialidad, pueden ser representativas y adecuadas para análisis molecular y fenotipificación del tumor. Material y método: Pacientes con sospecha de cáncer pulmonar fueron evaluados con radiografía, tomografía de tórax y abdomen contrastado, de acuerdo con la ubicación y tamaño de lesión se eligió el abordaje diagnóstico: biopsia endobronquial/broncoscopia, biopsia pleural o pleuroscopia, biopsia por aspiración/aguja fina guiados por fluoroscopia u tomografía computada y, además, estadificación con gammagrafía ósea. Todas las muestras llevadas a análisis molecular, 2 tipos biopsia de tejido fijada en formol y embebida en parafina o corte fijado en laminilla sin teñir. Análisis mutacional para búsqueda de EGFR y ALK por PCR y FISH. Resultados: 10 pacientes estudiados de enero 2013 a diciembre 2015, seis mujeres y cuatro hombres, siete no fumadores y tres fumadores. 6 BAAF 2 por TAC, 4 por fluoroscopia, 4 FBO y 1 biopsia de pleura. Confirmados con adenocarcinoma primario pulmonar por inmunohistoquímica positiva CK7, EGFR, TTF1 positivos y análisis mutacional positivo en $40 \%$ EGFR y el $60 \%$ negativas. Conclusiones: Incidencias de $31.2 \%$ de mutación de EGFR ha sido reportada en mexicanos con adenocarcinoma, en nuestra serie alcanza $40 \%$. Todas las muestras fueron adecuadas para estudio molecular. No hubo complicaciones durante los procedimientos.

\section{Prevalencia del mesotelioma pleural maligno en el noroeste de México}

\section{López ME, Sáenz FJA, Moncada \\ LAC, Martínez SG, Guzmán VN, Treviño GM, González CE, De La Fuente FL}

IMSS, UMAE 34, Monterrey

Introducción: No existe una incidencia exacta de mesotelioma maligno de pleura en el país. Casuísticas aisladas del centro del territorio mexicano y áreas sin inmunohistoquímica donde el estudio de la pleura en sospecha de malignidad puede llevar a un subdiagnóstico. Aun así, la incidencia por muertes de 1979 a 1997 en el IMSS fue de 487, un promedio de 25 casos por año y del 98 al 2000102 por año. 
Objetivos: Demostrar el aumento progresivo del MMP su diagnóstico en etapas avanzadas y la importancia de la inmunohistoquímica en el diagnóstico diferencial de la malignidad pleural. Material y método: Se revisaron expedientes clínicos y registros histopatológicos de pacientes de enero 19962016. Ingresados por derrame pleural, estudiados con RX y TAC de tórax, histopatología por biopsias: de pleura, toracotomía, toracoscopia, aspiración/ aguja fina, citologías de líquido pleural, pericárdico o necropsia. Resultados: Encontramos 175 casos de MMP, inmunohistoquímica +162 casos. Predominio epitelial y mayor frecuencia 139 hombres y 36 mujeres. Variables como: exposición laboral, tabaquismo, origen, latencia de cuadro clínico, hemitórax afectado, estadío, hallazgos radiológicos u tomográficos, tiempo en DX, casos quirúrgicos, comorbilidades requirieron análisis por subgrupos, debido a cambios en sistematización de expediente clínico. Conclusiones: Esta casuística confirma la existencia del mesotelioma maligno de pleura en el noroeste incremento y estadíos avanzados de una enfermedad letal prevenible, ocasionada por exposición laboral. Sin alternativas para prevención ni cambios en la legislación actual.

\section{Exposición a humo de leña y riesgo de cáncer de pulmón. Estudio de casos y controles}

\section{Báez SR, Canseco RA, Rumbo NU, Castillo GP, León DS, García TR, Ixcot $M B$}

go de desarrollar cáncer de pulmón en pacientes expuestos al humo de leña. Material y métodos: Se incluyeron 138 casos de cáncer de pulmón y 183 controles: 50 neumopatía intersticial, 46 tuberculosis pulmonar, 43, 33 tromboembolia pulmonar y 11 casos de otorrinolaringología. En ambos grupos se investigó sobre la exposición al humo de leña y otras exposiciones. La exposición al humo de leña se evaluó como variable dicotómica sí o no, y como índice de exposición en horas año (años de exposición multiplicado por el promedio de horas de exposición en un día). Resultados: La edad de los casos fue mayor que la de los controles, $66 \mathrm{vs}$. 62 años $(\mathrm{p}<0.05)$, los hombres fueron más frecuentes en los casos $57 \%$ vs. 44\% ( $\mathrm{p}<0.05)$. El índice de exposición al humo de leña fue mayor en los casos $v s$. los controles 144 y 88 horas año ( $\mathrm{p}$ $<0.05)$. Las razones de momio crudas para exposición al humo de leña en horas año fueron de 1.02 (IC 95\% 1.001.00) $\mathrm{p}=0.019$, índice de exposición $>$ 100 horas año 2.6 (IC 95\% 1.05-6.44) p $=0.039$ y vivienda con techo de lámina de asbesto 16 (IC 95\% 3.78-73.94) p = 0.000. La asociación entre exposición al humo de leña persistió después de ajustar por sexo, tabaquismo, nivel socioeconómico y vivienda con techo de lámina de asbesto. Conclusiones: $\mathrm{La}$ exposición al humo de leña es un factor de riesgo en la cadena de causalidad del cáncer de pulmón. El estudio permitió identificar otras fuentes de exposición fuertemente asociadas como la exposición en la vivienda a lámina de asbesto.

\section{Cáncer pulmonar de células pequeñas. Reporte de series de casos}

\section{Téllez NNA, Figueroa PM,} Rumbo NU

Antecedentes: Una proporción significativa de casos de cáncer de pulmón ocurren en nunca fumadores. La exposición a productos de la combustión de biomasa particularmente leña se considera como carcinógeno probable para el desarrollo de cáncer de pulmón en humanos. Objetivo: Evaluar el ries- debido a su rápido crecimiento metastásico en zonas regionales y distales. La mayoría de los casos al diagnóstico se encuentra en estadíos avanzados y la supervivencia es pobre. En este trabajo realizamos una revisión de los pacientes con diagnóstico de CPCP en el Instituto Nacional de Enfermedades Respiratorias de enero 2013 a diciembre 2014. Resultados: Se revisaron 32 casos de pacientes con diagnóstico de CPCP, 17 (53\%) hombres y 15 (47\%) mujeres, la media de edad fue de 66.4 años (IQR 59-72). Tenían antecedente de tabaquismo el $90.6 \%$ (29) e índice tabáquico con media de 39.85 p/a (IQR 9.20-52.5), con exposición al humo de leña en el 37.5\% (12) de los casos, media de 174 horas/año. E1 50\% (16) refirieron antecedente de cáncer en algún familiar de primer grado y de éstos el $18.8 \%$ (6) eran de origen pulmonar. Otras comorbilidades como DM2 estaba en $6(18.8 \%)$ pacientes y 25\% (8) tenían diagnóstico de EPOC. El $40.6 \%$ (13) presentaron derrame pleural de predominio derecho $76.9 \%$ (10). La mitad de los pacientes (16) tuvieron metástasis, cinco a hígado, cuatro a SNC, cuatro a pleura, dos a hueso y uno a glándulas suprarrenales. A los dos años, sólo el $12.5 \%$ (4) continuaban vivos y el mayor número de muertes ocurrió durante el primer mes $34.4 \%$ (11). Conclusiones: El CPCP es una enfermedad poco frecuente; sin embargo, es muy agresivo debido que al diagnóstico, la mitad de los pacientes tenían metástasis a algún sitio. Aunque estos tumores suelen responder bien a la quimioterapia, el pronóstico es malo a corto plazo, ya que de nuestros pacientes sólo permanecían vivos cuatro a los dos años del diagnóstico.

\section{Vascular}

\section{Teorema de inmersión de Takens (TIT) en el análisis electrocardiográfico del embolismo pulmonar masivo (EPM) ${ }^{\mathrm{a}}$}


Alvarado $P E,{ }^{\star}$ Mansilla $R,{ }^{\ddagger}$ Escalona $R,{ }^{*}$ Alvarado-Ávila $P E, \$$ González $A,{ }^{*}$ Brugada $R,{ }^{*}$ Segura $L,{ }^{\star}$ González $C^{*}$

*ISSSTE; ‡UNAM; §SSA

Antecedentes: El electrocardiograma convencional de doce derivaciones (ECG) se ha utilizado como una herramienta para el diagnóstico del embolismo pulmonar masivo (EPM). El análisis habitual del ECG se realiza básicamente en el dominio del tiempo. Existe evidencia que la señal eléctrica del corazón humano no es un oscilador perfecto y con naturaleza multifractal. Método: Estudiamos la señal bioeléctrica del ECG asumiendo su evolución como un sistema dinámico aperiódico, para lo cual utilizamos los archivos de datos numéricos provenientes de un registro Holter durante una hora, antes y después del tratamiento fibrinolítico (TFL) en pacientes con EPM. Los datos constan de 900,000 datos consecutivos en tres derivaciones del aparato. Se obtuvieron series temporales no lineales en cinco pacientes con EPM durante el evento agudo y 24 horas después del TFL de tres mujeres y dos masculinos, edad $50.3 \pm 19.2$ años. El diagnóstico y resolución del trombo de EPM se demostró mediante tomografía helicoidal computarizada. Se utilizó una técnica muy sofisticada de la teoría de los sistemas dinámicos conocida como método de inmersión (TIT) que consiste en recuperar la dinámica general del fenómeno (representado por su atractor) a partir de información incompleta sobre el fenómeno bajo estudio, obtenida en este caso a partir de una de las derivaciones del aparato. Resultados: De las series de tiempo obtenidas se reconstruyeron proyecciones bidimensionales de los atractores antes y después del TFL, los cuales mostraron una conformación topológica muy diferente en el espacio de fases antes y después del TFL. Discusión: La información visual que genera el cambio del atractor bidimensional de pacientes con EPM antes y después del TFL es muy relevante. Por otra parte, el atractor tiende a ser periódico en la medida que el paciente se acerca al fenómeno crítico y cuando se resuelve el EPM, el atractor recupera su habitual complejidad. La reconstrucción bidimensional del atractor repetida en el tiempo podría ser una forma de vigilancia de los pacientes en terapia intensiva.

a Trabajo seleccionado para ser presentado de forma oral.

\section{Efecto de los}

antagonistas de

receptores de

mineralocorticoides

sobre la hipertensión

arterial pulmonar en

los pacientes con

insuficiencia cardíaca ${ }^{a}$

Cíntora MC, González ID, Hernández $Z R$, Orea TA, Santellano JB, Sánchez SRN, Pineda JJ, Peláez HV, Pablo $S R$, Contreras RE, Pérez CE, Herrera

SR, Ramírez VA, Espinosa de los Monteros $C$, Velázquez MA, Sansores MR, Leija $A G$

INER Ismael Cosío Villegas

Introducción: Los antagonistas de receptores mineralocorticoides (ARM) en la hipertensión arterial pulmonar (HAP) están descritos a nivel experimental. Éstos han demostrado atenuación de la resistencia vascular y disminución de la remodelación vascular pulmonar y ventricular derecha. En ensayos clínicos se ha demostrado que disminuye la presión arterial pulmonar (PAP) cuando se administra de manera conjunta con otros tratamientos en pacientes con hipertensión arterial pulmonar e insuficiencia cardíaca (IC). Sin embargo, se desconoce el efecto de los ARM sobre la PAP en IC. Objetivo: Evaluar el efecto de los ARM sobre la PAP secundaria a IC. Material y métodos: Se realizó un estudio trasversal, con pacientes con diagnóstico de IC. Criterio de inclusión: mayores de 18 años con diagnóstico de IC de acuerdo con ecocardiograma. Se realizó una regresión lineal múltiple con el objetivo de evaluar el efecto de los ARM sobre la PAP. Resultados: Se evaluaron 615 pacientes, de los cuales $55.12 \%$ fueron hombres, de $62.82 \pm$ 16.17 años, las comorbilidades más frecuentes fueron; hipertensión $72.68 \%$, diabetes mellitus $45.37 \%$, dislipidemias $50.89 \%$, cardiopatía isquémica $34.13 \%$ e hipertensión arterial pulmonar $90.13 \%$. Al evaluar el efecto de los ARM sobre la PAP se observó que por cada miligramo de ARM (espironolactona $25 \mathrm{mg}$ por semana en promedio) utilizado, se reduce $0.91 \mathrm{mmHg}$ la $\mathrm{PAP}$, esto ajustado por sexo, edad, dosis de inhibidores de la enzima convertidora de angiotensina, beta bloqueadores, cardiopatía dilatada, fracción de expulsión del ventrículo derecho, ángulo de fase (con bioimpedancia eléctrica por análisis vectorial). Conclusiones: En pacientes con insuficiencia cardíaca e hipertensión pulmonar los ARM reducen de manera considerable la PAP.

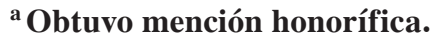

\section{Hipertensión pulmonar severa en pacientes con fibrosis pulmonar idiopática}

\section{Navarro VDI, ${ }^{\star}$ Barragán PG, ${ }^{\ddagger}$ Cueto $R G, \neq$ Saavedra de $R S I,{ }^{\ddagger}$ Álvarez MP, $\neq$ Cicero $S R^{\ddagger}$}

*IMSS; ‡Hospital General de México

Introducción: La presencia de hipertensión pulmonar (HP) empeora el pronóstico en los pacientes con fibrosis pulmonar idiopática (FPI), ocasionando disminución de capacidad de ejercicio, mayor hipoxemia y menor sobrevida. La HP severa en estos pacientes se define como PAPm (presión arterial pulmonar media) $\geq 35 \mathrm{o} \geq 25 \mathrm{mmHg}$ con gasto cardíaco $<2.5 \mathrm{~L} / \mathrm{min}$ no explicado por otras causas. Presentación de casos: Se presentan tres casos de pacientes con diagnóstico de FPI e hipertensión pulmonar severa, dos con diagnóstico de FPI por criterios tomográficos y uno por criterios histopatológicos. Dos mujeres y un hombre, edad promedio de 57 años, portadores de hipertensión arterial sistémica dos de ellos, uno diabetes mellitus y uno cardiopatía isquémica. Dentro de los datos clínicos, disnea, 
tos y acropaquias en los tres, dos con cianosis distal. Por gasometría pH 7.43, $\mathrm{paO}_{2}$ 53, $\mathrm{pCO}_{2}$ 32. Espirometría sugerente de restricción: relación VEF1/ CVF promedio 65.6, CVF 60 y VEF1 65. Ecocardiograma con promedio de PSAP 62 mmHg, FEVI 63, los tres con insuficiencia tricuspídea. Caminata de seis minutos: distancia promedio de 185.5 metros, $\mathrm{SO}_{2}$ basal promedio $78 \%$, suspendida a los dos y cuatro minutos. Cateterismo cardíaco derecho con PAPm de 42.7 basal y posterior a reto $38 \mathrm{mmHg}$, gasto cardíaco basal 8.2 posterior a reto 10 , resistencias pulmonares basal seis posterior a reto 4.2 unidades Wood. Discusión: La patogénesis de HP en estos pacientes no es del todo clara, se atribuye clásicamente a la vasoconstricción hipóxica y a la destrucción de lecho vascular pulmonar por fibrosis; así como a alteraciones en el balance de angiogénesis y la producción de mediadores profibróticos. Conclusiones: Generalmente la HP concuerda con el grado de fibrosis; sin embargo, hay casos en los que la severidad de hipertensión pulmonar es «desproporcionada» a las alteraciones pulmonares. En este caso nuestros pacientes se encontraron con PAPm de 45, 43 y $40 \mathrm{mmHg}$.

\section{Hipertensión pulmonar tromboembólica crónica. Informe de 10 casos}

Gómez LSA, Cueto RG, Barragán PG, Álvarez MP, Cicero SR

Hospital General de México

Antecedentes: La hipertensión pulmonar (HP) se define por la presencia de una presión arterial pulmonar media (PAPm) en reposo de $25 \mathrm{mmHg}$, durante el cateterismo cardíaco derecho (CCD). La HP del grupo IV corresponde a la HPTC. El tratamiento de elección es endarterectomía pulmonar (EP). Recién, en pacientes no candidatos a EP y en aquellos con HP residual reciben tratamiento médico con drogas específicas (DE). Objetivo: Presentar el protocolo y la experiencia en 10 pacientes estudiados con HPTC tratados con DE en el Servicio de Neumología del Hospital General de México (HGM). Material y métodos: El estudio fue realizado de enero de 2012 a diciembre de 2015. Se presentan 10 pacientes con diagnóstico de HPTC. Las variables demográficas de interés fueron sexo, edad, índice de masa corporal (IMC), y antecedente de enfermedad tromboembólica venosa (ETV). A todos los pacientes se les practicaron estudios de laboratorio básicos, angioTC de tórax y gammagrama pulmonar para confirmar el diagnóstico. Todos fueron sometidos a CCD y reto con iloprost inhalado. Resultados: No se encontró diferencia en cuanto a género (5/5). Edad media de 42 años. 90\% tuvieron antecedente de ETV. La clase funcional predominante fue II y III. La PAPm disminuyó de 51.2 a $46.7 \mathrm{mmHg}$ con iloprost, las RVP disminuyeron de 8.48 a 6.93 unidades Wood, y el índice cardíaco (IC) incrementó de 2.6 a 3.1 $\mathrm{L} / \mathrm{min} / \mathrm{m}^{2}$ en reposo. Conclusiones: $\mathrm{La}$ edad al diagnóstico de HPTC fue menor que la de otras series. El antecedente de ETV fue superior al reportado en la literatura consultada. Un perfil trombofílico fue documentado en tres pacientes. Todos recibían anticoagulantes orales (ACO), 70\% cumarínicos y 30\% ACO específicos. Los 10 pacientes recibieron DE (sildenafil 8, bosentán 2). La hemodinamia pulmonar posterior al reto mostró disminución de la PAPm, RVP e incremento del IC. La sobrevida durante el seguimiento fue del $80 \%$.

\section{Hipertensión arterial pulmonar: evaluación clínica, hemodinámica y tratamiento}

Barragán PG, * Navarro VDI, Cueto RG, ${ }^{*}$ Gómez $L S A,{ }^{\star}$ Álvarez MP, * Cicero $S R^{\star}$

*Hospital General de México; ‡IMSS

Introducción: La hipertensión arterial pulmonar (HAP), se refiere al grupo
1 de la clasificación de hipertensión pulmonar (HP). Sigue siendo una enfermedad de difícil diagnóstico, la incidencia y prevalencia se estima sea de 2.4-7.6 casos/millón/año y 15-26 casos/millón, respectivamente. Objetivo: Dar a conocer una serie de 58 pacientes estudiados con HAP en el Servicio de Neumología del Hospital General de México. Material y métodos: Estudio realizado de enero de 2012 a diciembre de 2015. Se incluyeron 58 pacientes con diagnóstico de HAP, sometidos a cateterismo cardíaco derecho y reto con iloprost. Se analizaron características clínicas, hemodinámicas y tratamiento con drogas específicas (DE). Resultados: Edad media de 38 años. La clase funcional predominante fue II. En la caminata de seis minutos recorrieron en promedio 376 metros. Presentaron disfunción del ventrículo derecho por ecocardiograma el $34.4 \%$. Las comorbilidades más frecuentes fueron hipotiroidismo (29.3\%), hipertensión arterial sistémica $(17.2 \%)$, obesidad (13.7\%) y diabetes mellitus $(8.6 \%)$. De acuerdo con los subgrupos de HAP el $51.7 \%$ correspondió a cardiopatías congénitas, $29.3 \%$ a hipertensión arterial pulmonar idiopática (HAPi) y el $19 \%$ a enfermedades del tejido conectivo. La presión arterial pulmonar media después del reto con iloprost disminuyó de 55.4 a $52.1 \mathrm{mmHg}$, las resistencias vasculares pulmonares disminuyeron de 7.7 a 7.2 unidades Wood y el índice cardíaco se mantuvo en 5.01 y $5.13 \mathrm{~L} /$ $\mathrm{min} / \mathrm{m}^{2}$. Los pacientes se encuentran en tratamiento con DE (bosentán 41, sildenafil 9 y terapia combinada 7). Conclusiones: La edad de diagnóstico fue menor que en otras series. El sexo predominante fue mujeres $(84 \%)$ similar a lo reportado en la literatura. La mayoría de los pacientes cursan con HP grave (46\%). En nuestros pacientes el principal subgrupo de HAP fue asociado con cardiopatías congénitas $(51.7 \%)$, a diferencia de la bibliografía que informa la HAPi hasta en $50 \%$. Sólo el $12 \%$ se encuentra con terapia combinada. 